\title{
Using Patterns For Multivariate Monitoring And Feedback Control Of Linear Accelerator Performance: Proof-Of- Concept Research
}

Gail A. Cordes Leo A. Van Ausdeln M. Elena Velasquez

April 2002

Idaho National Engineering and Environmental Laboratory Bechtel BWXT Idaho, LLC 

INEEL/EXT-02-00520

\title{
Using Patterns for Multivariate Monitoring and Feedback Control of Linear Accelerator Performance: Proof-of-Concept Research
}

\author{
Gail A. Cordes \\ Leo A. Van Ausdeln \\ M. Elena Velasquez \\ April 2002 \\ Idaho National Engineering and Environmental Laboratory \\ Waste Management Technologies Department \\ Idaho Falls, Idaho 83415
}

Prepared for the U.S. Department of Energy Through the INEEL LDRD Program Under DOE Idaho Operations Office Contract DE-AC07-99ID13727 
This page intentionally left blank 


\begin{abstract}
The report discusses preliminary proof-of-concept research for using the Advanced Data Validation and Verification System (ADVVS), a new INEEL software package, to add validation and verification and multivariate feedback control to the operation of nondestructive analysis (NDA) equipment. The software is based on human cognition, the recognition of patterns and changes in patterns in time-related data.

The first project applied ADVVS to monitor operations of a selectable energy linear electron accelerator, and showed how the software recognizes in real time any deviations from the optimal tune of the machine. The second project extended the software method to provide model-based multivariate feedback control for the same linear electron accelerator.

The projects successfully demonstrated proof-of-concept for the applications and focused attention on the common application of intelligent information processing techniques.
\end{abstract}


This page intentionally left blank 


\section{ACKNOWLEDGEMENTS}

The authors acknowledge the important contributions to the research from Kevin J.

Haskell, James L. Jones, and Michael J. Connolly of the Idaho National Engineering and Environmental Laboratory, and J. Frank Harmon of the Idaho Accelerator Center at the Idaho State University.

This research was supported by the U.S. Department of Energy, Assistant Secretary for Environmental Management, under DOE Idaho Operations Office Contract DE-AC0799IDI3727. 
This page intentionally left blank 


\section{CONTENTS}

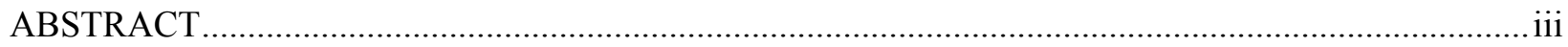

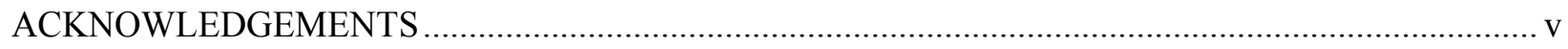

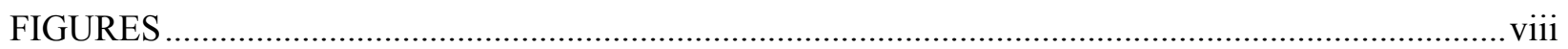

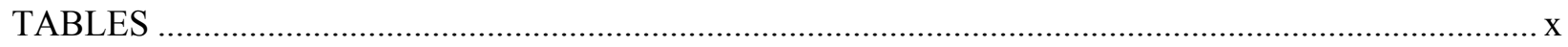

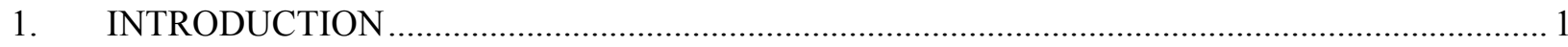

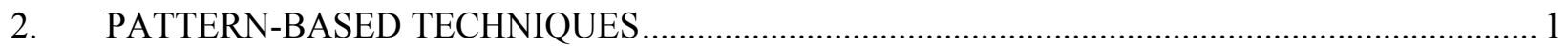

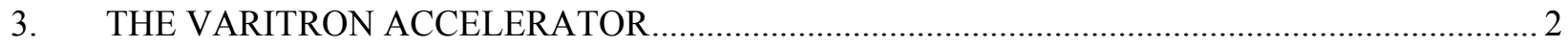

4. MONITORING OF EQUIPMENT OPERATION

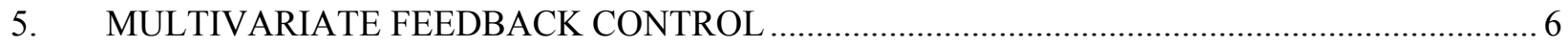

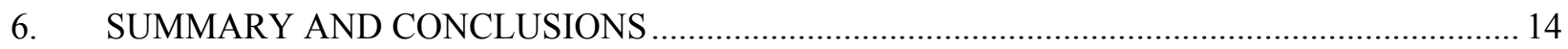

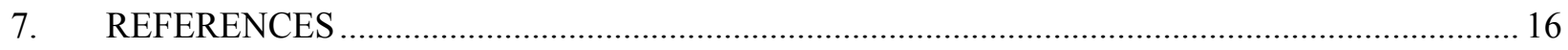

APPENDIX A: PLOTS FROM 6 MEV TEST CASES ................................................................ A-1

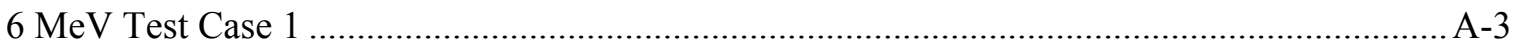

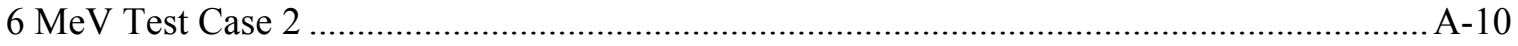

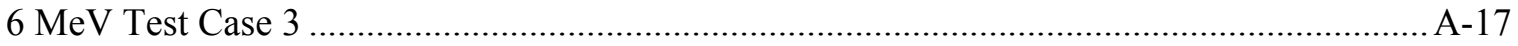

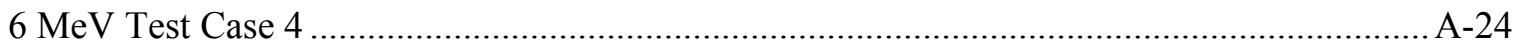

APPENDIX B: PLOTS FROM 7 MEV TEST CASE …................................................................... B-1

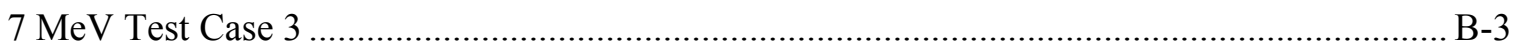

APPENDIX C: PLOTS FROM 8 MEV TEST CASES ….....................................................................

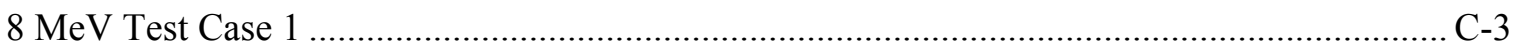

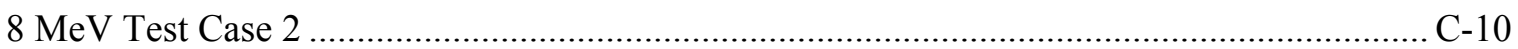

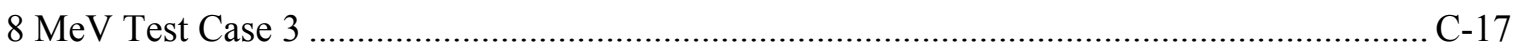

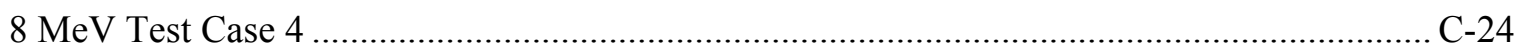




\section{FIGURES}

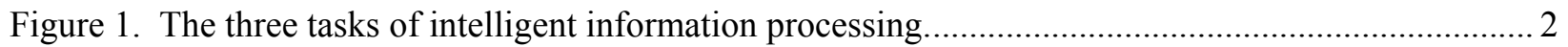

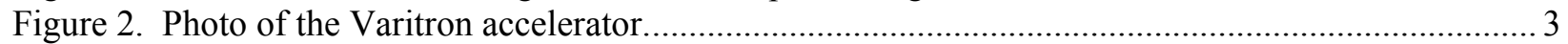

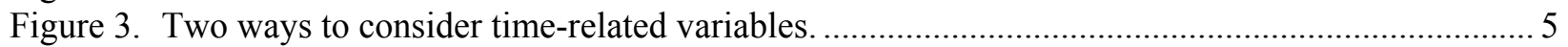

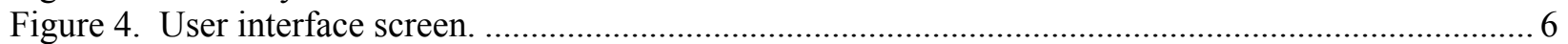

Figure 5. Software design for multivariate feedback control............................................................ 7

Figure 6. Plot of data stored in the three single-energy reference files................................................ 8

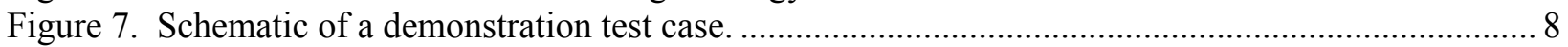

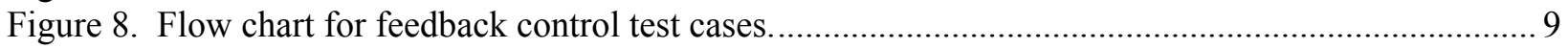

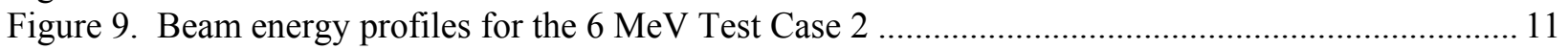

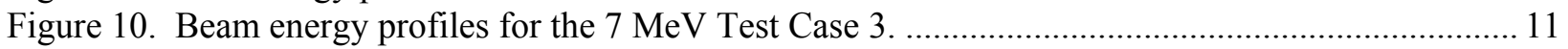

Figure 11. Beam energy profiles for the $8 \mathrm{MeV}$ Test Case 1...................................................... 12

Figure 12. The $6 \mathrm{MeV}$ data points from Table 3 overlaid on the reference file data (Figure 6)............... 13

Figure 13. The $7 \mathrm{MeV}$ data points from Table 3 overlaid on the reference file data (Figure 6)............... 13

Figure 14. The $8 \mathrm{MeV}$ data points from Table 3 overlaid on the reference file data (Figure 6)............... 14

Figure A1. $6 \mathrm{MeV}$ Test Case 1, energy profiles. ......................................................................... A-3

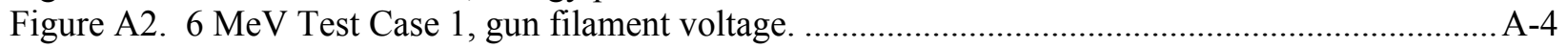

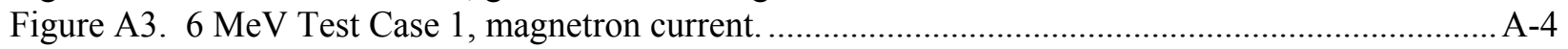

Figure A4. $6 \mathrm{MeV}$ Test Case 1, beam current. .......................................................................... A-5

Figure A5. $6 \mathrm{MeV}$ Test Case 1, cavity temperature...................................................................

Figure A6. $6 \mathrm{MeV}$ Test Case 1, dummy load temperature. ...............................................................

Figure A7. $6 \mathrm{MeV}$ Test Case 1, magnetron temperature. ............................................................. A-6

Figure A8. $6 \mathrm{MeV}$ Test Case 1, electromagnet temperature.............................................................. A-7

Figure A9. $6 \mathrm{MeV}$ Test Case 1, vacion pressure. …….................................................................... A-7

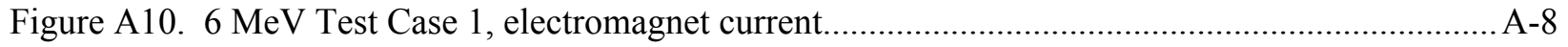

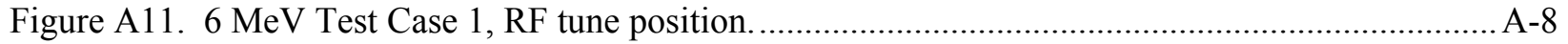

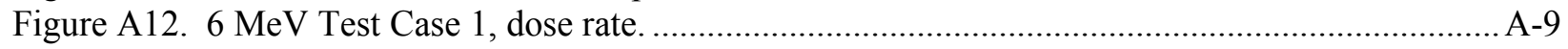

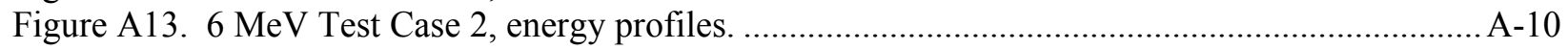

Figure A14. $6 \mathrm{MeV}$ Test Case 2, gun filament voltage. ................................................................

Figure A15. $6 \mathrm{MeV}$ Test Case 2, magnetron current. ...........................................................................11

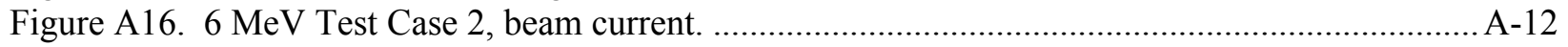

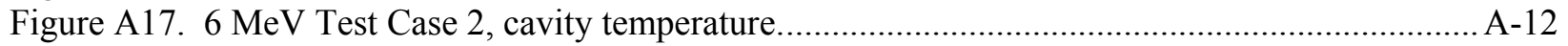

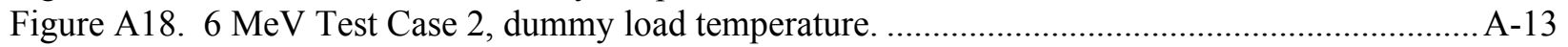

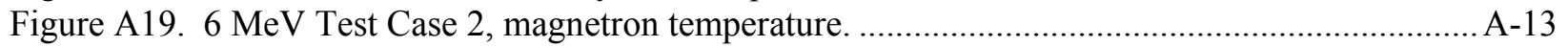

Figure A20. $6 \mathrm{MeV}$ Test Case 2, electromagnet temperature ........................................................ A-14

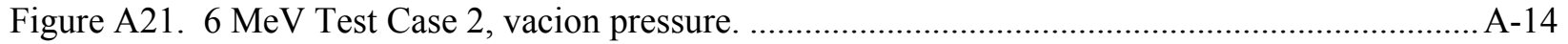

Figure A22. $6 \mathrm{MeV}$ Test Case 2, electromagnet current..................................................................

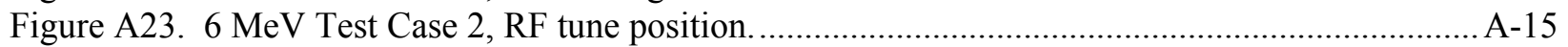

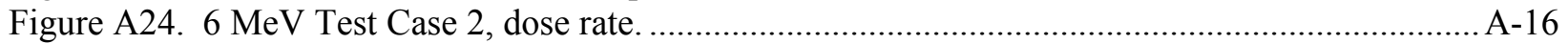

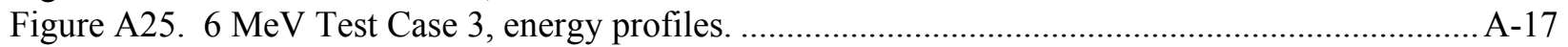

Figure A26. $6 \mathrm{MeV}$ Test Case 3, gun filament voltage. ................................................................. A-18

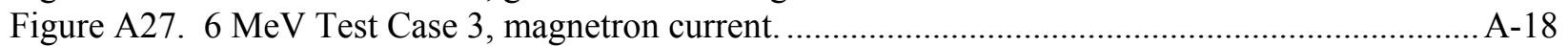

Figure A28. $6 \mathrm{MeV}$ Test Case 3, beam current. ............................................................................... A-19

Figure A29. $6 \mathrm{MeV}$ Test Case 3, cavity temperature................................................................. A-19

Figure A30. $6 \mathrm{MeV}$ Test Case 3, dummy load temperature. ....................................................... A-20

Figure A31. $6 \mathrm{MeV}$ Test Case 3, magnetron temperature. ..............................................................

Figure A32. $6 \mathrm{MeV}$ Test Case 3, electromagnet temperature .................................................. A-21

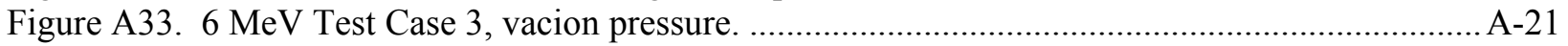

Figure A34. $6 \mathrm{MeV}$ Test Case 3, electromagnet current............................................................. A-22 


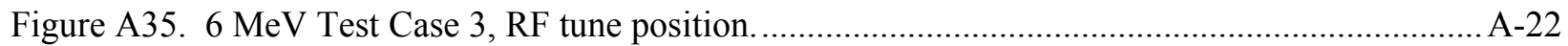

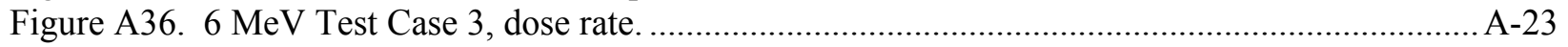

Figure A37. $6 \mathrm{MeV}$ Test Case 4, energy profiles. ................................................................

Figure A38. $6 \mathrm{MeV}$ Test Case 4, gun filament voltage. .......................................................... A-25

Figure A39. $6 \mathrm{MeV}$ Test Case 4, magnetron current. .............................................................. A-25

Figure A40. $6 \mathrm{MeV}$ Test Case 4, beam current. …...........................................................................

Figure A41. $6 \mathrm{MeV}$ Test Case 4, cavity temperature.......................................................................26

Figure A42. $6 \mathrm{MeV}$ Test Case 4, dummy load temperature. ........................................................ A-27

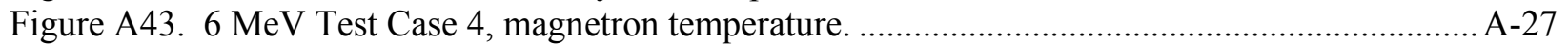

Figure A44. $6 \mathrm{MeV}$ Test Case 4, electromagnet temperature ..........................................................28

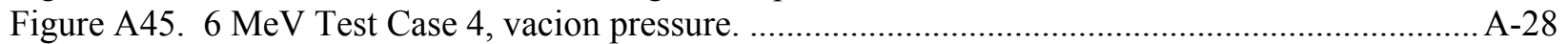

Figure A46. $6 \mathrm{MeV}$ Test Case 4, electromagnet current..................................................................29

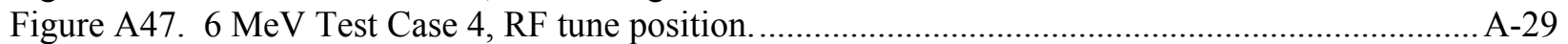

Figure A48. $6 \mathrm{MeV}$ Test Case 4, dose rate ....................................................................................

Figure B1. $7 \mathrm{MeV}$ Test Case 3, energy profiles........................................................................ B-3

Figure B2. $7 \mathrm{MeV}$ Test Case 3, gun filament voltage........................................................................

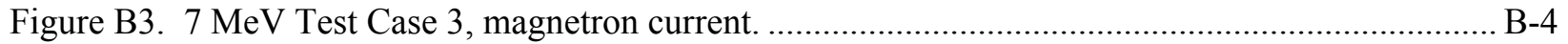

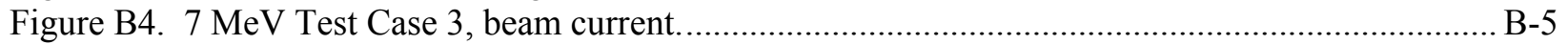

Figure B5. $7 \mathrm{MeV}$ Test Case 3, cavity temperature...................................................................... B-5

Figure B6. $7 \mathrm{MeV}$ Test Case 3, dummy load temperature .............................................................. B-6

Figure B7. $7 \mathrm{MeV}$ Test Case 3, magnetron temperature..................................................................

Figure B8. $7 \mathrm{MeV}$ Test Case 3, electromagnet temperature .............................................................. B-7

Figure B9. $7 \mathrm{MeV}$ Test Case 3, vacion pressure................................................................. B-7

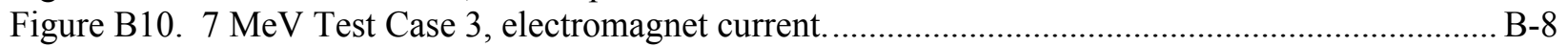

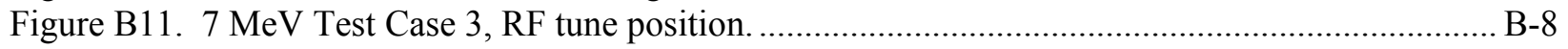

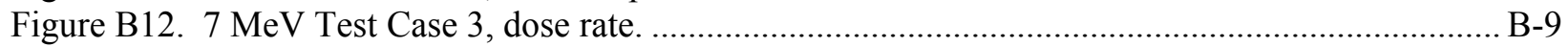

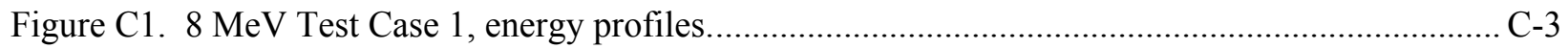

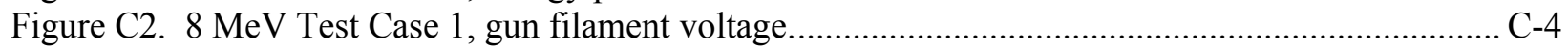

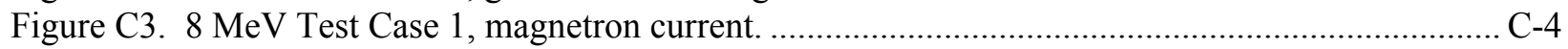

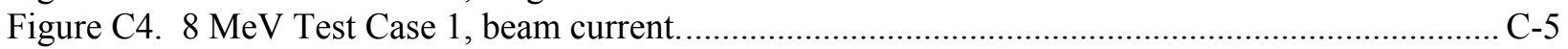

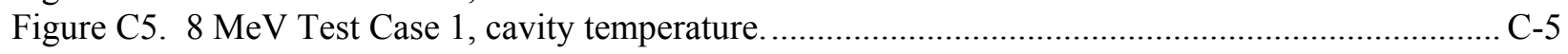

Figure C6. $8 \mathrm{MeV}$ Test Case 1, dummy load temperature.....................................................................

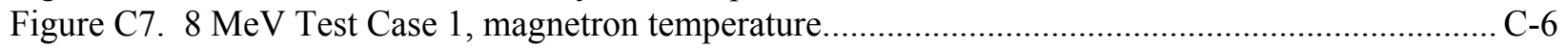

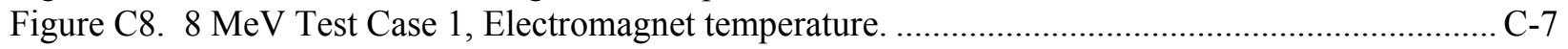

Figure C9. $8 \mathrm{MeV}$ Test Case 1, vacion pressure........................................................................

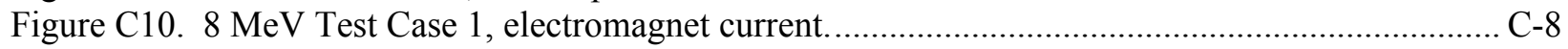

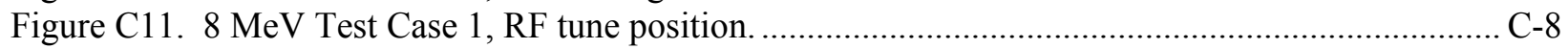

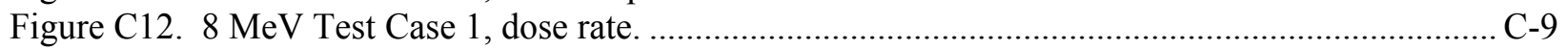

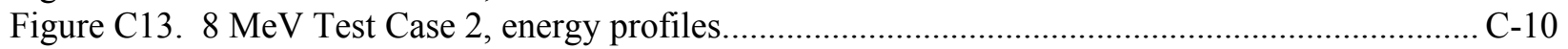

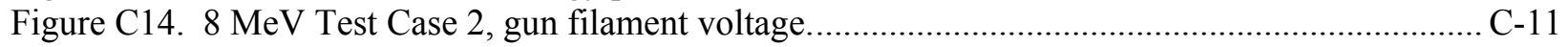

Figure C15. $8 \mathrm{MeV}$ Test Case 2, magnetron current. …......................................................................

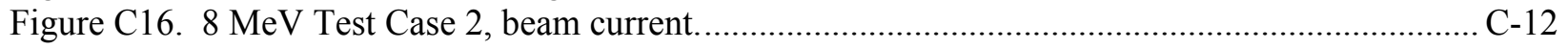

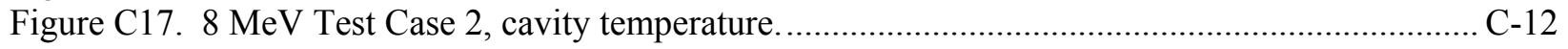

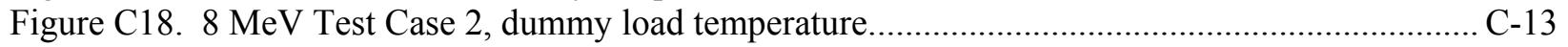

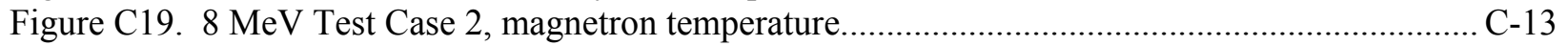

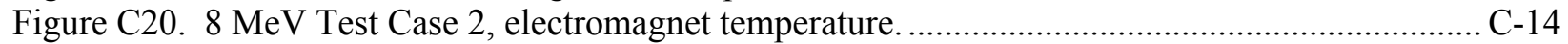

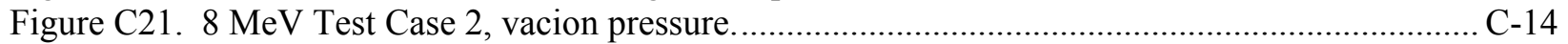

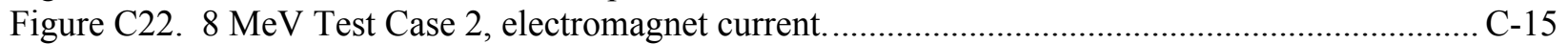

Figure C23. $8 \mathrm{MeV}$ Test Case 2, RF tune position......................................................................... 


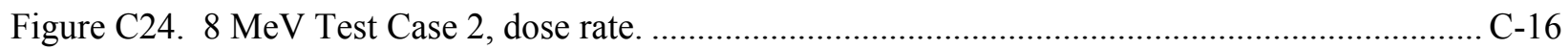

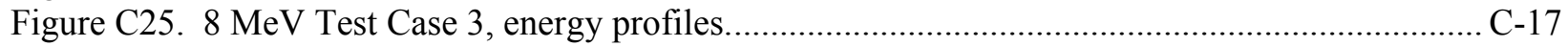

Figure C26. $8 \mathrm{MeV}$ Test Case 3, gun filament voltage.................................................................... C-18

Figure C27. $8 \mathrm{MeV}$ Test Case 3, magnetron current. ......................................................................... C-18

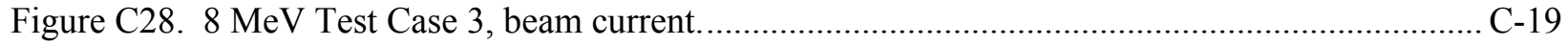

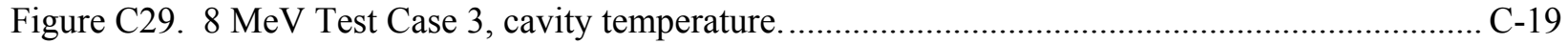

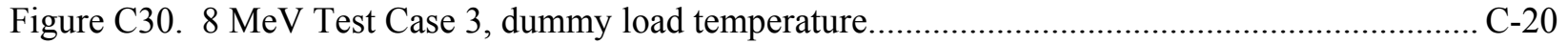

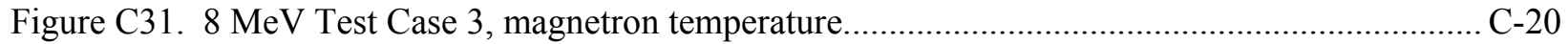

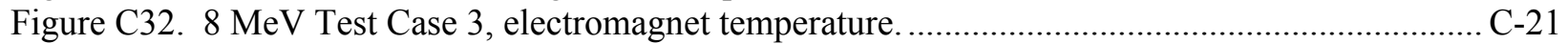

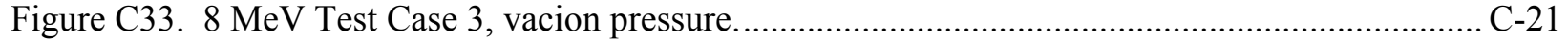

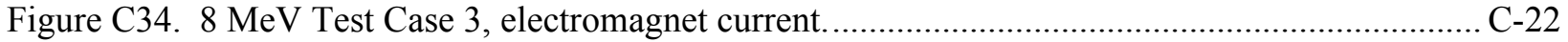

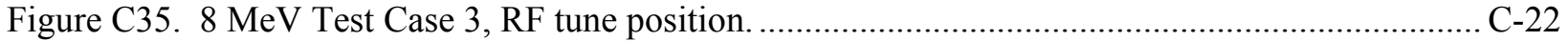

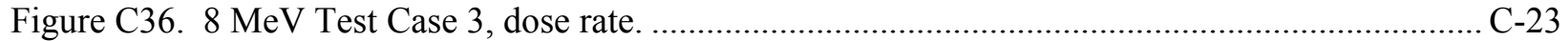

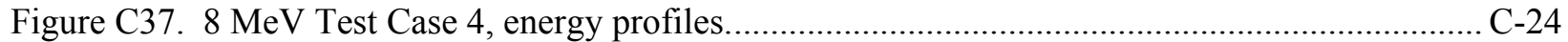

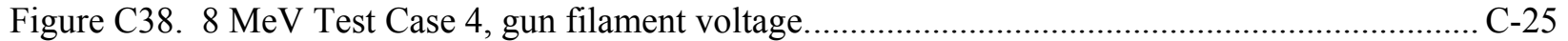

Figure C39. $8 \mathrm{MeV}$ Test Case 4, magnetron current. ..................................................................

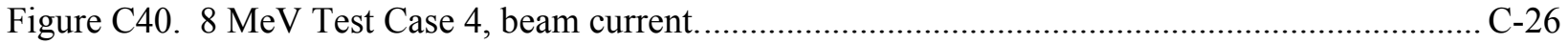

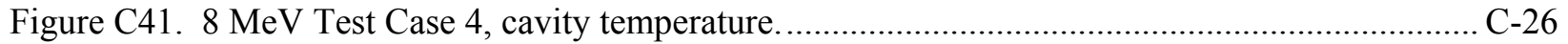

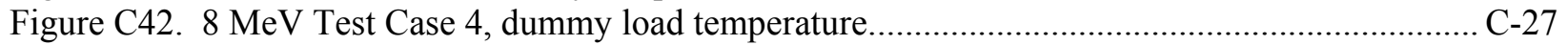

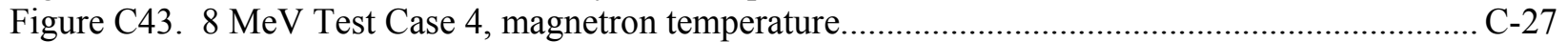

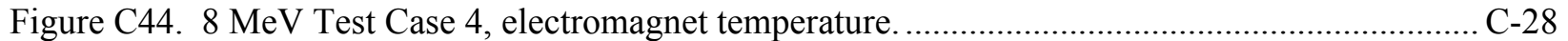

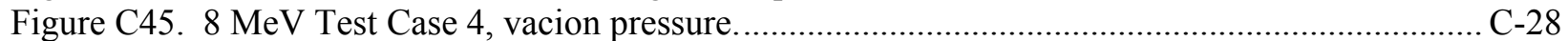

Figure C46. $8 \mathrm{MeV}$ Test Case 4, electromagnet current................................................................... C-29

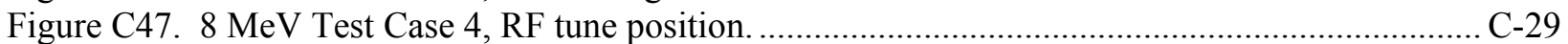

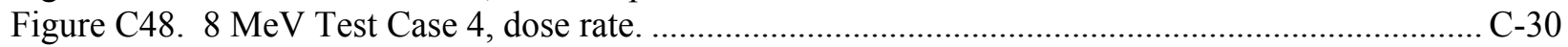

\section{TABLES}

Table 1. Accelerator operational and health parameters............................................................... 4

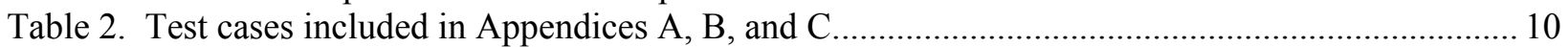

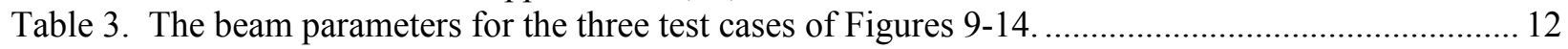

Table A1. $6 \mathrm{MeV}$ Test Case 1, timing chart for operator actions. .................................................... A-3

Table A2. $6 \mathrm{MeV}$ Test Case 2, timing chart for operator actions. ................................................... A-10

Table A3. $6 \mathrm{MeV}$ Test Case 3, timing chart for operator actions. .................................................... A-17

Table A4. $6 \mathrm{MeV}$ Test Case 4, timing chart for operator actions. .................................................. A-24

Table B1. $7 \mathrm{MeV}$ Test Case 3, timing chart for operator actions. ...................................................... B-3

Table C1. $8 \mathrm{MeV}$ Test Case 1, timing chart for operator actions. ...................................................... C-3

Table C1. $8 \mathrm{MeV}$ Test Case 2, timing chart for operator actions. .........................................................

Table C3. $8 \mathrm{MeV}$ Test Case 3, timing chart for operator actions. ....................................................... C-17

Table C4. $8 \mathrm{MeV}$ Test Case 4, timing chart for operator actions. ..................................................... C-24 


\section{Using Patterns for Multivariate Monitoring and Feedback Control of Linear Accelerator Performance: Proof-of-Concept Research}

\section{INTRODUCTION}

Two recent research projects of the Waste Management Technologies Department of the Idaho National Engineering and Environmental Laboratory (INEEL) provided proof-of-concept for using a new INEEL software package, the Advanced Data Validation and Verification System (ADVVS), to monitor the operation of nondestructive analysis (NDA) equipment and control the equipment through modelbased multivariate feedback control. The studies provided new software methods for waste management technologies that will add validation and verification to the operation and control of NDA equipment when it is deployed either separately or as part of an integrated system. ADVVS performs intelligent information processing through pattern recognition and analysis.

The first research project used ADVVS to monitor the operation of a linear electron accelerator. Signature patterns of accelerator operating data were collected for optimal tune conditions and analyzed with pattern recognition software techniques of ADVVS. It was shown during FY2001 in a proof-ofconcept demonstration that the software could recognize in real time any deviations from an optimal accelerator tune. The software package is ready for deployment with other NDA equipment.

The second project extended the first application to provide multivariate feedback control to the linear electron accelerator using signature patterns of operational data and pattern recognition techniques in a similar manner as the first project. The ADVVS modeled expected accelerator patterns for comparison with actual operating patterns. When suboptimal tune conditions were recognized, the ADVVS returned the accelerator to optimal tune conditions. The proof-of-concept for the extended application was demonstrated during FY2001 and FY2002.

The ADVVS uses pattern recognition and analysis such as found in human cognition. Human cognition recognizes patterns and changes in patterns in new and changing information.

The following sections expand upon the concept of intelligent information processing that uses pattern recognition and analysis, discuss the two research projects, present conclusions, and list the references. It is important to note that the report is not intended to analyze the accelerator operation or the performance of the system sensors.

The complete data plots are found in the Appendices. In both the report sections and the appendices, the data are presented as they were recorded without removing random noise or data spikes that are intrinsic to accelerator system performance.

\section{PATTERN-BASED TECHNIQUES}

One field of research at the INEEL is based on the recognition and analysis of evolving patterns as a unifying concept for studying and implementing intelligent information processing systems. The research considers that these systems should be modeled on human cognition, that is, the evolving spatial patterns within the human brain as new and changing information is perceived and interpreted. ${ }^{1}$

Human perception emerges from the evolving and changing patterns that the human observes either consciously or subconsciously, and the relationships of these new patterns to patterns that the human has 
mentally stored from the past. Implementing the processes of human cognition in software for practical NDA applications can be facilitated by extracting useful signature patterns from NDA operational and measurement data and manipulating the patterns in computer software. The software should recognize and understand the changes in the patterns, the direction in which the system is evolving, the acceptable direction of evolution (goal) and the conditions or attributes in the patterns that indicate significant changes.

The intelligent processing of information as defined above can be decomposed into three tasks, as shown in Figure 1. The first task is pre-processing the raw data to extract the patterns or data signatures. The second task is recognizing and analyzing the patterns to extract the useful information. The third task is to postprocess the information to achieve application goals. Automating these three tasks can provide consistent, accurate results in near real time.

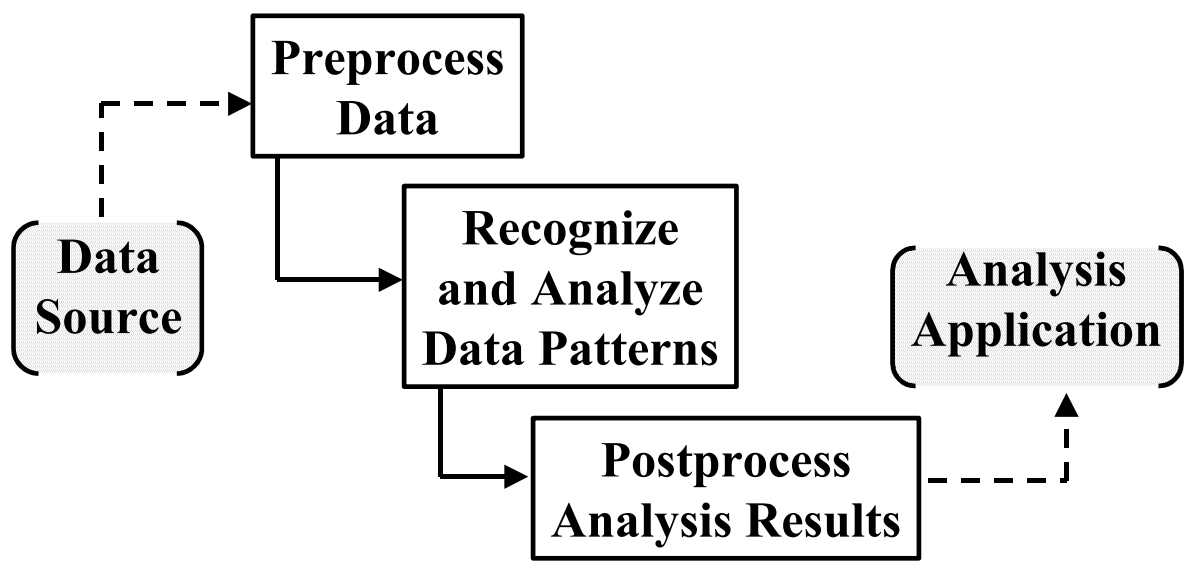

Figure 1. The three tasks of intelligent information processing.

The three tasks can actually be implemented with a variety of custom or commercial software packages. But the projects discussed here used variations of the same intelligent information processing software called the Advanced Data Validation and Verification System (ADVVS). The ADVVS has an INEEL-written shell that is tailored for each specific application. The shell collects the data, performs the pre- and post-processing tasks, and applies the results. It calls modules from a commercially available kernel to perform pattern recognition and analysis. The software selected for the ADVVS kernel is licensed by INEEL from Triant Technologies Inc. and is named Universal Process Modeling (UPM) ${ }^{\mathrm{TM}} .^{2}$ The kernel performs multivariate analysis of incoming data as compared with a set of established data patterns. It recognizes patterns and flags changes or features in the patterns that are statistically significant.

\section{THE VARITRON ACCELERATOR}

The selectable-energy electron accelerator used in the project is shown in Figure 2. It consists of a Varian, Inc. Model 3000A linear accelerator waveguide, an electron gun filament, injection control system, control cabling, signal output, water cooling connections, and enclosure; a radio-frequency (RF)drive system that provides the RF power to the accelerator via microwaves generated by a $2.1 \mathrm{MW}$ magnetron tube; and an electron beam energy and beam current measurement assembly. It is referred to as the 'Varitron' and is transportable. The accelerator waveguide is a series of tuned RF cavities that, when excited by microwave energy, will capture and accelerate injected electrons. ${ }^{3}$ 


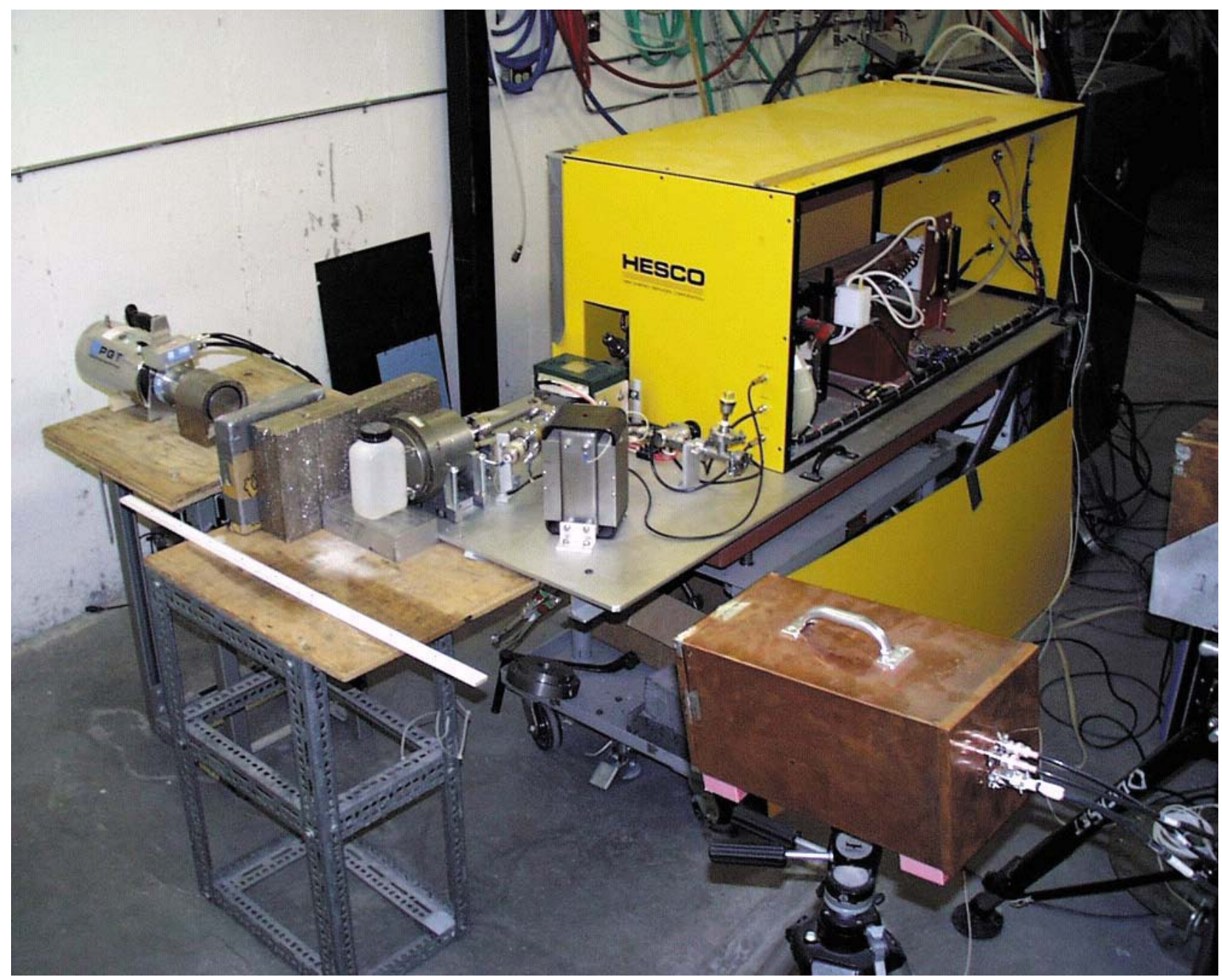

Figure 2. Photo of the Varitron accelerator.

During FY2000, the Varitron was used in subsurface science experiments that demanded precise knowledge of the energy of the electron beam and the deposited dose to the target, more precise demands than had previously been encountered. Running the Varitron accelerator was at that time an art form using the limited available real-time information of accelerator performance, and two manual control points. The Varitron was manually tuned and re-tuned during each day of use to keep a steady nominal electron beam energy. An accelerator tune is control settings that result in a dose rate, beam current, and beam energy that is judged acceptable by the operator. The three parameters are related by Equation (1).

Dose rate $=\mathrm{a} * \mathrm{I}_{\mathrm{c}} * \mathrm{E}^{2.7}$

where
$\mathrm{a}=$ constant
$\mathrm{I}_{\mathrm{c}}=$ beam current in amps
$\mathrm{E}=$ energy in $\mathrm{MeV}$. 
The Varitron was a logical choice for the parallel research project of demonstrating proof-ofconcept for using ADVVS to automatically monitor the operation of NDA equipment and provide the operators with a real-time validation and verification of equipment operational health.

Initially, seven Varitron operation parameters were available to the accelerator operators: the magnetron current, electron source gun filament voltage, vacuum pressure, beam target current, radiation exposure (dose), position of the radio-frequency (RF) tuning probe in the magnetron, and accelerator waveguide temperature. As both projects progressed, four more parameters were added to the Varitron system using three new temperature sensors and a new link to the electromagnetic current. The RF probe and the electromagnet current were enabled to be manually adjustable. By the end of the project, there were a total of 11 parameters of which four were control parameters, two were output parameters showing electron beam state, and five provided additional information on the accelerator operation health. A list of these parameters, their units of measure, function, and description are given in Table 1.

Table 1. Accelerator operational and health parameters.

\begin{tabular}{|c|c|c|}
\hline Parameter & Unit & Comments \\
\hline \multicolumn{3}{|l|}{ Direct Control Parameters } \\
\hline Gun Filament Voltage & volts & Voltage that controls the amount of source electrons \\
\hline Magnetron Current & amps & Electron current in the magnetron RF tube \\
\hline Electromagnet Current & amps & $\begin{array}{l}\text { Current applied to electromagnet to generate the magnetic } \\
\text { field that affects the magnetron }\end{array}$ \\
\hline Radio Frequency (RF) Position & percent & Position of tuning probe in the magnetron \\
\hline \multicolumn{3}{|l|}{ Electron Beam State Parameters } \\
\hline Target Beam Current & micro-amps & Average electron current at the accelerator's converter \\
\hline Radiation Dose Rate (Exposure) & Rads/min & $\begin{array}{l}\text { Radiation dose rate from electron bremsstrahlung radiation } \\
\text { as measured at the accelerator table }\end{array}$ \\
\hline \multicolumn{3}{|l|}{ Accelerator Health Parameters } \\
\hline Magnetron Temperature & ${ }^{\circ} \mathrm{C}$ & Temperature of magnetron tube \\
\hline Dummy Load Temperature & ${ }^{\circ} \mathrm{C}$ & Wall temperature of RF enclosure \\
\hline Electromagnet Temperature & ${ }^{\circ} \mathrm{C}$ & Temperature of electromagnet \\
\hline Cavity Assembly Temperature & ${ }^{\circ} \mathrm{C}$ & Temperature of accelerator waveguide \\
\hline Vacuum Ion Pump Pressure & micro-amps & Accelerator waveguide vacuum pressure \\
\hline
\end{tabular}

\section{MONITORING OF EQUIPMENT OPERATION}

The first project was conducted during FY2000-FY2001. It used a variation of ADVVS to monitor the operation of a selectable energy accelerator during subsurface science experiments at the Idaho Accelerator Center (IAC) at the Idaho State University. The results of the proof-of-concept demonstration can be generalized to monitoring the performance and health of more complex equipment or systems of components.

In current practice, most equipment modeling and control applications are based on time-related variables that can be plotted as shown on the left side of Figure 3. For example, displays of time versus pressure will show the pressure changes with time. In this application, information is considered as a 
vector of variable values at one point in time, as shown on the right of Figure 3. The time-stamped vector is a pattern that changes with time, and it is the signature of equipment operating condition. Analysis of the evolving signatures can reveal not only the changes within the operating parameters of the equipment but also the statistical importance of these changes to the operation of the equipment.
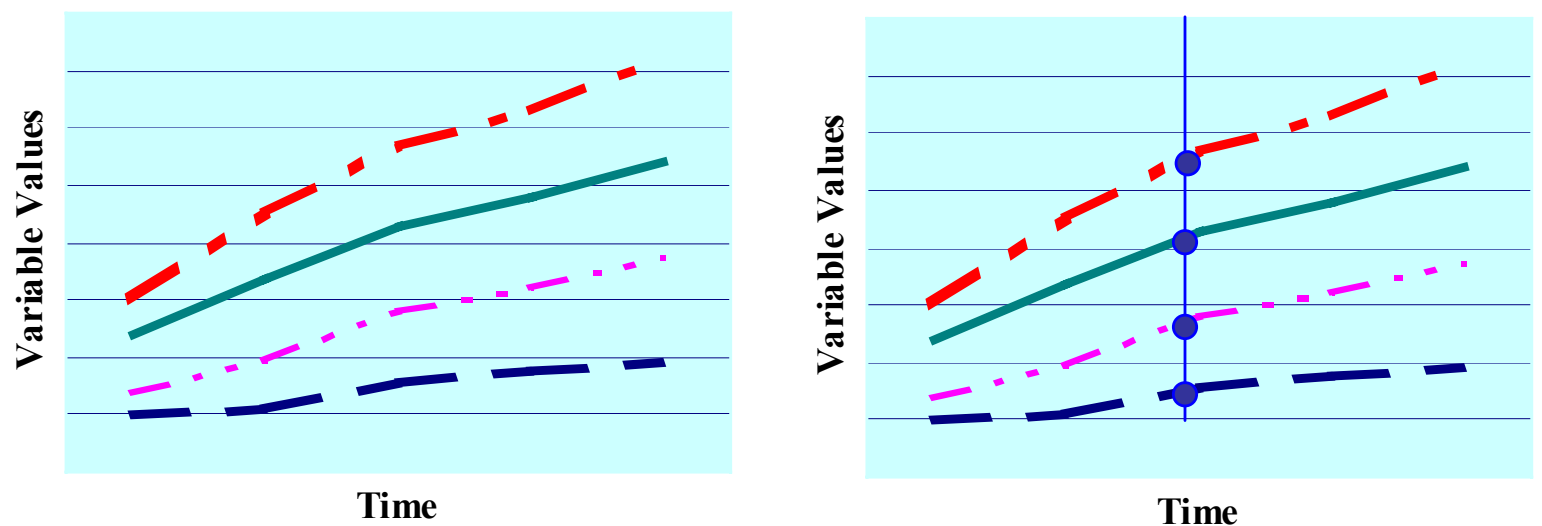

Figure 3. Two ways to consider time-related variables.

Pattern recognition techniques using the signatures provide real time capability to monitor the performance of NDA systems and interpret the resulting performance data.

Referring to the three tasks of intelligent information processing in Figure 1, the parameter data were acquired and preprocessed using the National Instruments (NI) LabVIEW ${ }^{\mathrm{TM}}$ graphical software package, NI isolation interface components, and LAB-PC-1200 NI-DAQ data acquisition cards. The analog data were converted to digital metric values and displayed to the operator in LabVIEW ${ }^{\text {ТM }}$ windows. Time-stamped data signals from the Varitron were logged during the subsurface science research to provide signature patterns of known accelerator operation.

For the pattern recognition and analysis task, the kernel first was used to model the functional relationships of the known operational modes off-line and prepare reference files. During subsequent accelerator operation, the kernel accepted the pattern of variable values in real time, compared the pattern with models of the stored patterns in the reference files, and mathematically analyzed both the relationship of the real time pattern with past performance patterns and the inter-relationship of the variables in the current pattern.

The post-processing task was facilitated through the LabVIEW ${ }^{\mathrm{TM}}$ interface that displayed the values and changes of the parameter and model variables, either as a time-stamped vector of the parameter values or as single-variable plots of the parameters versus time. The changes could be interpreted by the accelerator operator as newly identified data characteristics to be added off-line to the reference file of known operation modes, or as operating system anomalies. Depending on the operators' decisions, the Varitron could be retuned or turned off.

The upper lefthand portion of Figure 4 shows a simulation of the output window that displayed the real-time data pattern and the expected value in the model of variables as calculated from the reference files. The real-time values of the parameters are in the column labeled 'Varitron'. The calculated values of these parameters based on the historic data files are shown in the column titled 'model'. A real-time 
Varitron variable that is statistically different from the modeled value is identified in red; in this simulation it is the beam current value.

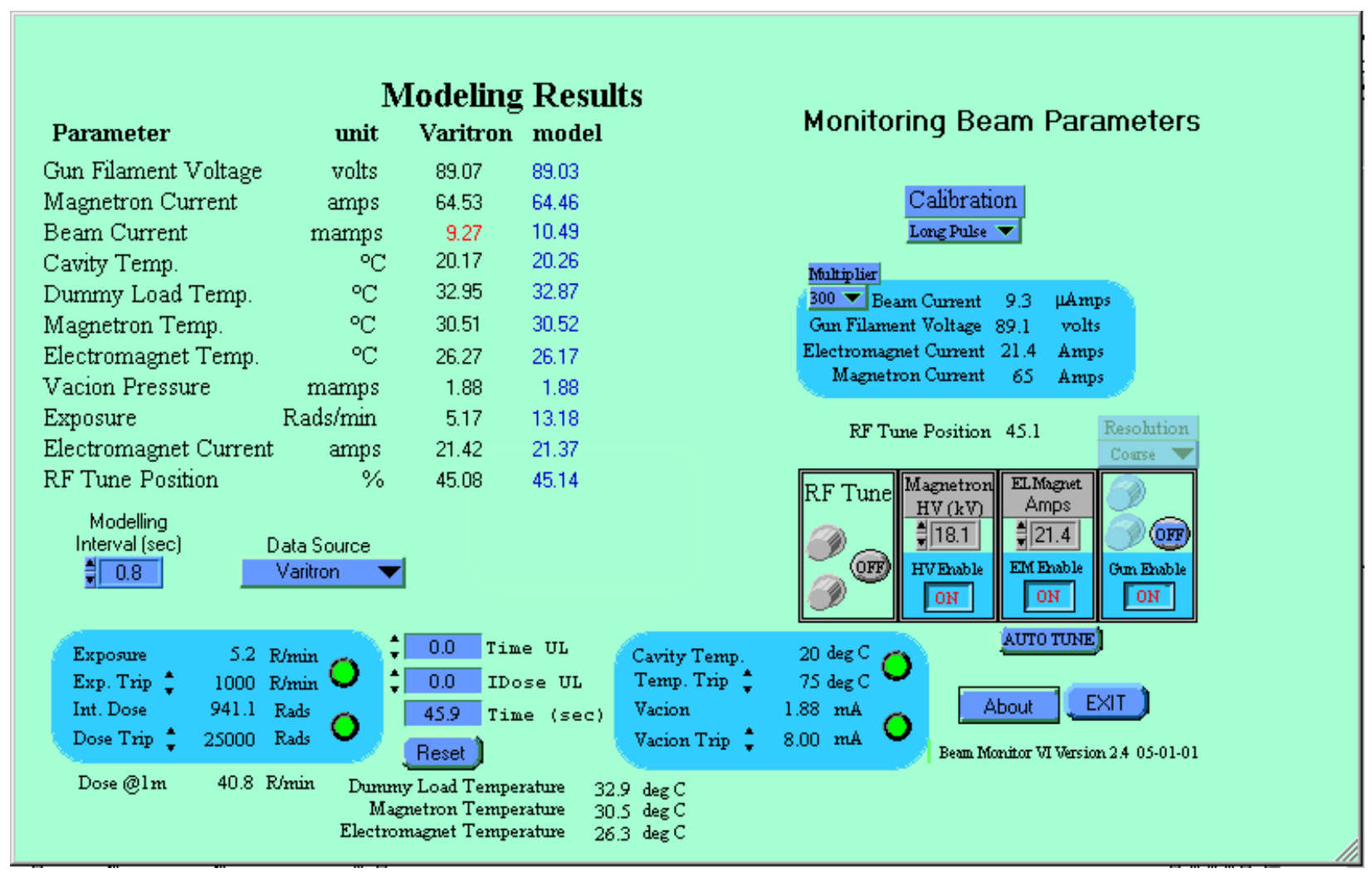

Figure 4. User interface screen.

The software was successfully demonstrated in real time during accelerator operation, ${ }^{4}$ and the operators acknowledged that the ADVVS process resulted in a better characterization and operation of the Varitron for the subsurface science research. The software is ready for deployment.

\section{MULTIVARIATE FEEDBACK CONTROL}

The second project was conducted during FY2001 and FY2002. The work was proposed when the software research team realized that the multivariate pattern recognition approach similar to that of the first project might prove valuable for automatic, model-based multivariate, real-time feedback control of the Varitron or other NDA equipment. The proof-of-concept was successfully demonstrated and the results can be generalized to other applications of pattern-based feedback control.

The second project again used the Varitron accelerator and instrumentation. The operational data was preprocessed with the same LabVIEW ${ }^{\mathrm{TM}}$ hardware interface, the windows from the first project being retained to monitor the operation of the accelerator. The ADVVS kernel was again used for pattern recognition and analysis.

The two projects differed in the post-processing of the analysis information. In the first project, the accelerator operator referred to the LabVIEW ${ }^{\mathrm{TM}}$ windows and manually adjusted the control parameters one at a time until an acceptable tune was achieved. In the second project, the modeled values for the control variables were automatically used by ADVVS to reset the four accelerator controls when one or 
more of the real-time parameter values were flagged by ADVVS as representing an out-of-tune condition. The software modifications for the second project were coded into the INEEL-written shell, using the design shown in Figure 5.

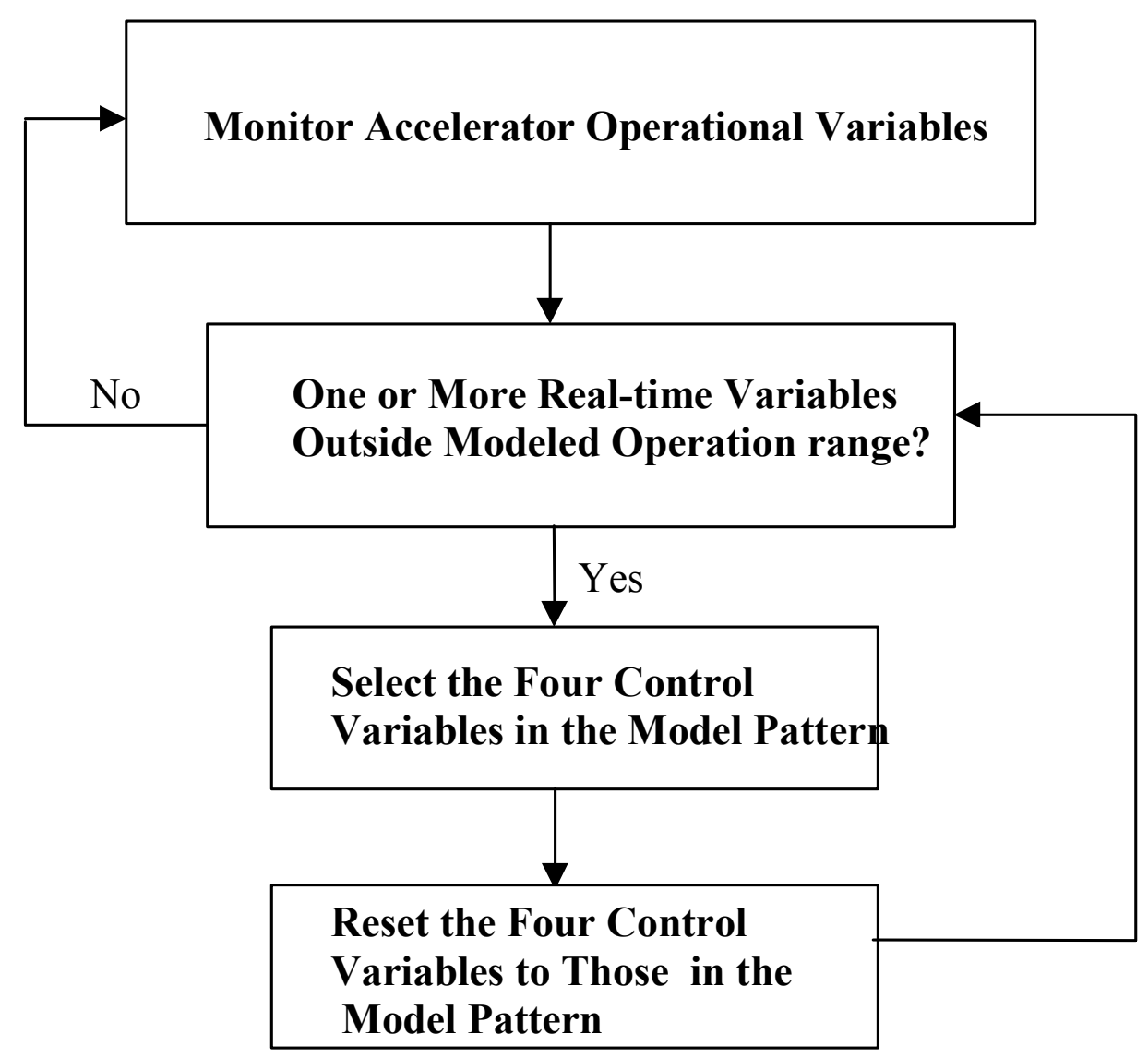

Figure 5. Software design for multivariate feedback control.

The proof-of-concept demonstration of this approach was limited to accelerator operations at beam energies of 6,7 , and $8 \mathrm{MeV}$. Patterns of operational data were logged during actual in-tune accelerator operation at the three energies. The data represented the wide range of combinations of control parameter values that produced optimal tunes for 6,7 , and $8 \mathrm{MeV}$. Once the reference file was prepared, it actually stored three mono-energetic multi-dimensional phase surfaces of patterns representing the range of useful accelerator operational tunes at the three energies. The data stored in the reference file is shown in Figure 6. Note that the three volumes are disjoint. 


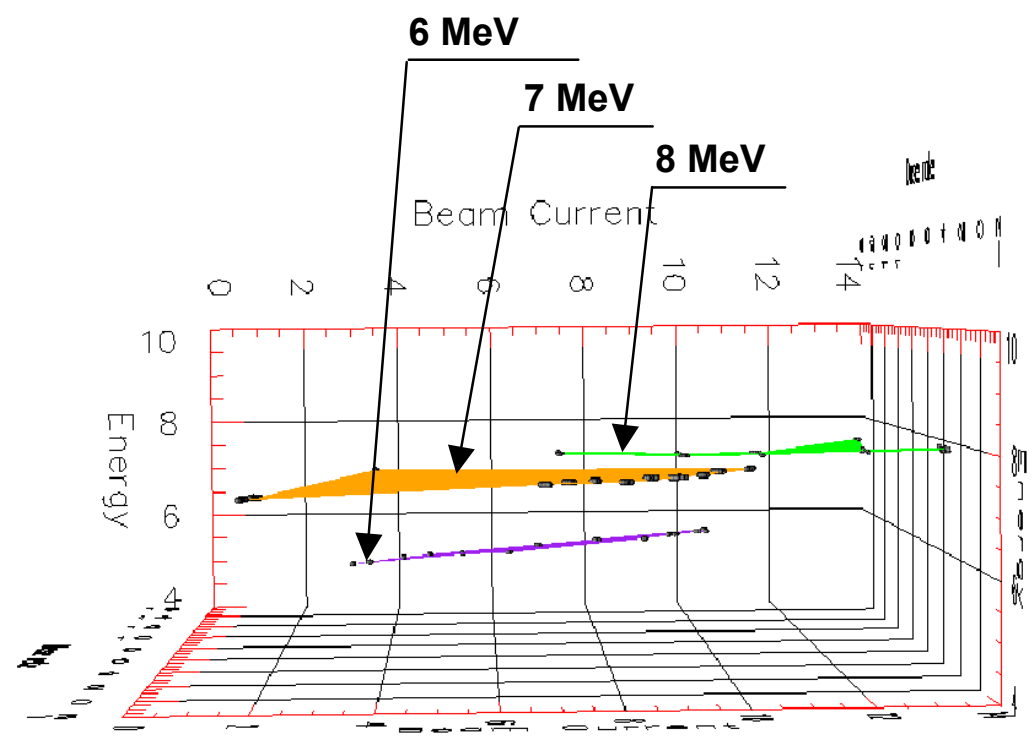

Figure 6. Plot of data stored in the three single-energy reference files.

Figure 7 gives a schematic of a demonstration test case. The accelerator was initially tuned to a selected energy (point A in Figure 7). A change to the energy level was artificially induced by a manual change of the gun filament voltage that perturbed all of the accelerator operating parameters, including energy level (point B in Figure 7). ADVVS in monitoring mode detected the out-of-tune condition since the nearest model state differed from the current operating condition of the accelerator by more than the user-defined tolerance. When the feedback control mode of ADVVS was enabled, ADVVS automatically and simultaneously reset all four accelerator control parameters to the values in the nearest model state. The nearest model state is the point on the phase surface for the selected energy (point $\mathrm{C}$ in Figure 7) closest in phase space to the perturbed state. The feedback loop was automatically repeated by ADVVS until the accelerator was returned to an optimal tune for the energy (not necessarily the same optimal tune as used initially).

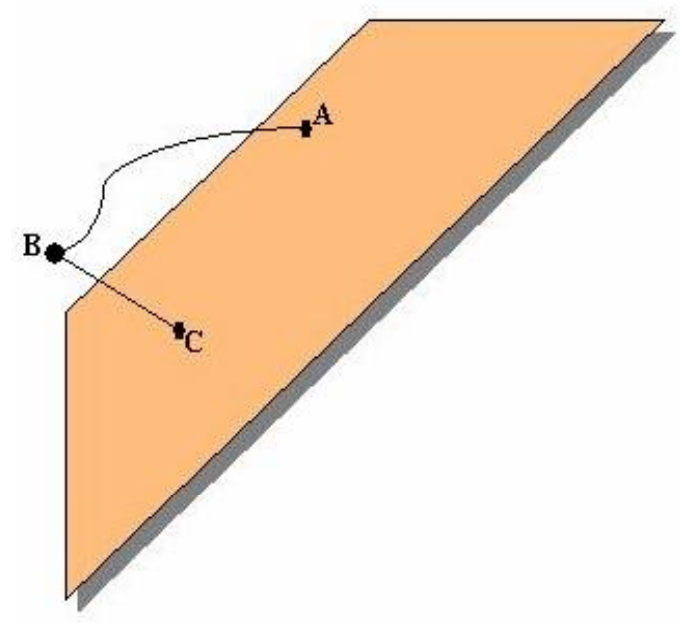

Figure 7. Schematic of a demonstration test case. 
The planned sequence of operations for each test case is given in Figure 8.

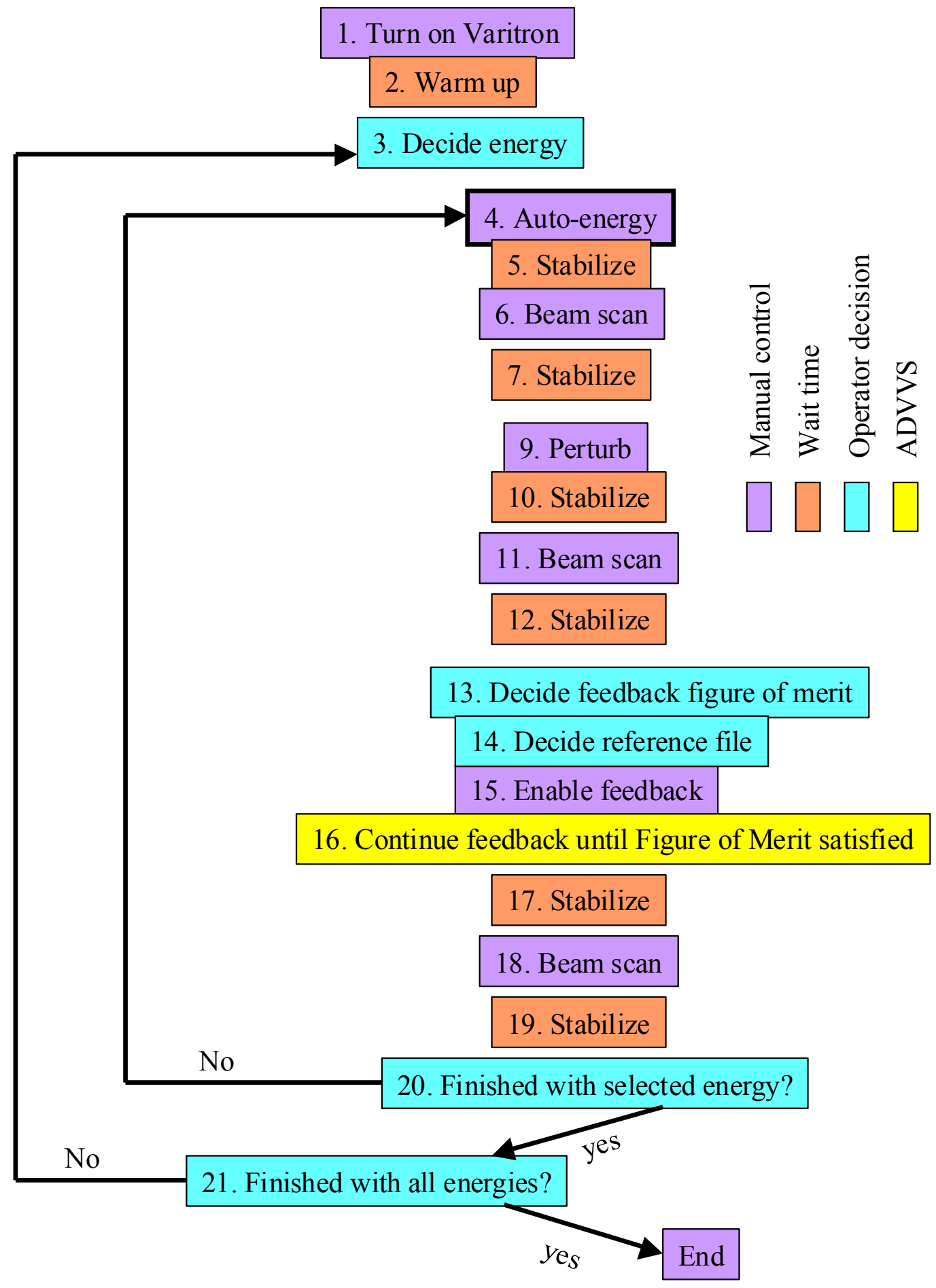

Figure 8. Flow chart for feedback control test cases.

Test cases were run at the three energies of 6,7 , and $8 \mathrm{MeV}$. For each test case, it was necessary to select the figure of merit to be used by ADVVS to decide when the accelerator tune had been restored and 
the feedback control operation was complete. It was possible to select either the beam current value for a single-parameter figure of merit, or the entire set of eleven parameters for an all-parameter figure of merit. Also for each test case, it was necessary to select the reference file to be used by ADVVS. This selection could be either the single reference file specific to the accelerator energy tune or the combined reference files of all three energies. Thus, twelve distinct test cases were identified for the test matrix. Many test cases were run on two separate days, and data for nine of the test case scenarios are included in this report using the test case designations given in Table 2 . They successfully demonstrate the proof-ofconcept, as do the test case runs not included in the report.

Appendices A, B, and C present data plots from the nine test cases for the recorded twelve parameters. The data gaps in the $7 \mathrm{MeV}$ Test Case 3 plots resulted in a lack of recorded data during beam scans during the earlier test case runs.

Table 2. Test cases included in Appendices A, B, and C.

\begin{tabular}{|c|c|c|c|c|}
\hline Test Case Designation & Energy & Reference File & Figure of Merit & Appendix \\
\hline & & & & \\
\hline $6 \mathrm{MeV}$ Test Case 1 & $6 \mathrm{MeV}$ & Single energy, $6 \mathrm{MeV}$ & Beam current & $\mathrm{A}$ \\
\hline $6 \mathrm{MeV}$ Test Case 2 & $6 \mathrm{MeV}$ & Single energy, $6 \mathrm{MeV}$ & All parameters & $\mathrm{A}$ \\
\hline $6 \mathrm{MeV}$ Test Case 3 & $6 \mathrm{MeV}$ & Combined energies & Beam current & $\mathrm{A}$ \\
\hline $6 \mathrm{MeV}$ Test Case 4 & $6 \mathrm{MeV}$ & Combined energies & All parameters & $\mathrm{A}$ \\
\hline & & & & \\
\hline $7 \mathrm{MeV}$ Test Case 1 & $7 \mathrm{MeV}$ & Single energy, $7 \mathrm{MeV}$ & Beam current & $\mathrm{n} / \mathrm{a}$ \\
\hline $7 \mathrm{MeV}$ Test Case 2 & $7 \mathrm{MeV}$ & Single energy, $7 \mathrm{MeV}$ & All parameters & $\mathrm{n} / \mathrm{a}$ \\
\hline $7 \mathrm{MeV}$ Test Case 3 & $7 \mathrm{MeV}$ & Combined energies & Beam current & $\mathrm{B}$ \\
\hline $7 \mathrm{MeV}$ Test Case 4 & $7 \mathrm{MeV}$ & Combined energies & All parameters & $\mathrm{n} / \mathrm{a}$ \\
\hline & & & & \\
\hline $8 \mathrm{MeV}$ Test Case 1 & $8 \mathrm{MeV}$ & Single energy, $8 \mathrm{MeV}$ & Beam current & $\mathrm{C}$ \\
\hline $8 \mathrm{MeV}$ Test Case 2 & $8 \mathrm{MeV}$ & Single energy, $8 \mathrm{MeV}$ & All parameters & $\mathrm{C}$ \\
\hline $8 \mathrm{MeV}$ Test Case 3 & $8 \mathrm{MeV}$ & Combined energies & Beam current & $\mathrm{C}$ \\
\hline $8 \mathrm{MeV}$ Test Case 4 & $8 \mathrm{MeV}$ & Combined energies & All parameters & $\mathrm{C}$ \\
\hline
\end{tabular}

As shown in the flow chart, each test case included three beam scans, one each to measure the initial accelerator beam energy, the perturbed beam energy, and the restored beam energy. During a beam scan, the beam current exiting the accelerator is magnetically bent to cross a secondary Faraday cup. The peak current measured by the secondary Faraday cup during the scan is mathematically related to the energy of the beam by Equation (2).

$$
\mathrm{E}=\left[\mathrm{I}_{\mathrm{p}}-1.06150\right] / 1.0715
$$

where

$$
\begin{aligned}
& \mathrm{E}=\text { energy in } \mathrm{MeV} \\
& \mathrm{I}_{\mathrm{p}}=\text { current in amps. }
\end{aligned}
$$

Given below in Figures 9, 10, and 11 are energy profiles for representative test cases at 6, 7, and 8 $\mathrm{MeV}$, respectively. They show that the ADVVS feedback control did indeed return the acceleration operation to the initial energy after the manual perturbation of the gun filament changed the accelerator tune to a point outside the initial tune space. 


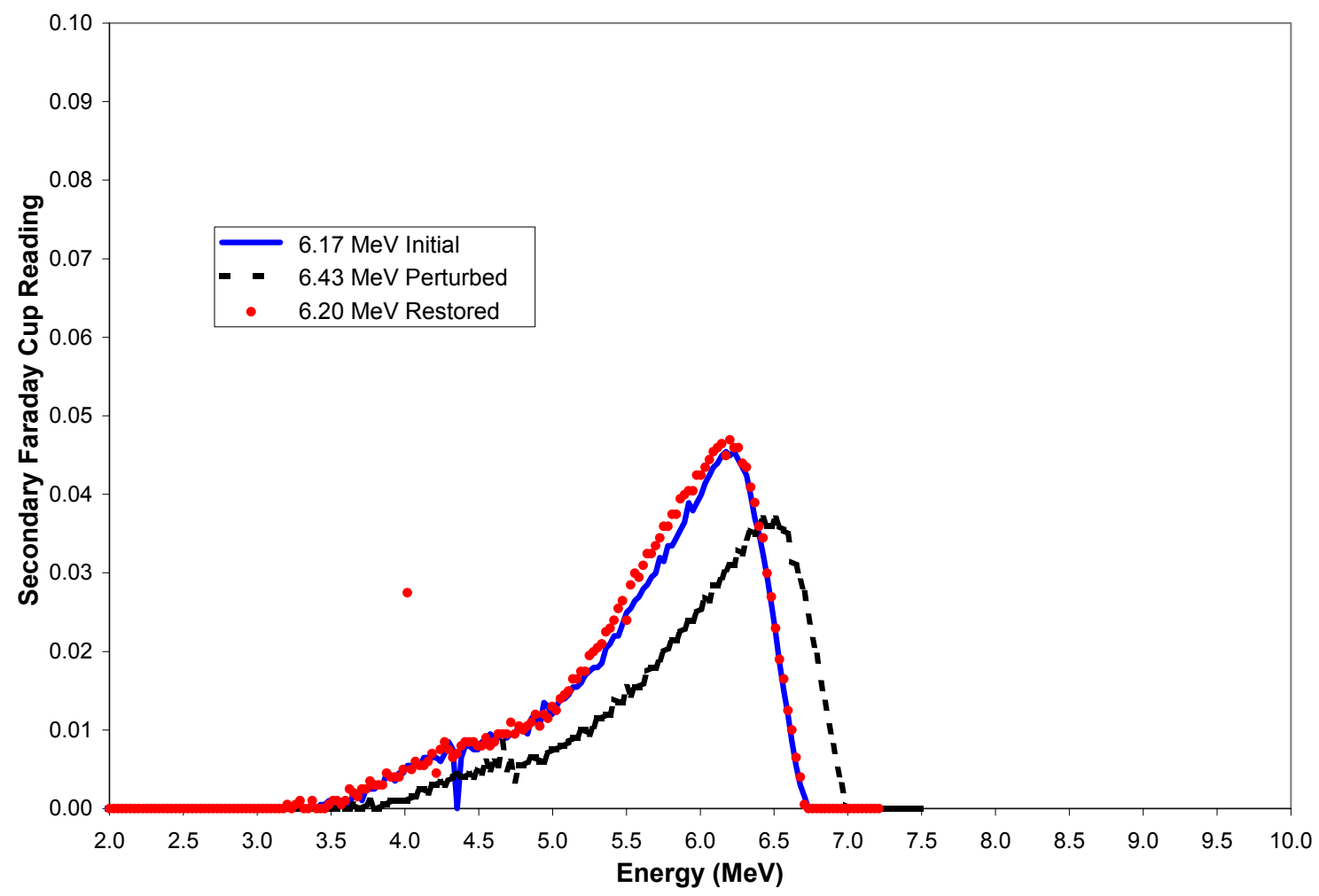

Figure 9. Beam energy profiles for the $6 \mathrm{MeV}$ Test Case 2.

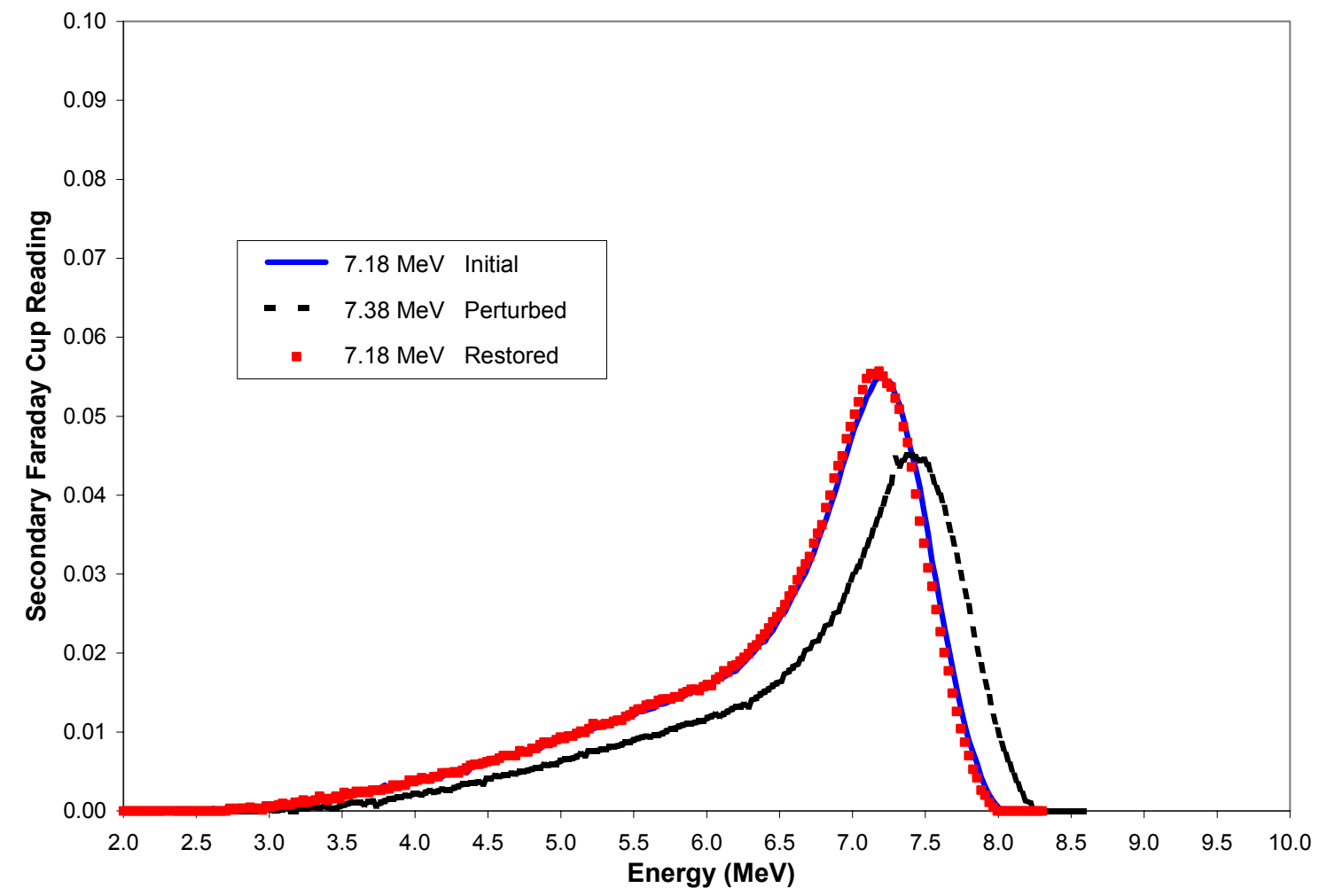

Figure 10. Beam energy profiles for the $7 \mathrm{MeV}$ Test Case 3 . 


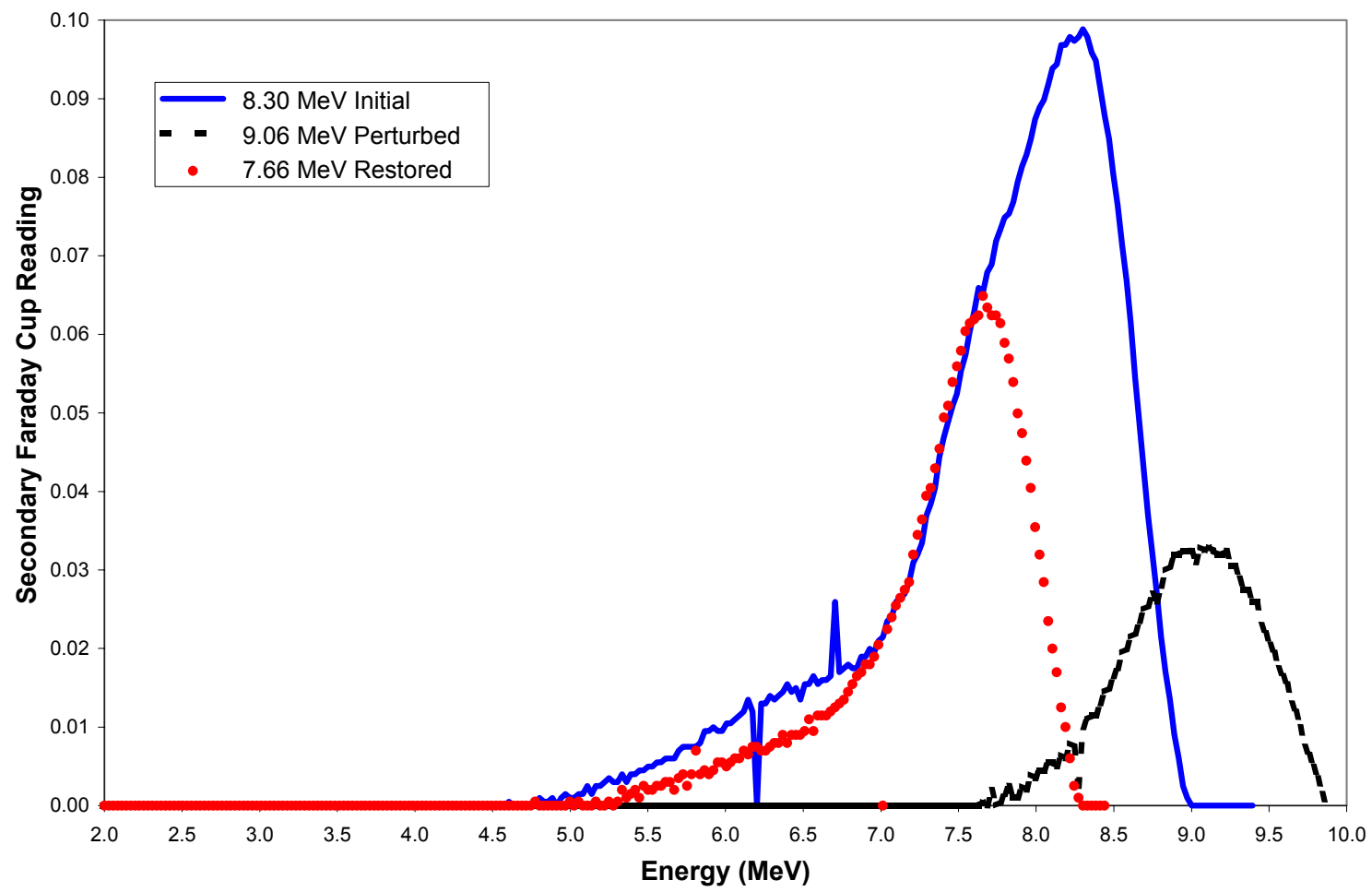

Figure 11. Beam energy profiles for the $8 \mathrm{MeV}$ Test Case 1.

Another way to visualize the initial tune, perturbed tune, and restored tune is to examine the three electron beam parameters of dose rate, beam current, and energy for each tune. Table 3 lists the three sets of beam parameters (initial, perturbed, restored) for the three test cases shown in Figures 9, 10, and 11. In Figure 12, 13 and 14, data points for the 6, 7, and $8 \mathrm{MeV}$ test cases, respectively, are shown overlaid on the plot of reference file data given previously as Figure 6.

Table 3. The beam parameters for the three test cases of Figures 9-14.

\begin{tabular}{|c|c|c|c|c|c|c|c|c|c|c|}
\hline $\begin{array}{c}\text { Figure } \\
\text { Number }\end{array}$ & Test Case Designation & \multicolumn{9}{|c|}{ Overplot Data } \\
\hline & & \multicolumn{3}{|c|}{ Initial } & \multicolumn{3}{|c|}{ Perturbed } & \multicolumn{3}{c|}{ Restored } \\
\hline & & Dose Rate & $\begin{array}{c}\text { Beam } \\
\text { Current }\end{array}$ & Energy & Dose Rate & $\begin{array}{c}\text { Beam } \\
\text { Current }\end{array}$ & Energy & Dose Rate & $\begin{array}{c}\text { Beam } \\
\text { Current }\end{array}$ & Energy \\
\hline & & & & & & & & & & \\
\hline 9 and 12 & $6 \mathrm{MeV}$ Test Case 2 & 7.75 & 8.33 & 6.17 & 7.42 & 7.55 & 6.43 & 8.11 & 8.78 & 6.2 \\
\hline & & & & & & & & & & \\
\hline 10 and 13 & $7 \mathrm{MeV}$ Test Case 3 & 6.42 & 7.2 & 7.18 & 5.87 & 6.3 & 7.38 & 6.33 & 7.3 & 7.18 \\
\hline & & & & & & & & & & \\
\hline 11 and 14 & $8 \mathrm{MeV}$ Test Case 1 & 20.58 & 11.95 & 8.3 & 9.8 & 4.7 & 9.06 & 11.2 & 7.9 & 7.66 \\
\hline
\end{tabular}




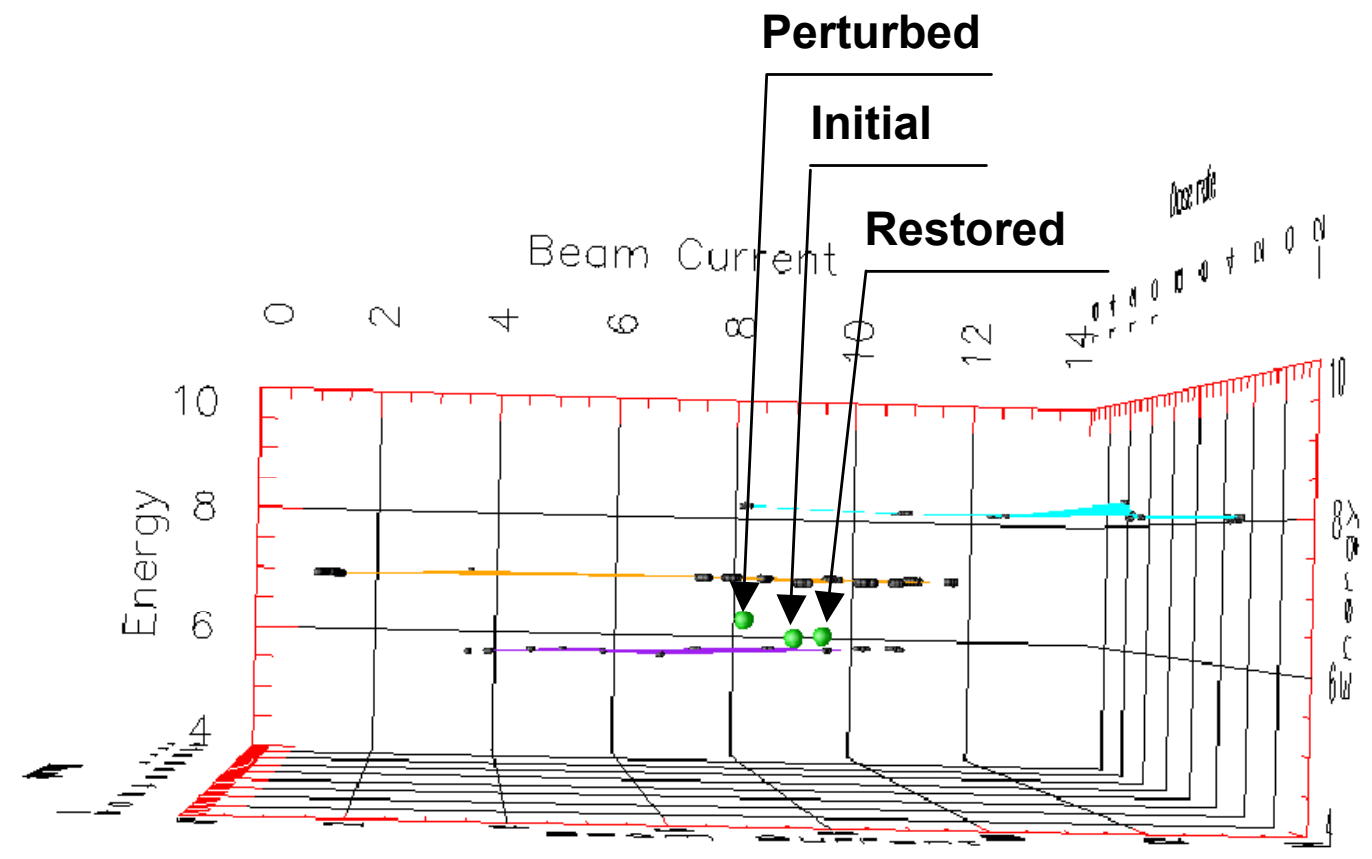

Figure 12. The $6 \mathrm{MeV}$ data points from Table 3 overlaid on the reference file data (Figure 6).

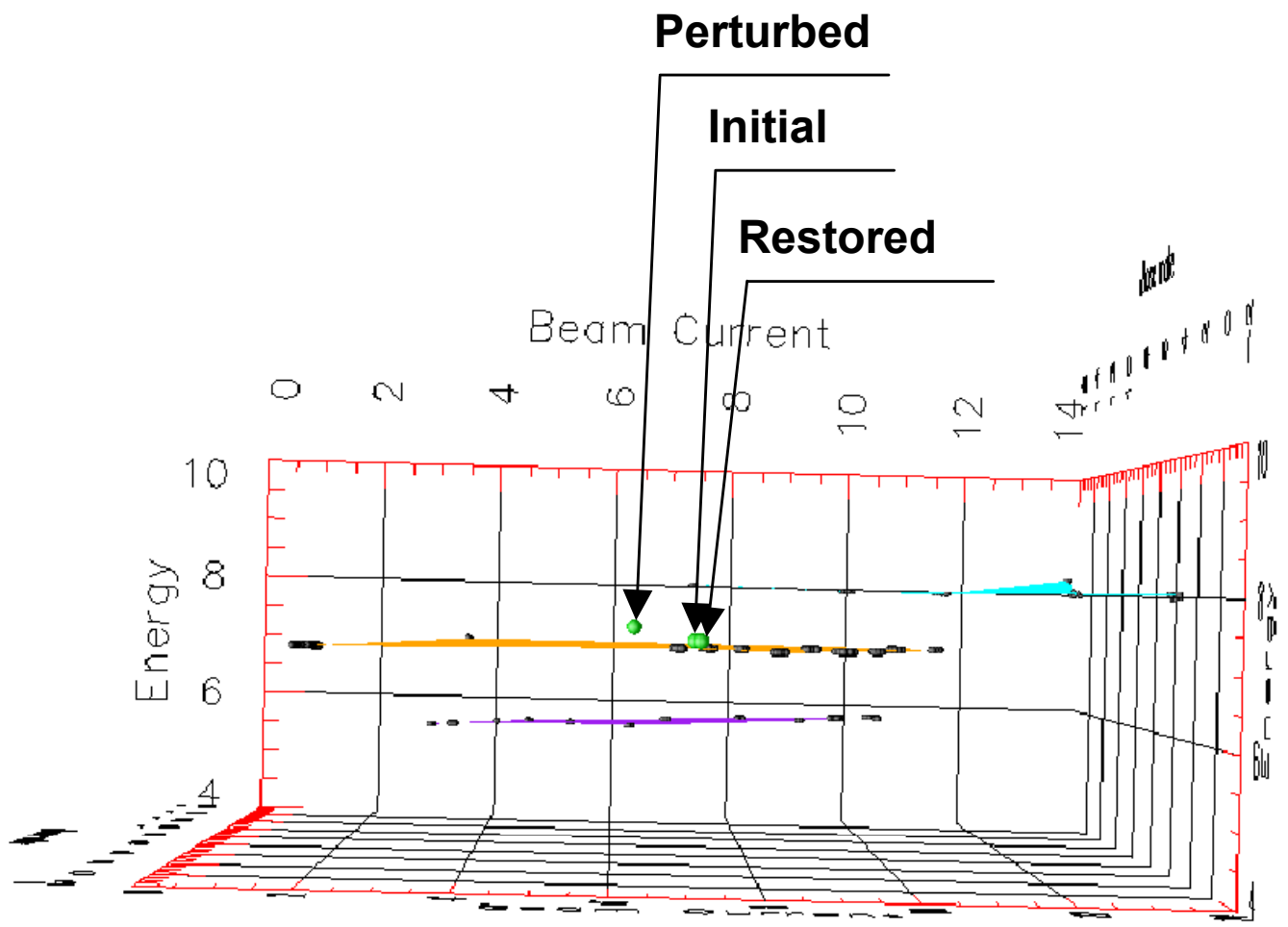

Figure 13. The $7 \mathrm{MeV}$ data points from Table 3 overlaid on the reference file data (Figure 6). 


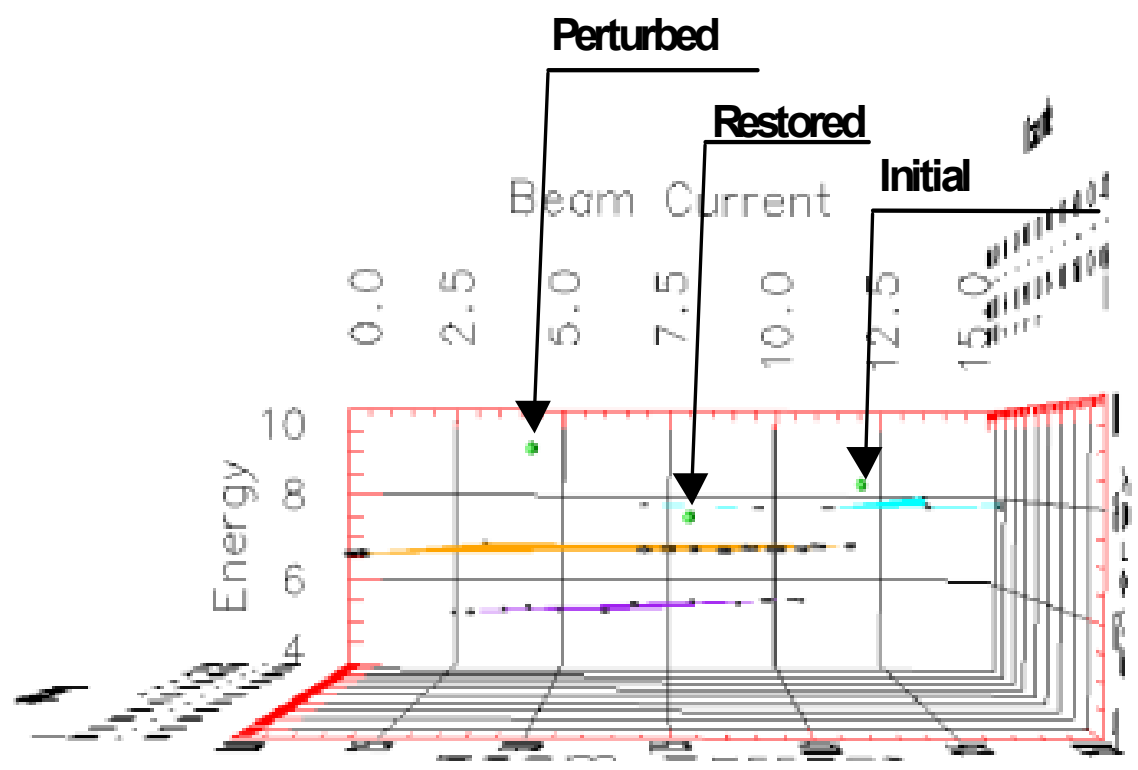

Figure 14. The $8 \mathrm{MeV}$ data points from Table 3 overlaid on the reference file data (Figure 6).

The proof-of-concept test cases successfully demonstrated that ADVVS could be used for modelbased feedback control, ${ }^{5}$ and the research was concluded. With additional funding, further work could explore the test case results in order to improve accelerator performance and develop a deployable controller for routine operations.

\section{SUMMARY AND CONCLUSIONS}

Two INEEL waste management projects are discussed in this paper: 1) monitoring the performance of NDA equipment, and 2) using the performance data for multivariate feedback control of NDA equipment. The work began with research into intelligent information processing techniques as modeled on human cognition and then applied the techniques to the two waste management NDA applications. The same software design was used in the two projects: 1) the data were acquired and preprocessed to extract signature patterns, 2) pattern recognition and analysis software extracted pertinent information from the signatures, and 3) the information was applied to meet the goals of the projects. The projects had different goals but used the unifying idea of recognizing and analyzing evolving patterns.

In each project, the ADVVS software shell was tailored to the disparate pre- and post-processing requirements for extracting signatures from the data and interpreting and applying the information gained from pattern recognition and analysis. The ADVVS kernel used for pattern recognition and analysis was identical in each project.

Both projects achieved their goals. At this time, the software for monitoring performance health is ready for deployment. The approach has been demonstrated outside INEEL with non-NDA equipment, and INEEL now has the knowledge and expertise to apply it to NDA equipment other than selectable energy accelerators. With the proof-of-concept demonstrated for using the same software design and approach for multivariate feedback control, continuing research could explore other applications. 
In conclusion, the value of the two projects lies in their demonstration of the strength of their common basis in pattern recognition and analysis despite their disparate goals. Human experts already used their individual experience and understanding - their human cognition/pattern recognition skills - to accomplish the goals of monitoring equipment health and equipment control. Accomplished scientists and engineers are able to do that well with classical, time-proven methods. However, intelligent information processing software based on pattern recognition and analysis can automatically and without fatigue achieve the same goals much faster and more accurately. The capabilities of trained, experienced scientists and engineers are captured in the modern software for use by the community of users without such specialty training. The INEEL waste management department is continuing to explore modern software approaches to add validation and verification to the operation of NDA equipment and speed and accuracy to the analysis of NDA data. 


\section{REFERENCES}

1. Cordes, G.A., "Patterns and Intelligent Systems", Proceedings of the $3^{\text {rd }}$ American Nuclear Society International Topical Meeting on Nuclear Plant Instrumentation, Control and Human-Machine Interface Technologies, Washington D.C., November 2000.

2. O'Sullivan, P.J., et.al., "Using UPM for Real-Time Multivariate Modeling of Semiconductor Manufacturing Equipment", SEMATECH AEC/APC Workshop VII, November 5-8, New Orleans, Louisiana, 1995.

3. Jones, J.L., et.al., "Pulsed Photoneutron Interrogation: The GNT Demonstration System", Idaho National Engineering and Environmental Laboratory report, WINCO-1225, October 1994.

4. Cordes, G.A., Van Ausdeln, L.A., Jones, J.L., and Haskell, K.J., "Intelligent Pattern-based Techniques to Monitor the Operation of Nondestructive Analysis Equipment and Contribute to Multivariate Feedback Control", Proceedings of ANNIE 2001: Smart Engineering System Design, St. Louis, Missouri, 4-7 November 2001.

5. Van Ausdeln, L.A., Cordes, G.A., Haskell, K.J., and Jones, J.L., "Research on Utilizing a Multivariate Feedback Algorithm to Maintain Stable Operation of Variable Energy Electron Accelerators", Proceedings of the American Nuclear Society Topical Meeting 'Nuclear Applications in the New in the New Millenium', Reno, Nevada, 11-15 November 2001. 


\section{APPENDIX A}

PLOTS FROM 6 MEV TEST CASES 
This page intentionally left blank. 


\section{APPENDIX A}

\section{PLOTS FROM 6 MEV TEST CASES}

\section{$6 \mathrm{MeV}$ Test Case 1}

Reference File : Single Energy

Figure of Merit : 1 Beam Parameter ( Beam Current )

Table A1. $6 \mathrm{MeV}$ Test Case 1, timing chart for operator actions.

\begin{tabular}{lcccccc}
\hline & start & end & T1 & T2 & dT & dGFV \\
\hline Auto Tune & $6: 10: 58$ & $6: 11: 43$ & -482 & -437 & 45 & \\
Beam Scan & $6: 13: 47$ & $6: 15: 39$ & -313 & -201 & 112 & \\
Perturb Tune & $6: 16: 14$ & $6: 16: 20$ & -166 & -160 & 6 & $-1.5 \mathrm{~V}$ \\
Perturb Tune & $6: 16: 38$ & $6: 16: 42$ & -142 & -138 & 4 & $-1.5 \mathrm{~V}$ \\
Beam Scan & $6: 17: 02$ & $6: 18: 50$ & -118 & -10 & 108 & \\
Feedback Correction & $6: 19: 00$ & $6: 19: 05$ & 0 & 5 & 5 & \\
Beam Scan & $6: 20: 10$ & $6: 21: 47$ & 70 & 167 & 97 & \\
\hline
\end{tabular}

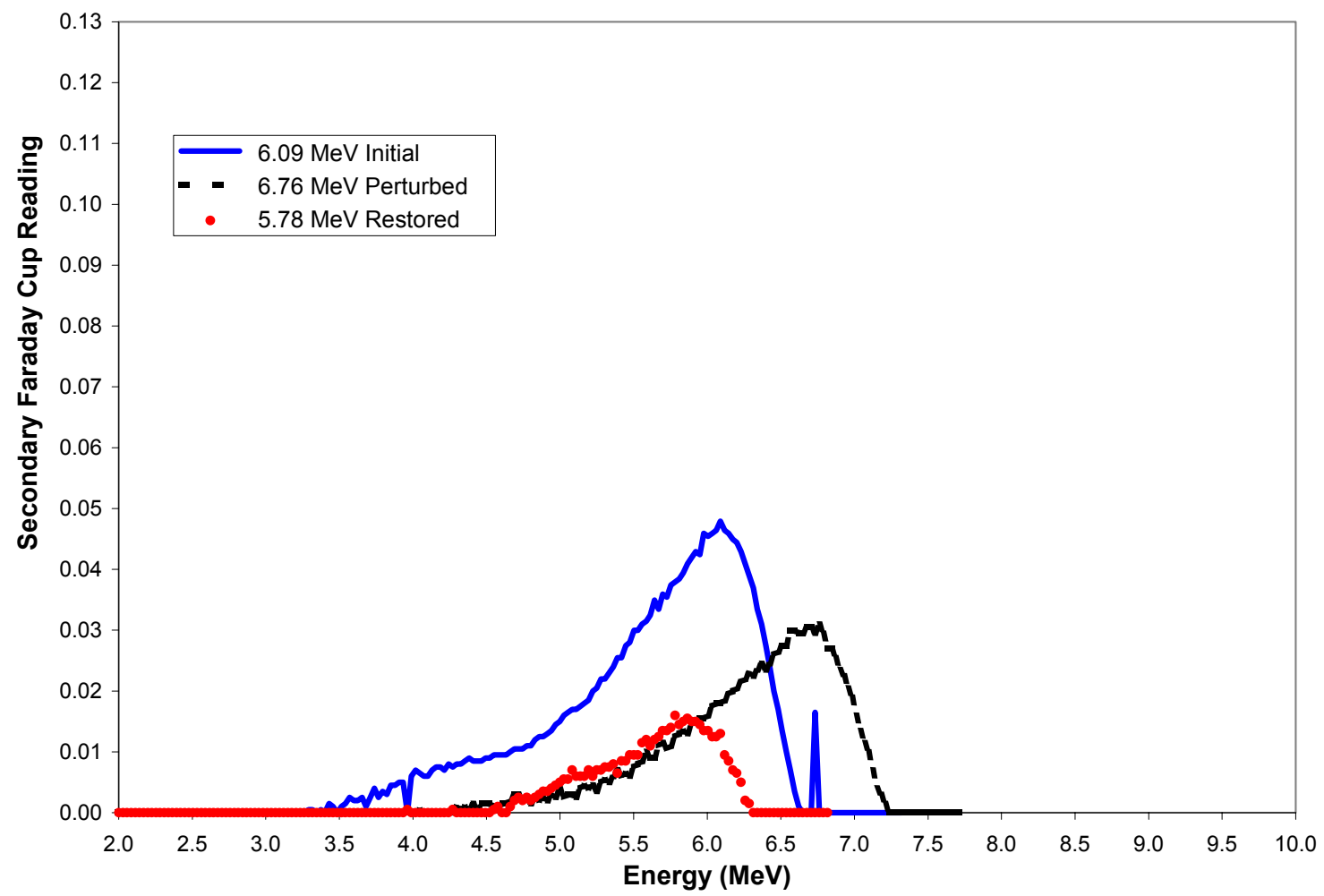

Figure A1. $6 \mathrm{MeV}$ Test Case 1, energy profiles. 


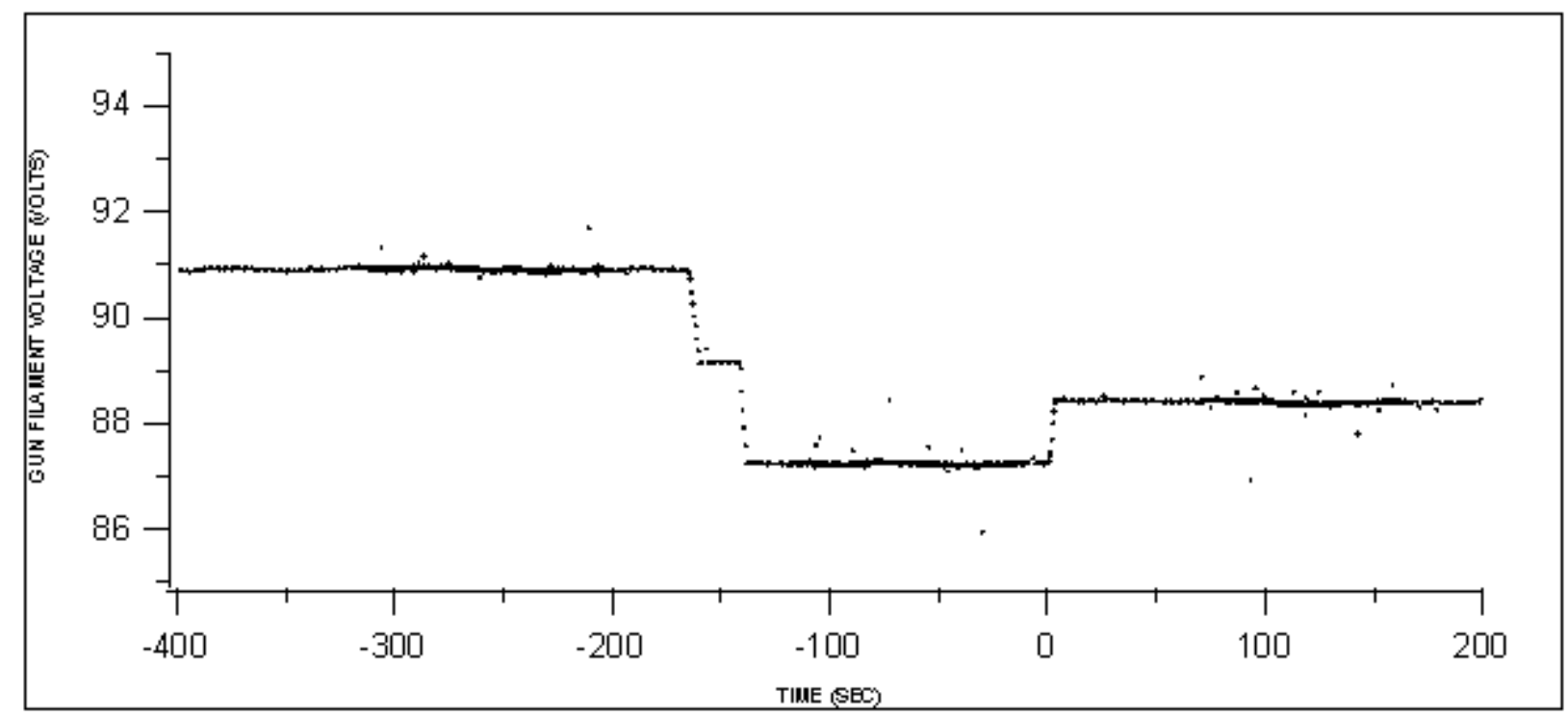

Figure A2. $6 \mathrm{MeV}$ Test Case 1, gun filament voltage.

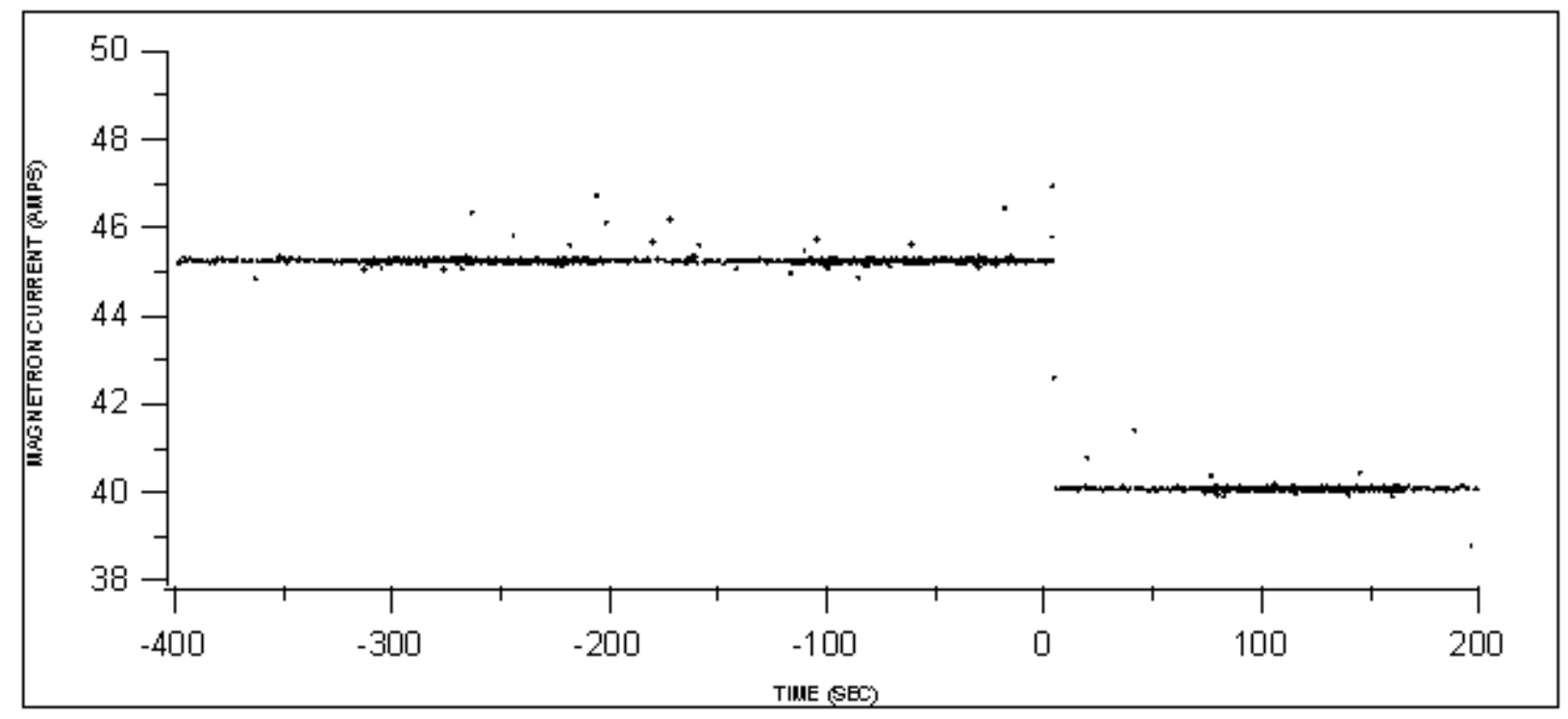

Figure A3. $6 \mathrm{MeV}$ Test Case 1, magnetron current. 


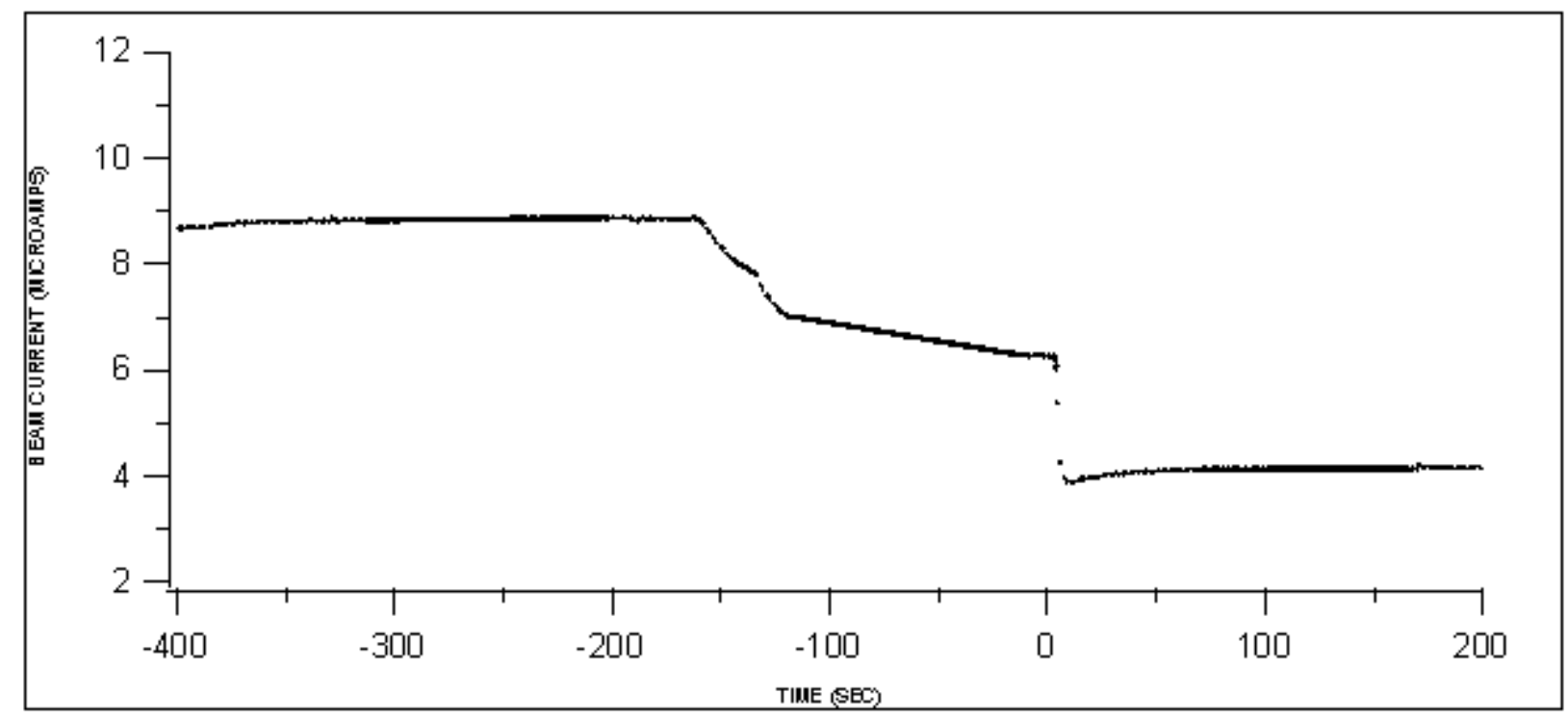

Figure A4. $6 \mathrm{MeV}$ Test Case 1, beam current.

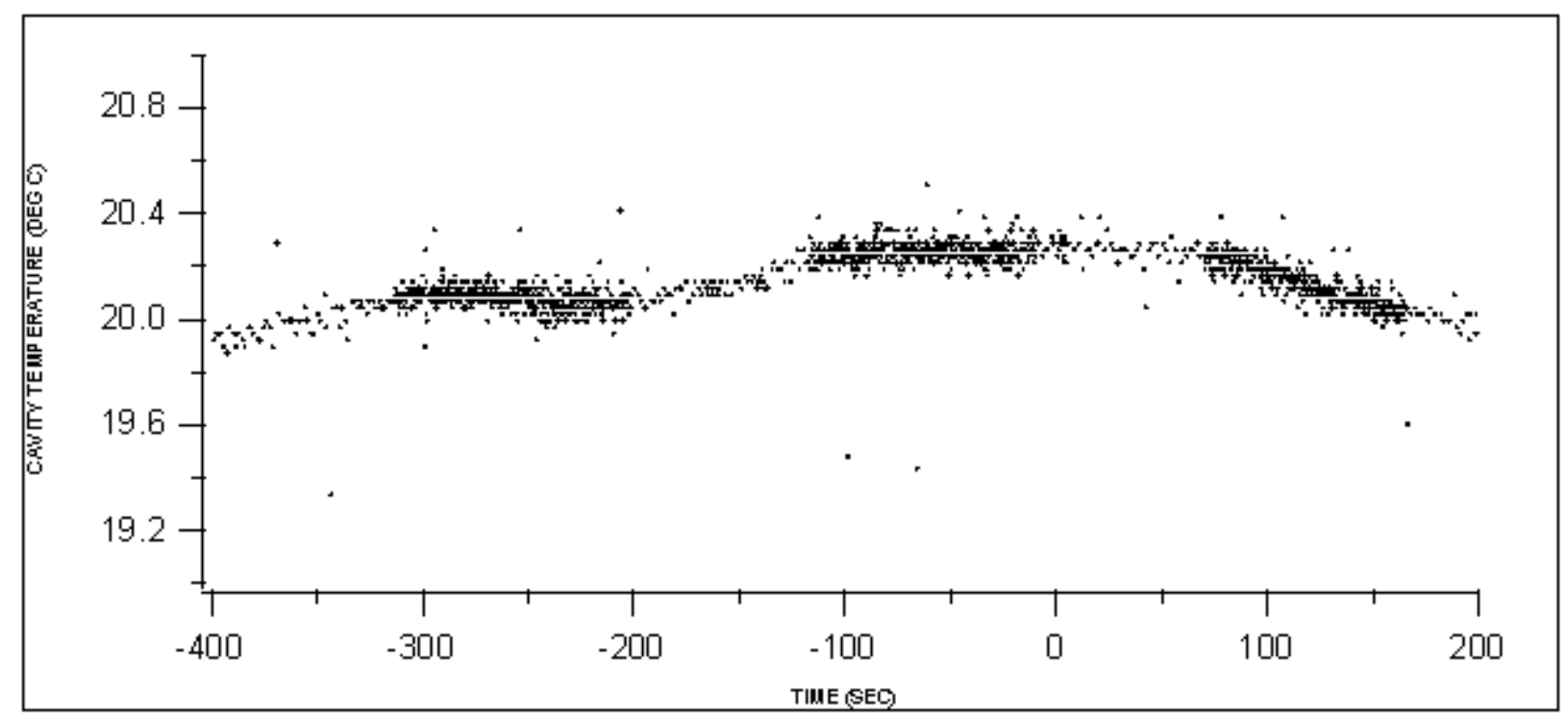

Figure A5. $6 \mathrm{MeV}$ Test Case 1, cavity temperature. 


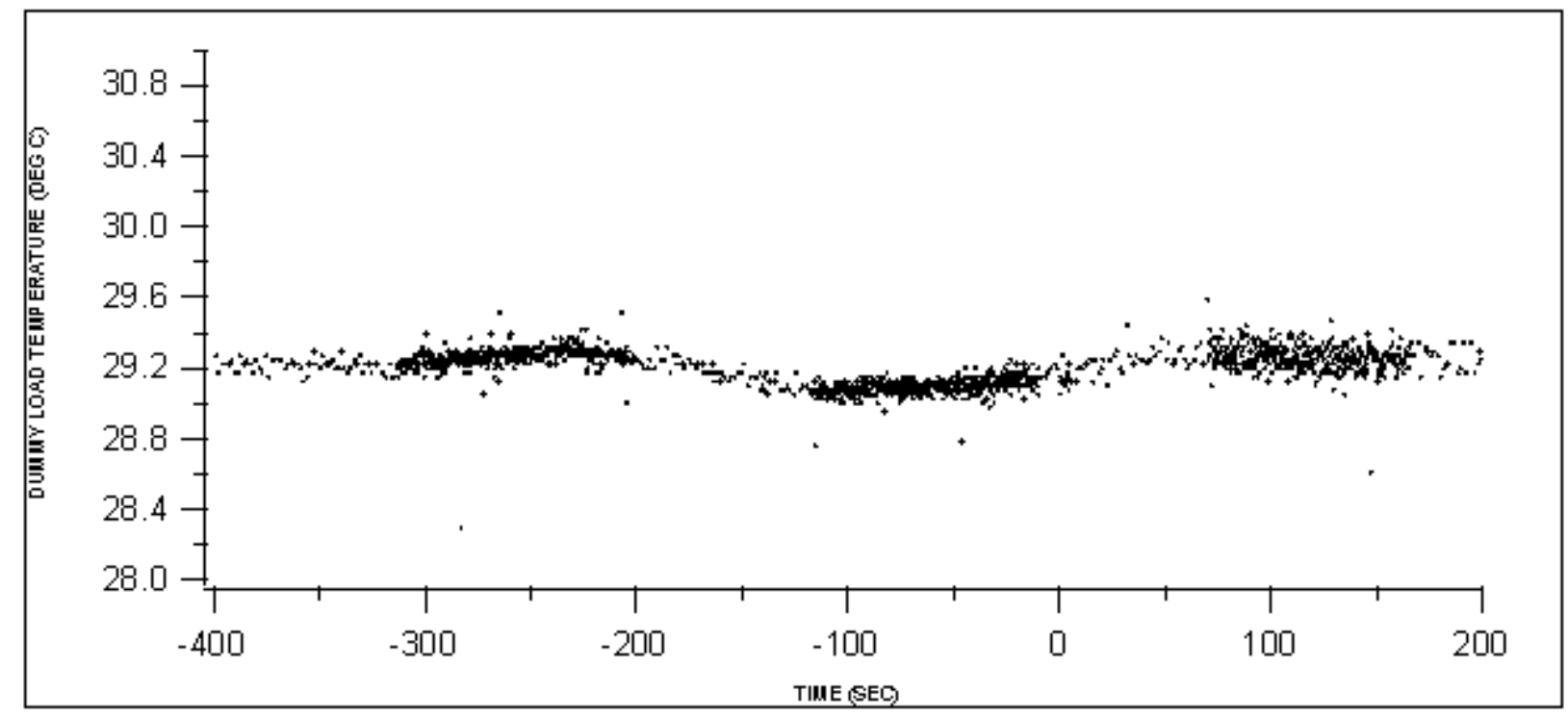

Figure A6. $6 \mathrm{MeV}$ Test Case 1, dummy load temperature.

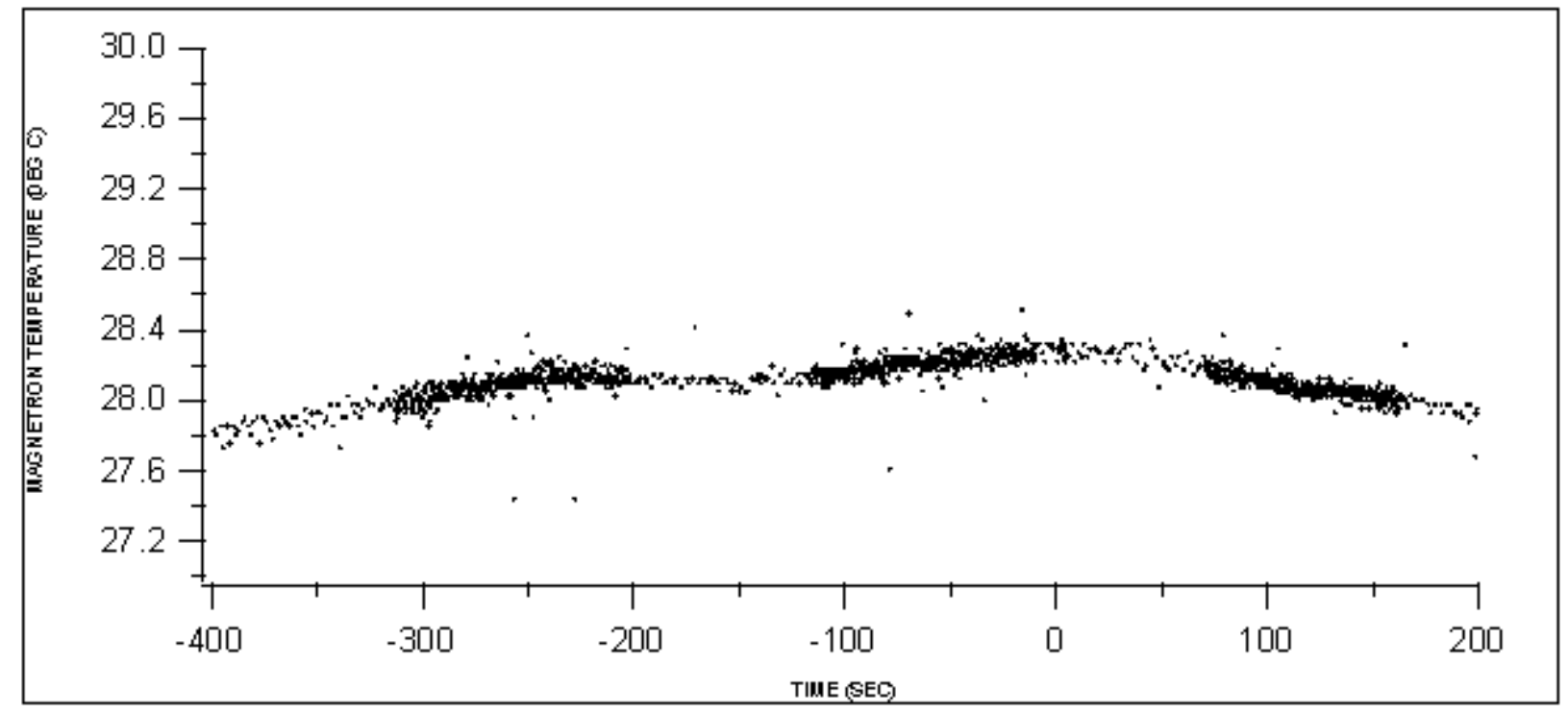

Figure A7. $6 \mathrm{MeV}$ Test Case 1, magnetron temperature. 


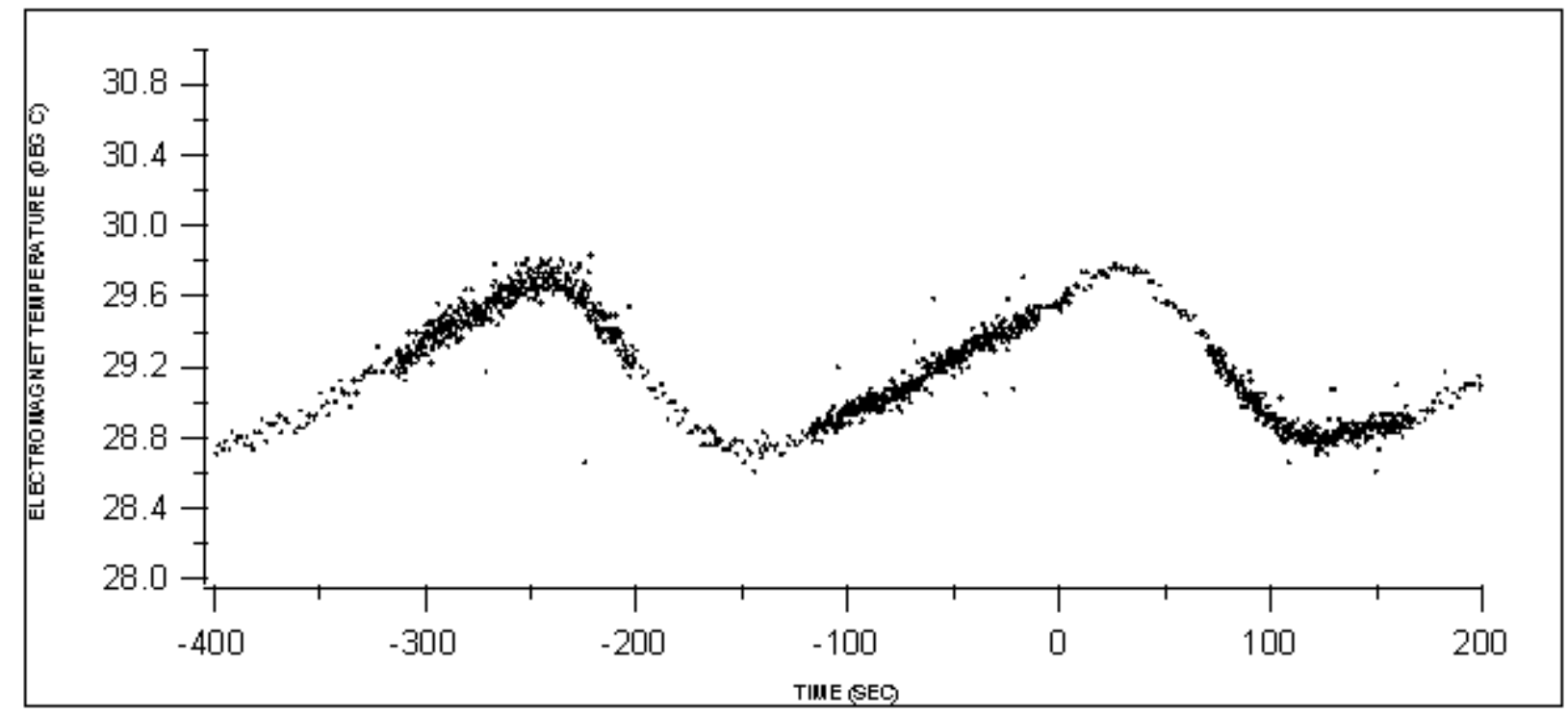

Figure A8. $6 \mathrm{MeV}$ Test Case 1, electromagnet temperature.

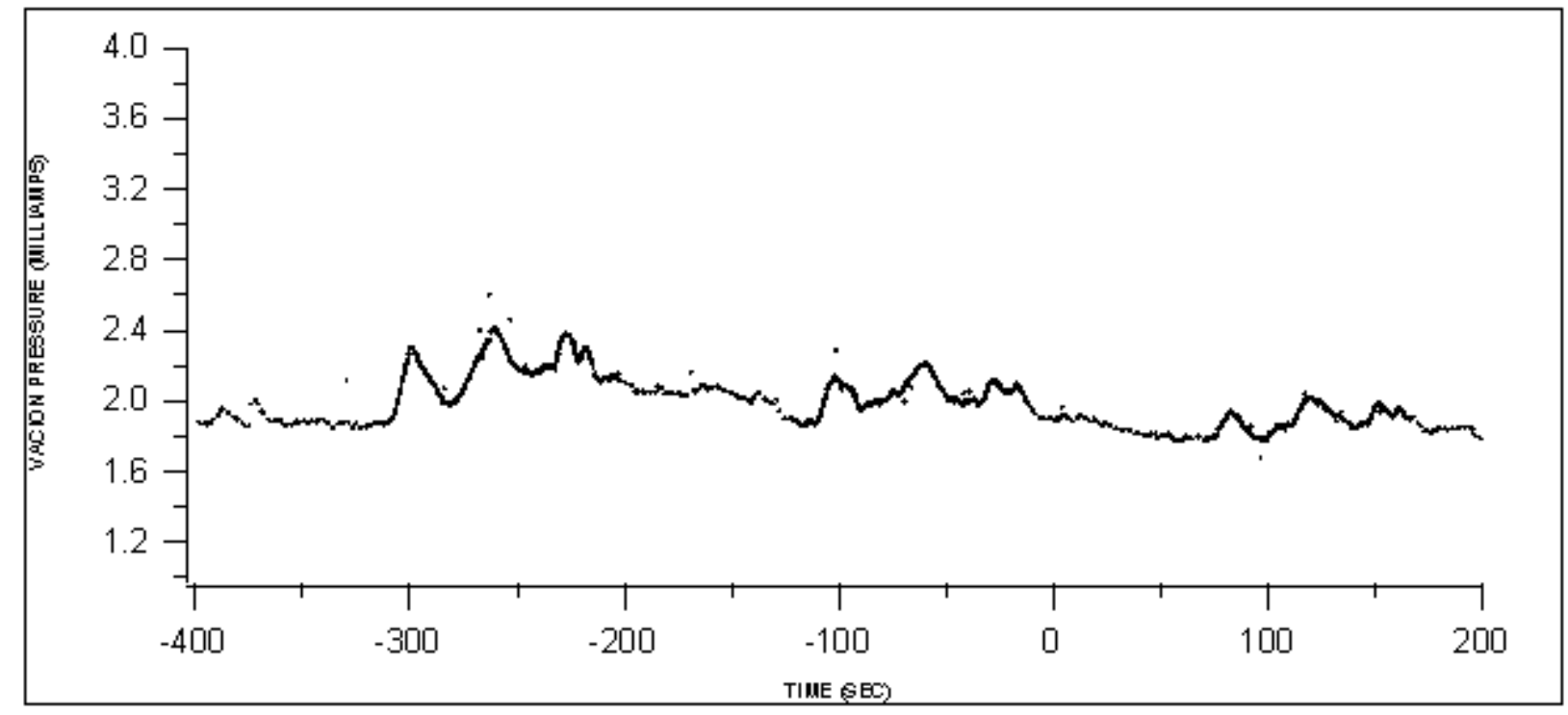

Figure A9. $6 \mathrm{MeV}$ Test Case 1, vacion pressure. 


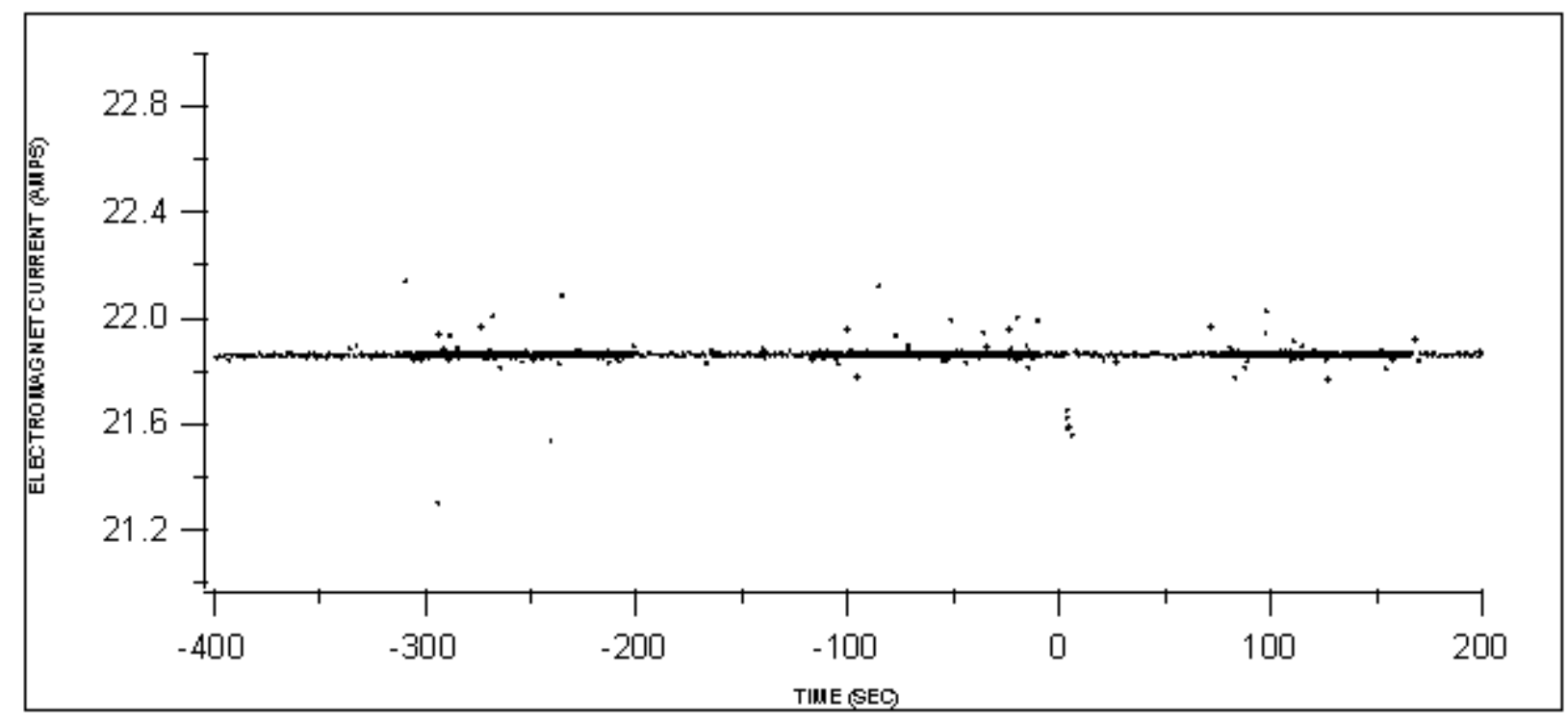

Figure A10. $6 \mathrm{MeV}$ Test Case 1, electromagnet current.

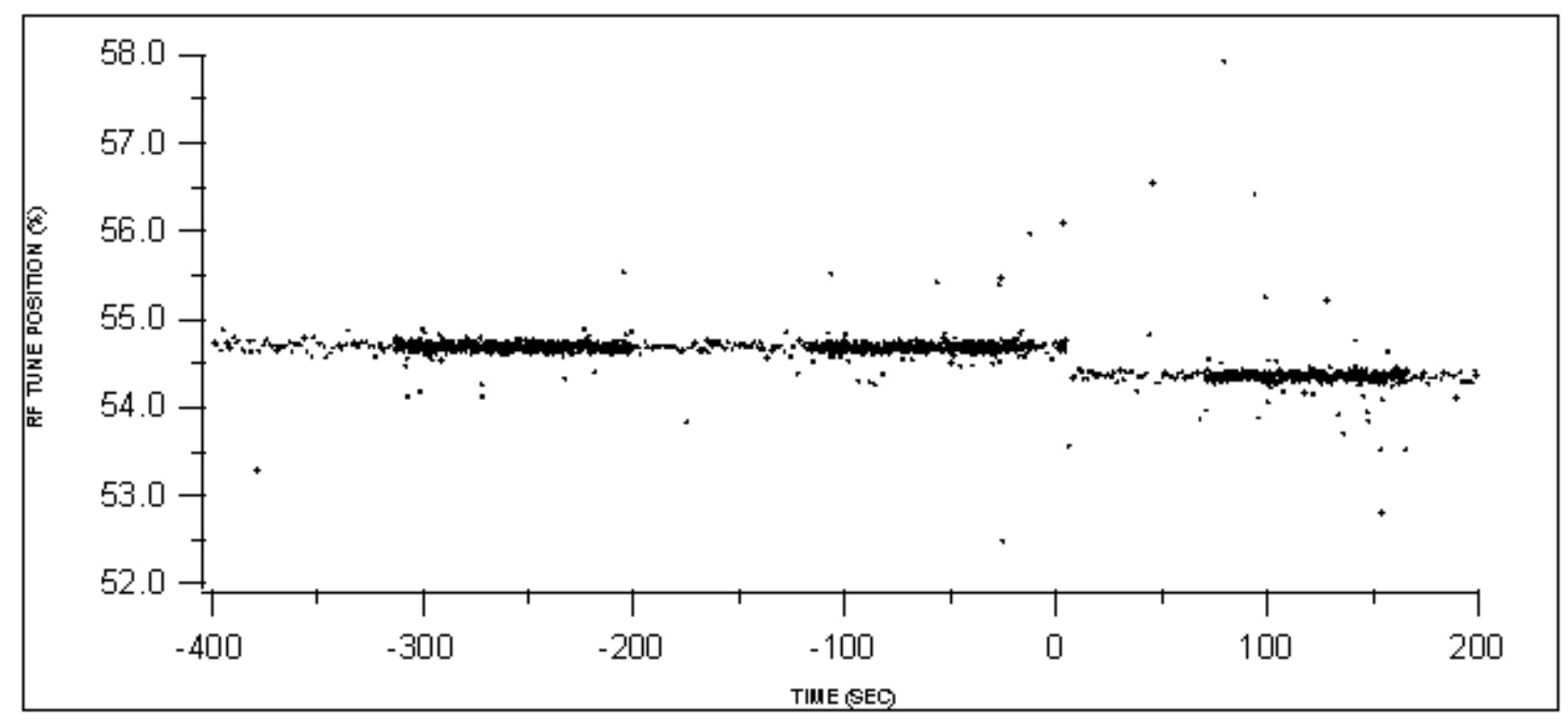

Figure A11. $6 \mathrm{MeV}$ Test Case 1, RF tune position. 


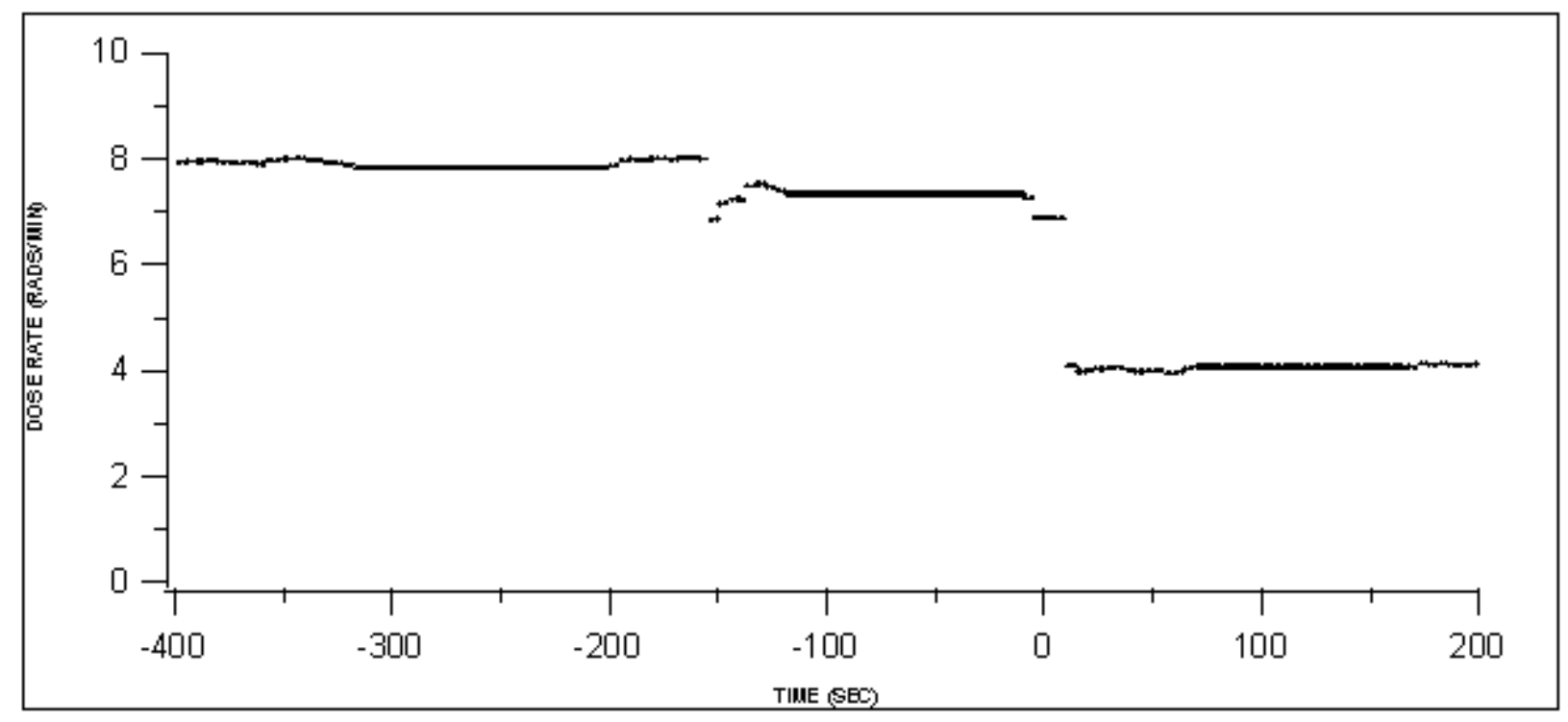

Figure A12. $6 \mathrm{MeV}$ Test Case 1, dose rate. 


\section{$6 \mathrm{MeV}$ Test Case 2}

Reference File : Single Energy

Figure of Merit : All Parameters

Table A2. $6 \mathrm{MeV}$ Test Case 2, timing chart for operator actions.

\begin{tabular}{lcccccc}
\hline & start & end & T1 & T2 & dT & dGFV \\
\hline Auto Tune & $7: 24: 58$ & $7: 25: 45$ & -521 & -474 & 47 & \\
Beam Scan & $7: 27: 42$ & $7: 29: 43$ & -357 & -236 & 121 & \\
Perturb Tune & $7: 30: 08$ & $7: 30: 14$ & -211 & -205 & 6 & $-1.5 \mathrm{~V}$ \\
Beam Scan & $7: 30: 36$ & $7: 32: 33$ & -183 & -66 & 117 & \\
Feedback Correction & $7: 33: 39$ & $7: 33: 43$ & 0 & 4 & 4 & \\
Feedback Correction & $7: 33: 45$ & $7: 33: 50$ & 6 & 11 & 5 & \\
Beam Scan & $7: 35: 12$ & $7: 37: 06$ & 93 & 207 & 114 & \\
\hline
\end{tabular}

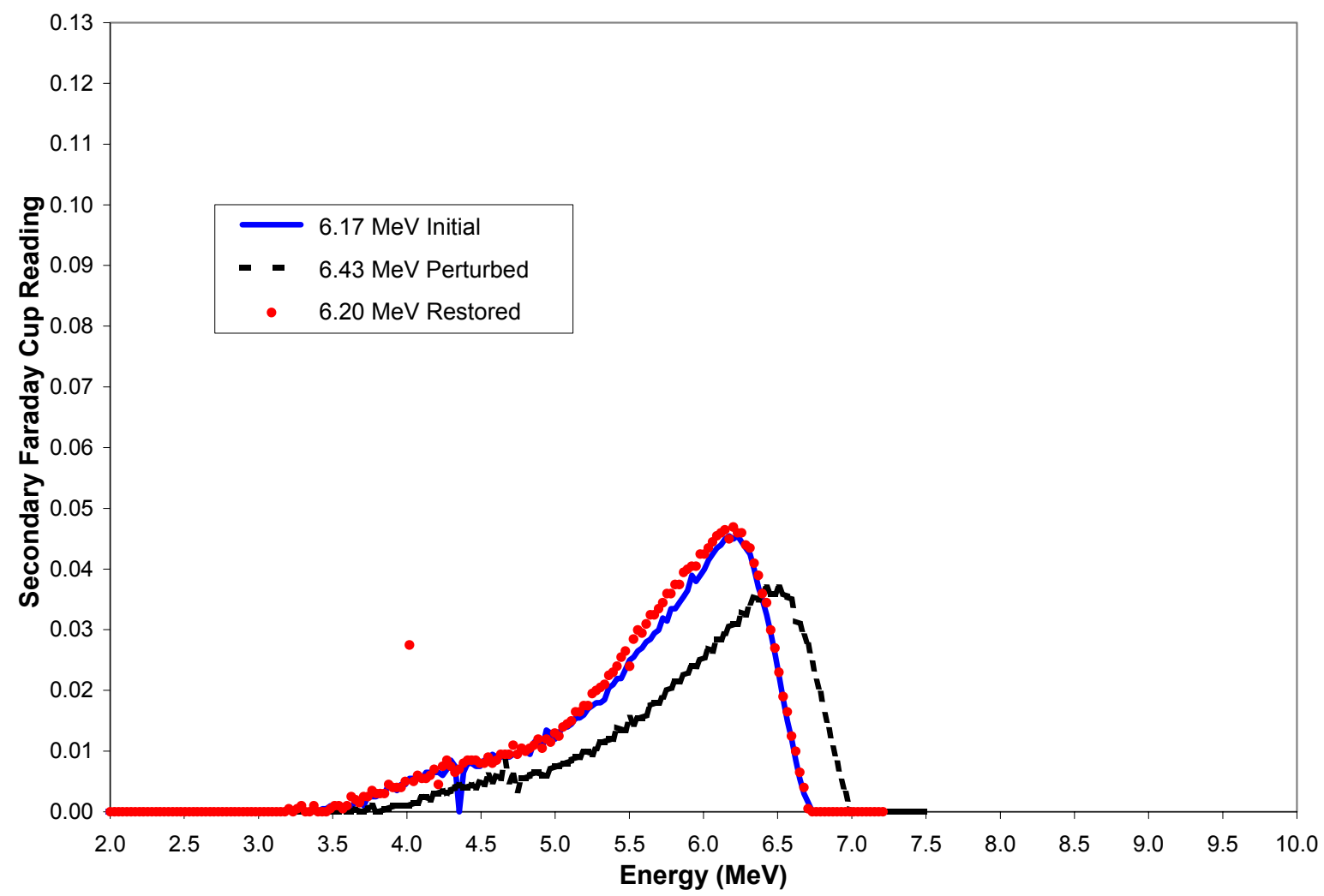

Figure A13. $6 \mathrm{MeV}$ Test Case 2, energy profiles. 


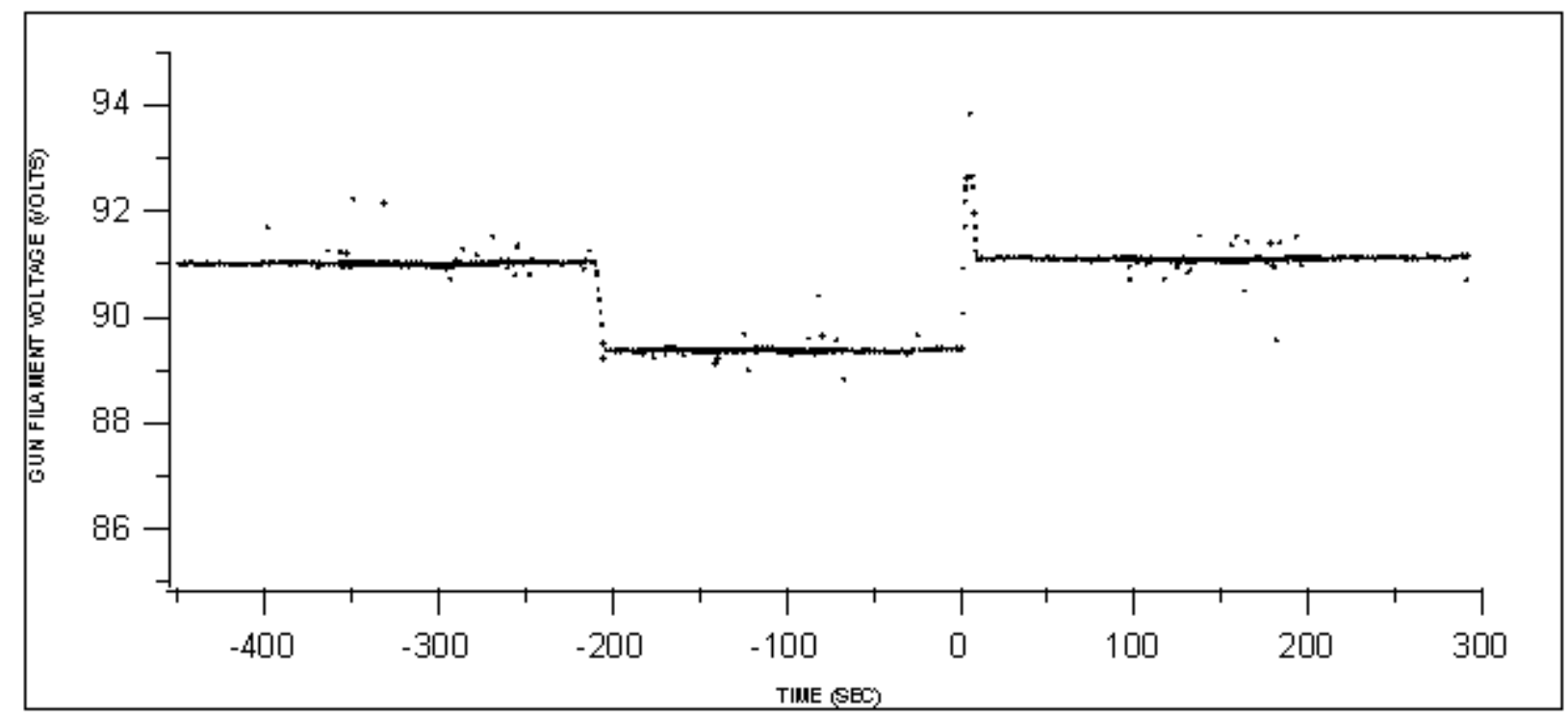

Figure A14. $6 \mathrm{MeV}$ Test Case 2, gun filament voltage.

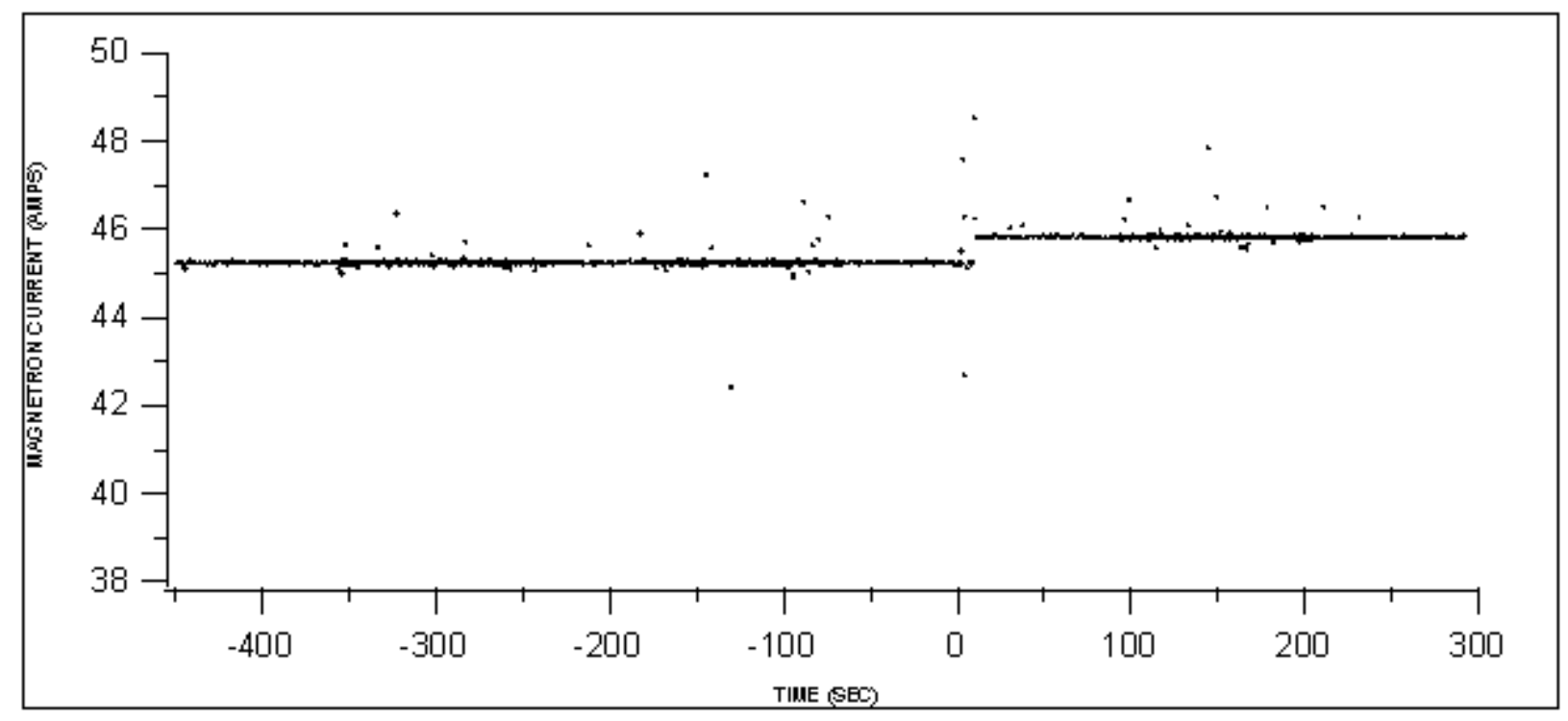

Figure A15. $6 \mathrm{MeV}$ Test Case 2, magnetron current. 


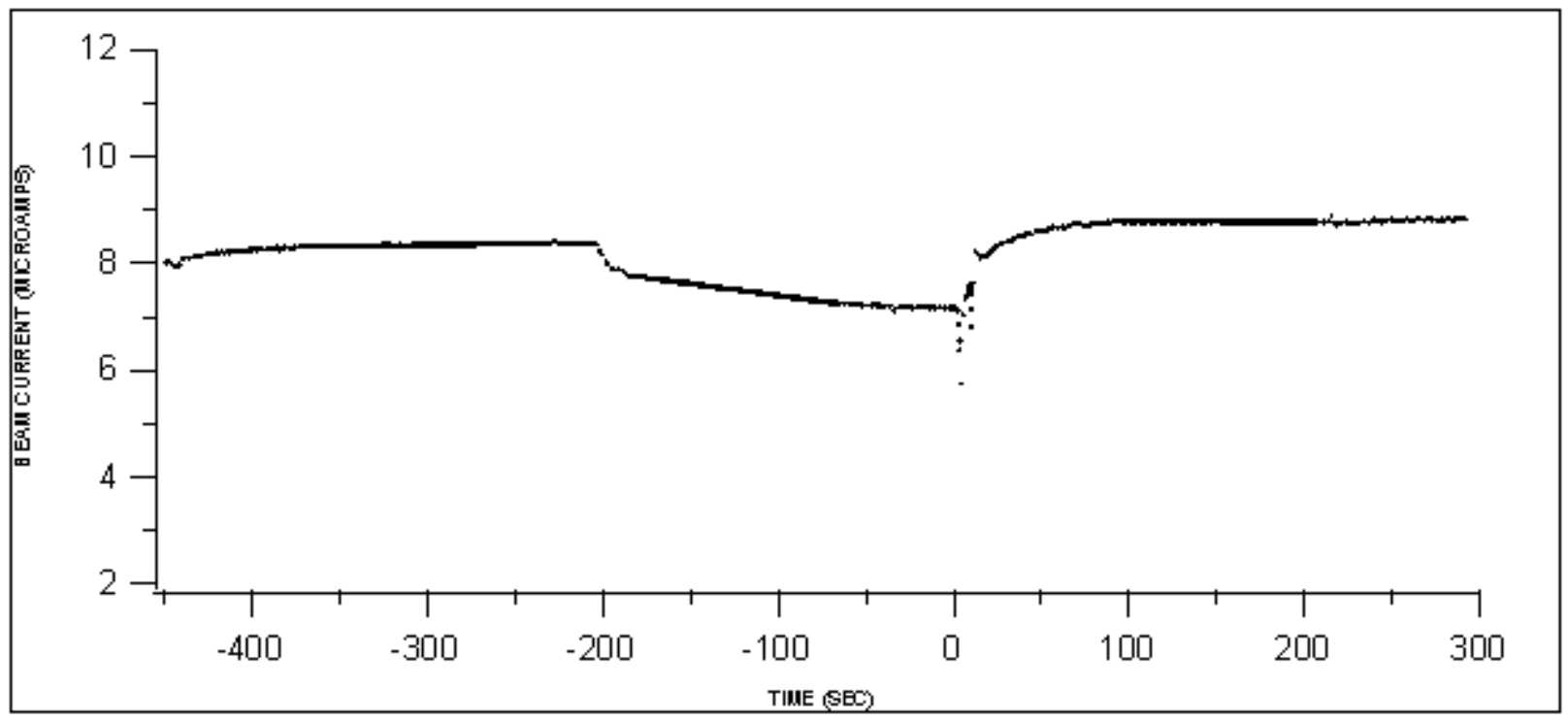

Figure A16. $6 \mathrm{MeV}$ Test Case 2, beam current.

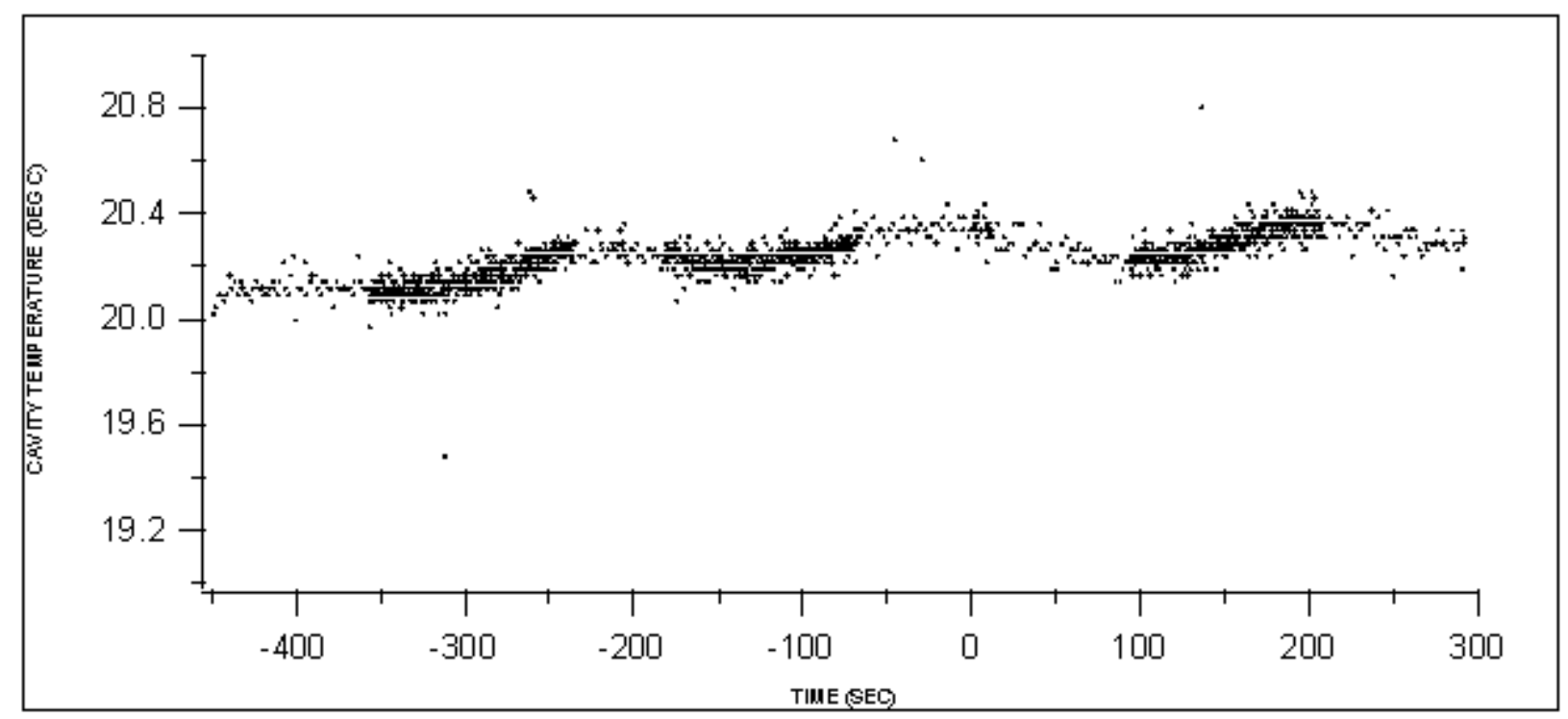

Figure A17. $6 \mathrm{MeV}$ Test Case 2, cavity temperature. 


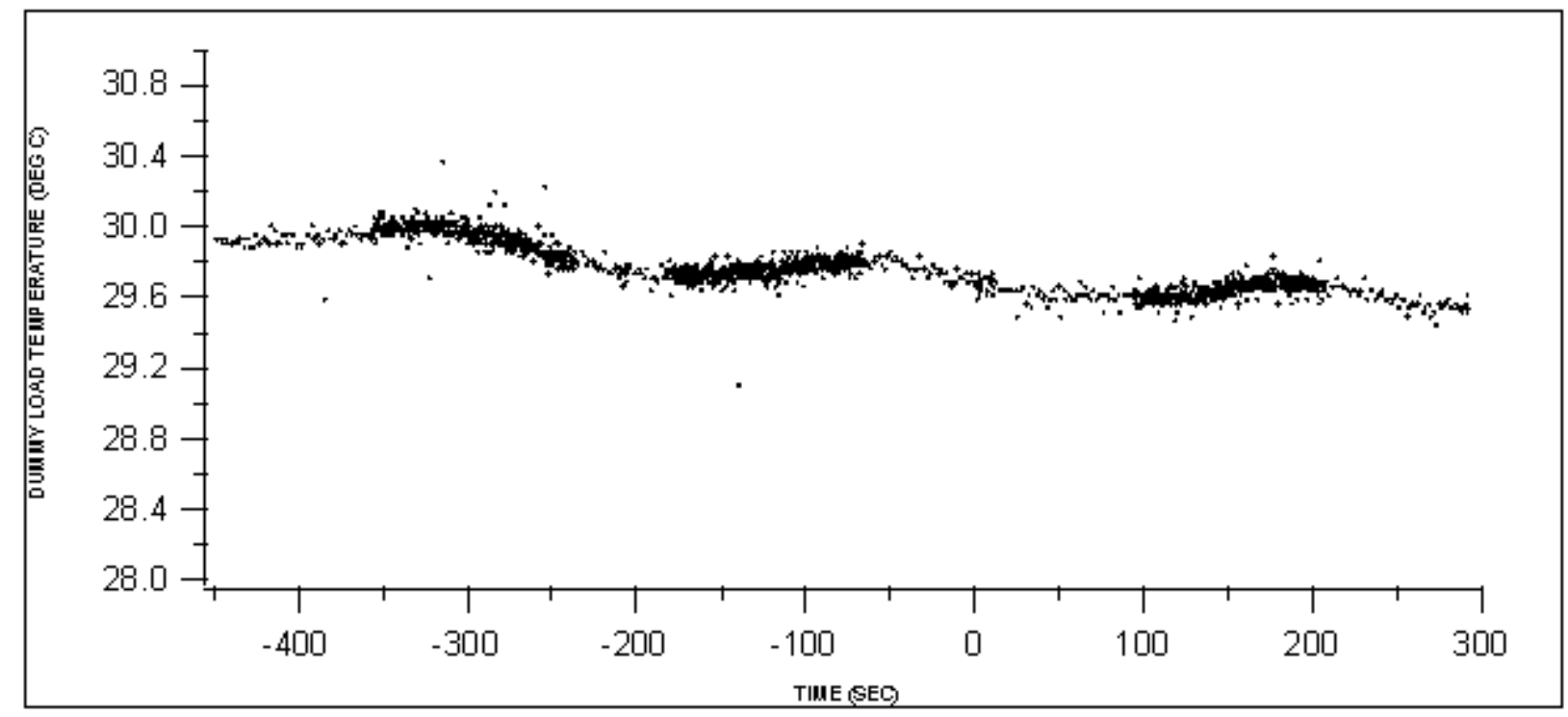

Figure A18. $6 \mathrm{MeV}$ Test Case 2, dummy load temperature.

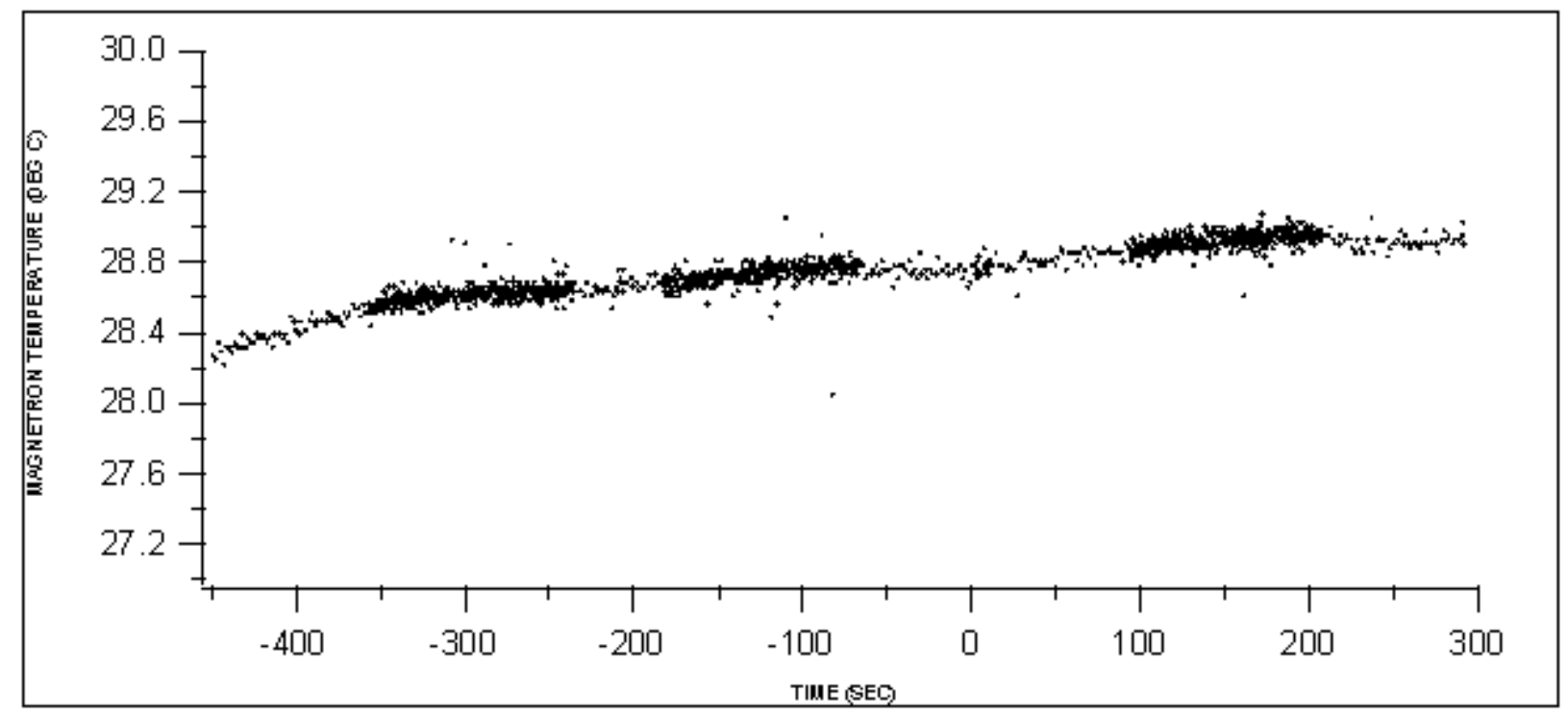

Figure A19. $6 \mathrm{MeV}$ Test Case 2, magnetron temperature. 


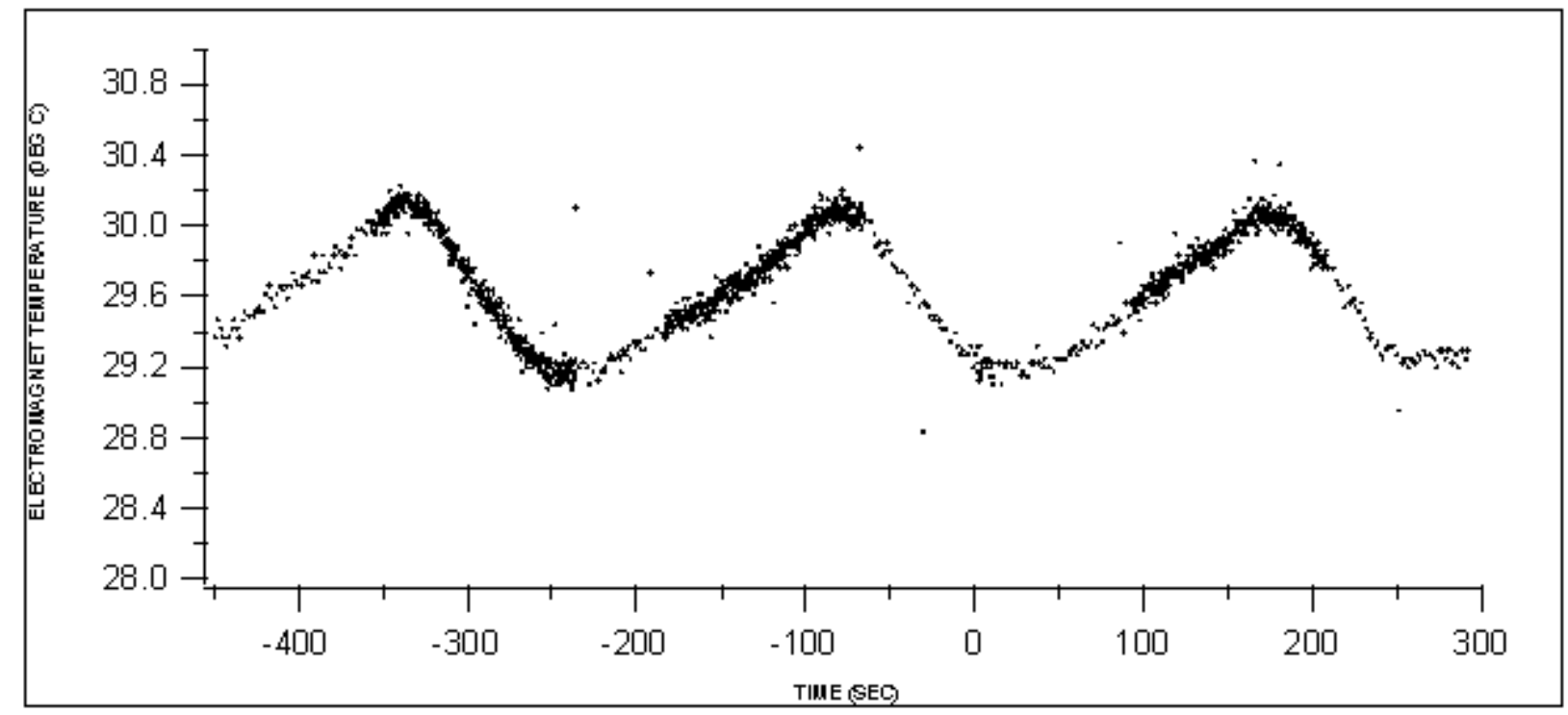

Figure A20. $6 \mathrm{MeV}$ Test Case 2, electromagnet temperature.

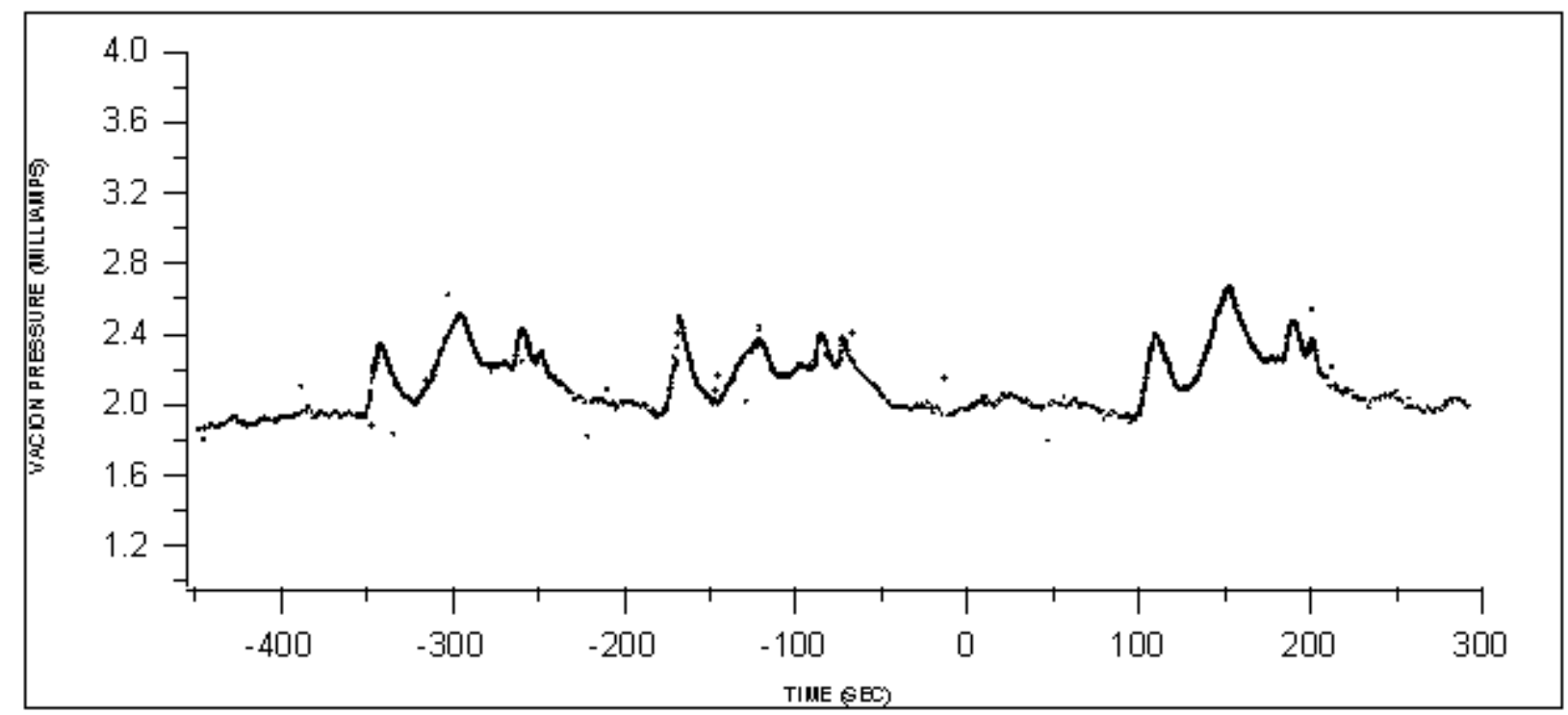

Figure A21. $6 \mathrm{MeV}$ Test Case 2, vacion pressure. 


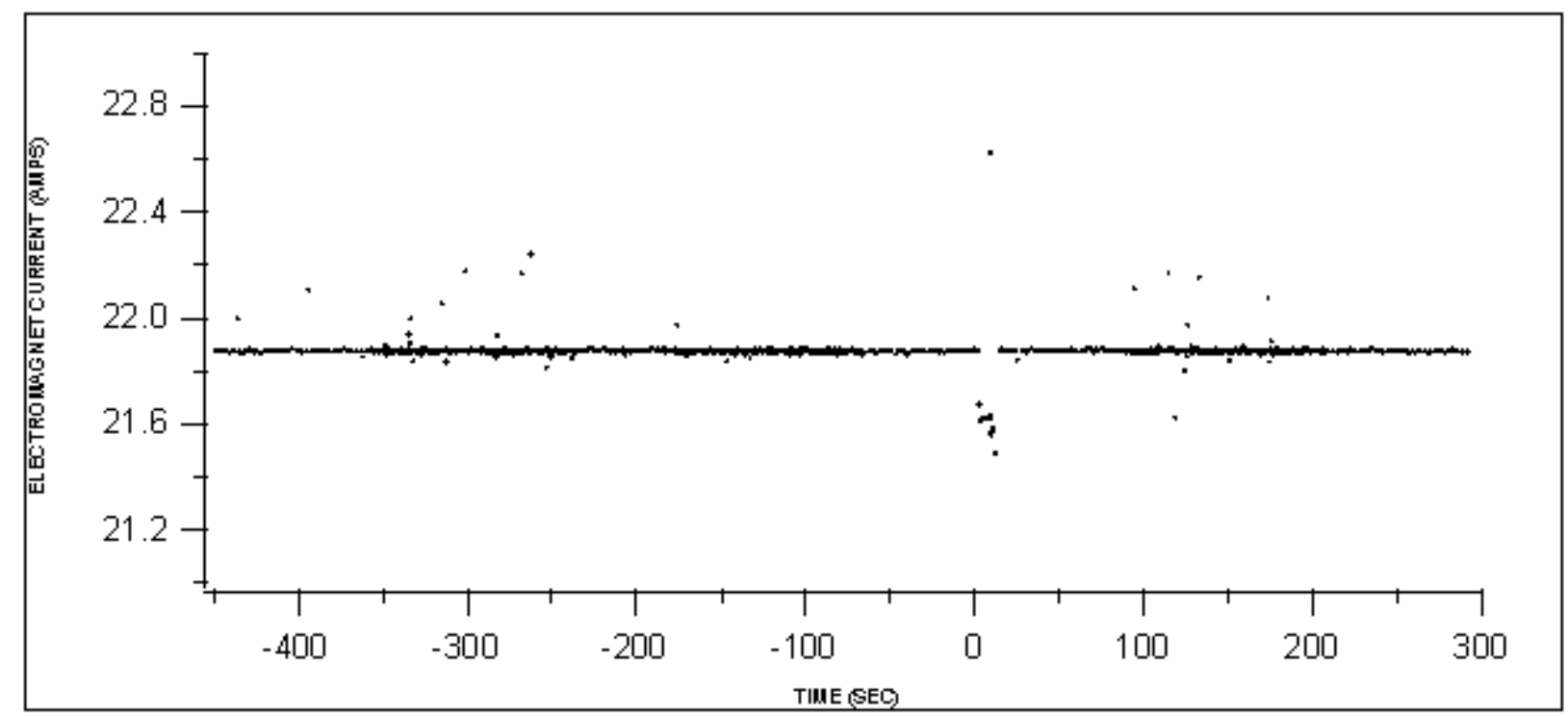

Figure A22. $6 \mathrm{MeV}$ Test Case 2, electromagnet current.

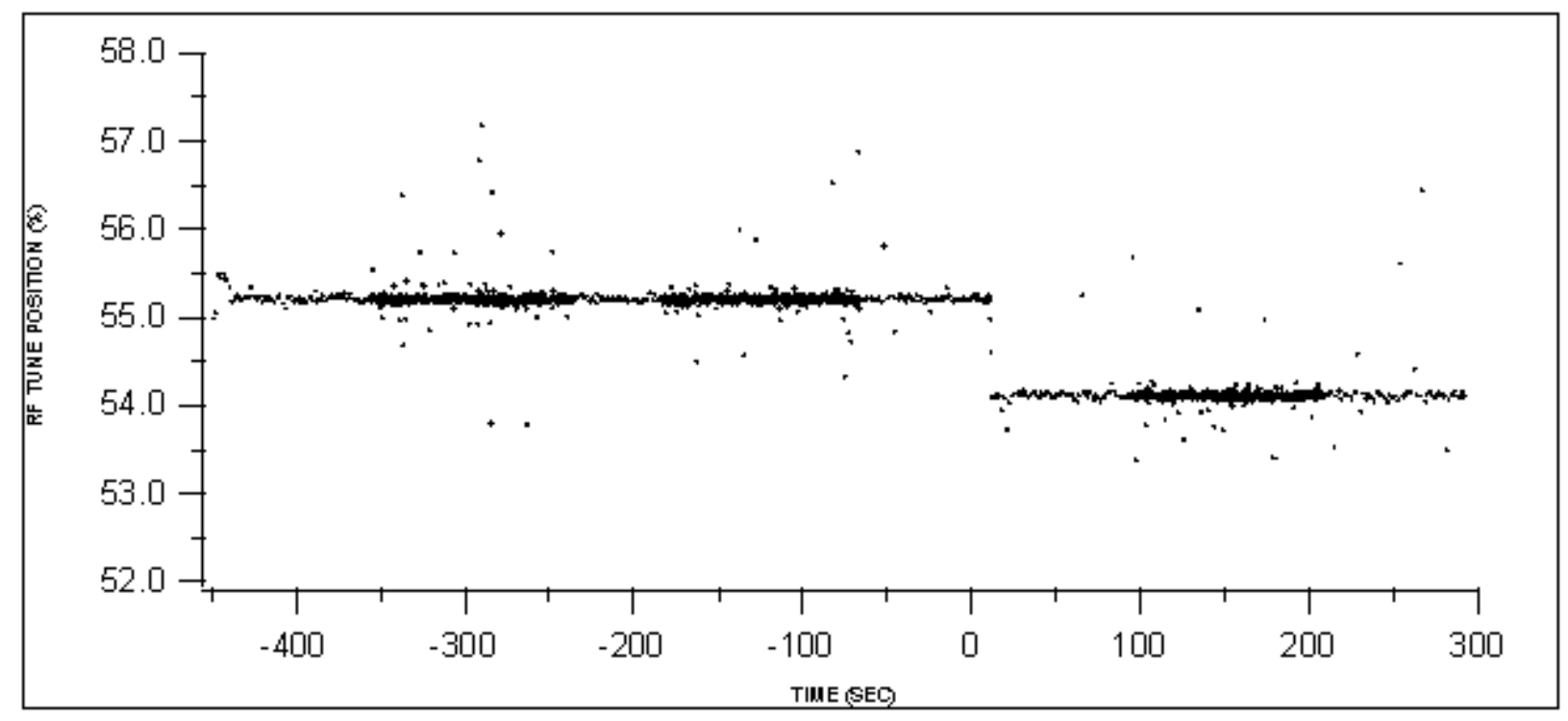

Figure A23. $6 \mathrm{MeV}$ Test Case 2, RF tune position. 


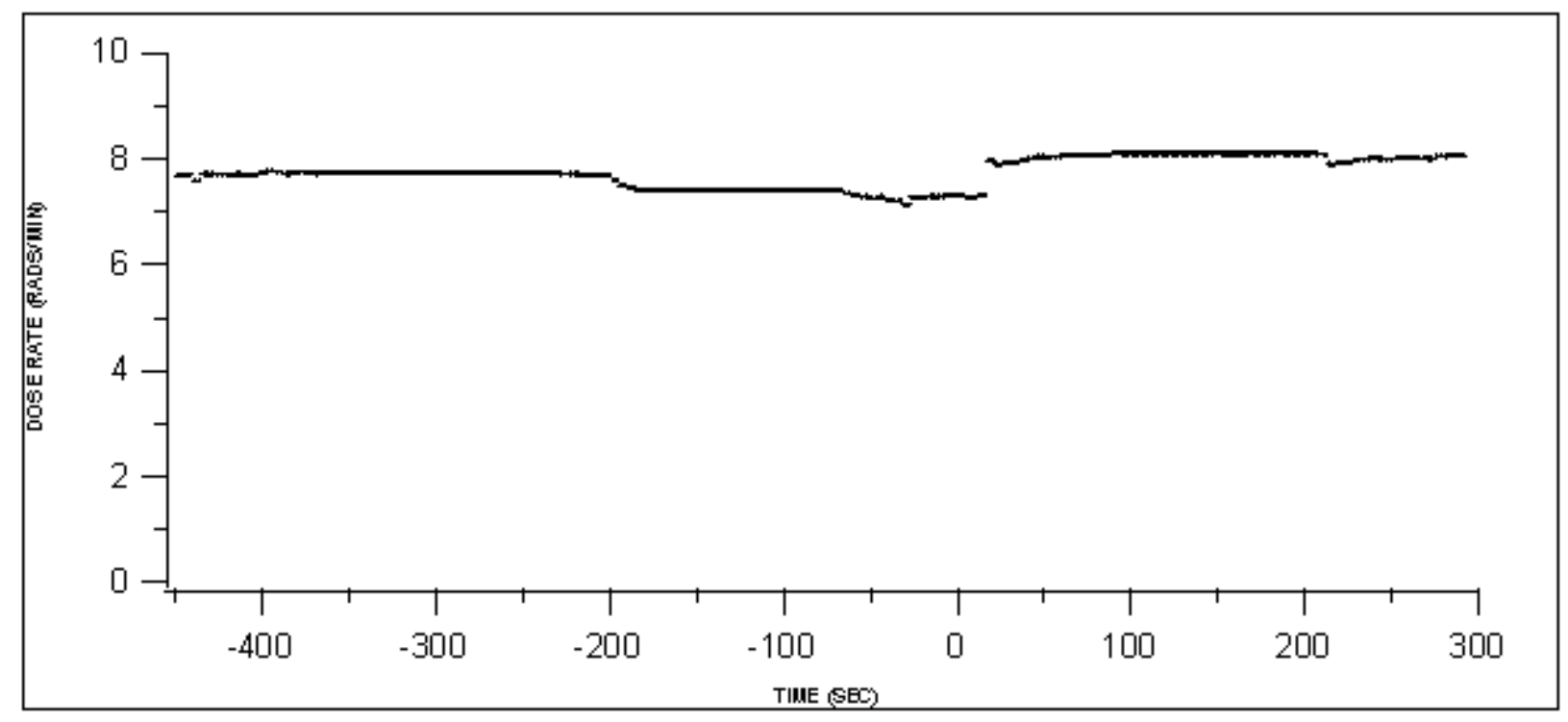

Figure A24. $6 \mathrm{MeV}$ Test Case 2, dose rate. 


\section{$6 \mathrm{MeV}$ Test Case 3}

Reference File : Composite Energy

Figure of Merit : 1 Beam Parameter ( Beam Current )

Table A3. $6 \mathrm{MeV}$ Test Case 3, timing chart for operator actions.

\begin{tabular}{lcccccc}
\hline & start & end & T1 & T2 & dT & dGFV \\
\hline Auto Tune & $6: 46: 17$ & $6: 47: 26$ & -481 & -412 & 69 & \\
Beam Scan & $6: 48: 38$ & $6: 50: 25$ & -340 & -233 & 107 & \\
Perturb Tune & $6: 51: 27$ & $6: 51: 33$ & -171 & -165 & 6 & $-1.5 \mathrm{~V}$ \\
Beam Scan & $6: 52: 03$ & $6: 53: 53$ & -135 & -25 & 110 & \\
Feedback Correction & $6: 54: 18$ & $6: 54: 26$ & 0 & 8 & 8 & \\
Beam Scan & $6: 55: 08$ & $6: 56: 49$ & 50 & 151 & 101 & \\
\hline
\end{tabular}

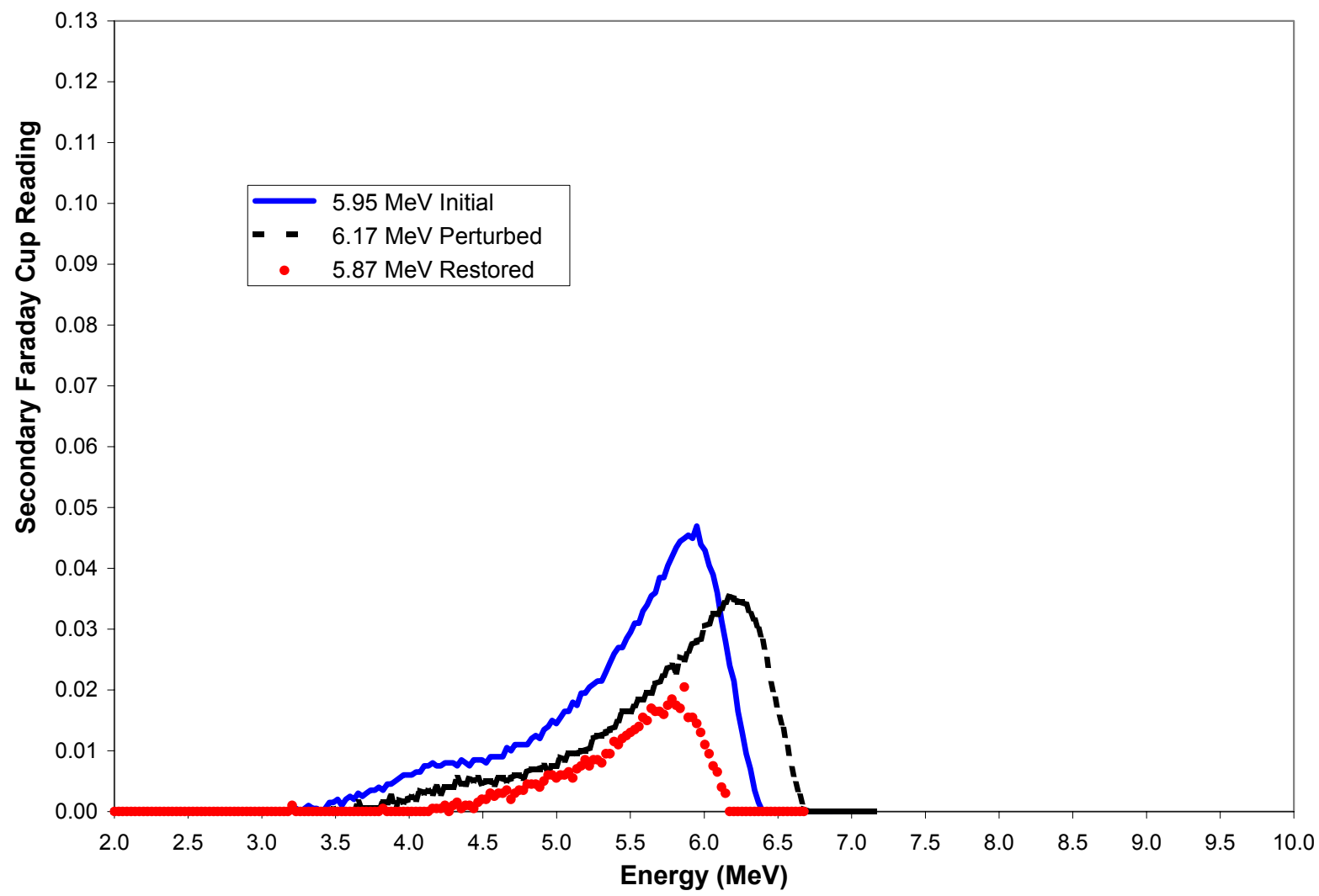

Figure A25. $6 \mathrm{MeV}$ Test Case 3, energy profiles. 


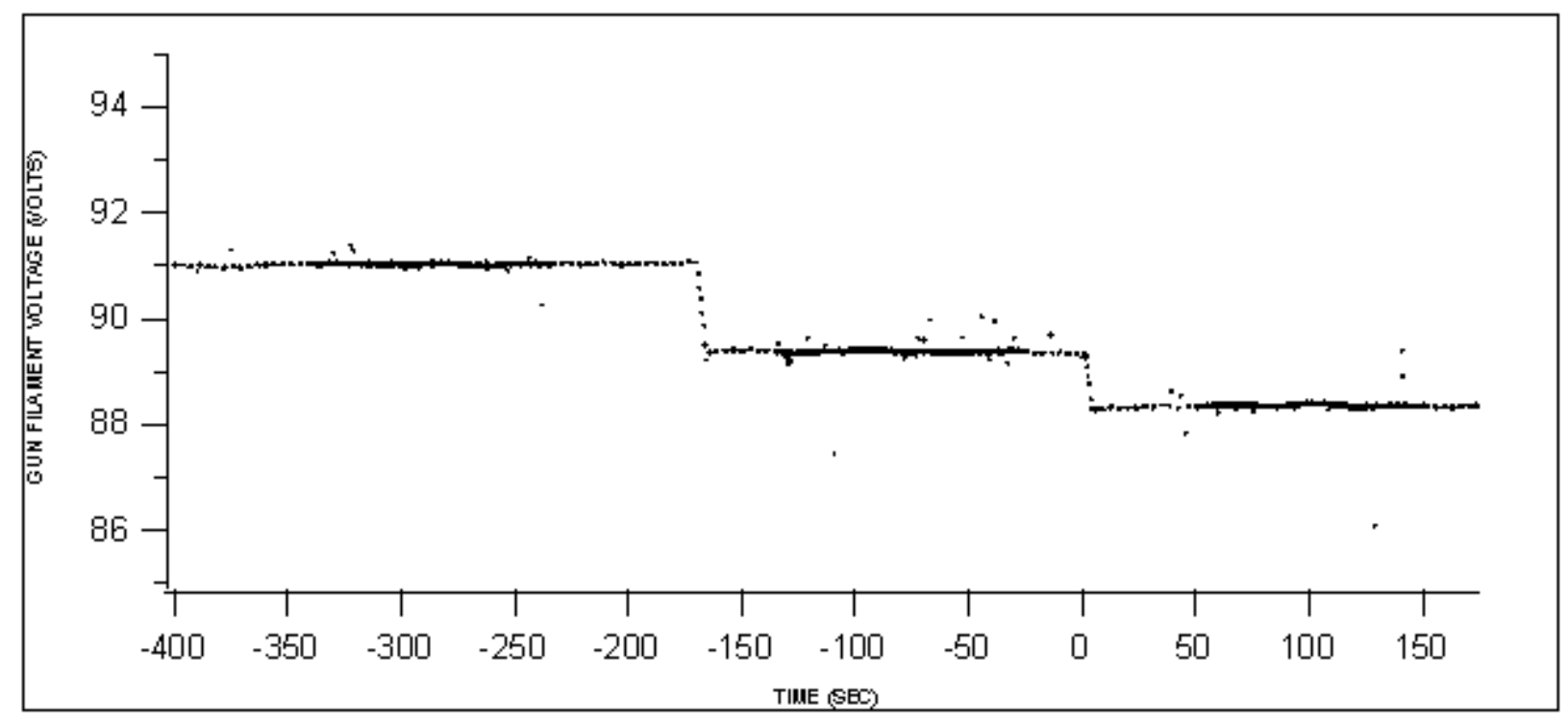

Figure A26. $6 \mathrm{MeV}$ Test Case 3, gun filament voltage.

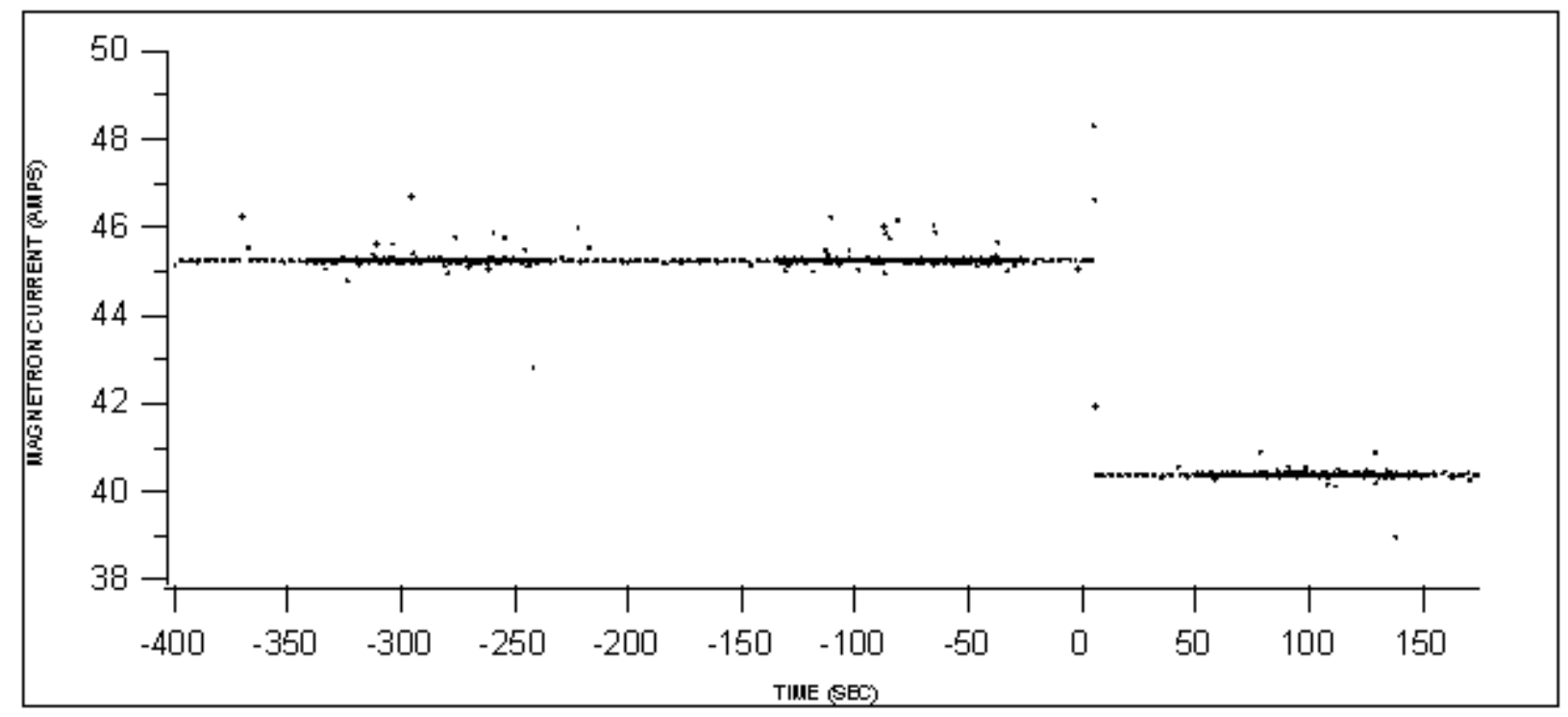

Figure A27. $6 \mathrm{MeV}$ Test Case 3, magnetron current. 


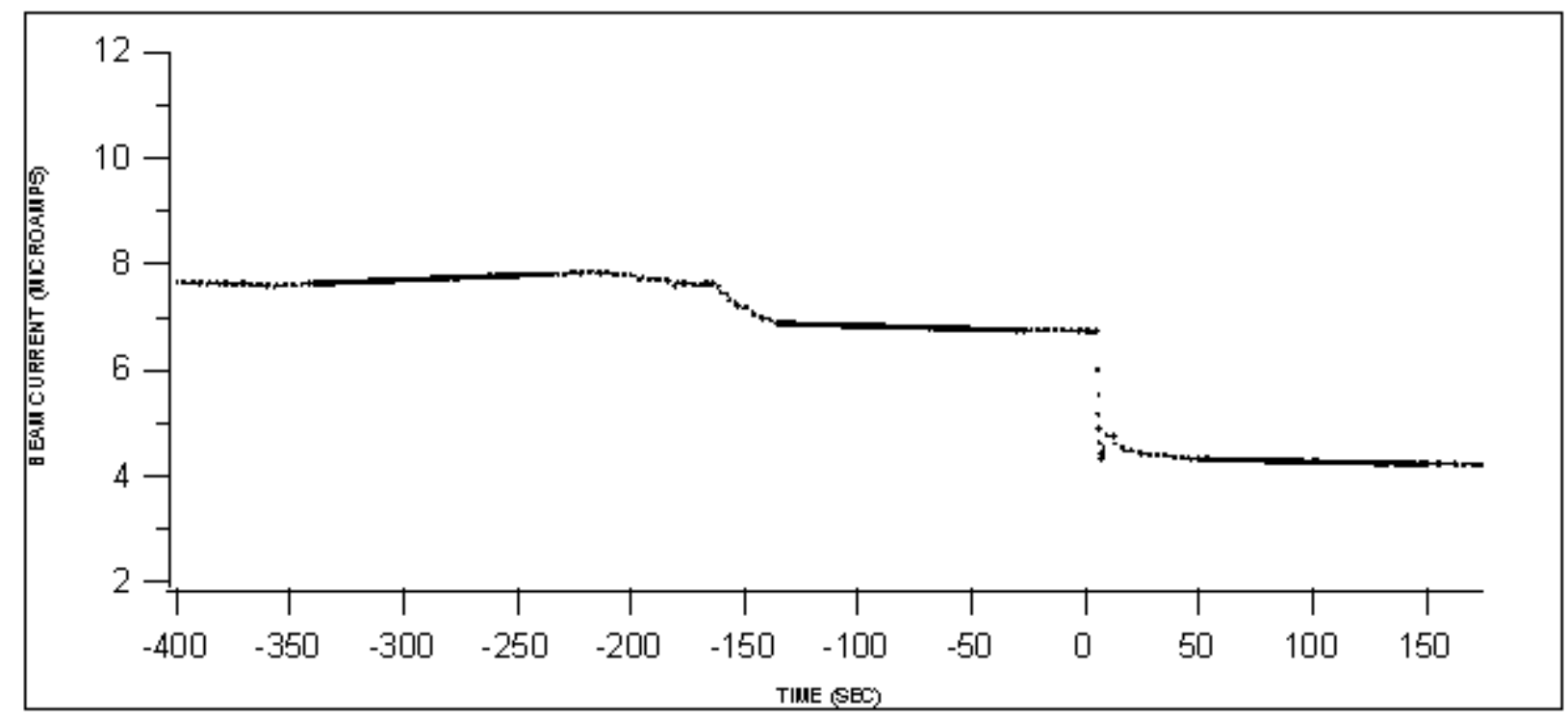

Figure A28. $6 \mathrm{MeV}$ Test Case 3, beam current.

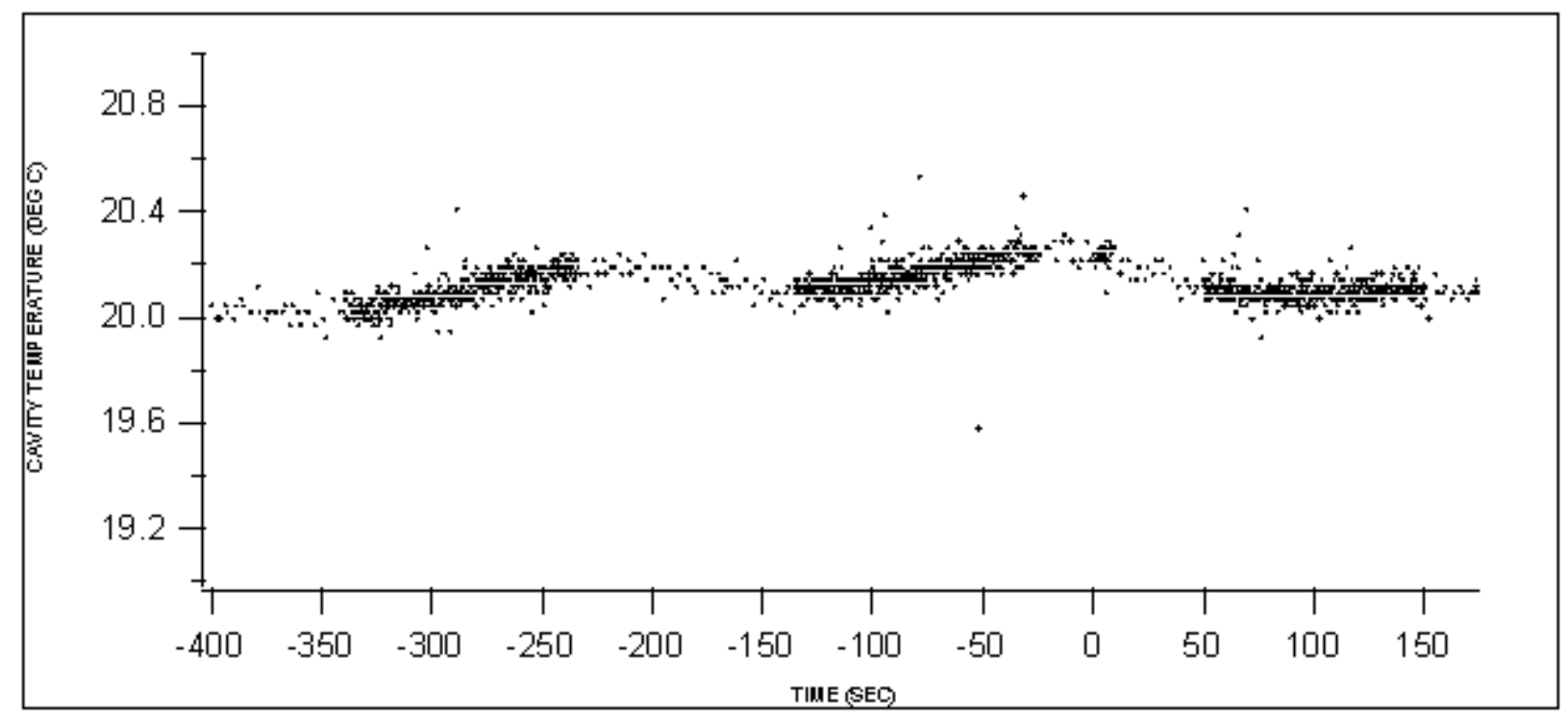

Figure A29. $6 \mathrm{MeV}$ Test Case 3, cavity temperature. 


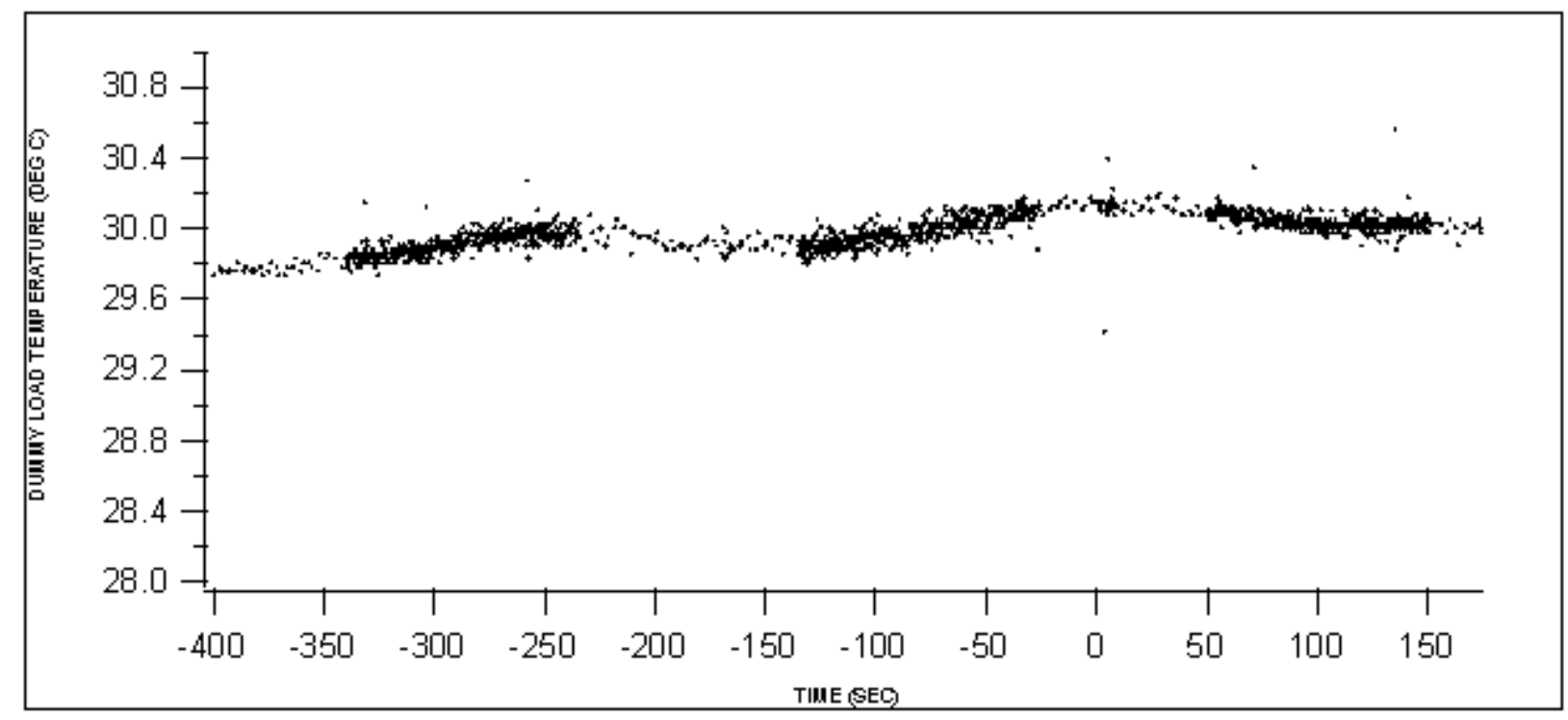

Figure A30. $6 \mathrm{MeV}$ Test Case 3, dummy load temperature.

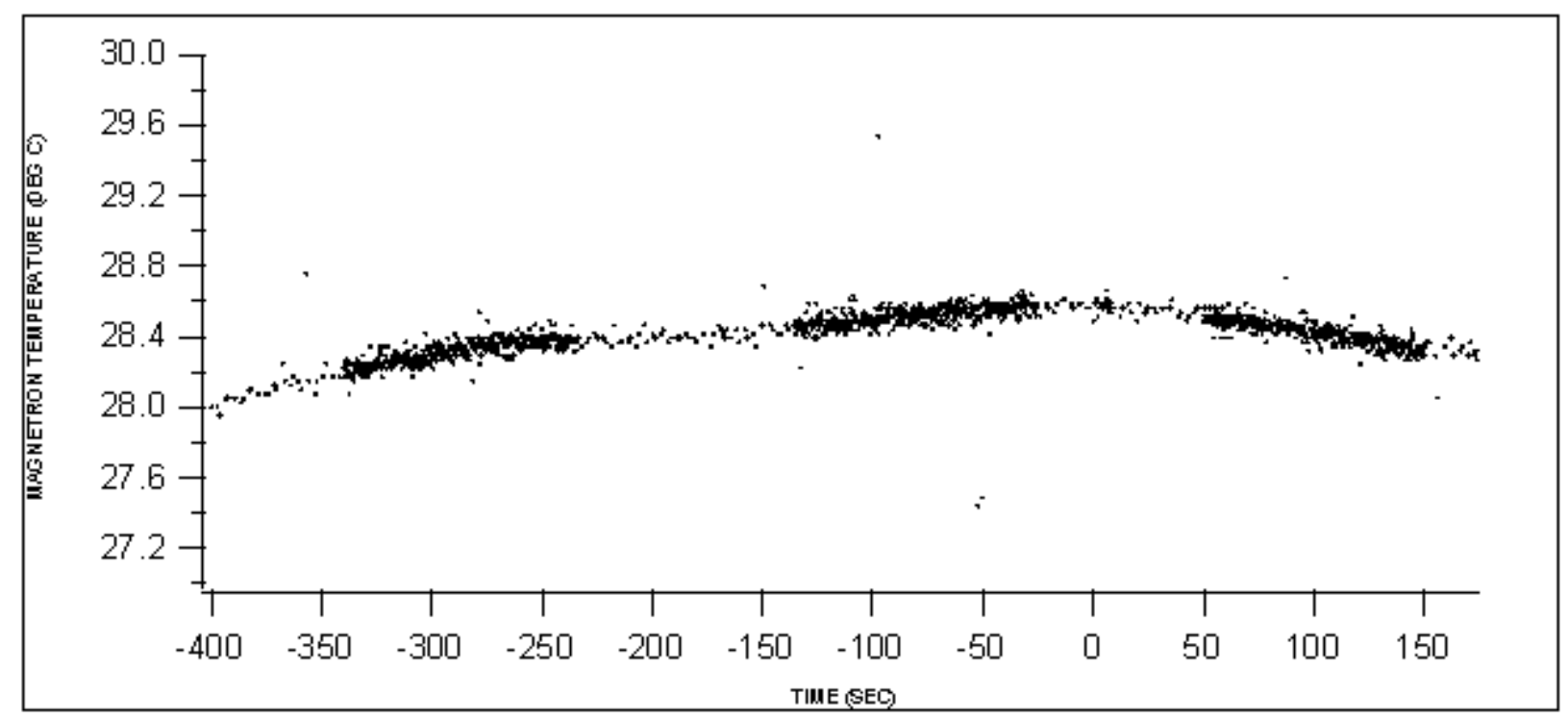

Figure A31. $6 \mathrm{MeV}$ Test Case 3, magnetron temperature. 


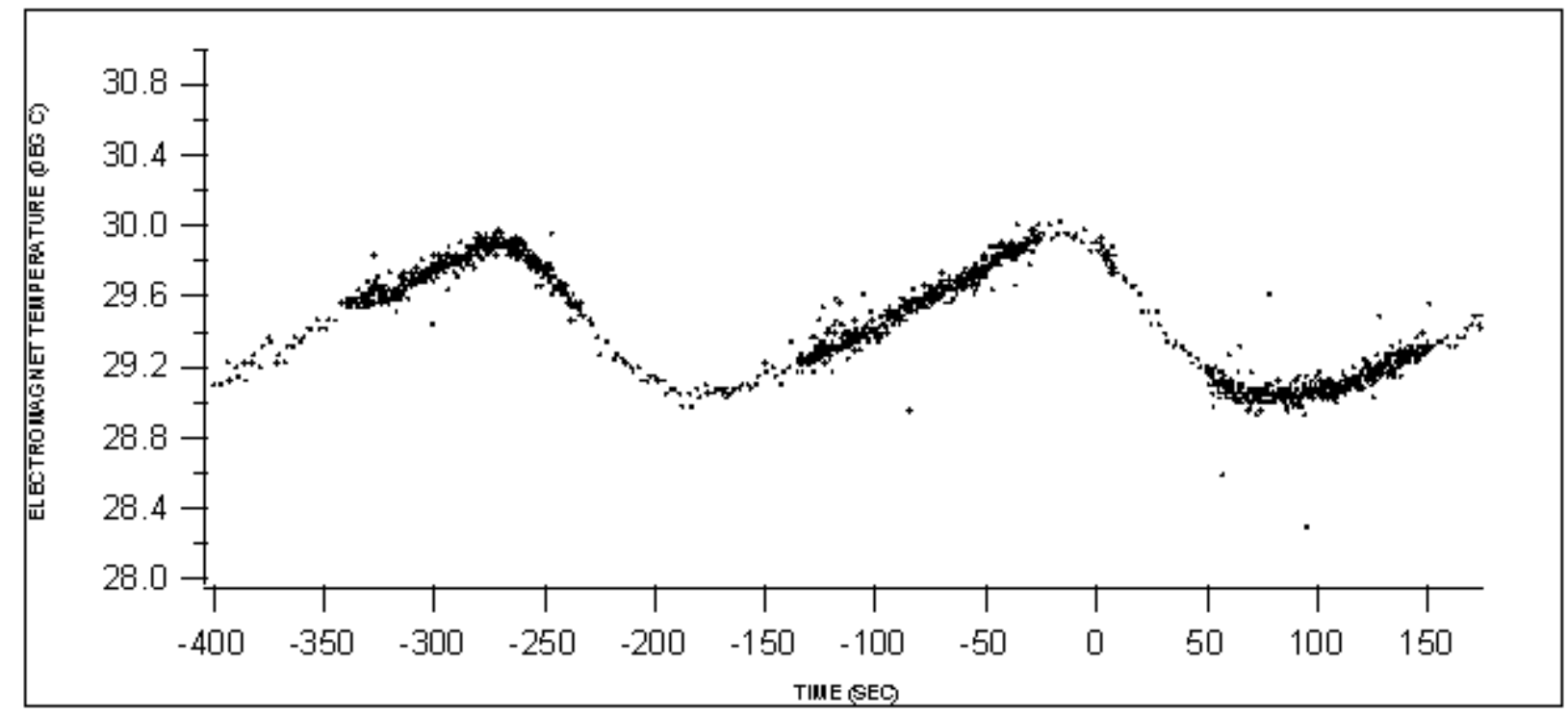

Figure A32. $6 \mathrm{MeV}$ Test Case 3, electromagnet temperature.

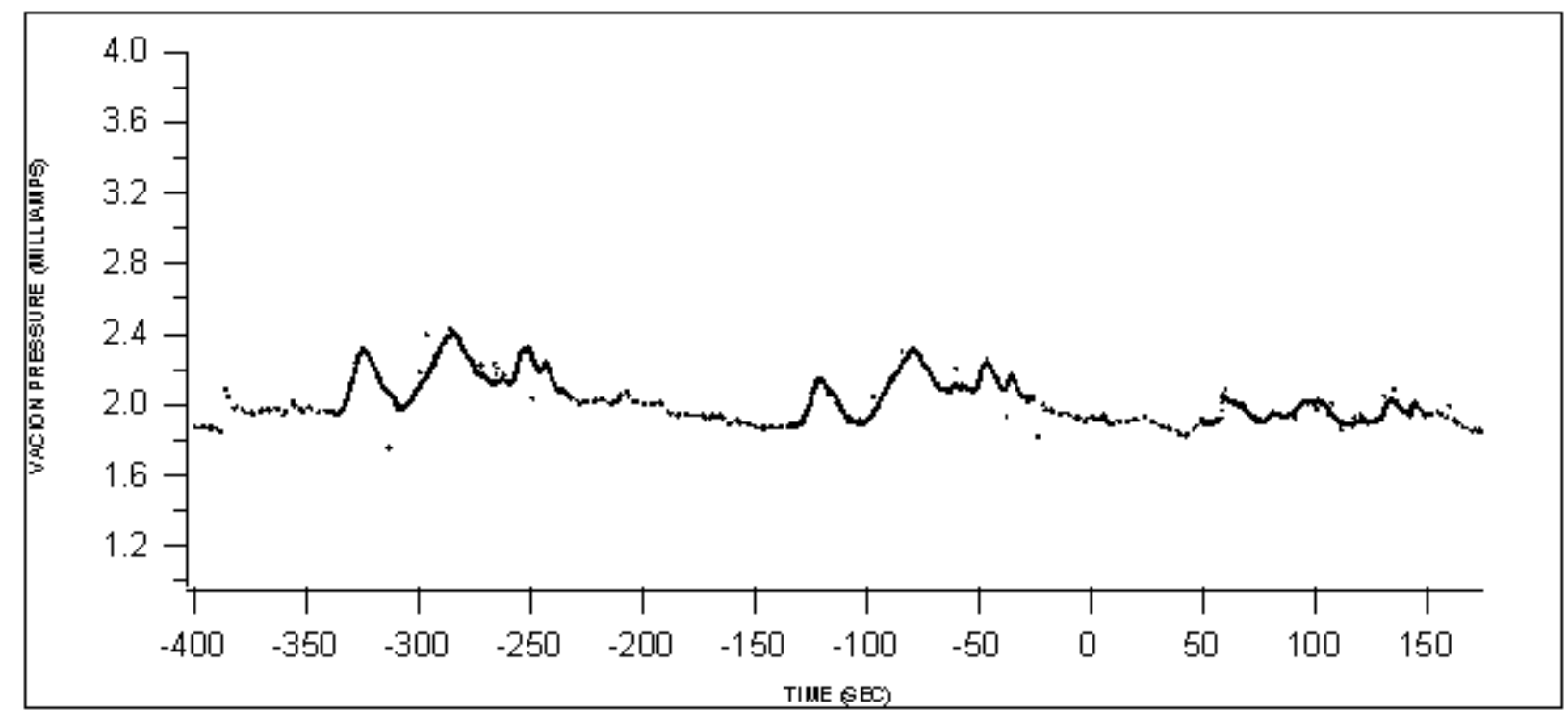

Figure A33. $6 \mathrm{MeV}$ Test Case 3, vacion pressure. 


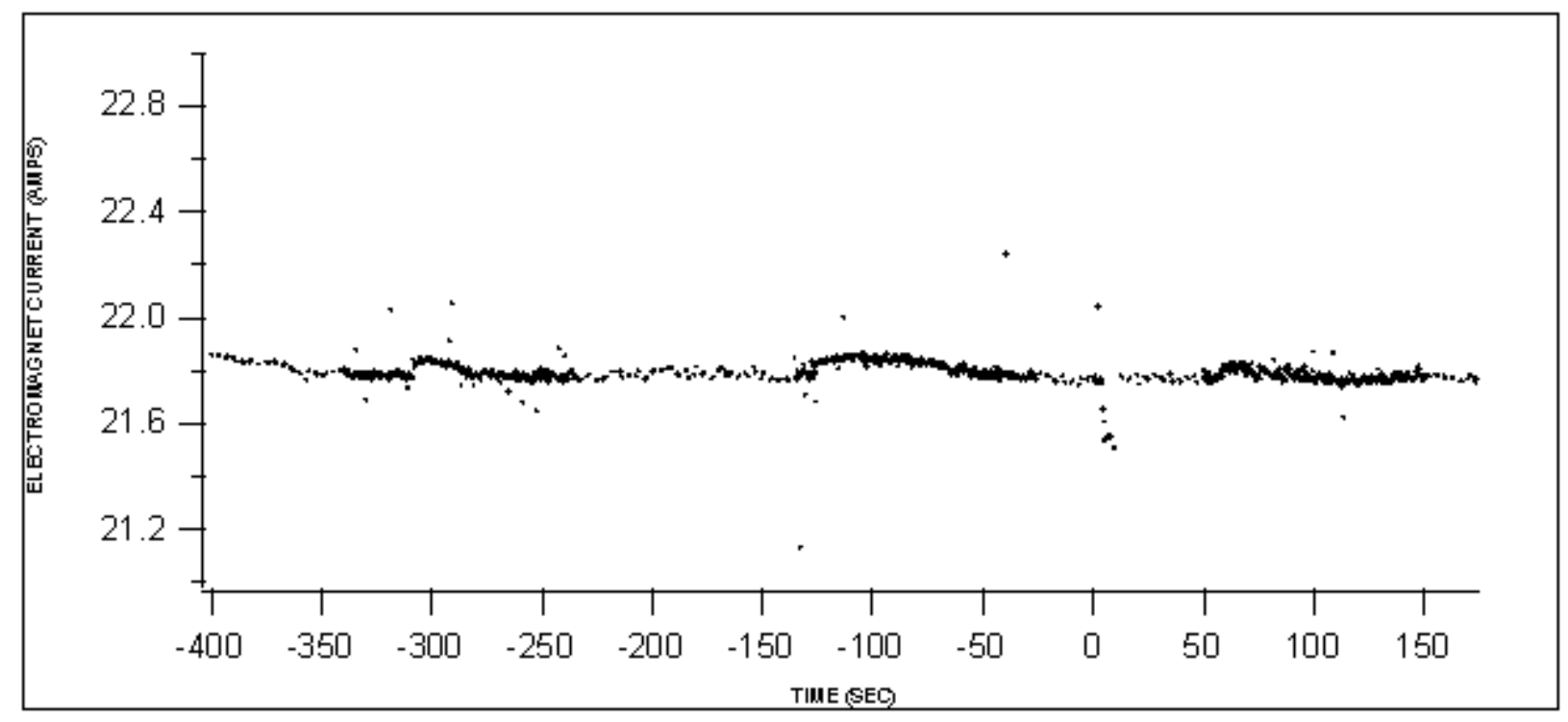

Figure A34. $6 \mathrm{MeV}$ Test Case 3, electromagnet current.

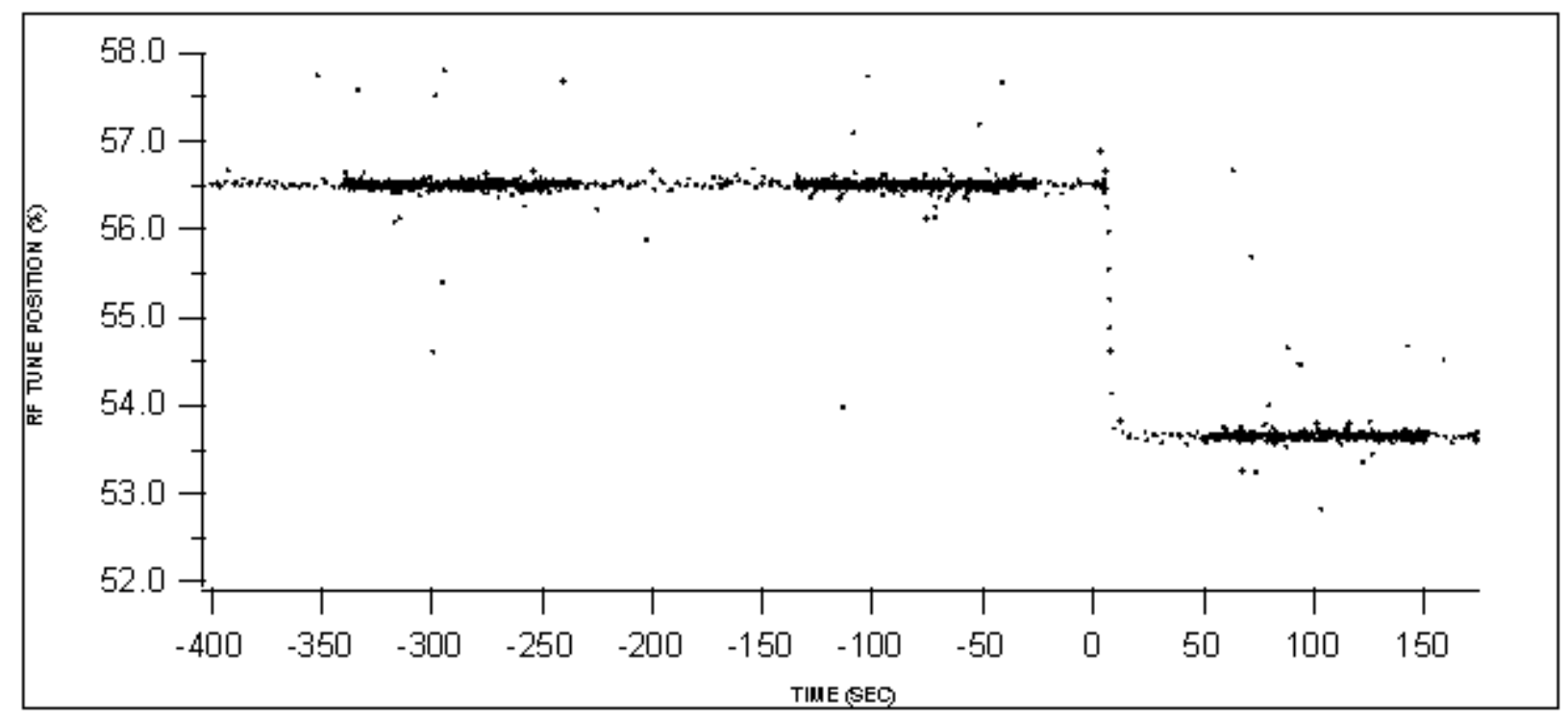

Figure A35. $6 \mathrm{MeV}$ Test Case 3, RF tune position. 


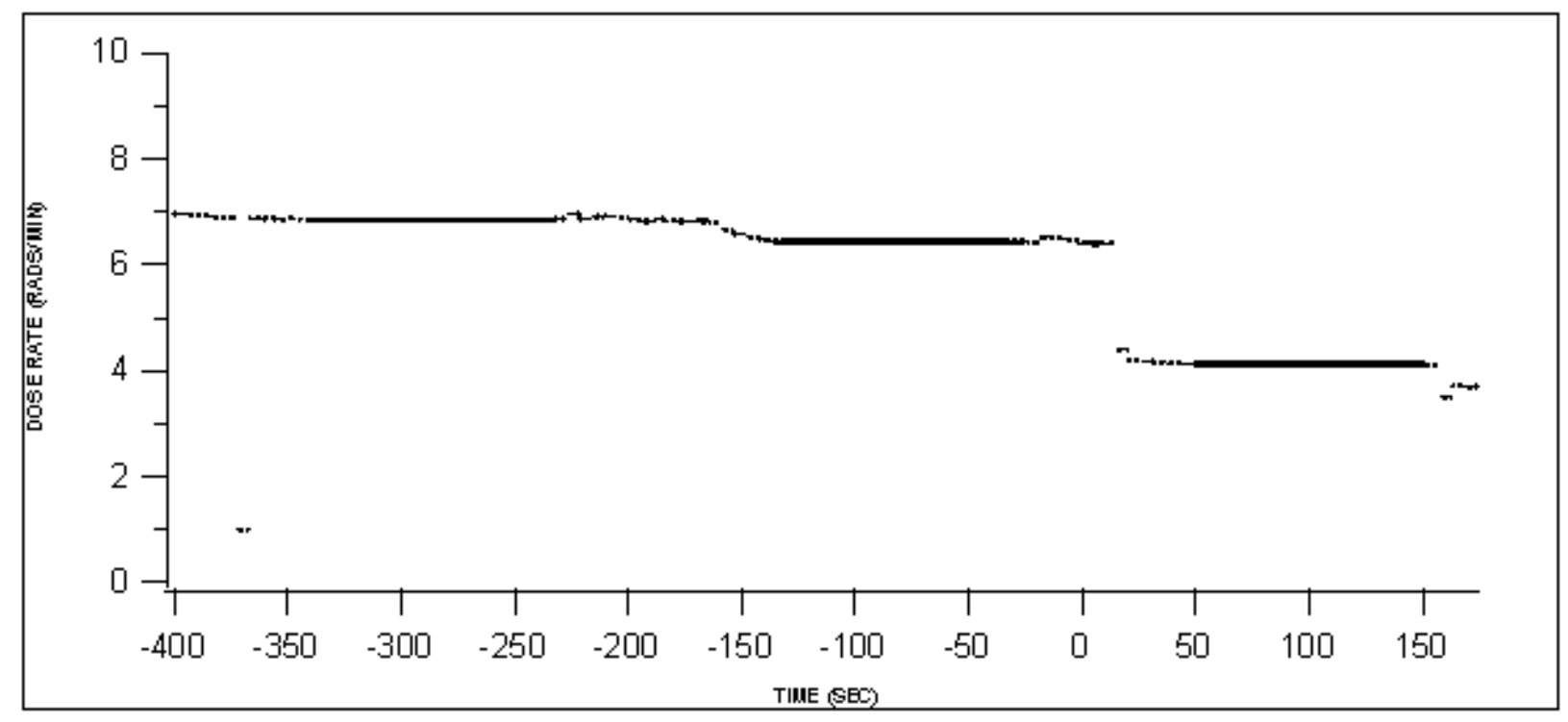

Figure A36. $6 \mathrm{MeV}$ Test Case 3, dose rate. 


\section{$6 \mathrm{MeV}$ Test Case 4}

Reference File : Composite Energy

Figure of Merit : All Parameters

Table A4. $6 \mathrm{MeV}$ Test Case 4, timing chart for operator actions.

\begin{tabular}{lcccccc}
\hline & start & end & T1 & T2 & dT & dGFV \\
\hline Auto Tune & $7: 54: 11$ & $7: 54: 49$ & -640 & -602 & 38 & \\
Beam Scan & $7: 57: 29$ & $7: 59: 29$ & -442 & -322 & 120 & \\
Perturb Tune & $8: 00: 50$ & $8: 01: 01$ & -241 & -230 & 11 & $-1 \mathrm{~V}$ \\
Beam Scan & $8: 01: 42$ & $8: 03: 46$ & -189 & -65 & 124 & \\
Feedback Correction & $8: 04: 51$ & $8: 04: 59$ & 0 & 8 & 8 \\
Feedback Correction & $8: 05: 02$ & $8: 05: 04$ & 11 & 13 & 2 \\
Beam Scan & $8: 06: 22$ & $8: 08: 19$ & 91 & 208 & 117 & \\
\hline
\end{tabular}

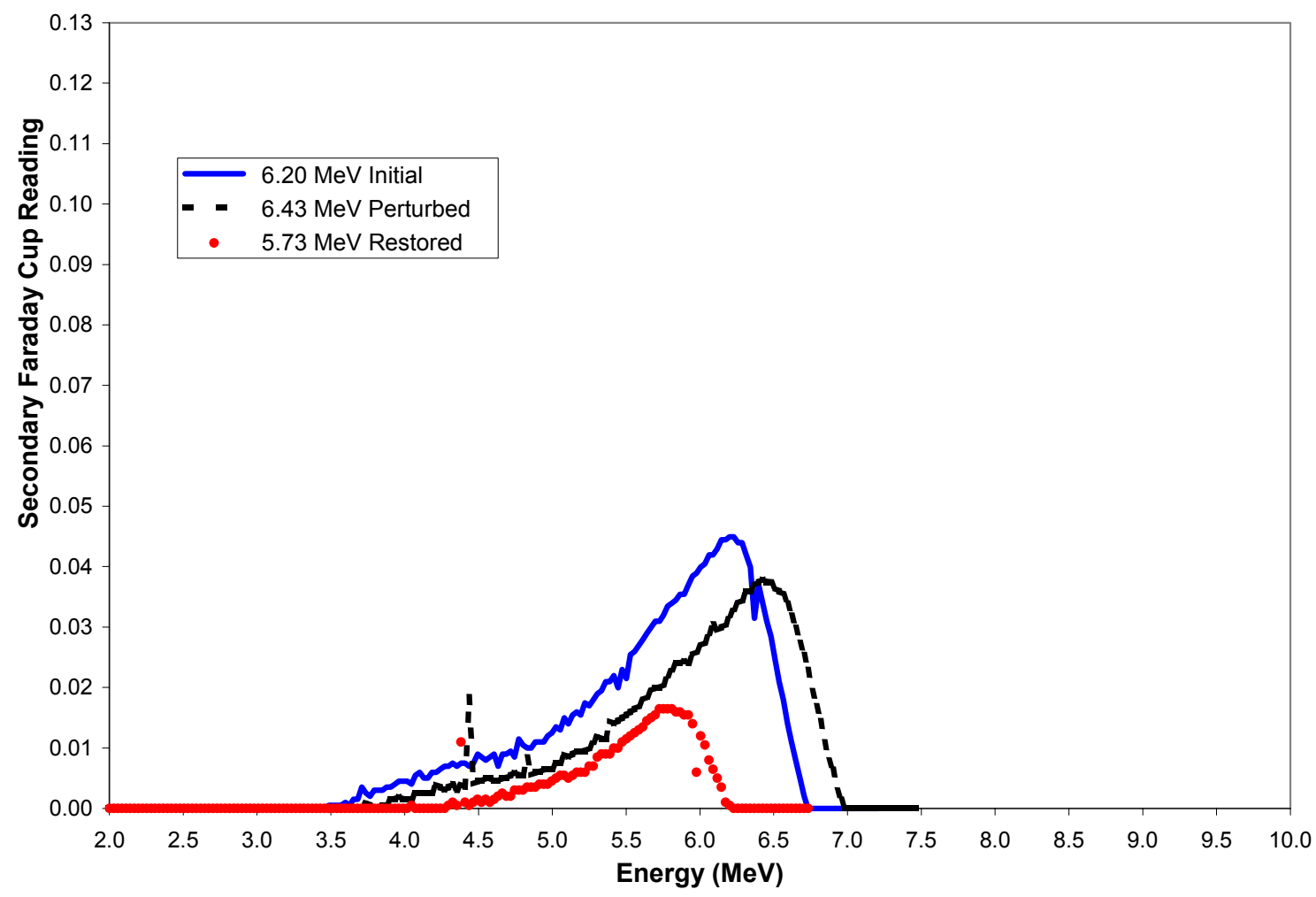

Figure A37. $6 \mathrm{MeV}$ Test Case 4, energy profiles. 


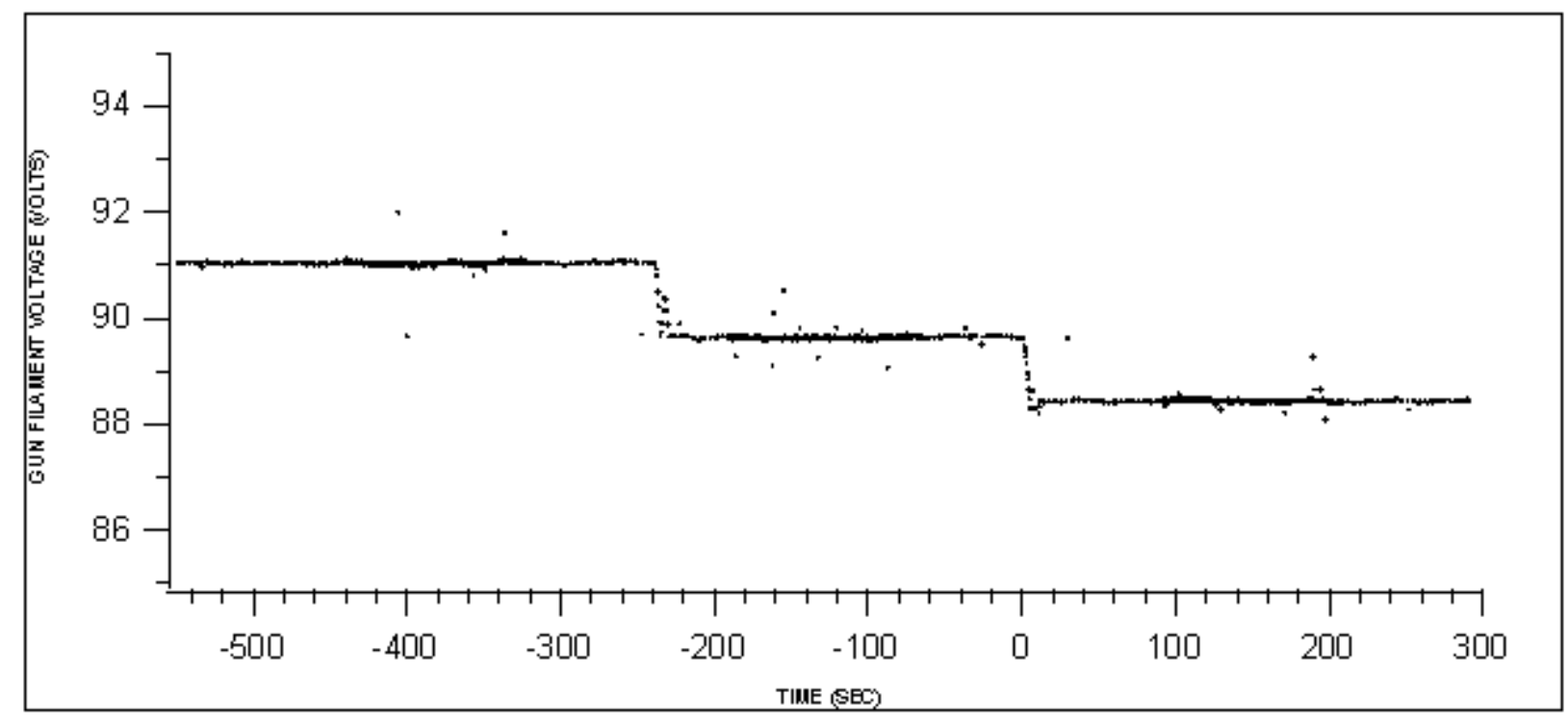

Figure A38. $6 \mathrm{MeV}$ Test Case 4, gun filament voltage.

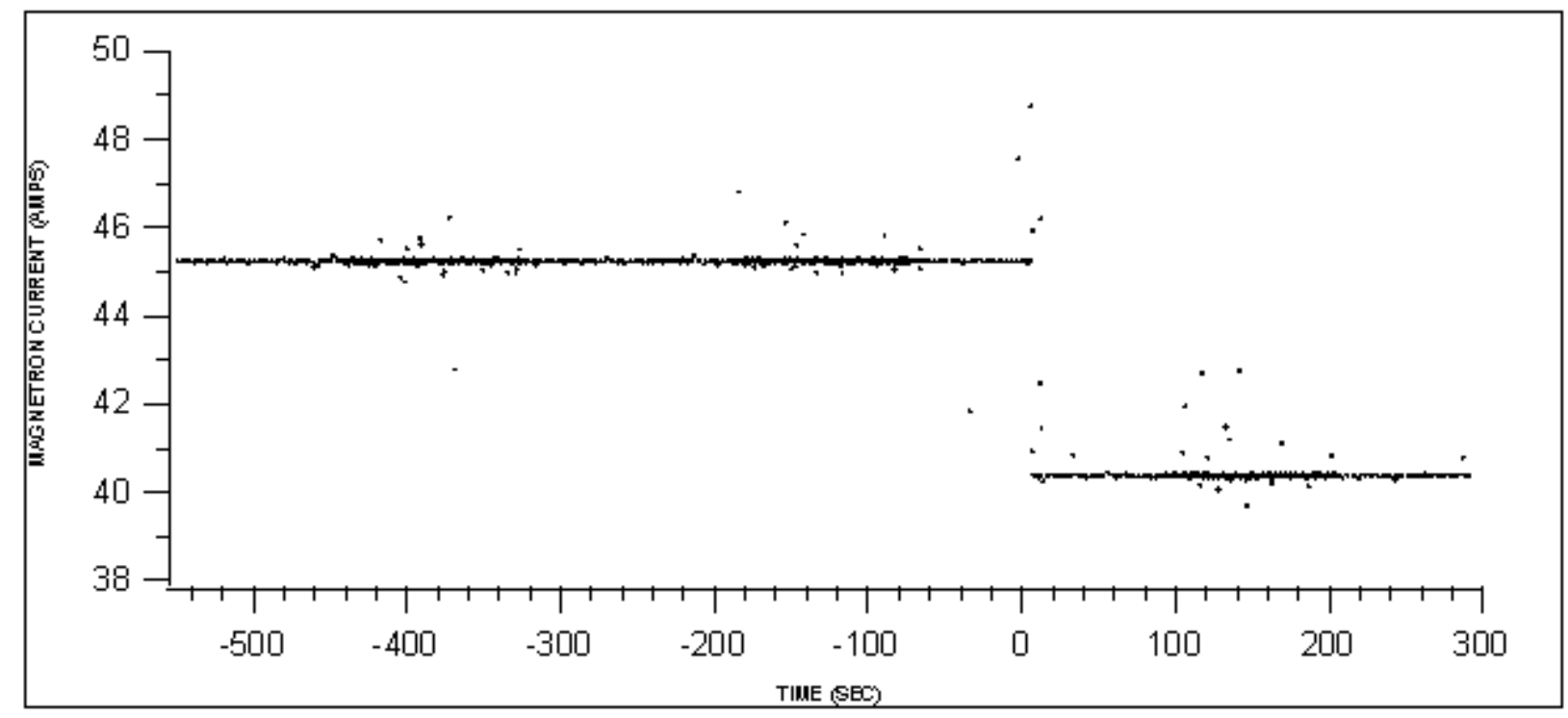

Figure A39. $6 \mathrm{MeV}$ Test Case 4, magnetron current. 


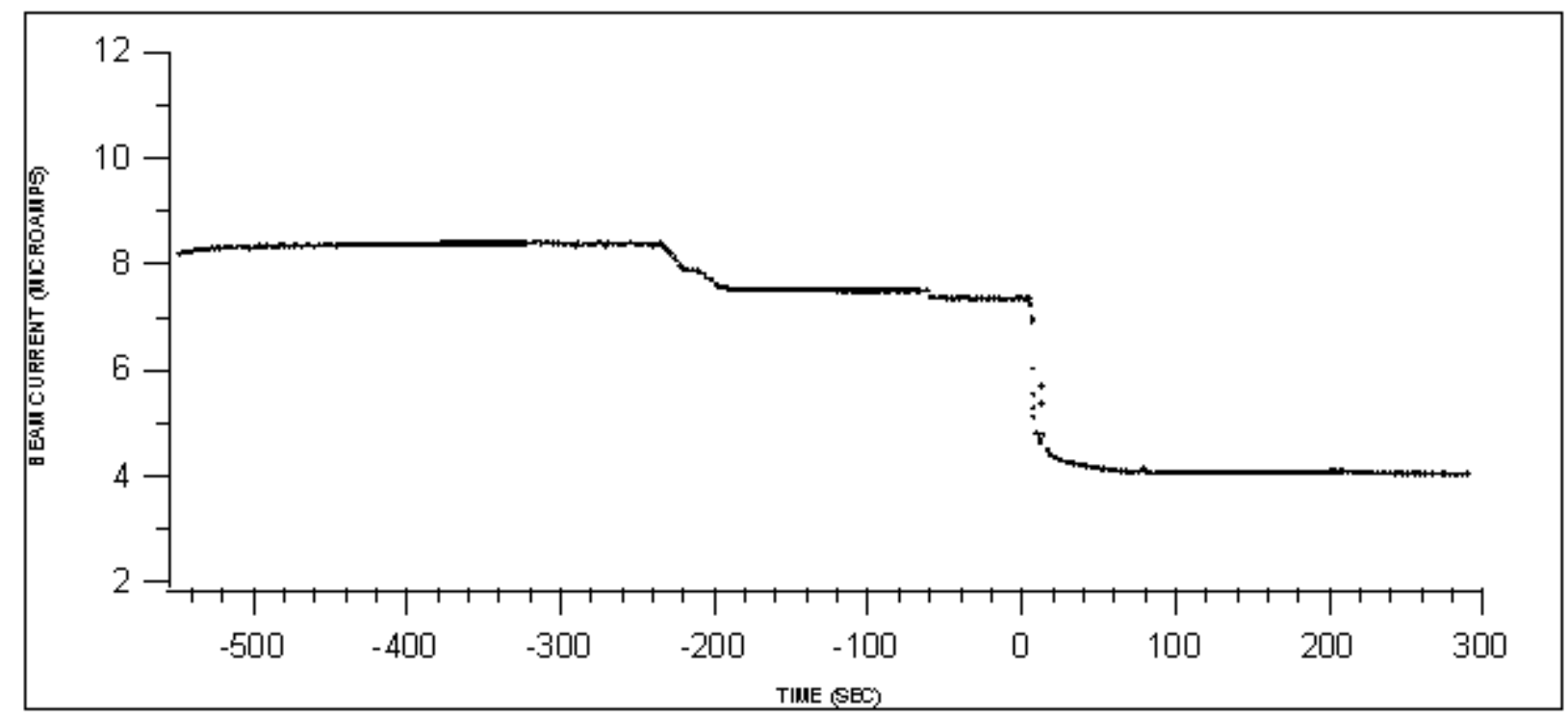

Figure A40. $6 \mathrm{MeV}$ Test Case 4, beam current.

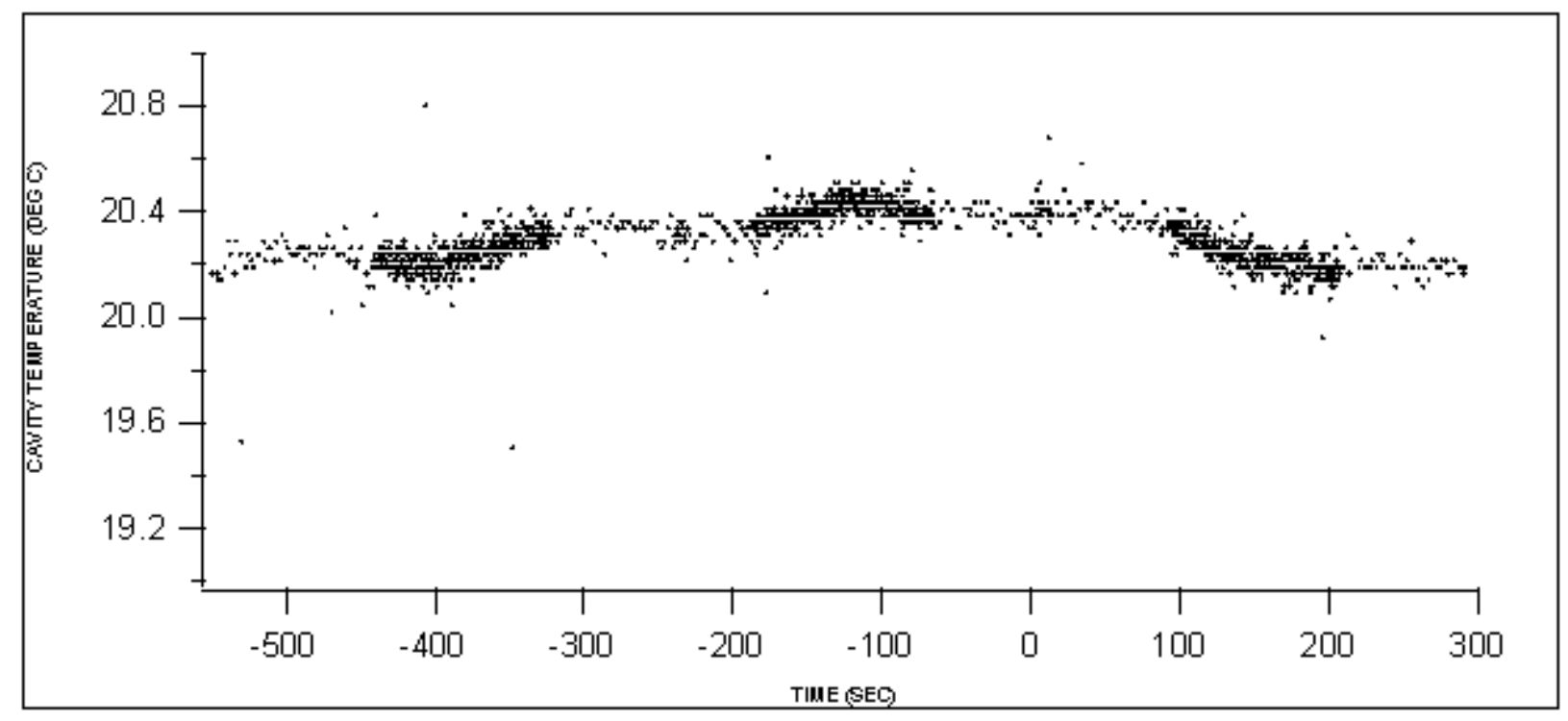

Figure A41. $6 \mathrm{MeV}$ Test Case 4, cavity temperature. 


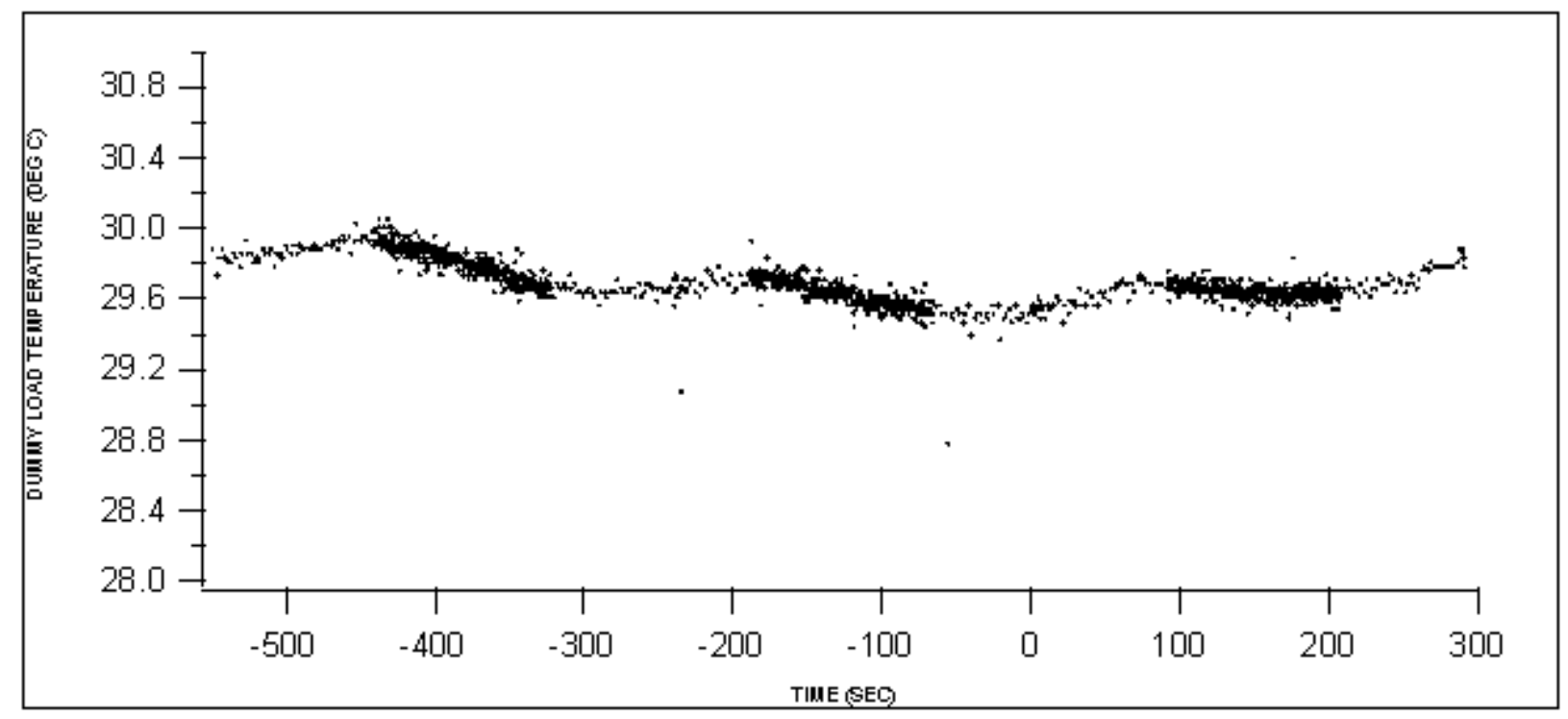

Figure A42. $6 \mathrm{MeV}$ Test Case 4, dummy load temperature.

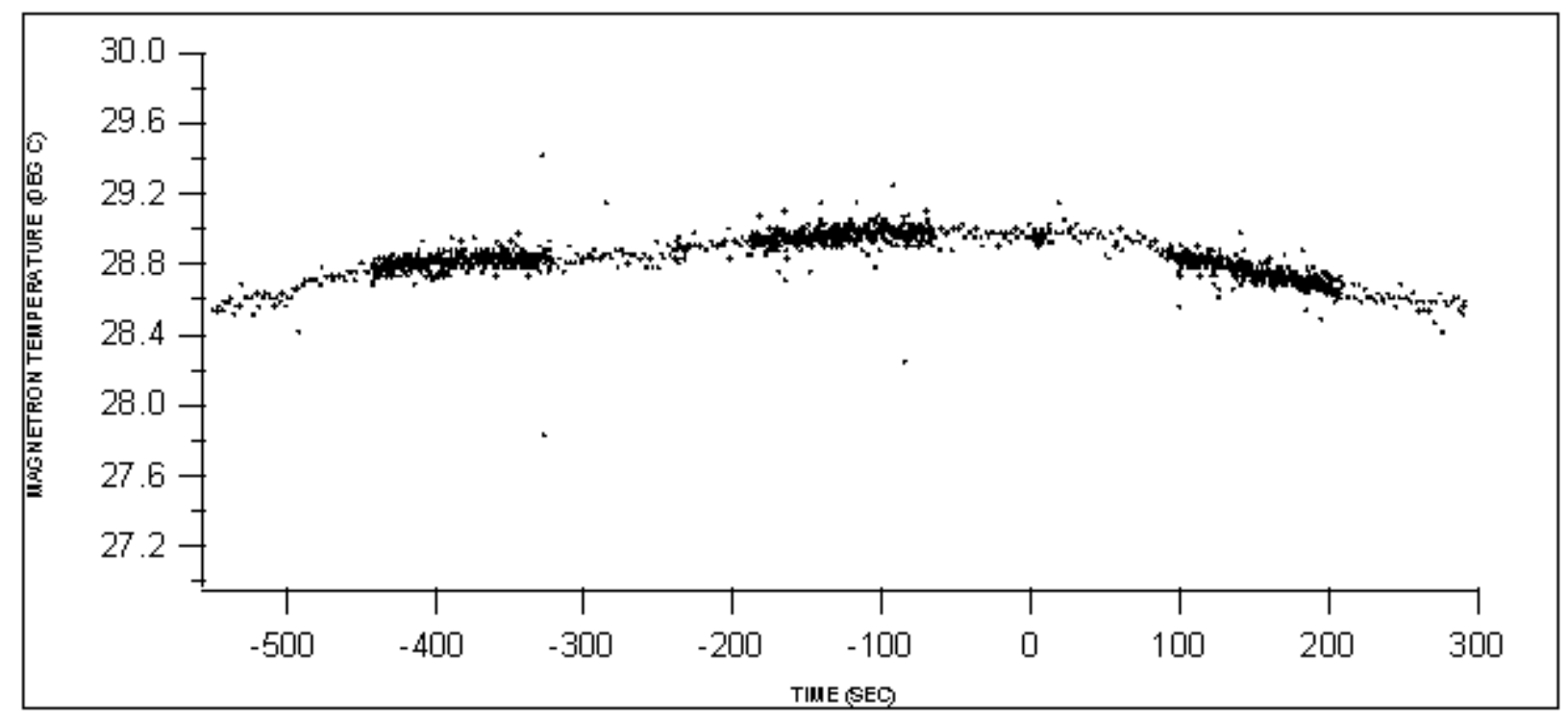

Figure A43. $6 \mathrm{MeV}$ Test Case 4, magnetron temperature. 


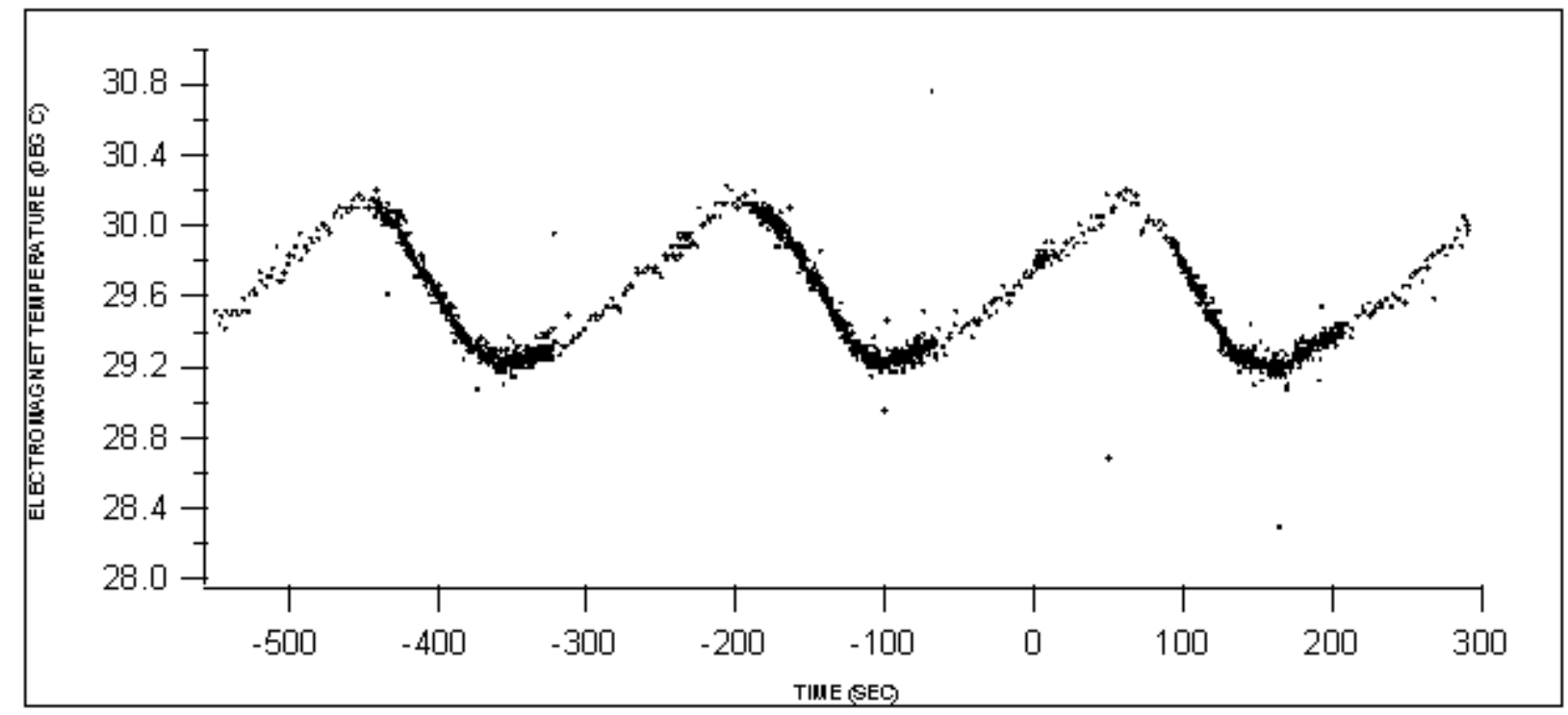

Figure A44. $6 \mathrm{MeV}$ Test Case 4, electromagnet temperature.

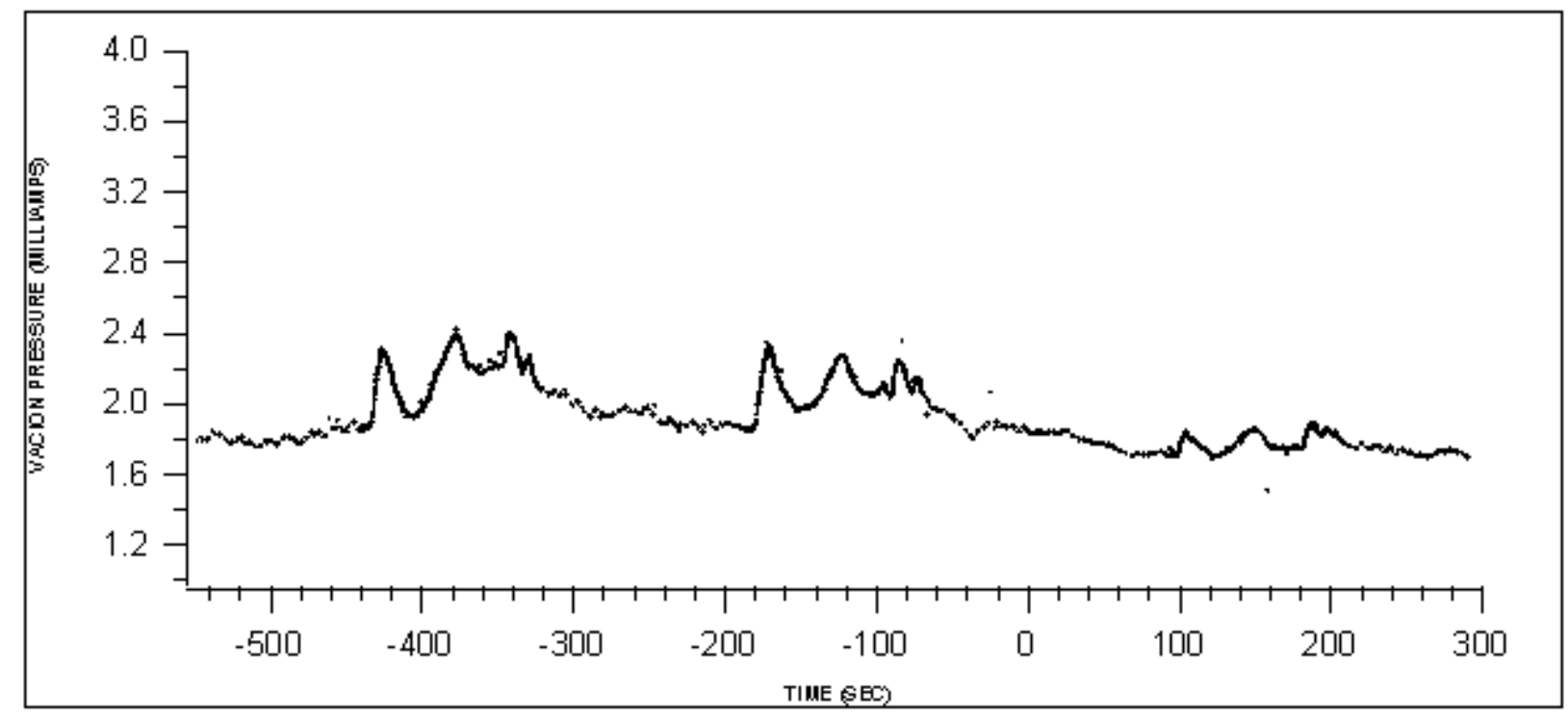

Figure A45. $6 \mathrm{MeV}$ Test Case 4, vacion pressure. 


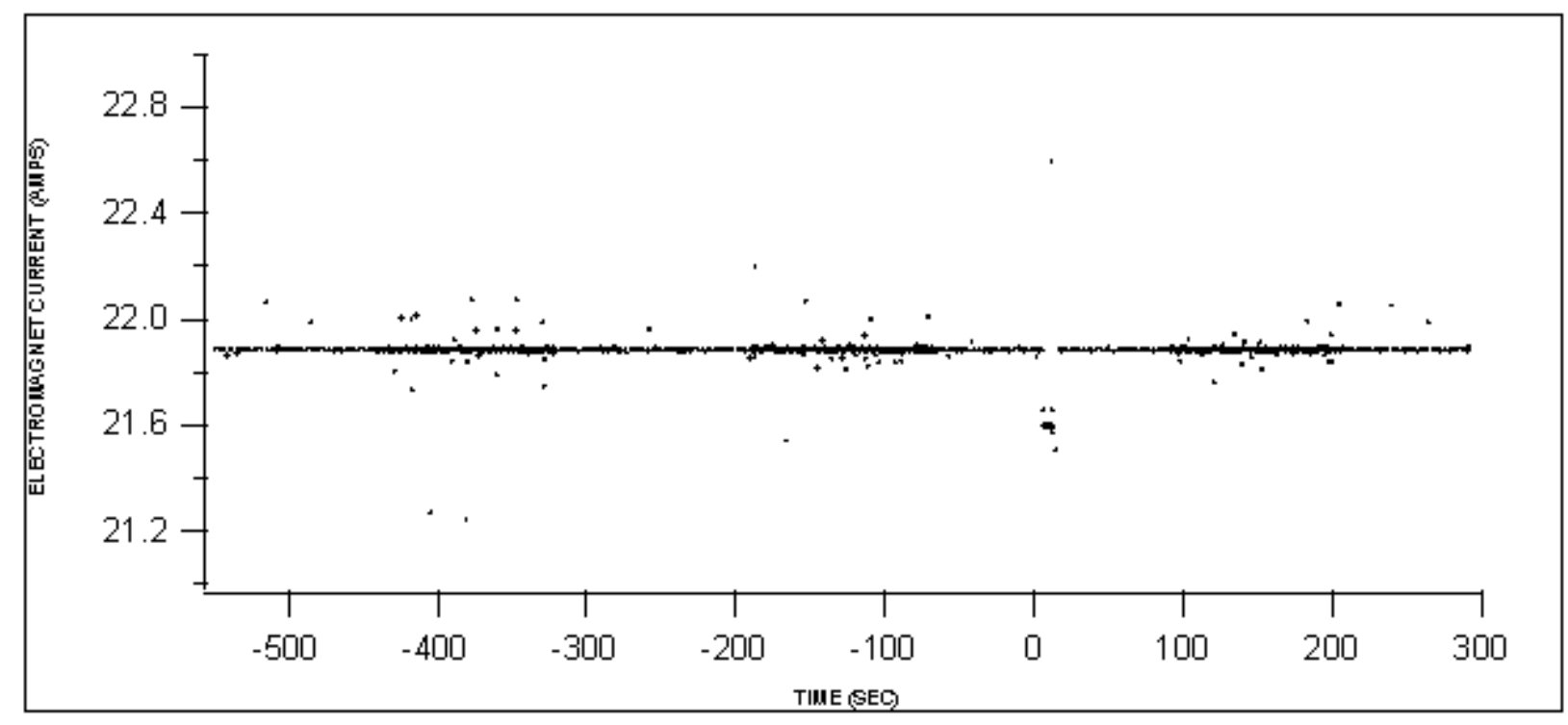

Figure A46. $6 \mathrm{MeV}$ Test Case 4, electromagnet current.

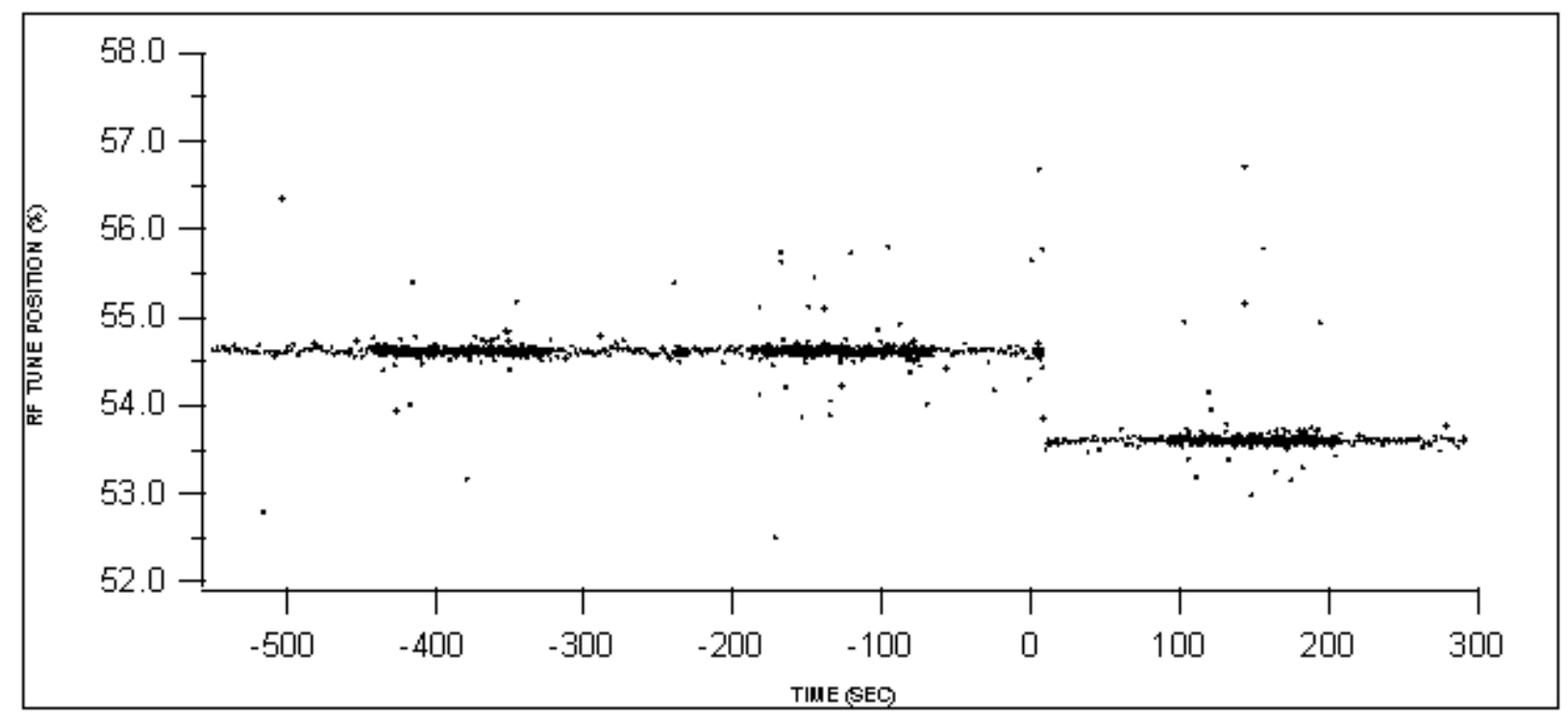

Figure A47. $6 \mathrm{MeV}$ Test Case 4, RF tune position. 


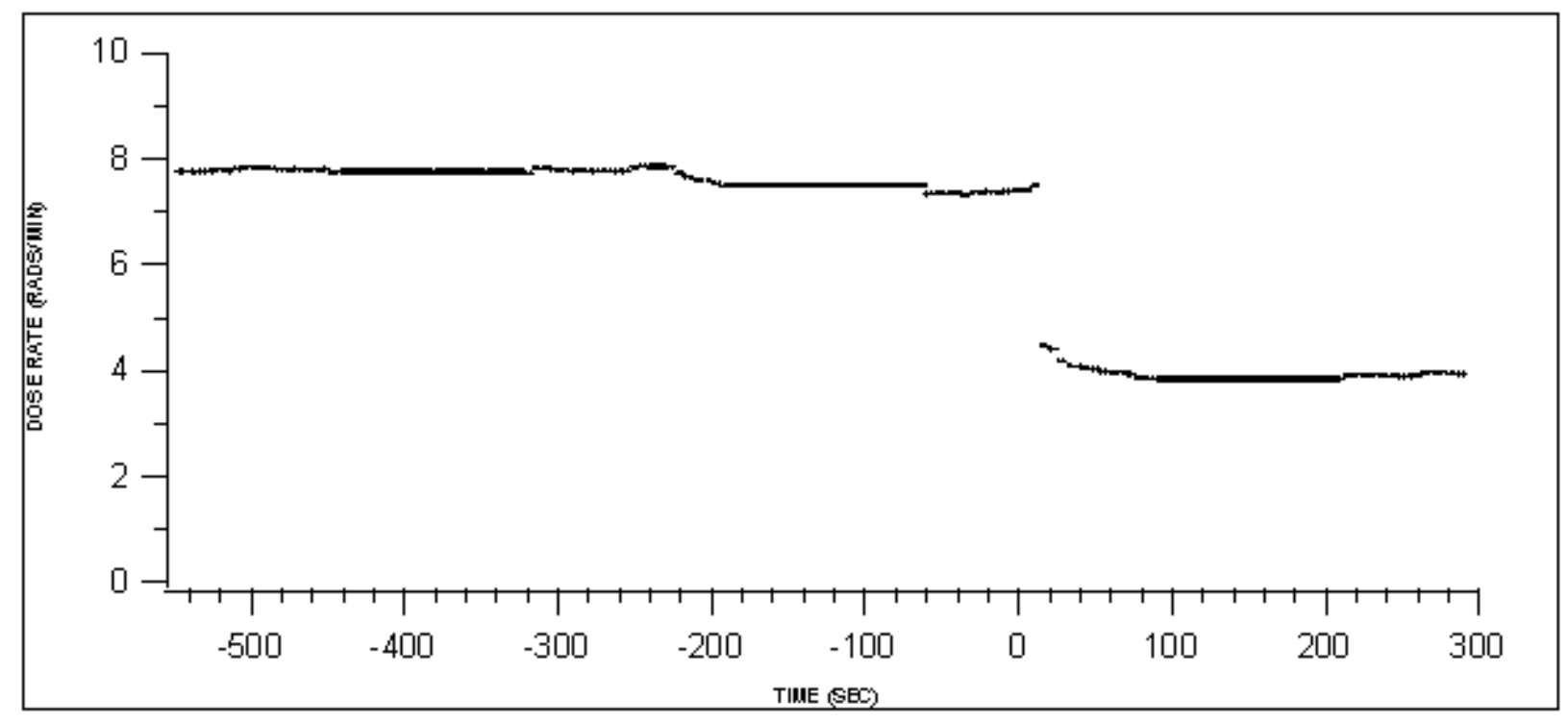

Figure A48. $6 \mathrm{MeV}$ Test Case 4, dose rate. 


\section{APPENDIX B}

\section{PLOTS FROM 7 MEV TEST CASE}


This page intentionally left blank. 


\section{APPENDIX B}

\section{PLOTS FROM 7 MEV TEST CASES}

\section{MeV Test Case 3}

Reference File : Composite Energy

Figure of Merit : 1 Beam Parameter ( Beam Current )

Table B1. $7 \mathrm{MeV}$ Test Case 3, timing chart for operator actions.

\begin{tabular}{lcccccc}
\hline & start & end & T1 & T2 & dT & dGFV \\
\hline 7 MeV Stabilize & $16: 08: 27$ & $16: 14: 35$ & -602 & -234 & 368 & \\
Beam Scan & $16: 14: 35$ & $16: 15: 36$ & -234 & -173 & 61 & \\
Beam Scan & $16: 15: 44$ & $16: 16: 09$ & -165 & -140 & 25 & \\
Perturb Tune & $16: 16: 38$ & $16: 16: 46$ & -111 & -103 & 8 & $-1.5 \mathrm{~V}$ \\
Beam Scan & $16: 17: 04$ & $16: 18: 14$ & -85 & -15 & 70 & \\
Feedback Correction & $16: 18: 29$ & $16: 18: 35$ & 0 & 6 & 6 \\
Feedback Correction & $16: 18: 36$ & $16: 18: 45$ & 7 & 16 & 9 \\
Feedback Correction & $16: 18: 45$ & $16: 18: 49$ & 16 & 20 & 4 \\
Feedback Correction & $16: 18: 52$ & $16: 18: 56$ & 23 & 27 & 4 \\
Feedback Correction & $16: 18: 59$ & $16: 19: 03$ & 30 & 34 & 4 & \\
Beam Scan & $16: 19: 21$ & $16: 20: 23$ & 52 & 114 & 62 &
\end{tabular}

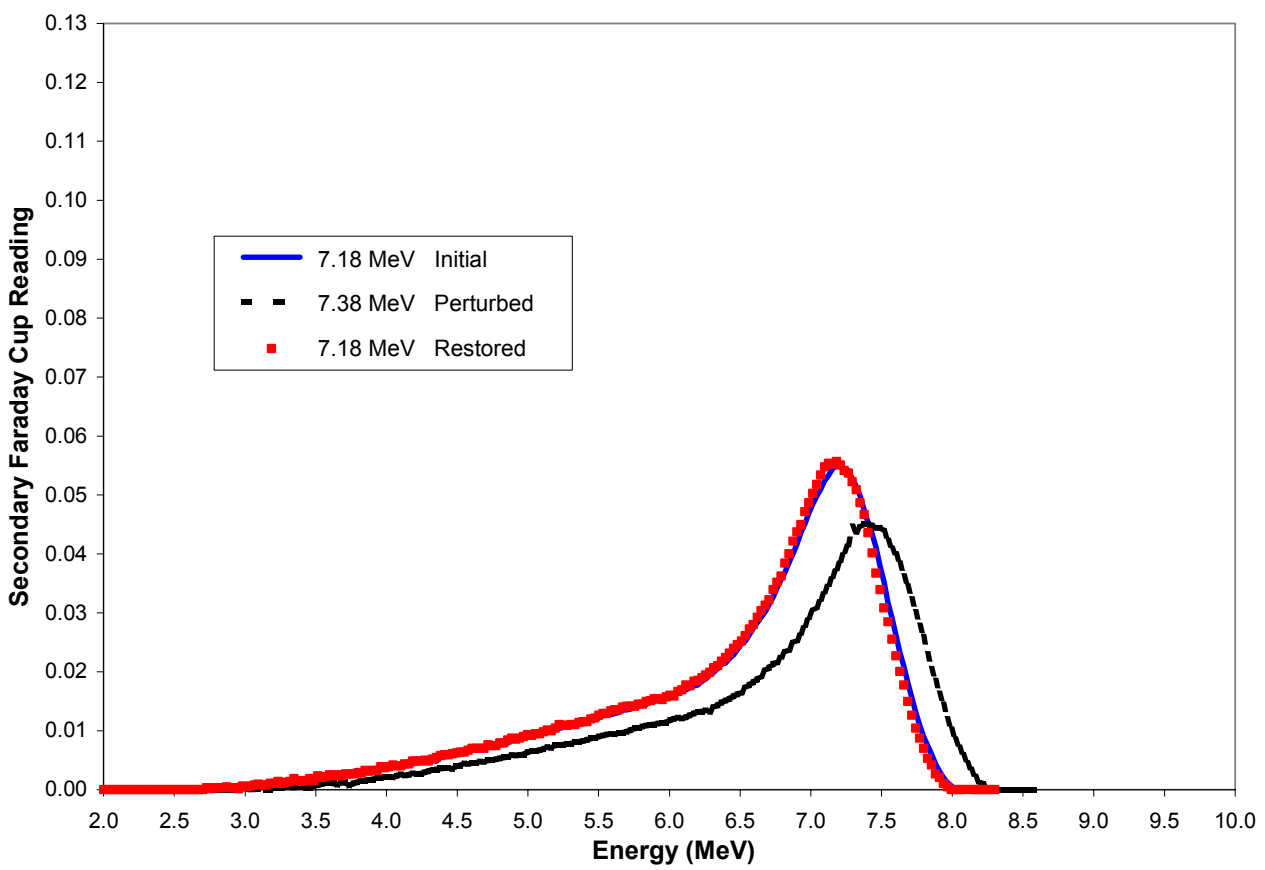

Figure B1. $7 \mathrm{MeV}$ Test Case 3, energy profiles. 


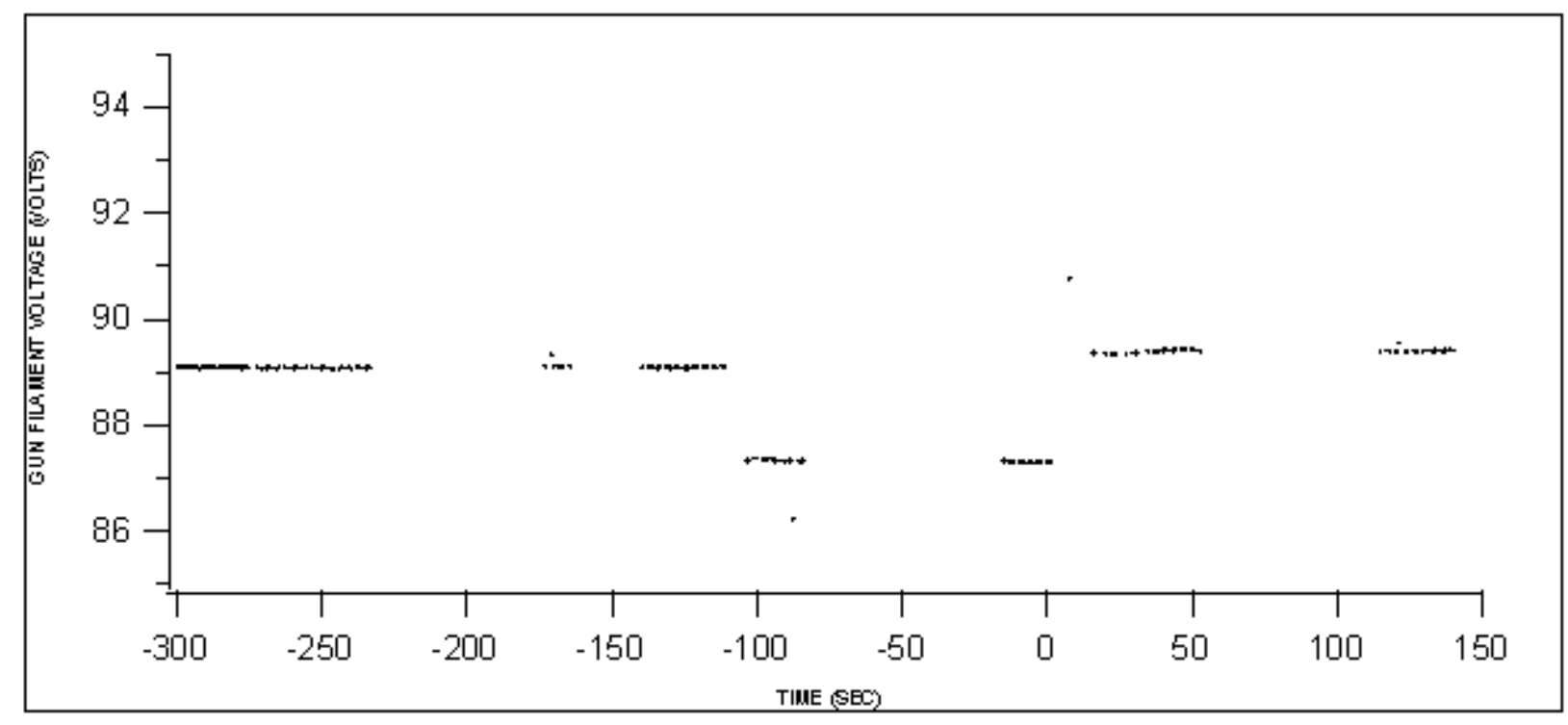

Figure B2. $7 \mathrm{MeV}$ Test Case 3, gun filament voltage.

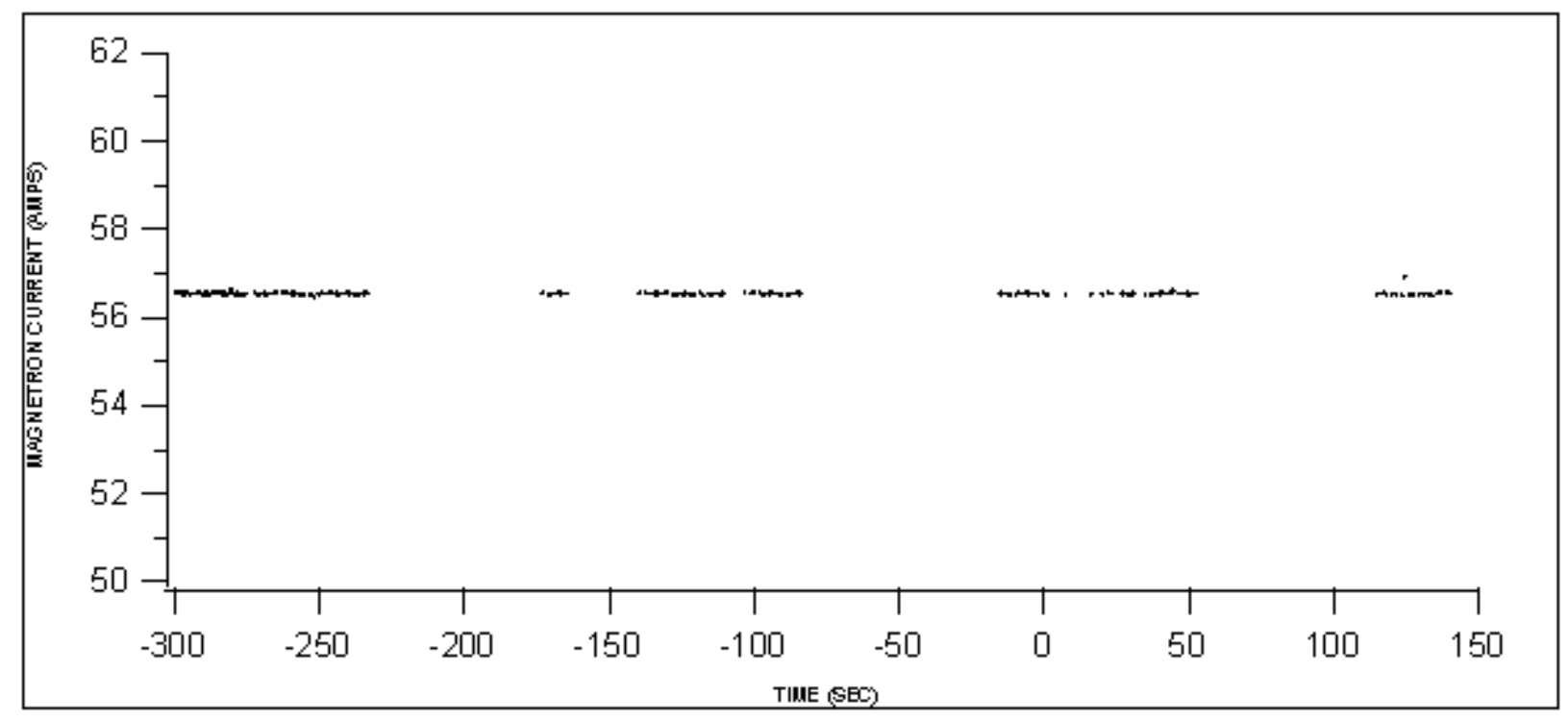

Figure B3. $7 \mathrm{MeV}$ Test Case 3, magnetron current. 


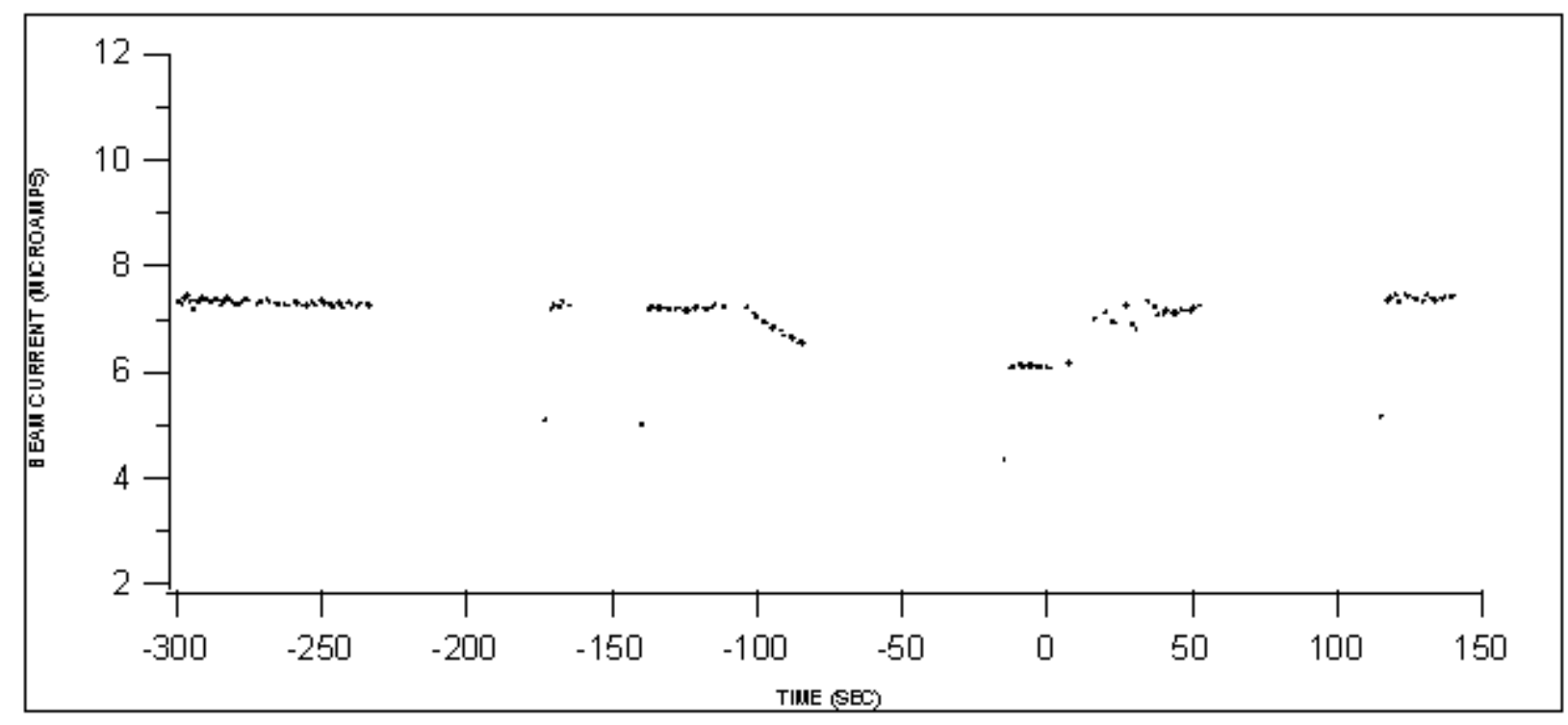

Figure B4. $7 \mathrm{MeV}$ Test Case 3, beam current.

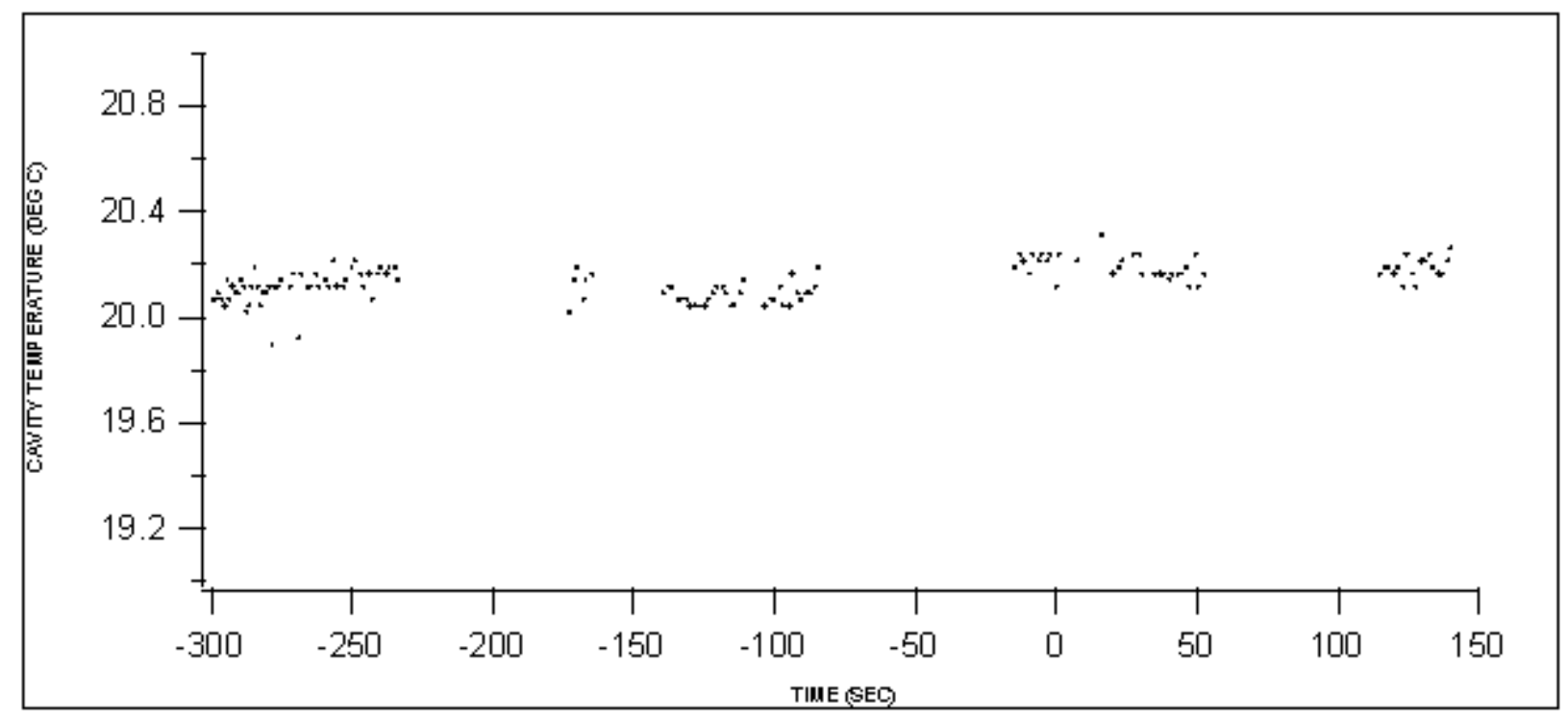

Figure B5. $7 \mathrm{MeV}$ Test Case 3, cavity temperature. 


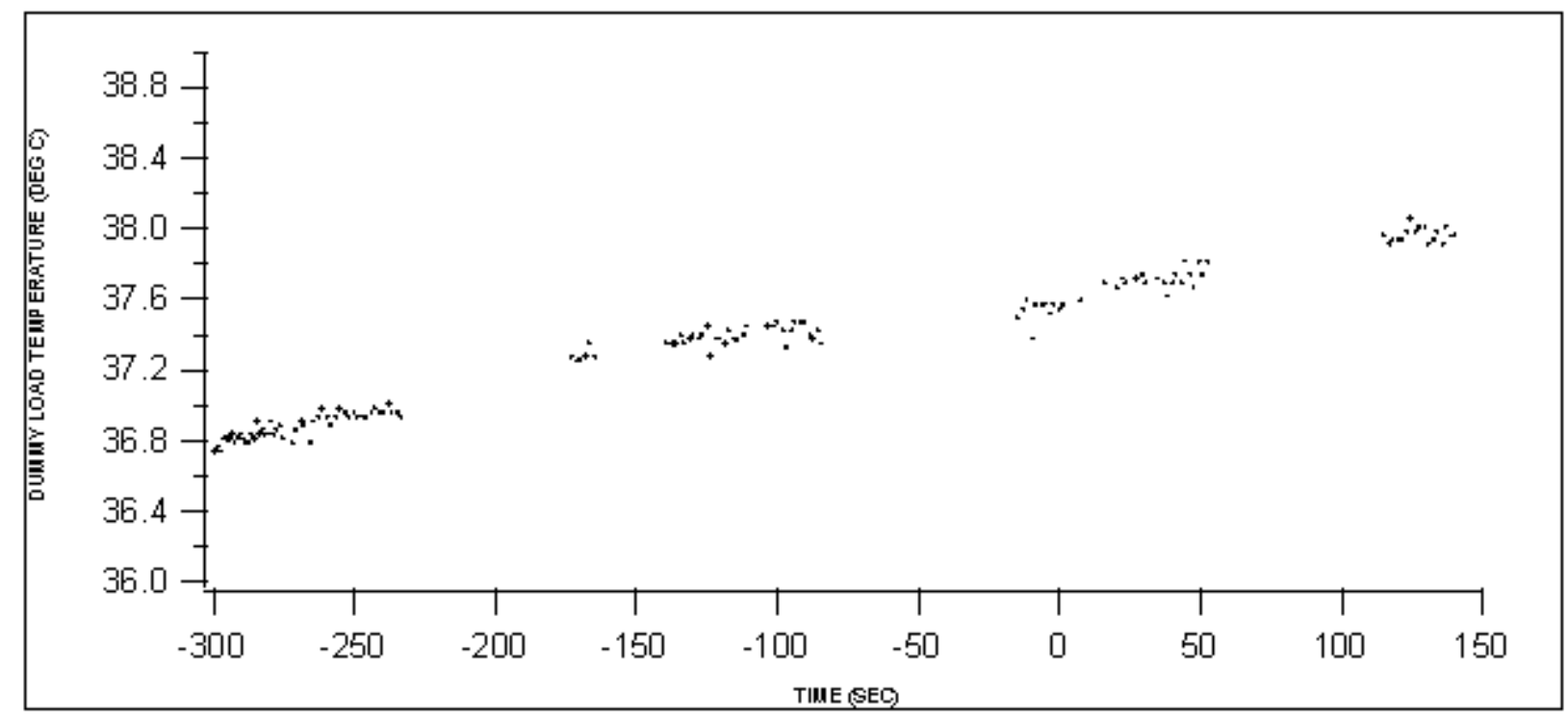

Figure B6. $7 \mathrm{MeV}$ Test Case 3, dummy load temperature.

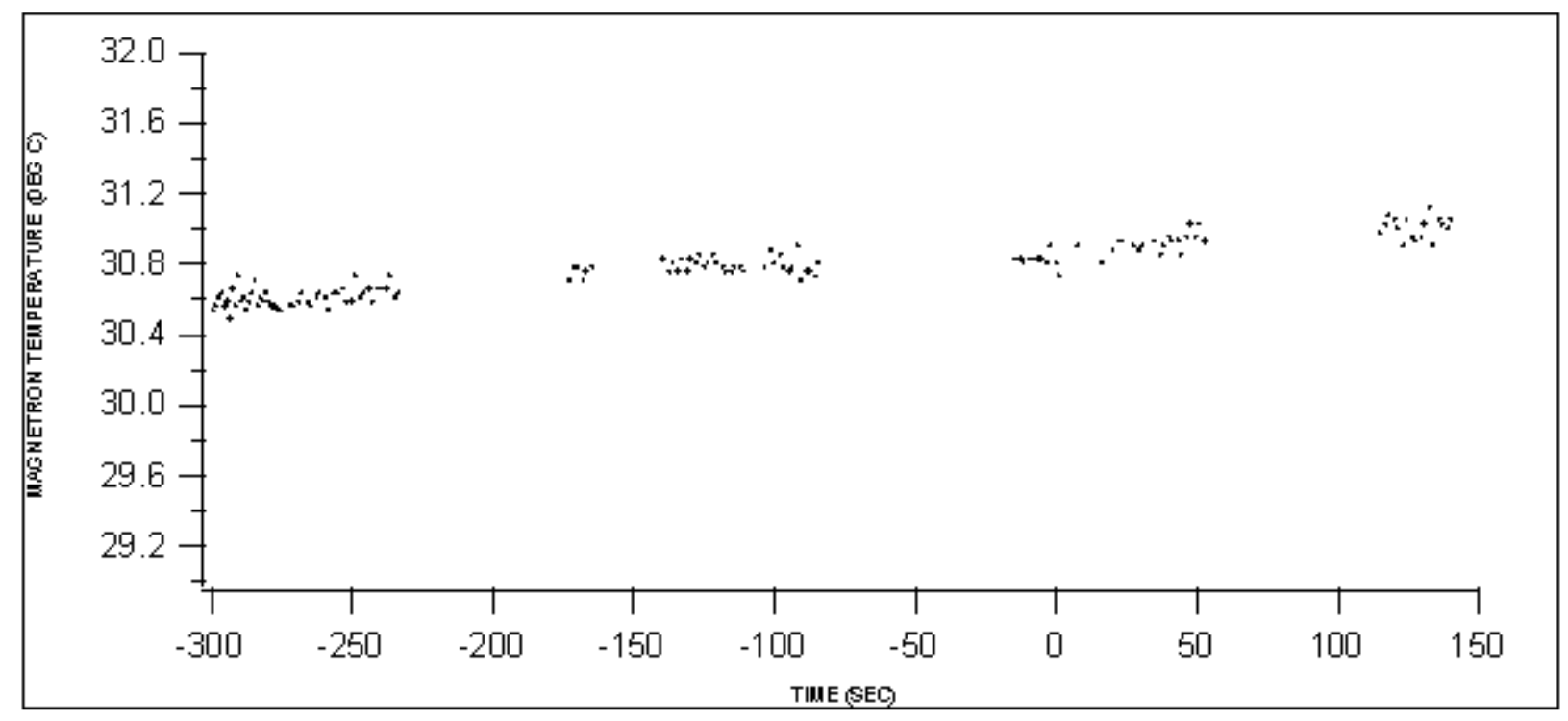

Figure B7. $7 \mathrm{MeV}$ Test Case 3, magnetron temperature. 


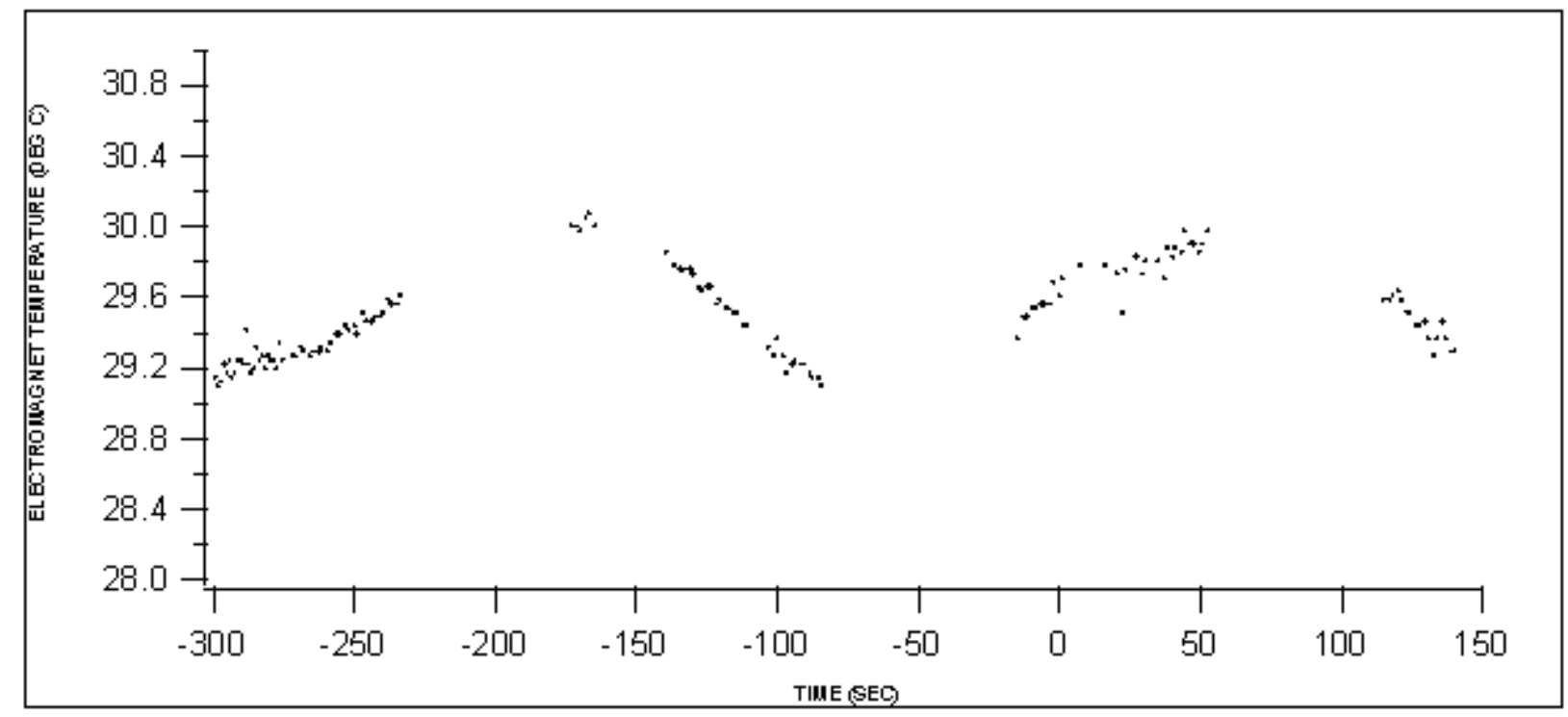

Figure B8. $7 \mathrm{MeV}$ Tesst Case 3, electromagnet temperature.

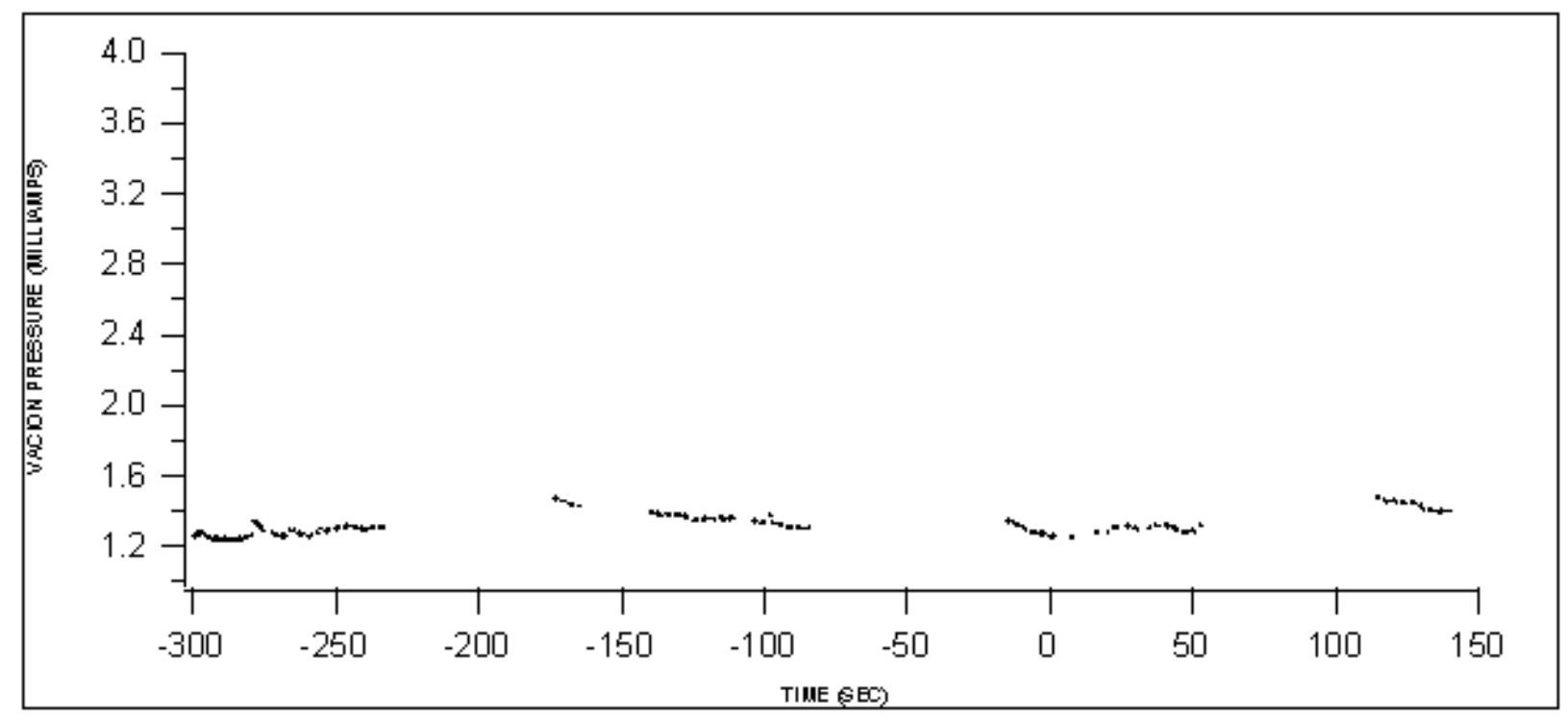

Figure B9. $7 \mathrm{MeV}$ Test Case 3, vacion pressure. 


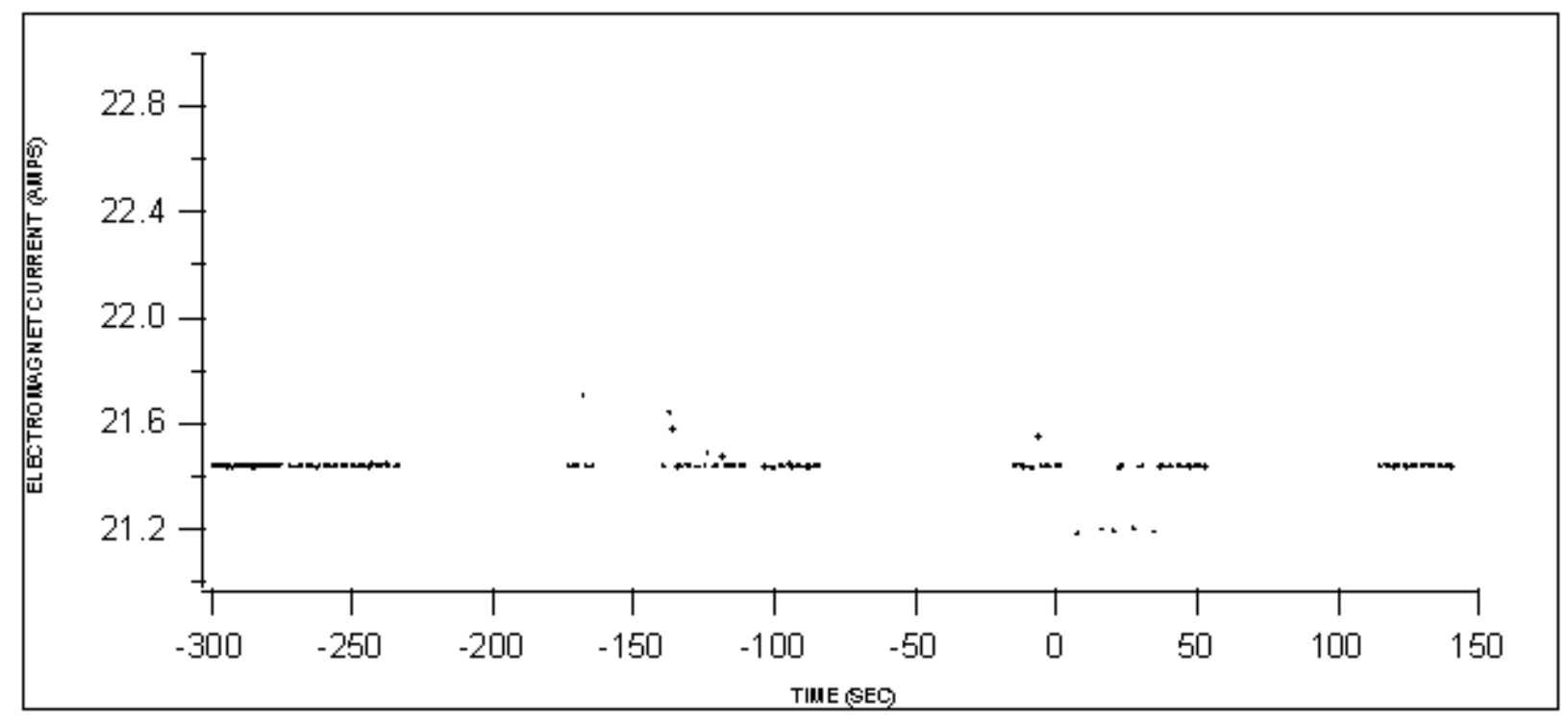

Figure B10. $7 \mathrm{MeV}$ Test Case 3, electromagnet current.

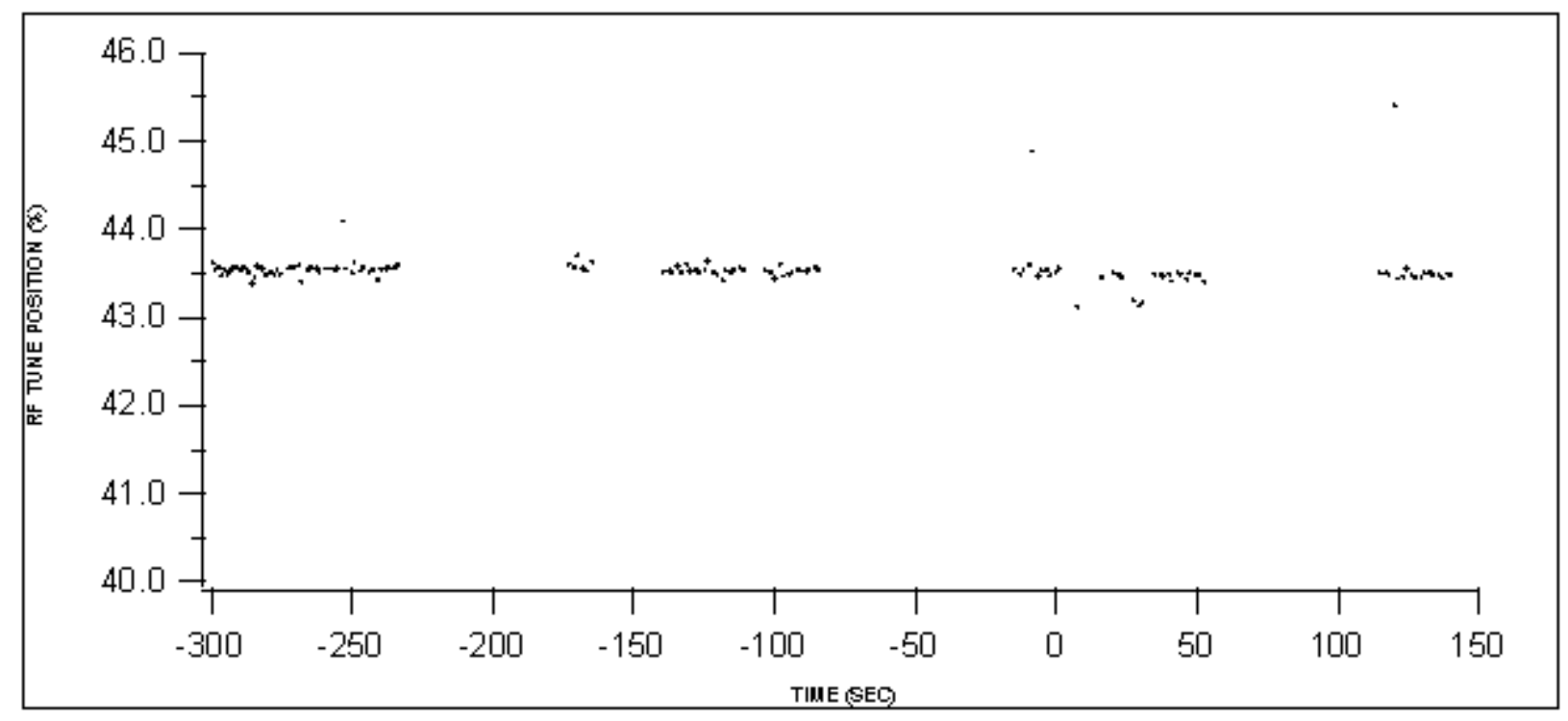

Figure B11. $7 \mathrm{MeV}$ Test Case 3, RF tune position. 


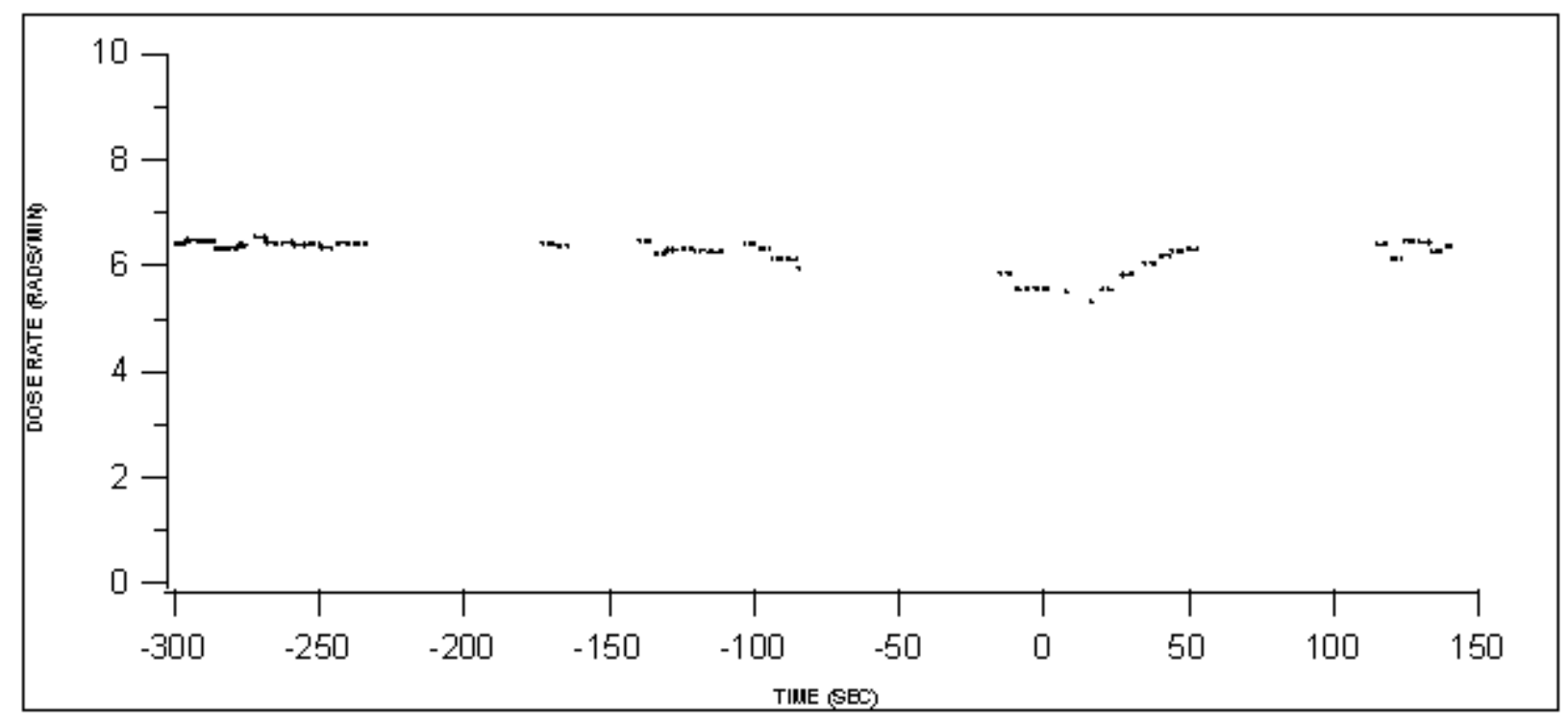

Figure B12. $7 \mathrm{MeV}$ Test Case 3, dose rate. 
This page intentionally left blank.

B-10 


\section{APPENDIX C}

PLOTS FROM 8 MEV TEST CASES 
This page intentionally left blank. 


\section{APPENDIX C \\ PLOTS FROM 8 MEV TEST CASES}

\section{$8 \mathrm{MeV}$ Test Case 1}

Reference File : Single Energy

Figure of Merit : 1 Beam Parameter ( Beam Current )

Table C1. $8 \mathrm{MeV}$ Test Case 1, timing chart for operator actions.

\begin{tabular}{lcccccc}
\hline & start & end & T1 & T2 & dT & dGFV \\
\hline Auto Tune & $10: 00: 38$ & $10: 01: 08$ & -783 & -753 & 30 & \\
Beam Scan & $10: 02: 37$ & $10: 04: 53$ & -664 & -528 & 136 & \\
Perturb Tune & $10: 05: 42$ & $10: 05: 52$ & -479 & -469 & 10 & $-1.5 \mathrm{~V}$ \\
Perturb Tune & $10: 06: 32$ & $10: 06: 45$ & -429 & -416 & 13 & $-1.5 \mathrm{~V}$ \\
Perturb Tune & $10: 08: 02$ & $10: 08: 07$ & -339 & -334 & 5 & $-1.5 \mathrm{~V}$ \\
Perturb Tune & $10: 09: 06$ & $10: 09: 10$ & -275 & -271 & 4 & $-1.5 \mathrm{~V}$ \\
Beam Scan & $10: 10: 01$ & $10: 13: 01$ & -220 & -40 & 180 & \\
Feedback Correction & $10: 13: 41$ & $10: 13: 48$ & 0 & 7 & 7 & \\
Feedback Correction & $10: 13: 50$ & $10: 13: 58$ & 9 & 17 & 8 & \\
Beam Scan & $10: 15: 03$ & $10: 17: 12$ & 82 & 211 & 129 & \\
\hline
\end{tabular}

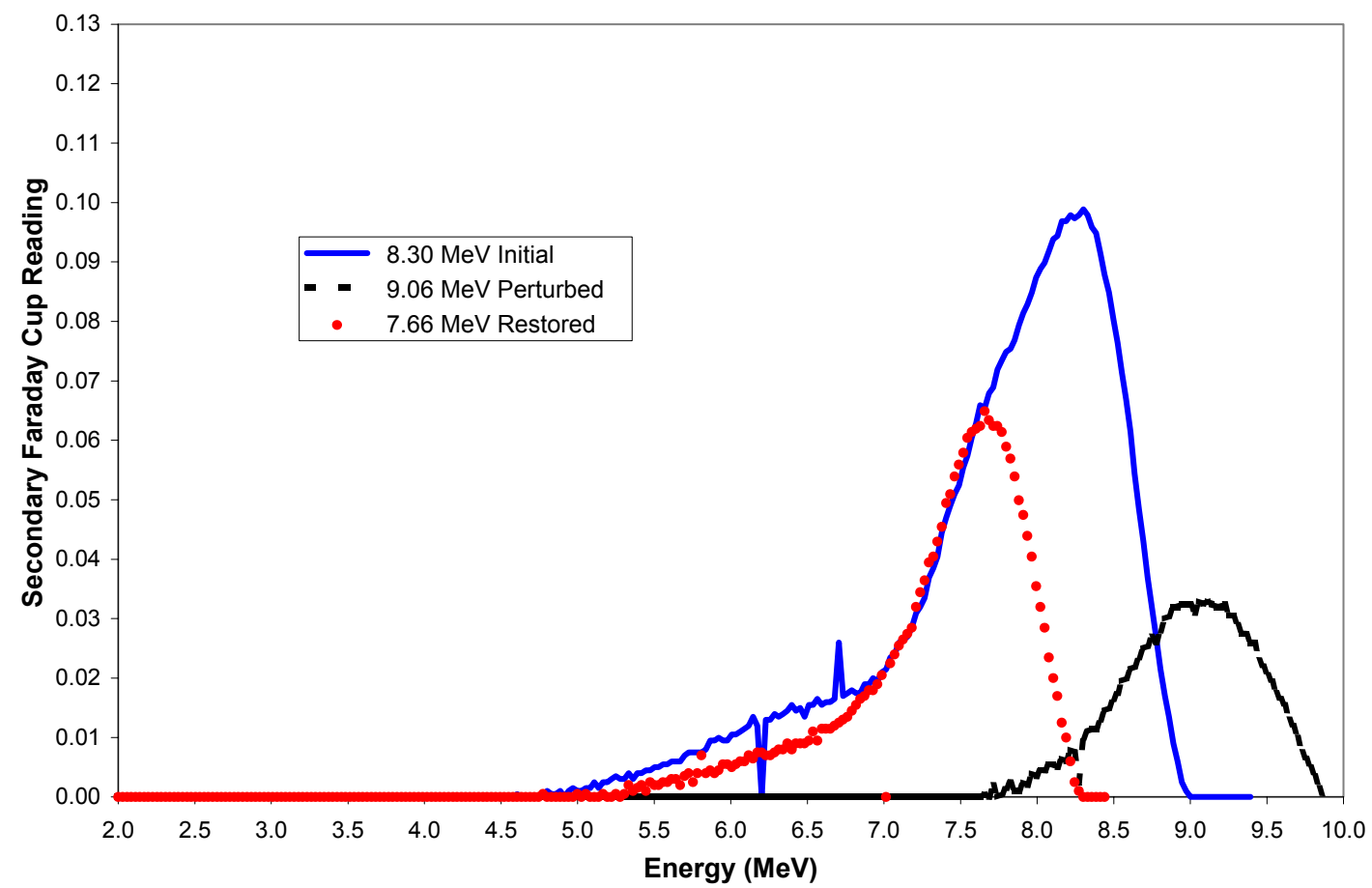

Figure $\mathrm{C} 1.8 \mathrm{MeV}$ Test Case 1, energy profiles. 


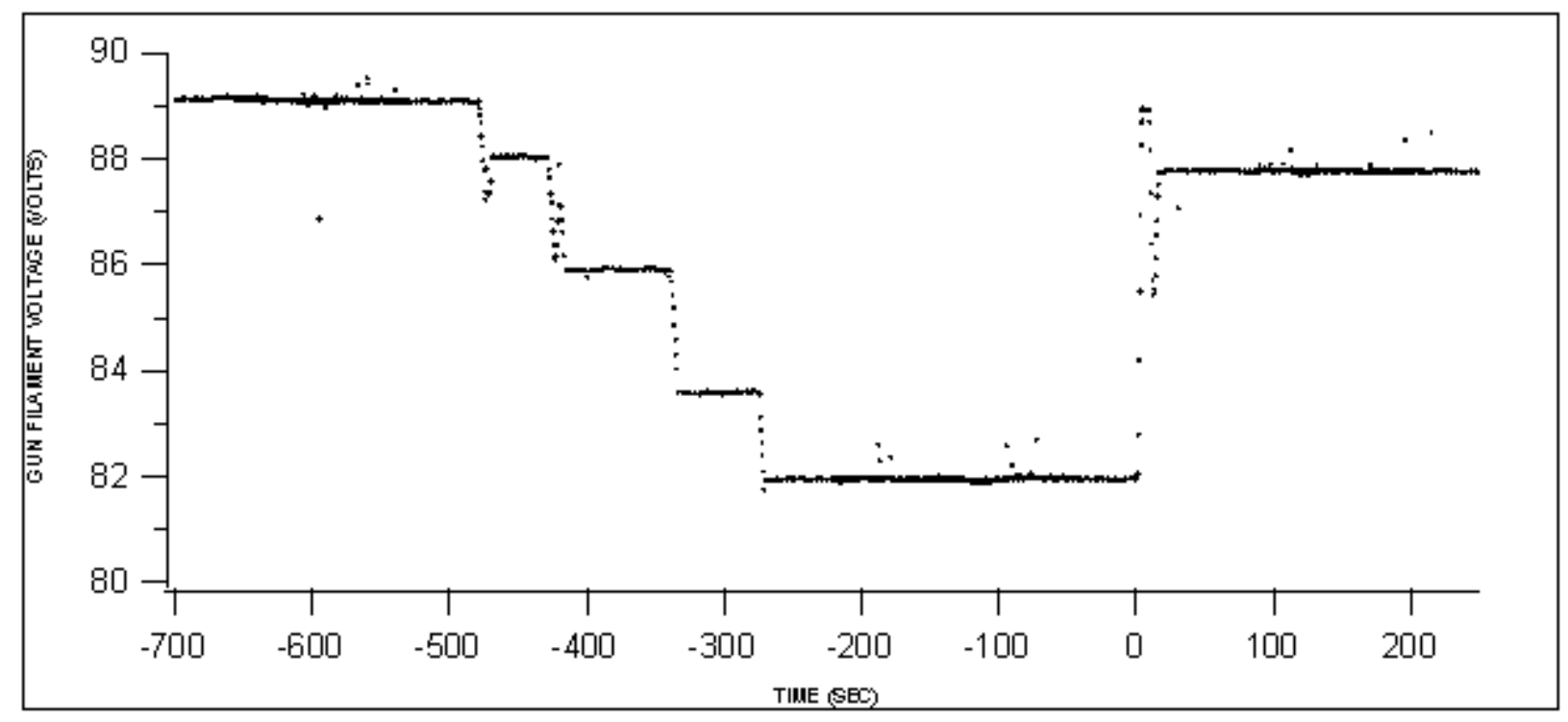

Figure C2. $8 \mathrm{MeV}$ Test Case 1, gun filament voltage.

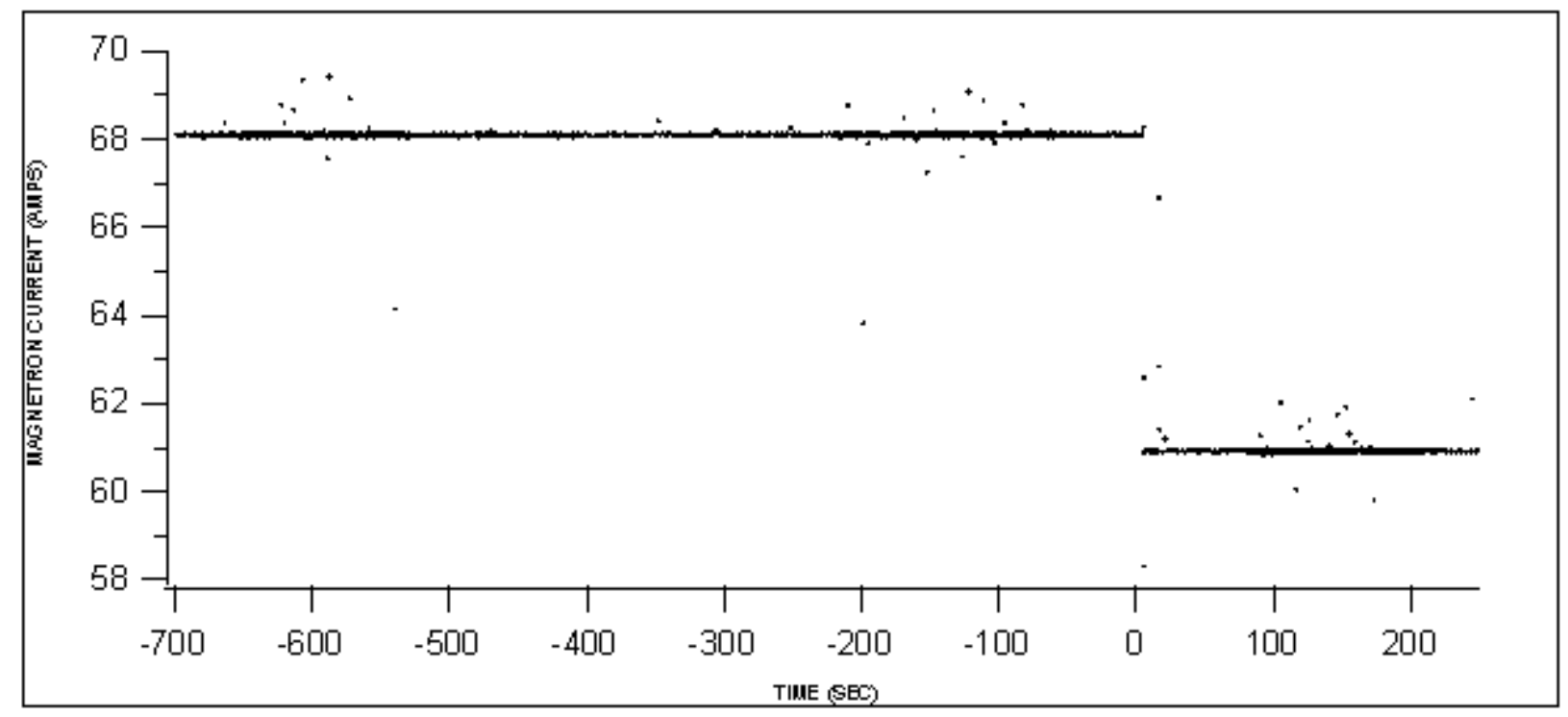

Figure C3. $8 \mathrm{MeV}$ Test Case 1, magnetron current. 


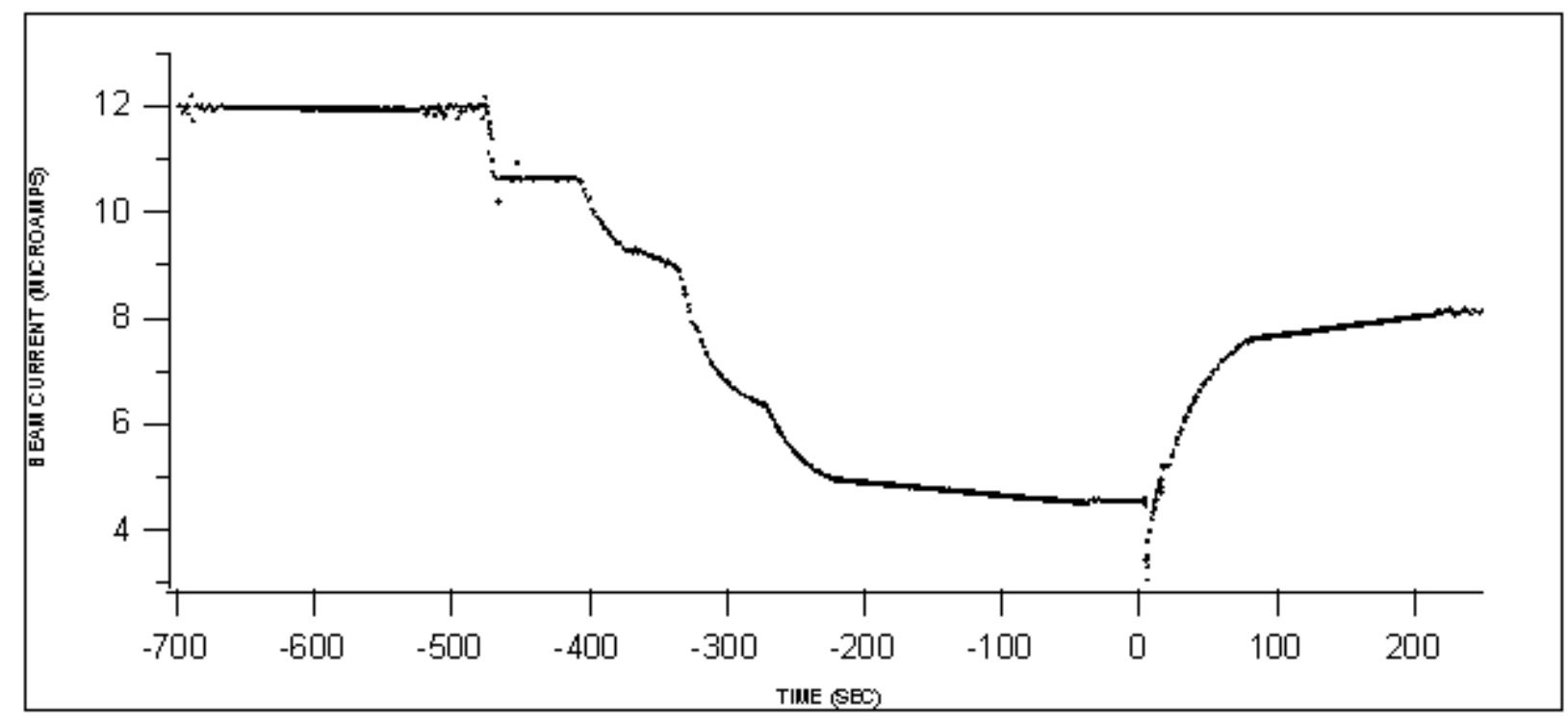

Figure C4. $8 \mathrm{MeV}$ Test Case 1, beam current.

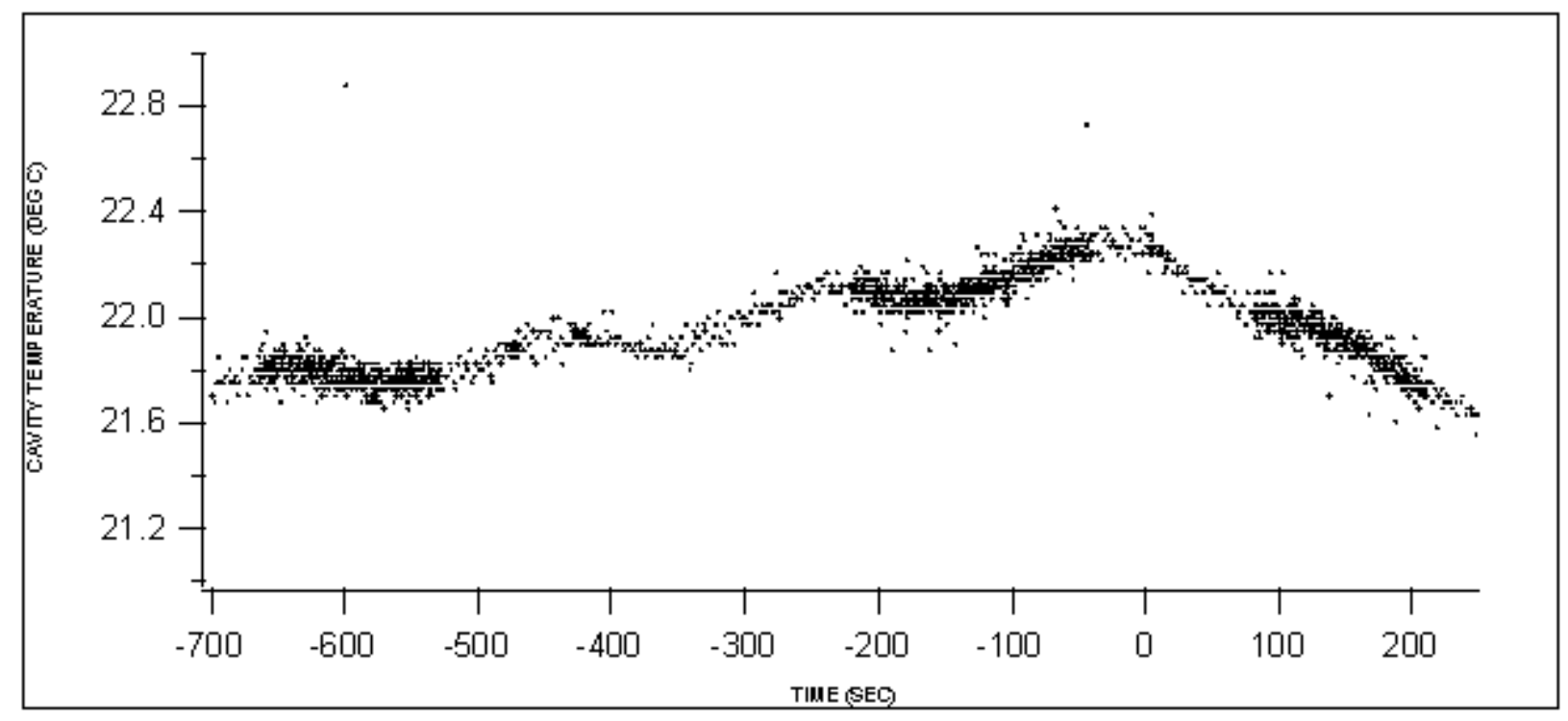

Figure C5. $8 \mathrm{MeV}$ Test Case 1, cavity temperature. 


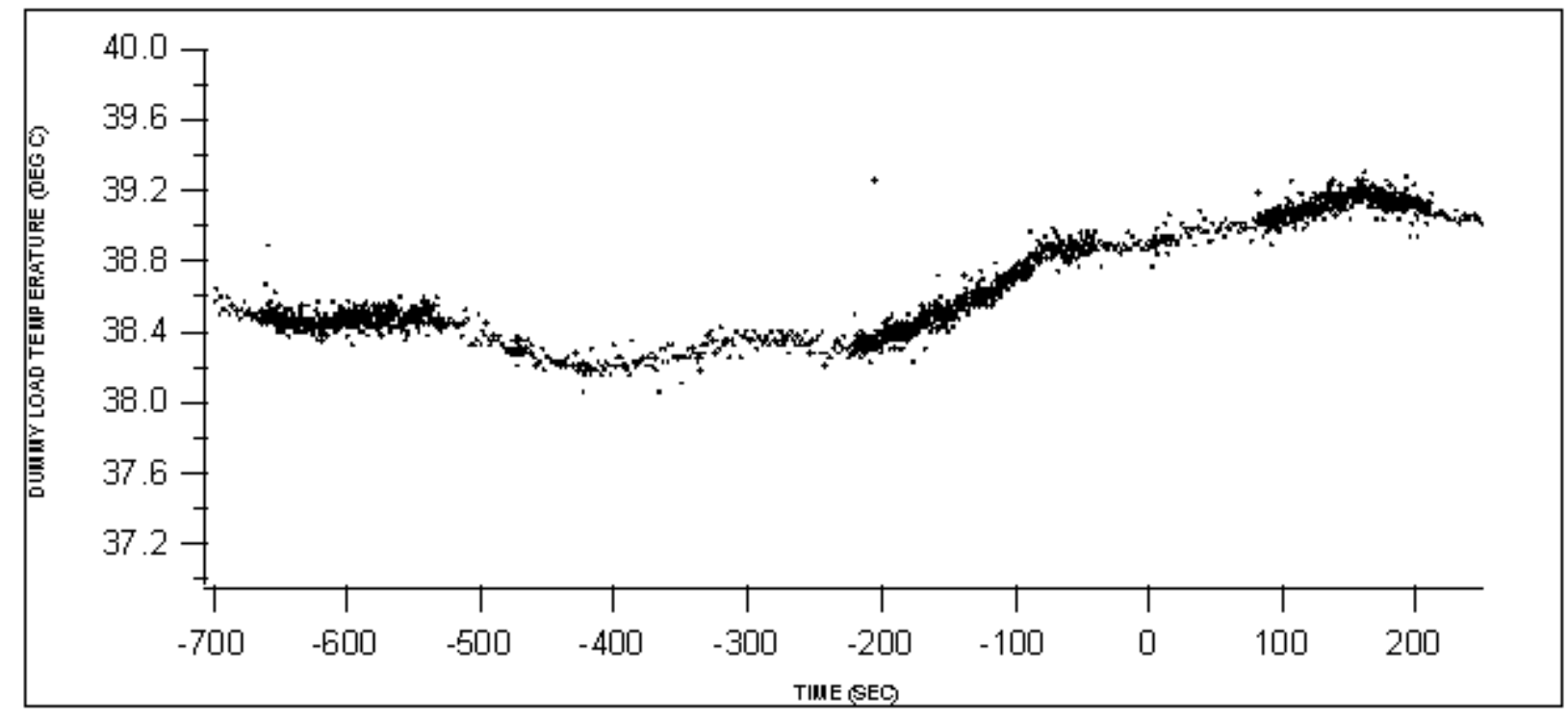

Figure C6. $8 \mathrm{MeV}$ Test Case 1, dummy load temperature.

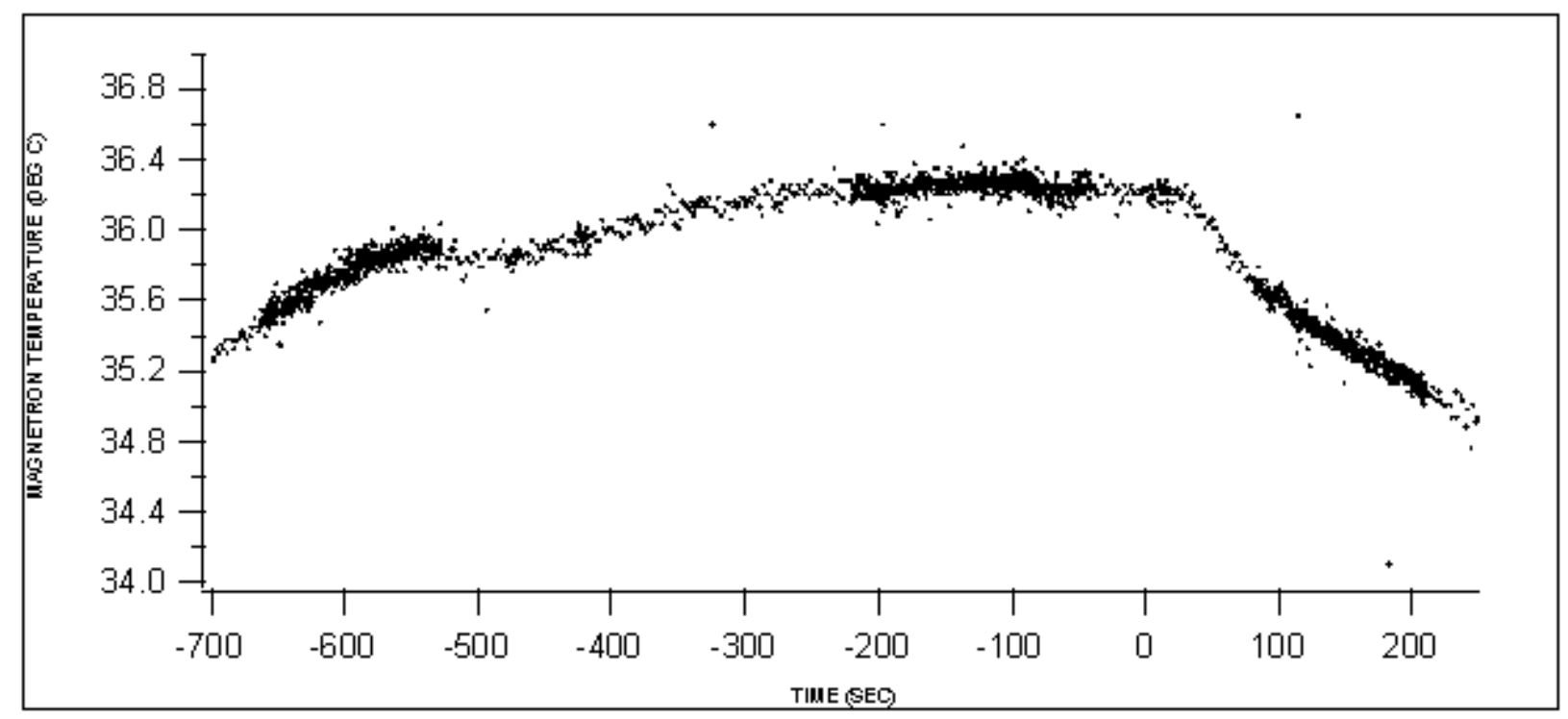

Figure C7. $8 \mathrm{MeV}$ Test Case 1, magnetron temperature. 


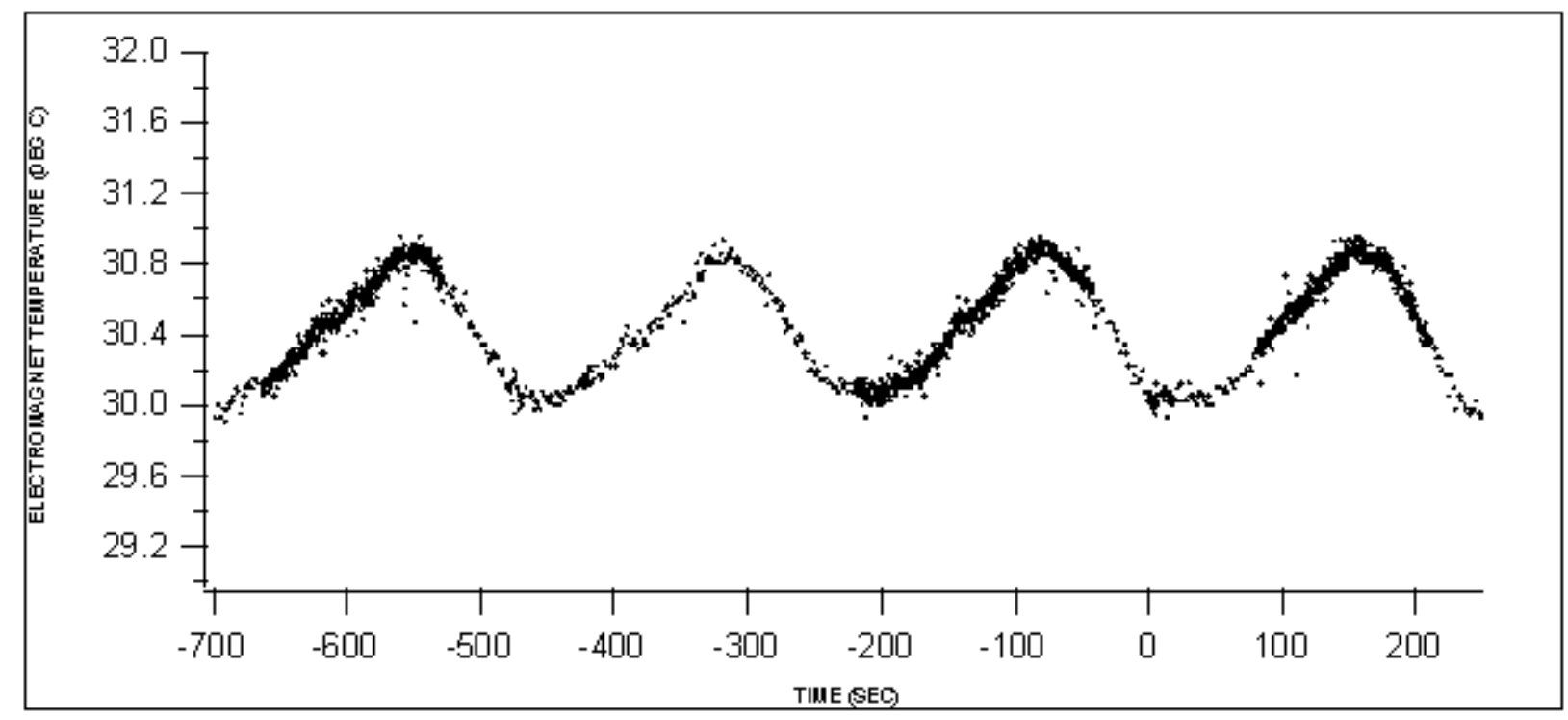

Figure C8. $8 \mathrm{MeV}$ Test Case 1, Electromagnet temperature.

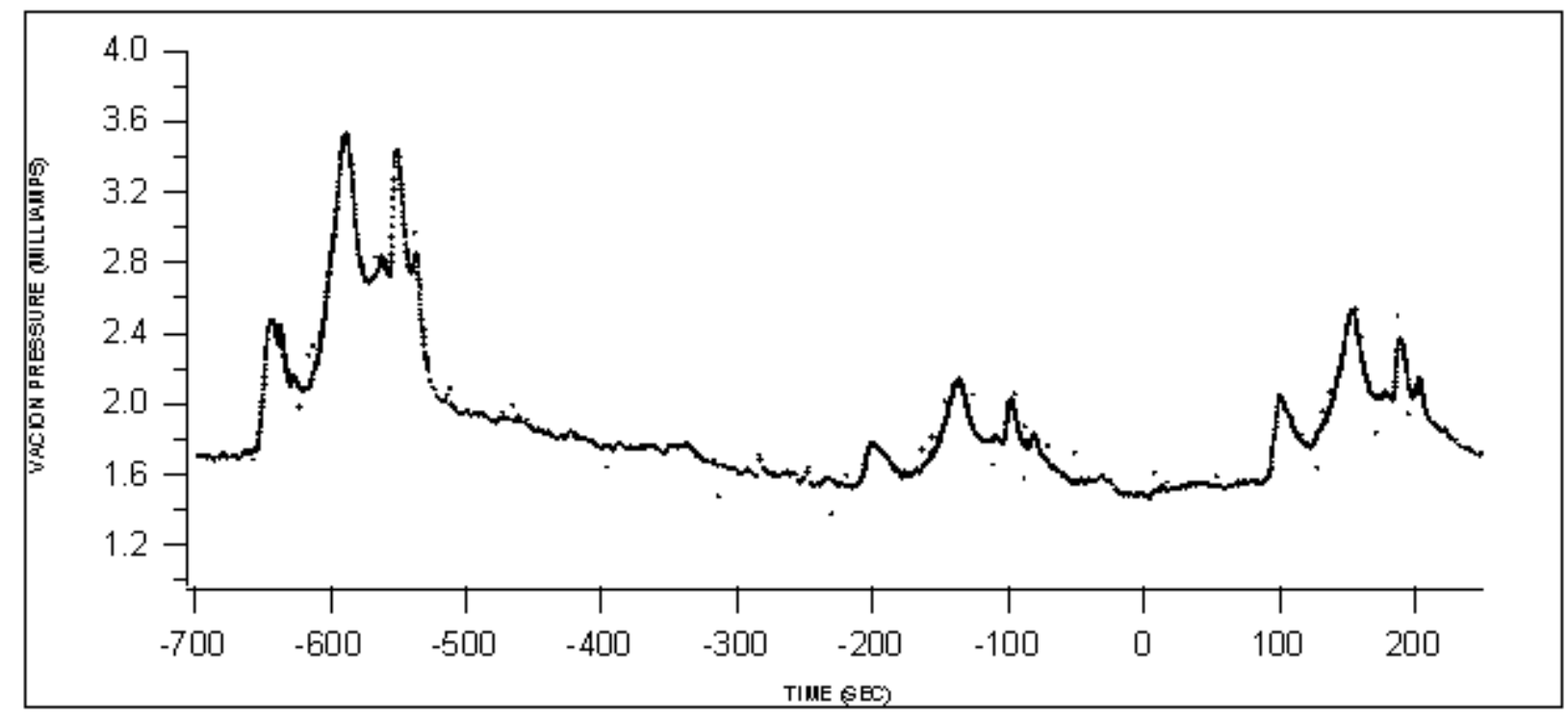

Figure C9. $8 \mathrm{MeV}$ Test Case 1, vacion pressure. 


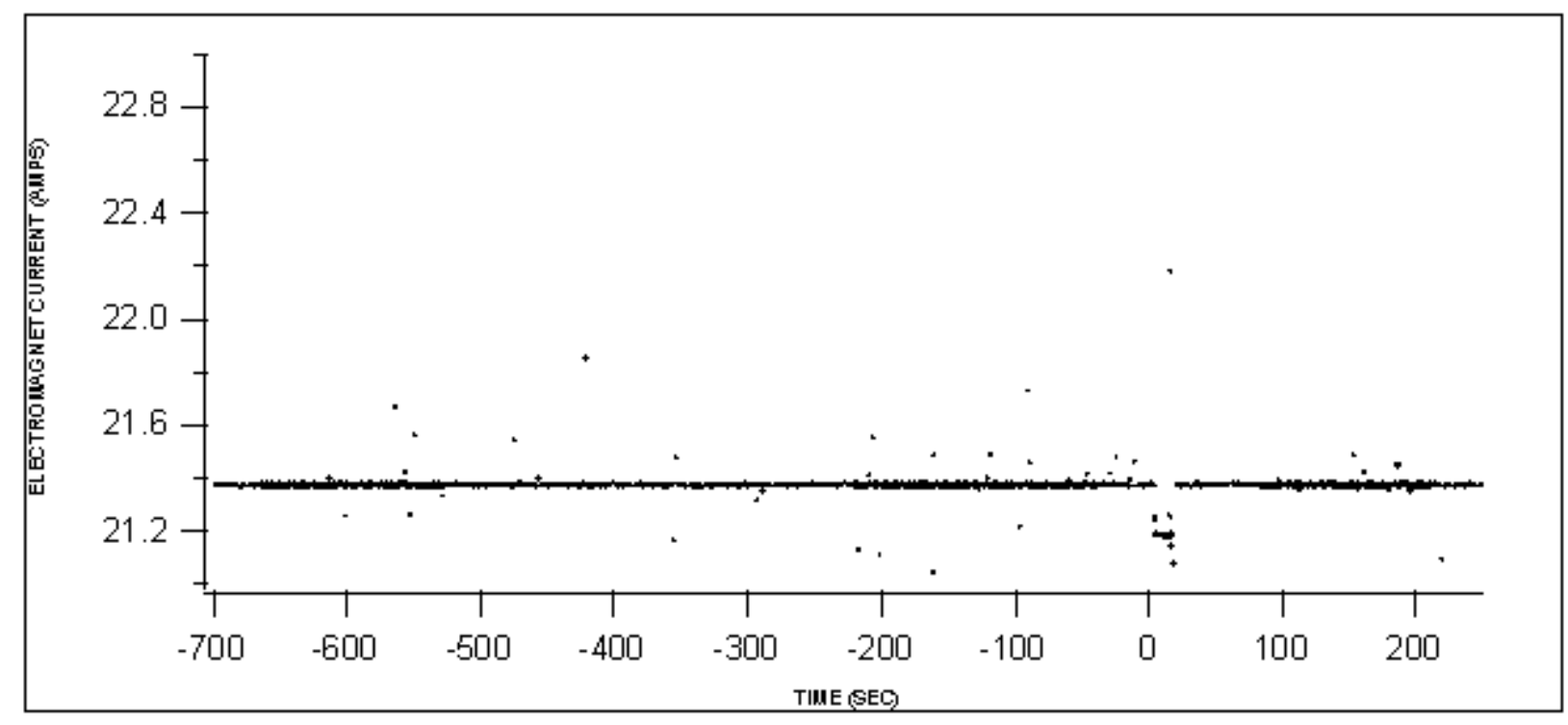

Figure C10. $8 \mathrm{MeV}$ Test Case 1, electromagnet current.

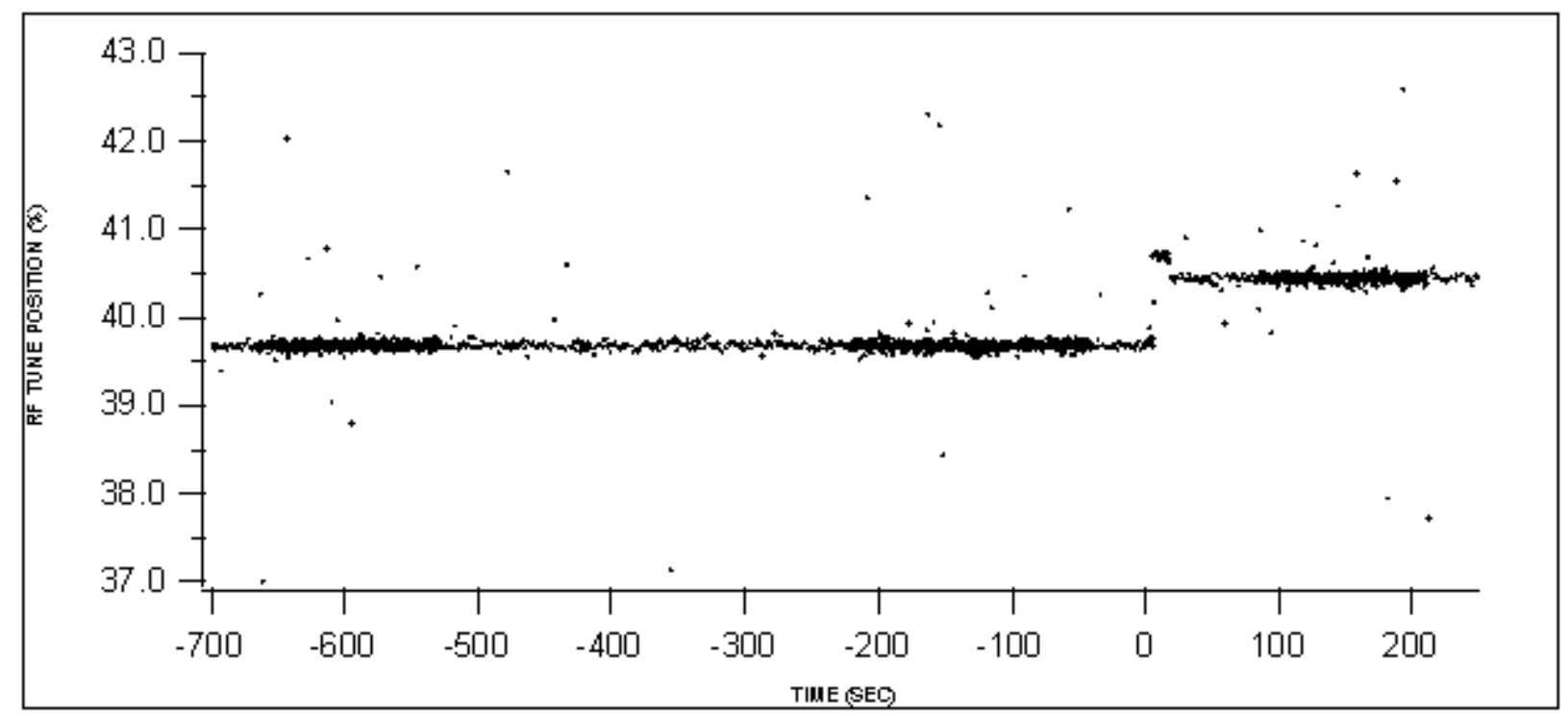

Figure C11. $8 \mathrm{MeV}$ Test Case 1, RF tune position. 


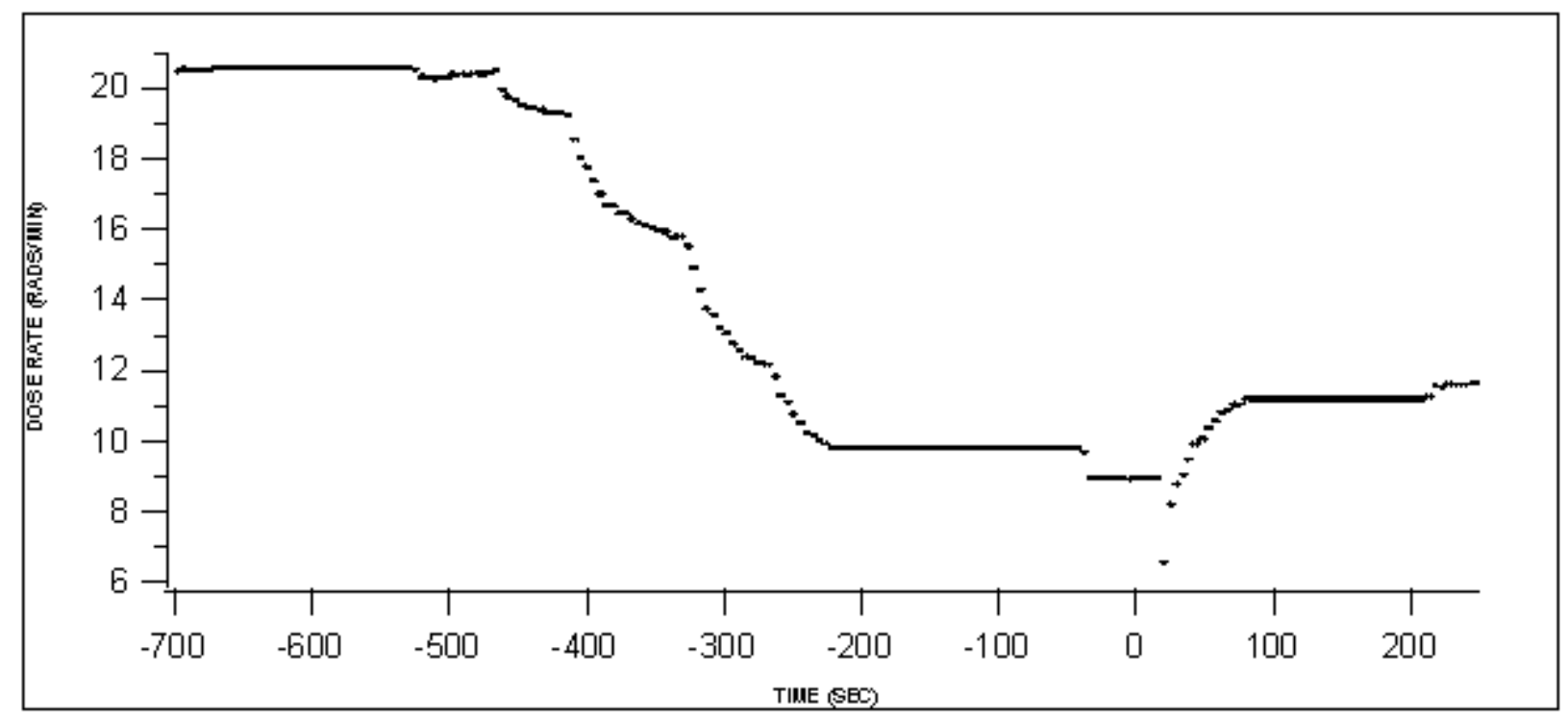

Figure C12. $8 \mathrm{MeV}$ Test Case 1, dose rate. 


\section{$8 \mathrm{MeV}$ Test Case 2}

Reference File : Single Energy

Figure of Merit : All Parameters

Table C1. $8 \mathrm{MeV}$ Test Case 2, timing chart for operator actions.

\begin{tabular}{lcccccc}
\hline & start & end & T1 & T2 & dT & dGFV \\
\hline Auto Tune & $10: 48: 25$ & $10: 49: 00$ & -725 & -690 & 35 & \\
Beam Scan & $10: 51: 23$ & $10: 53: 54$ & -547 & -396 & 151 & \\
Perturb Tune & $10: 55: 15$ & $10: 55: 27$ & -315 & -303 & 12 & $-1.5 \mathrm{~V}$ \\
Beam Scan & $10: 56: 24$ & $10: 58: 51$ & -246 & -99 & 147 & \\
Feedback Correction & $11: 00: 30$ & $11: 00: 35$ & 0 & 5 & 5 & \\
Feedback Correction & $11: 00: 41$ & $11: 00: 48$ & 11 & 18 & 7 & \\
Feedback Correction & $11: 01: 00$ & $11: 01: 02$ & 30 & 32 & 2 & \\
Beam Scan & $11: 02: 31$ & $11: 04: 56$ & 121 & 266 & 145 & \\
\hline
\end{tabular}

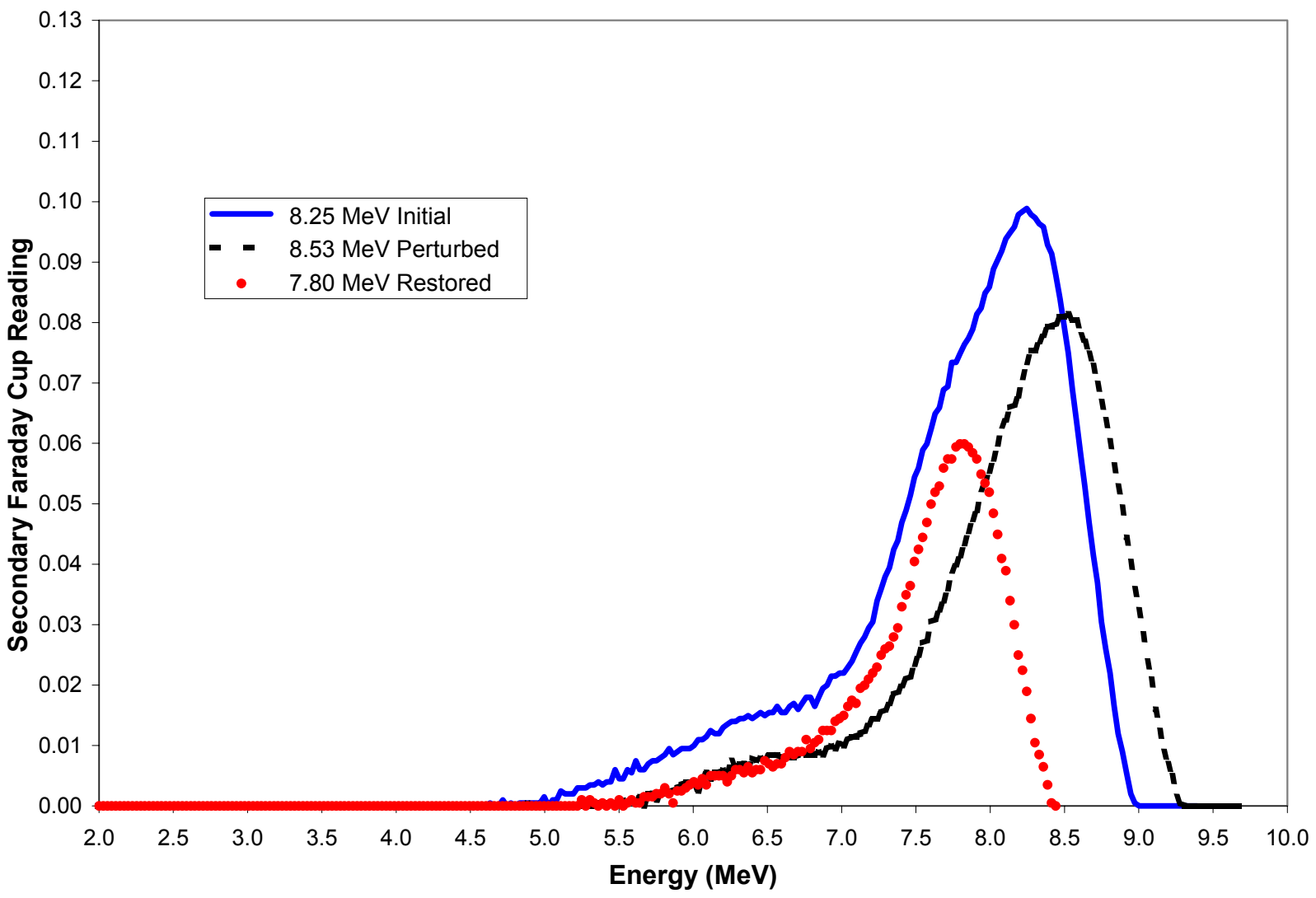

Figure C13. $8 \mathrm{MeV}$ Test Case 2, energy profiles. 


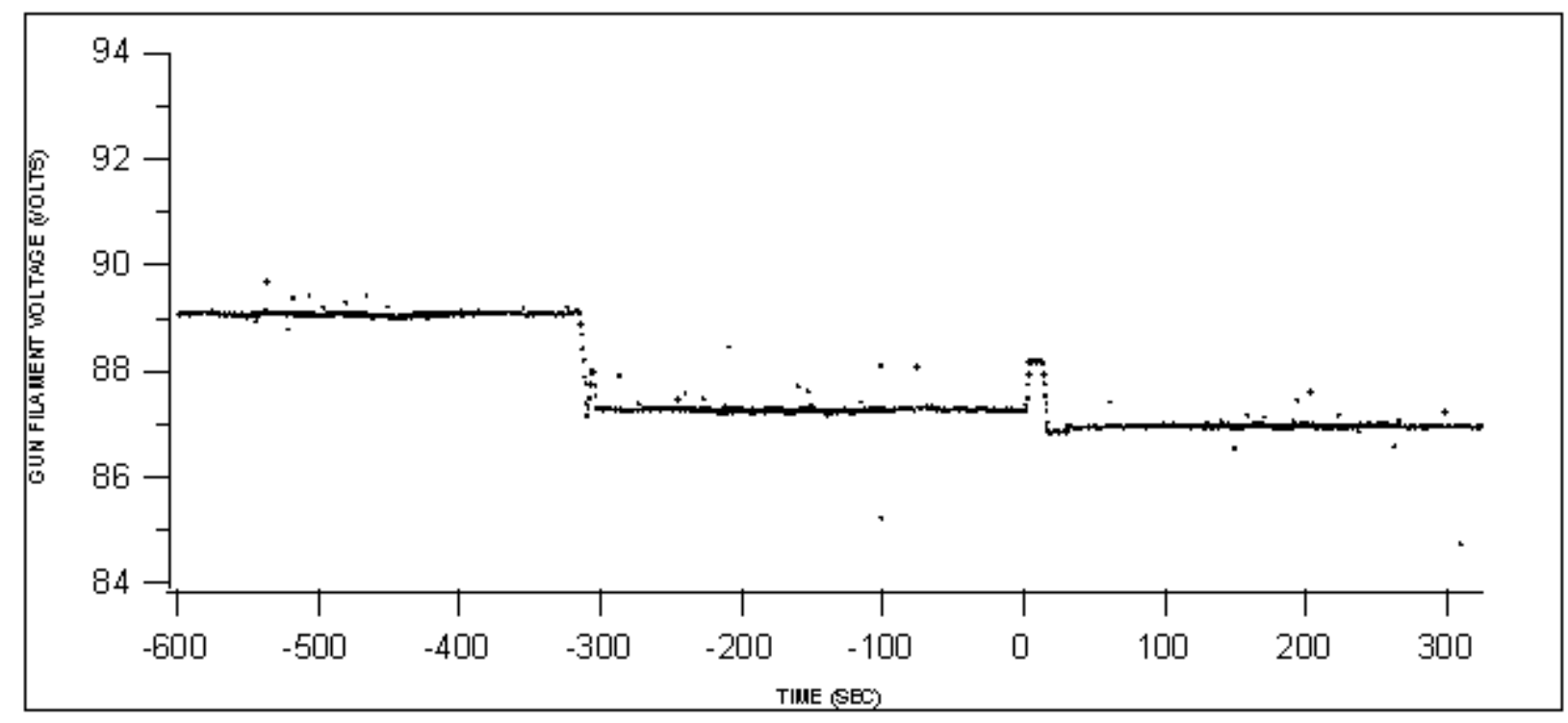

Figure C14. $8 \mathrm{MeV}$ Test Case 2, gun filament voltage.

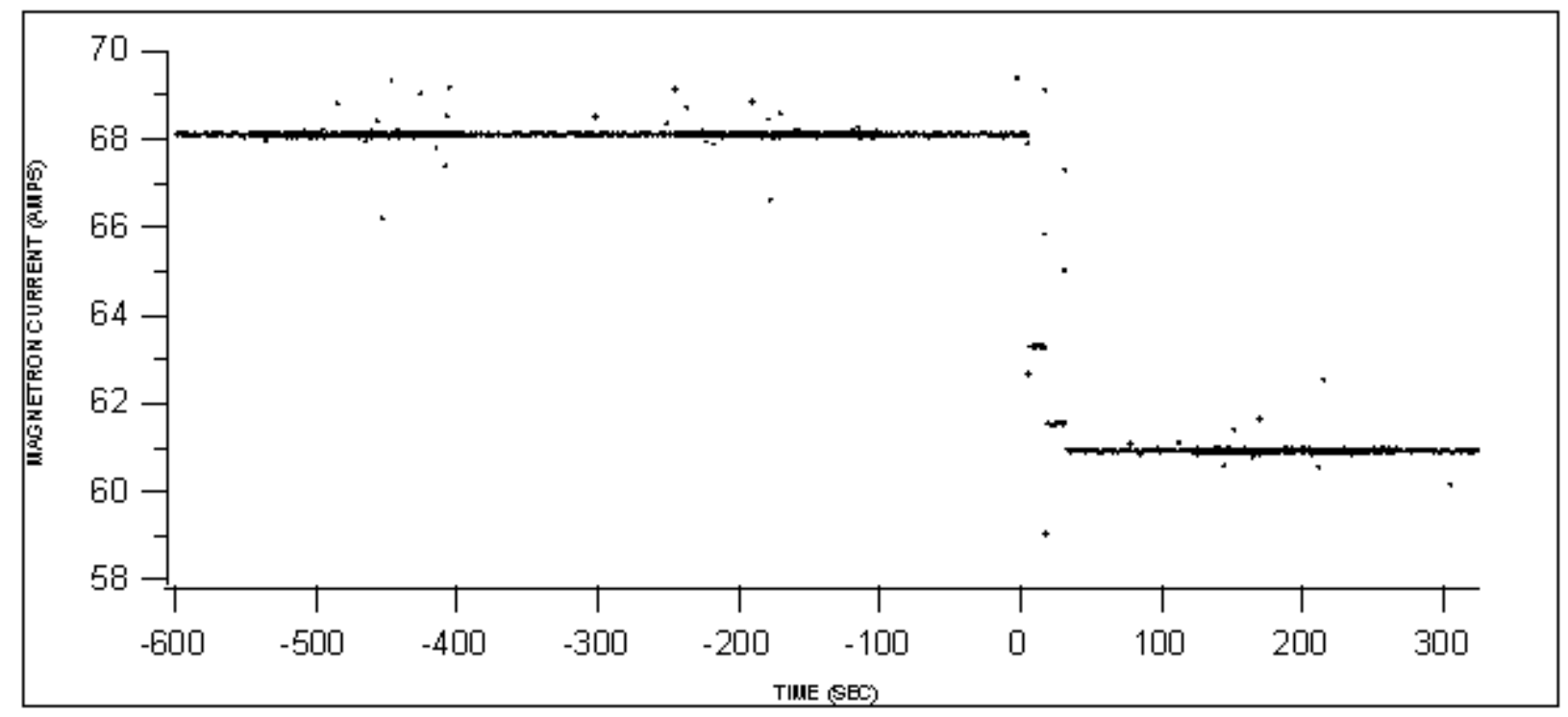

Figure C15. $8 \mathrm{MeV}$ Test Case 2, magnetron current. 


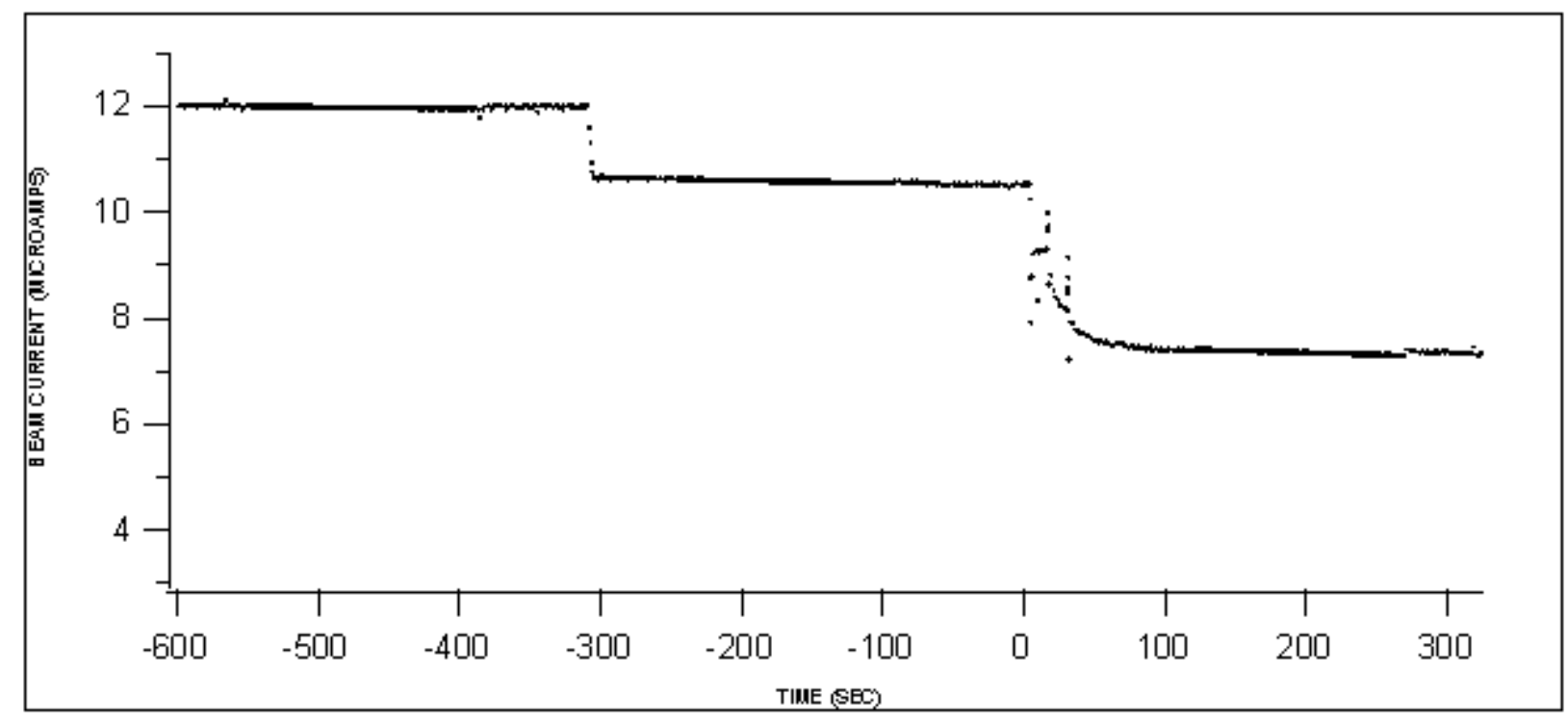

Figure C16. $8 \mathrm{MeV}$ Test Case 2, beam current.

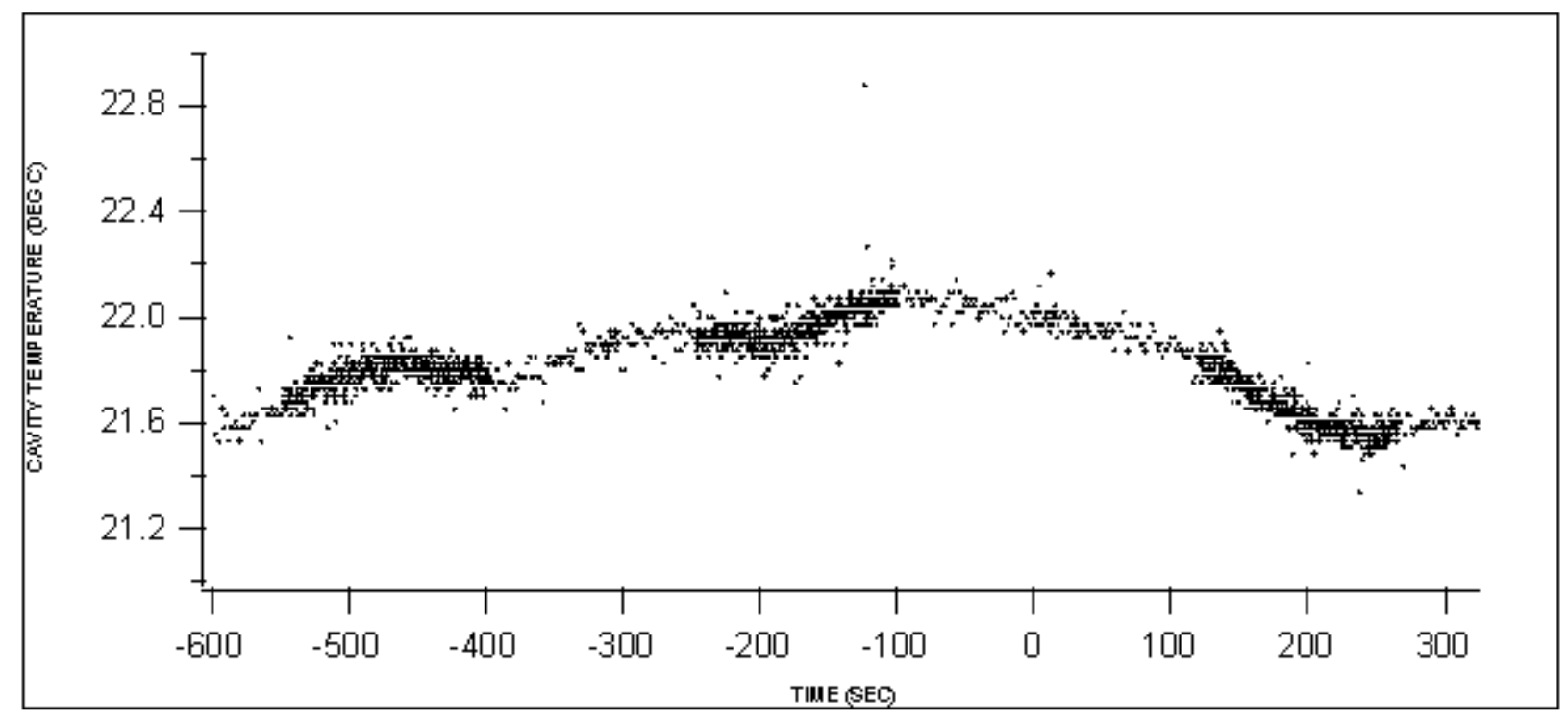

Figure C17. $8 \mathrm{MeV}$ Test Case 2, cavity temperature. 


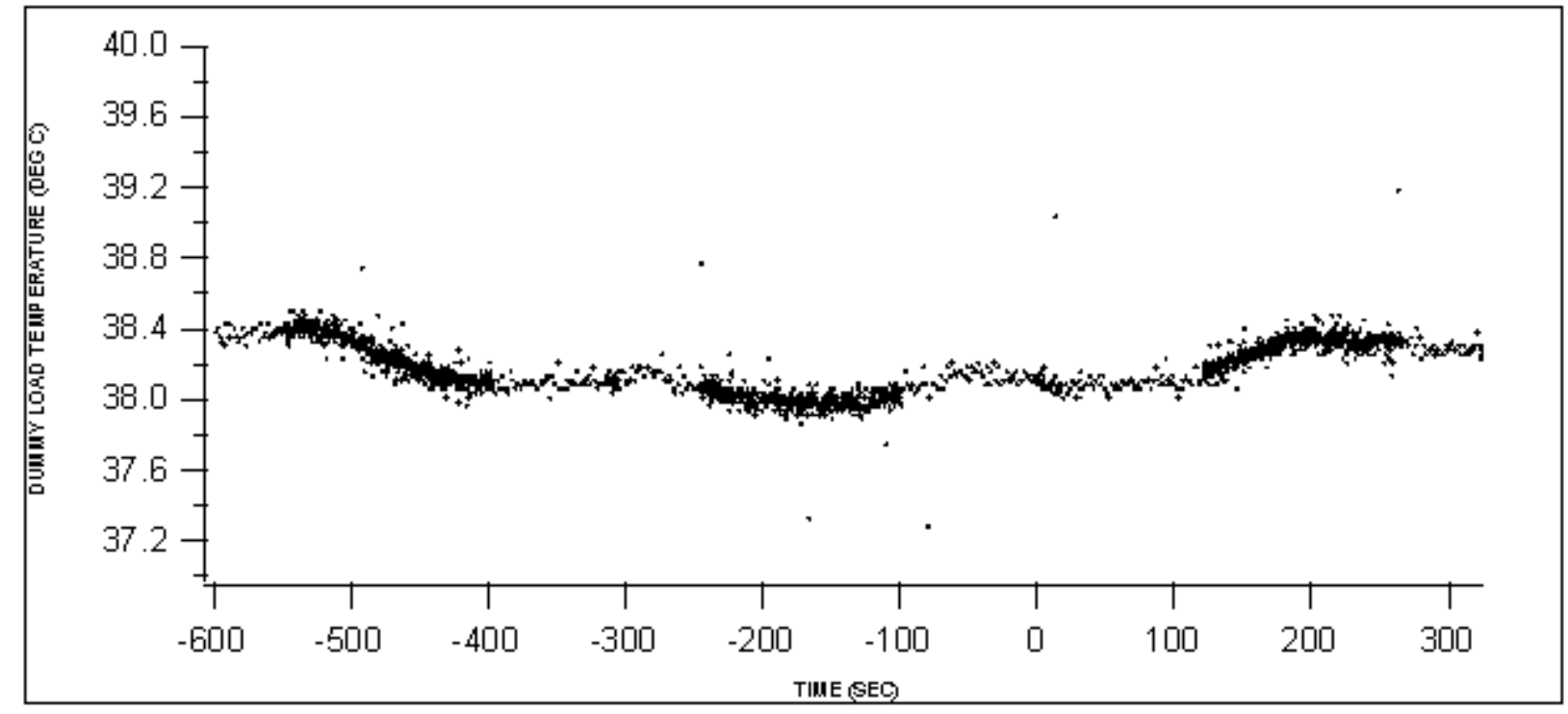

Figure C18. $8 \mathrm{MeV}$ Test Case 2, dummy load temperature.

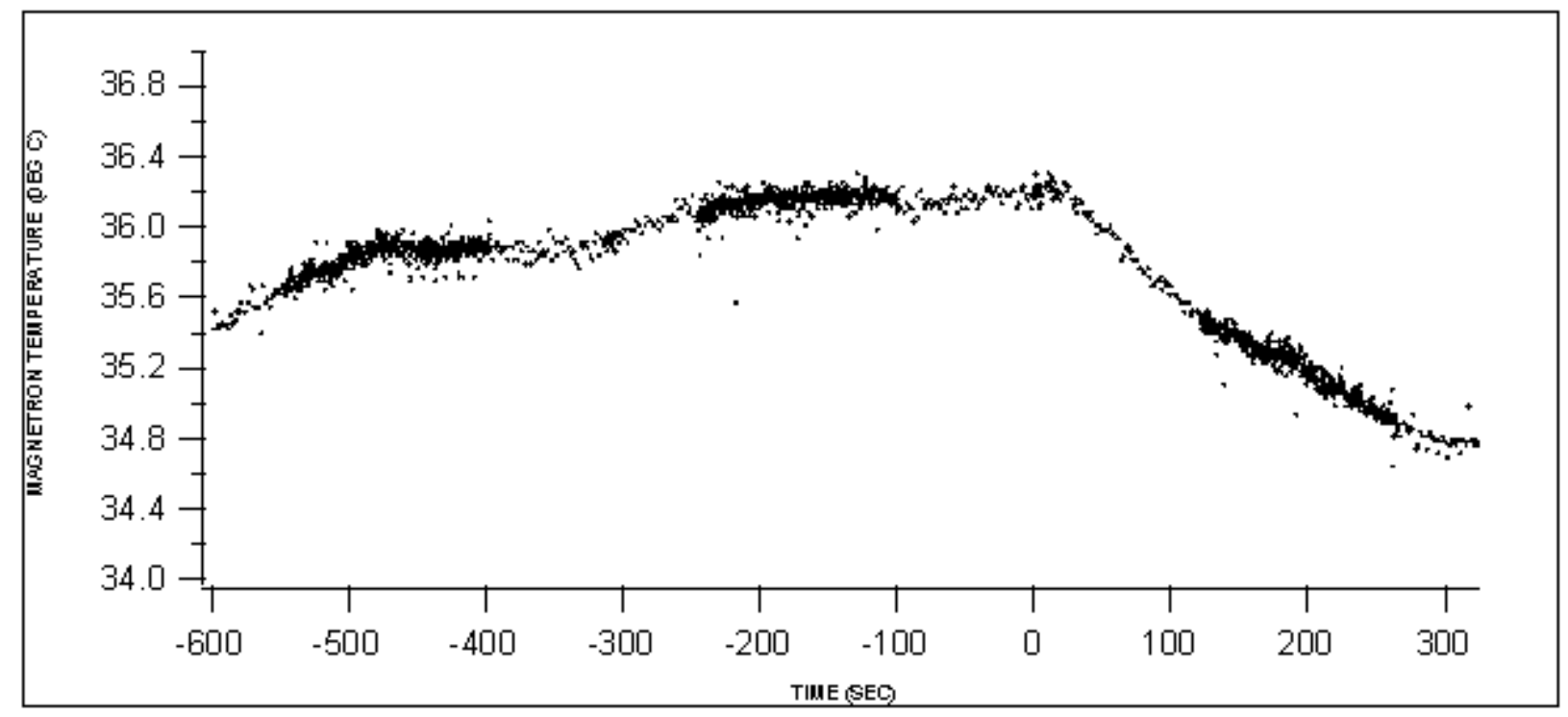

Figure C19. $8 \mathrm{MeV}$ Test Case 2, magnetron temperature. 


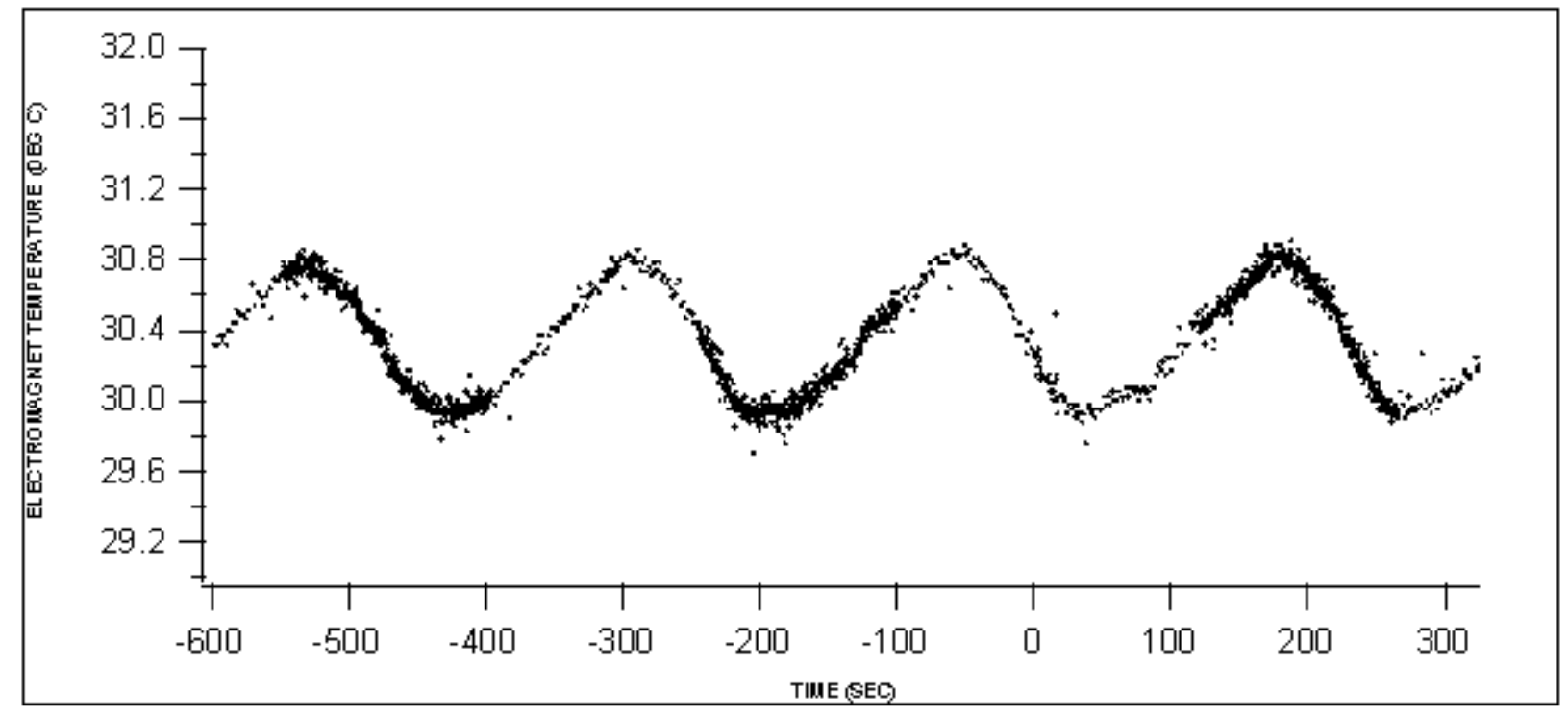

Figure C20. $8 \mathrm{MeV}$ Test Case 2, electromagnet temperature.

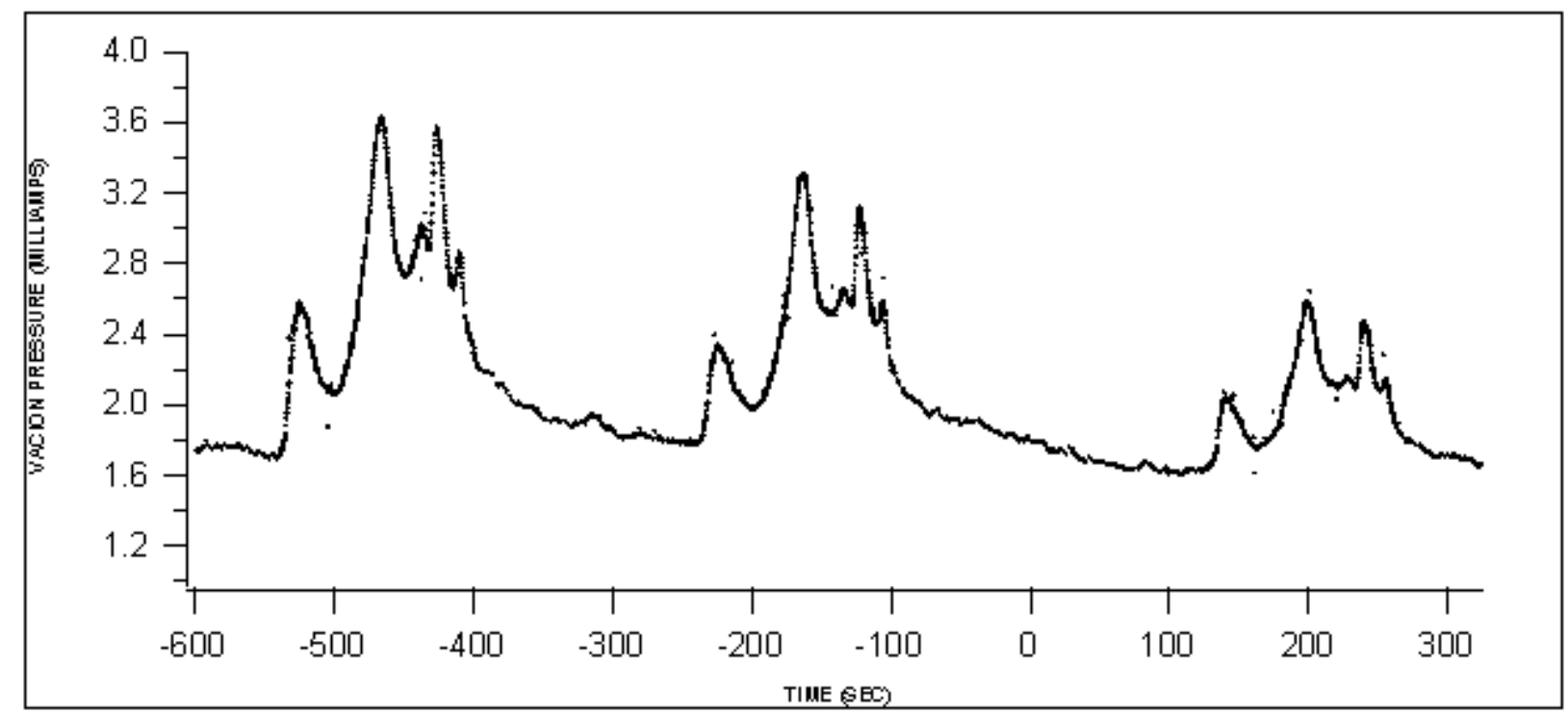

Figure C21. $8 \mathrm{MeV}$ Test Case 2, vacion pressure. 


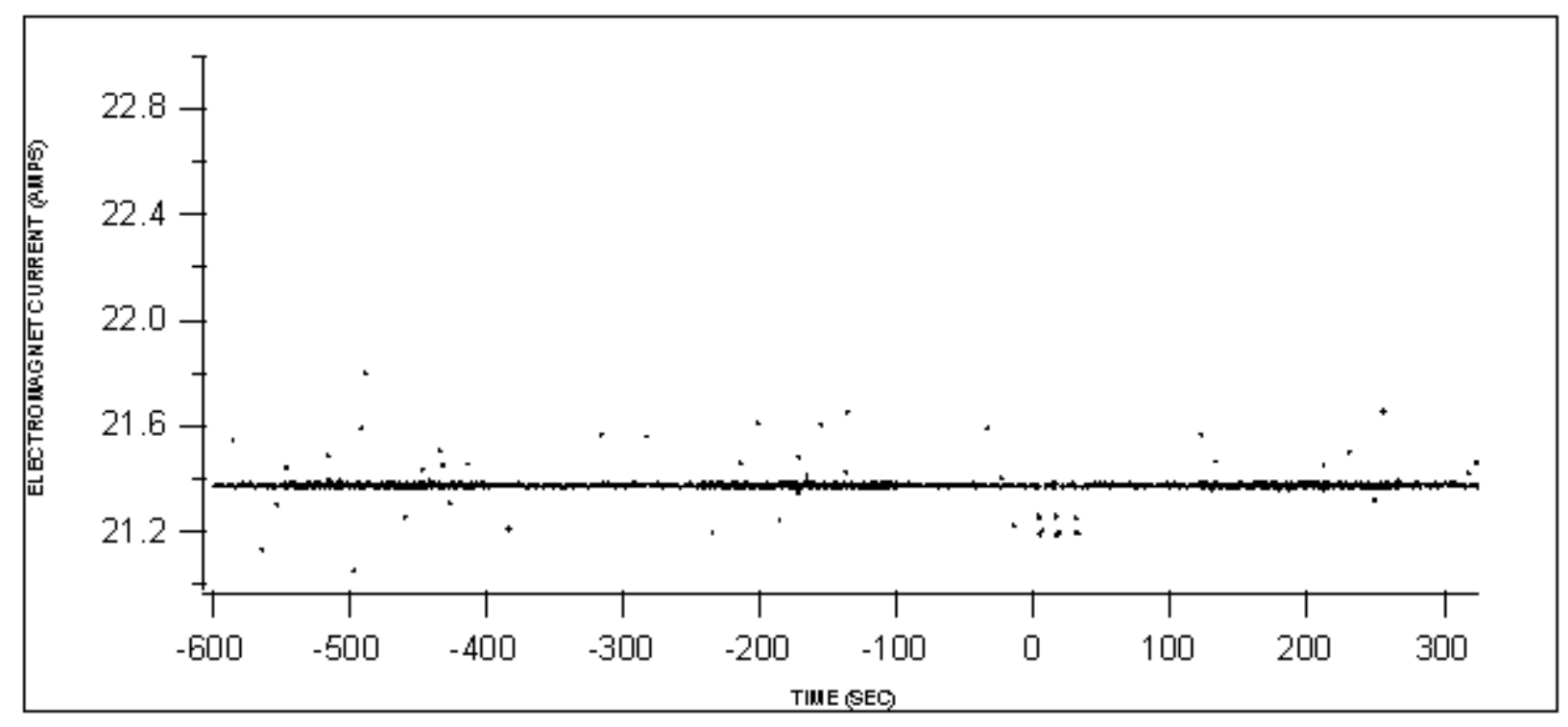

Figure C22. $8 \mathrm{MeV}$ Test Case 2, electromagnet current.

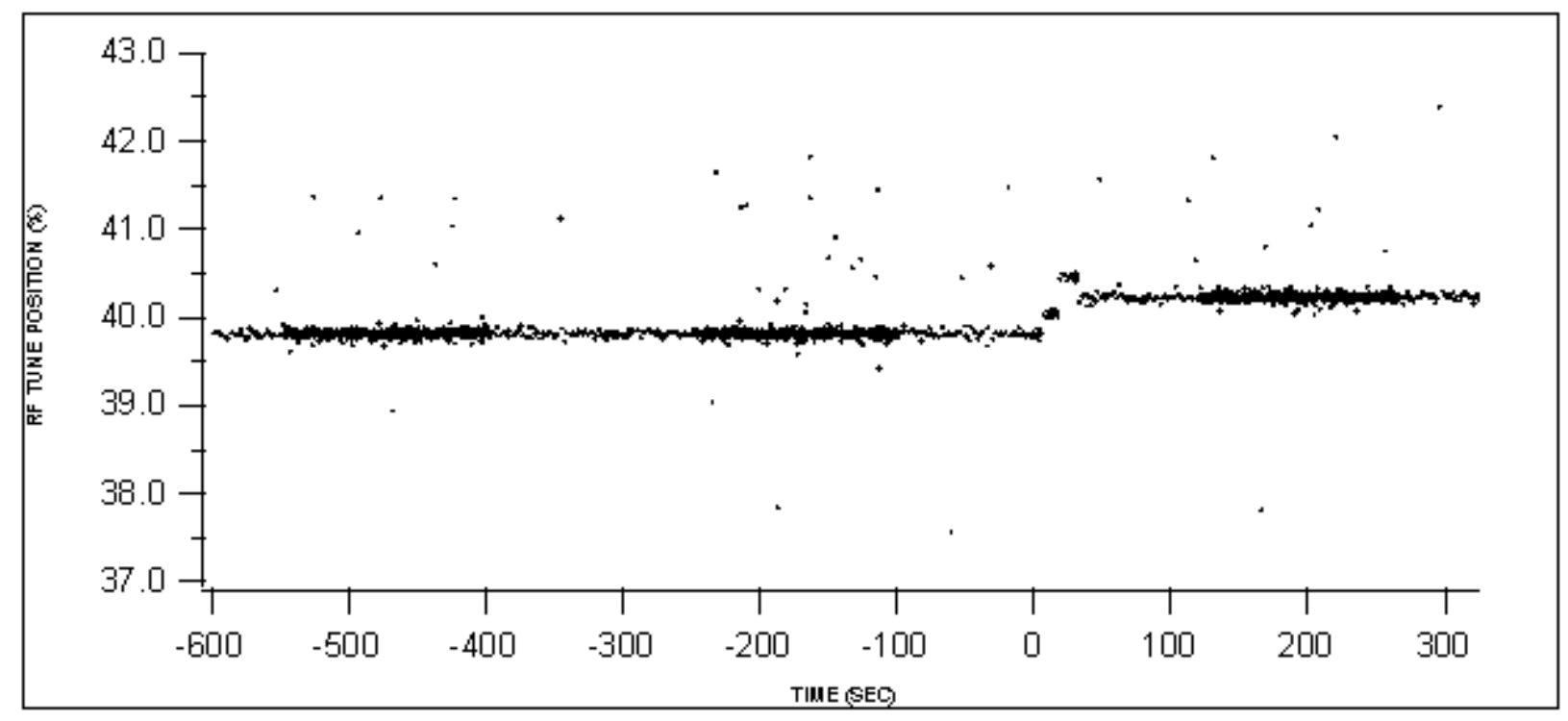

Figure C23. $8 \mathrm{MeV}$ Test Case 2, RF tune position. 


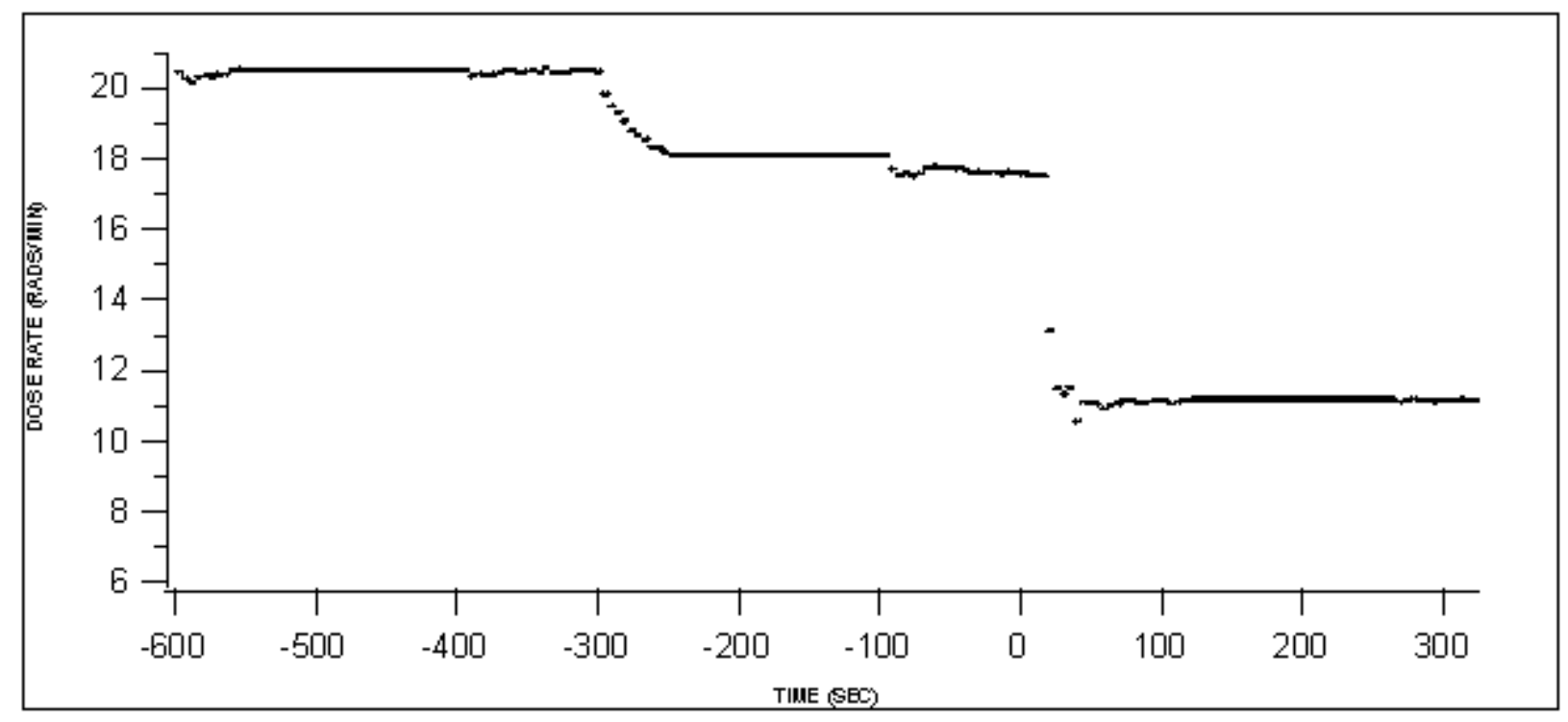

Figure C24. $8 \mathrm{MeV}$ Test Case 2, dose rate. 


\section{$8 \mathrm{MeV}$ Test Case 3}

Reference File : Composite Energy

Figure of Merit : 1 Beam Parameter ( Beam Current )

Table C3. $8 \mathrm{MeV}$ Test Case 3, timing chart for operator actions.

\begin{tabular}{lcccccc}
\hline & start & end & T1 & T2 & dT & dGFV \\
\hline Auto Tune & $10: 18: 07$ & $10: 18: 44$ & -628 & -591 & 37 & \\
Beam Scan & $10: 20: 27$ & $10: 22: 47$ & -488 & -348 & 140 & \\
Perturb Tune & $10: 23: 55$ & $10: 24: 01$ & -280 & -274 & 6 & $-1.5 \mathrm{~V}$ \\
Perturb Tune & $10: 24: 42$ & $10: 24: 49$ & -233 & -226 & 7 & $-1.5 \mathrm{~V}$ \\
Beam Scan & $10: 25: 19$ & $10: 27: 46$ & -196 & -49 & 147 & \\
Feedback Correction & $10: 28: 35$ & $10: 28: 45$ & 0 & 10 & 10 & \\
Feedback Correction & $10: 28: 48$ & $10: 28: 55$ & 13 & 20 & 7 & \\
Feedback Correction & $10: 28: 58$ & $10: 29: 03$ & 23 & 28 & 5 & \\
Beam Scan & $10: 30: 01$ & $10: 30: 08$ & 86 & 93 & 7 & \\
Beam Scan & $10: 30: 12$ & $10: 32: 27$ & 97 & 232 & 135 & \\
\hline
\end{tabular}

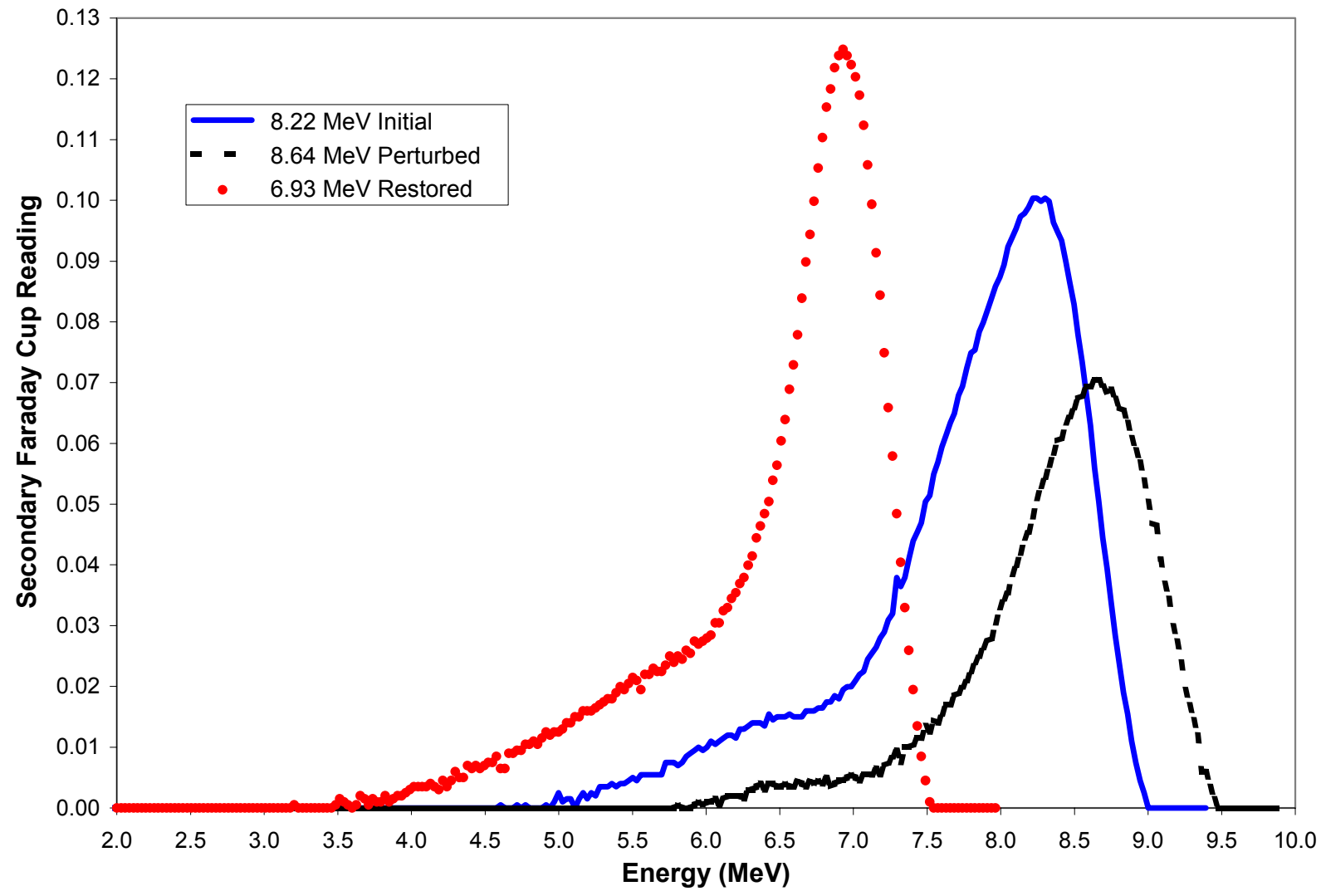

Figure C25. $8 \mathrm{MeV}$ Test Case 3, energy profiles. 


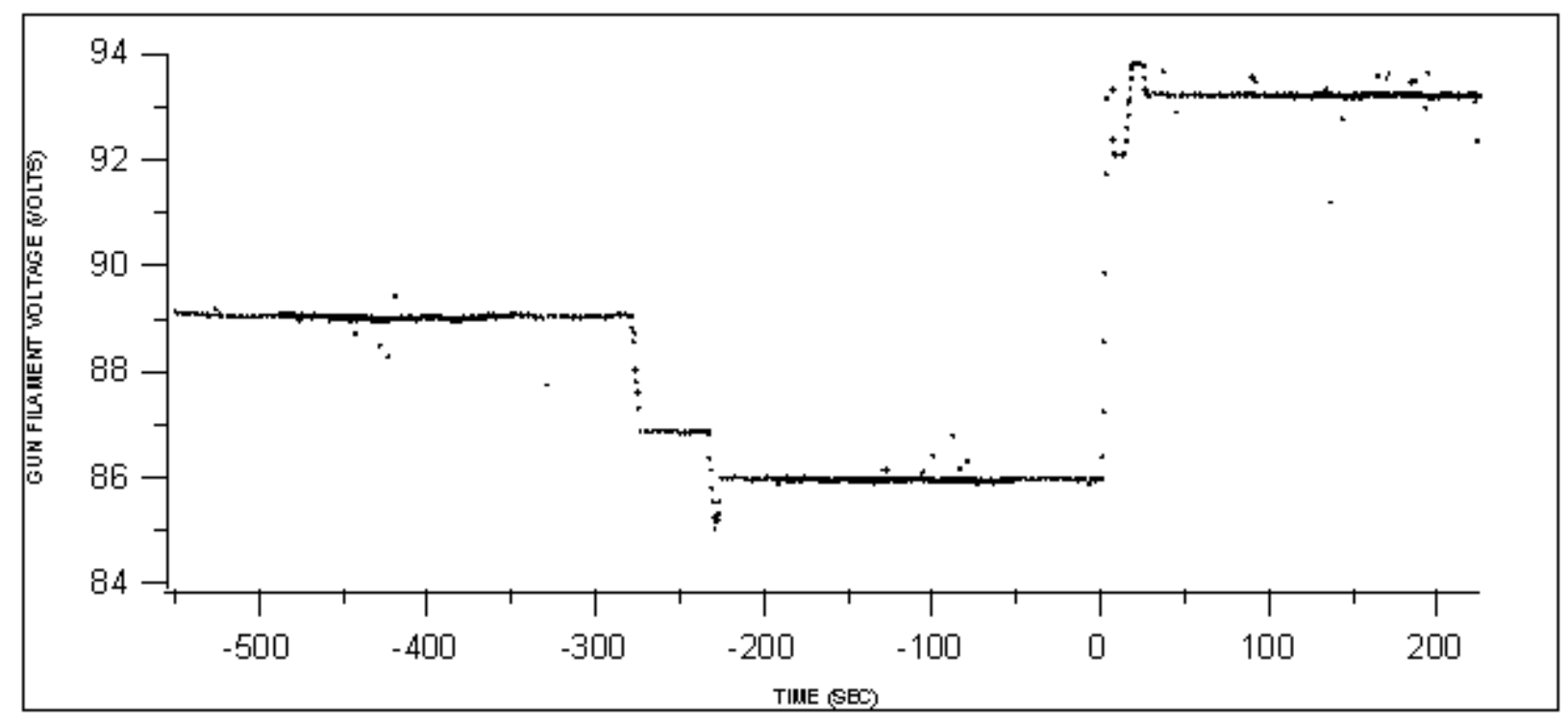

Figure C26. $8 \mathrm{MeV}$ Test Case 3, gun filament voltage.

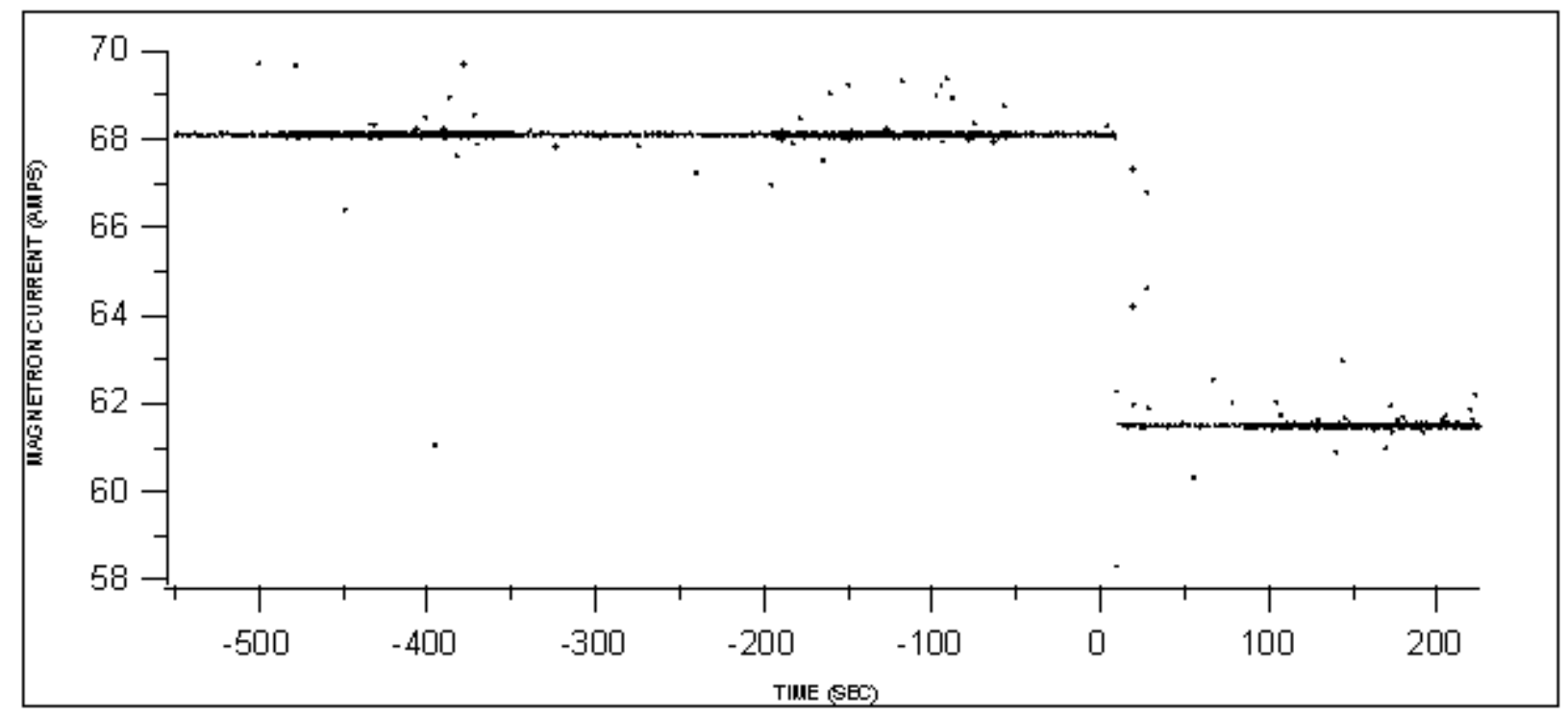

Figure C27. $8 \mathrm{MeV}$ Test Case 3, magnetron current. 


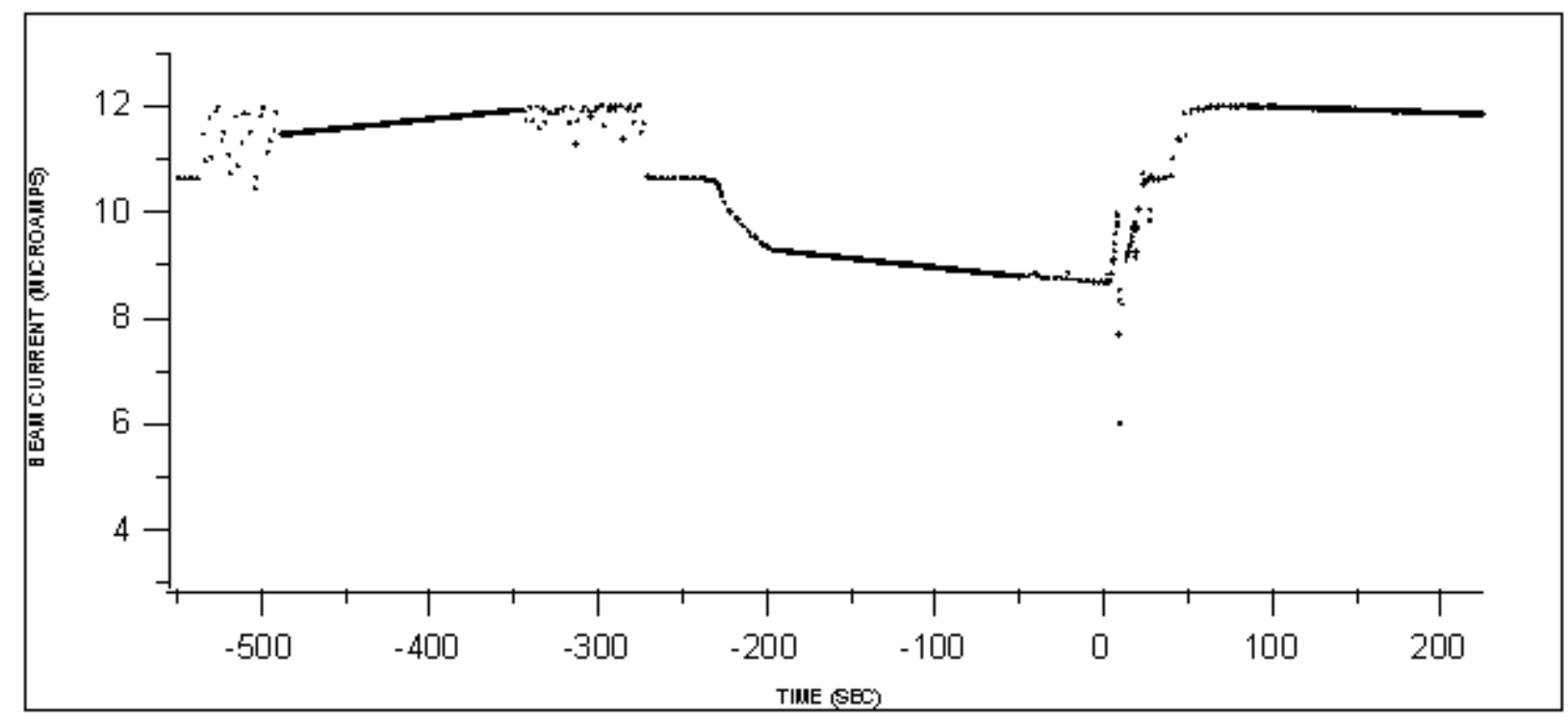

Figure C28. $8 \mathrm{MeV}$ Test Case 3, beam current.

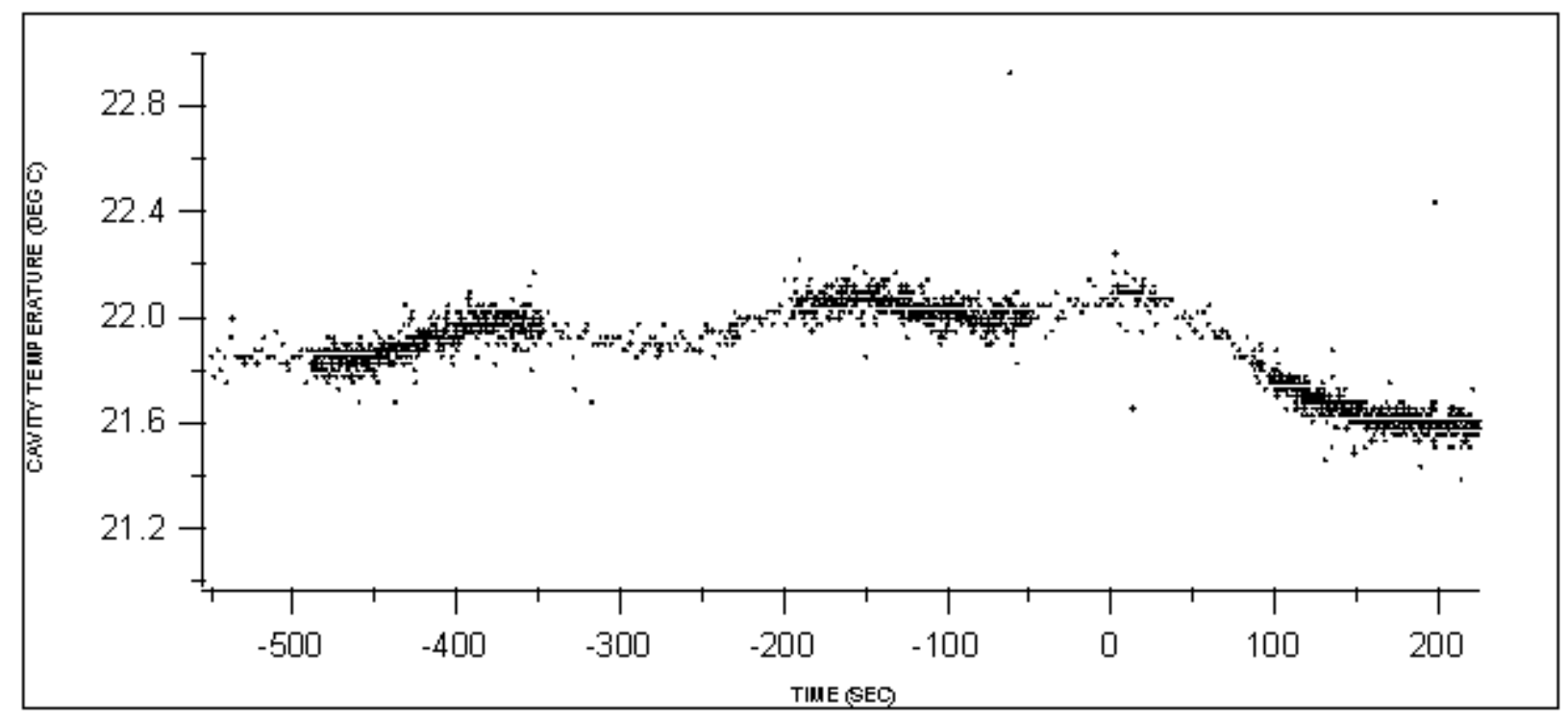

Figure C29. $8 \mathrm{MeV}$ Test Case 3, cavity temperature. 


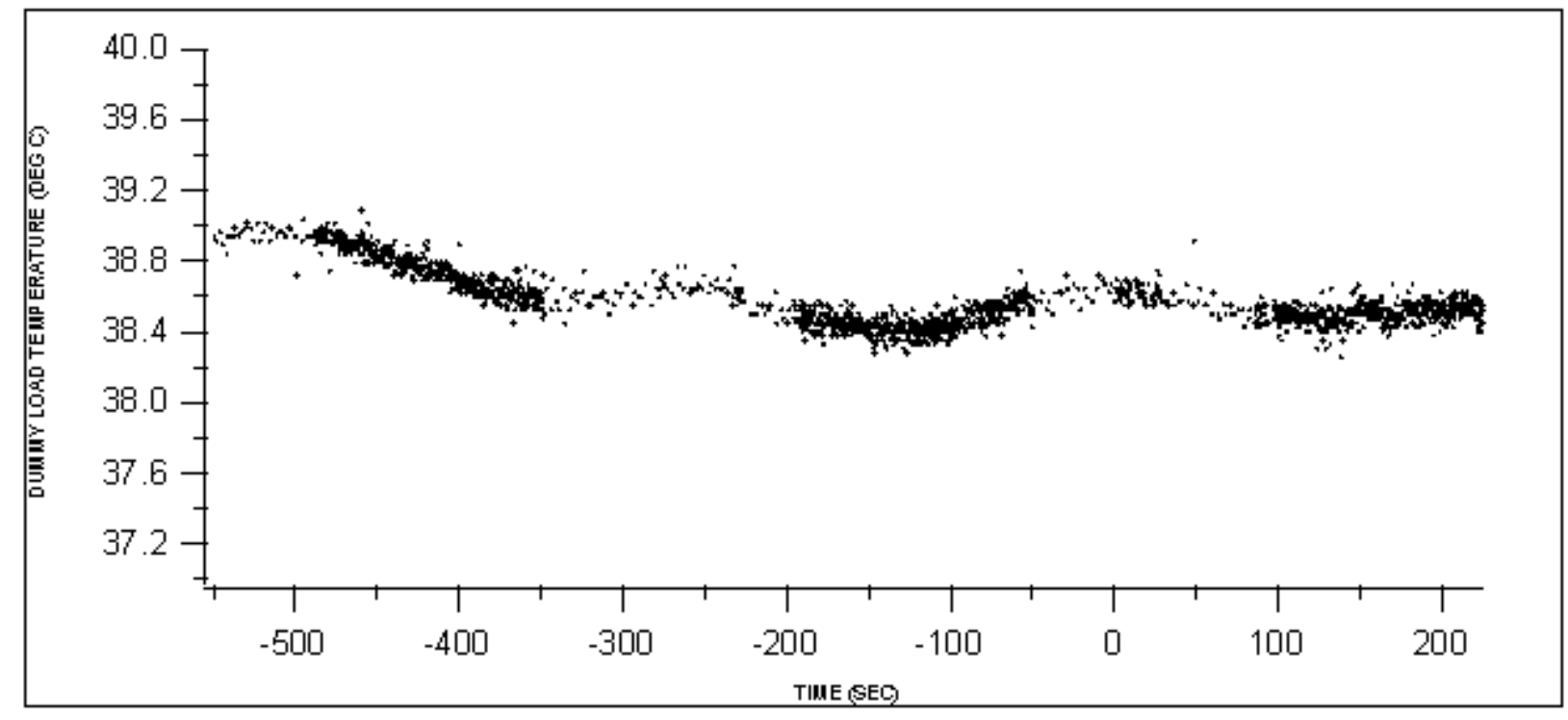

Figure C30. $8 \mathrm{MeV}$ Test Case 3, dummy load temperature.

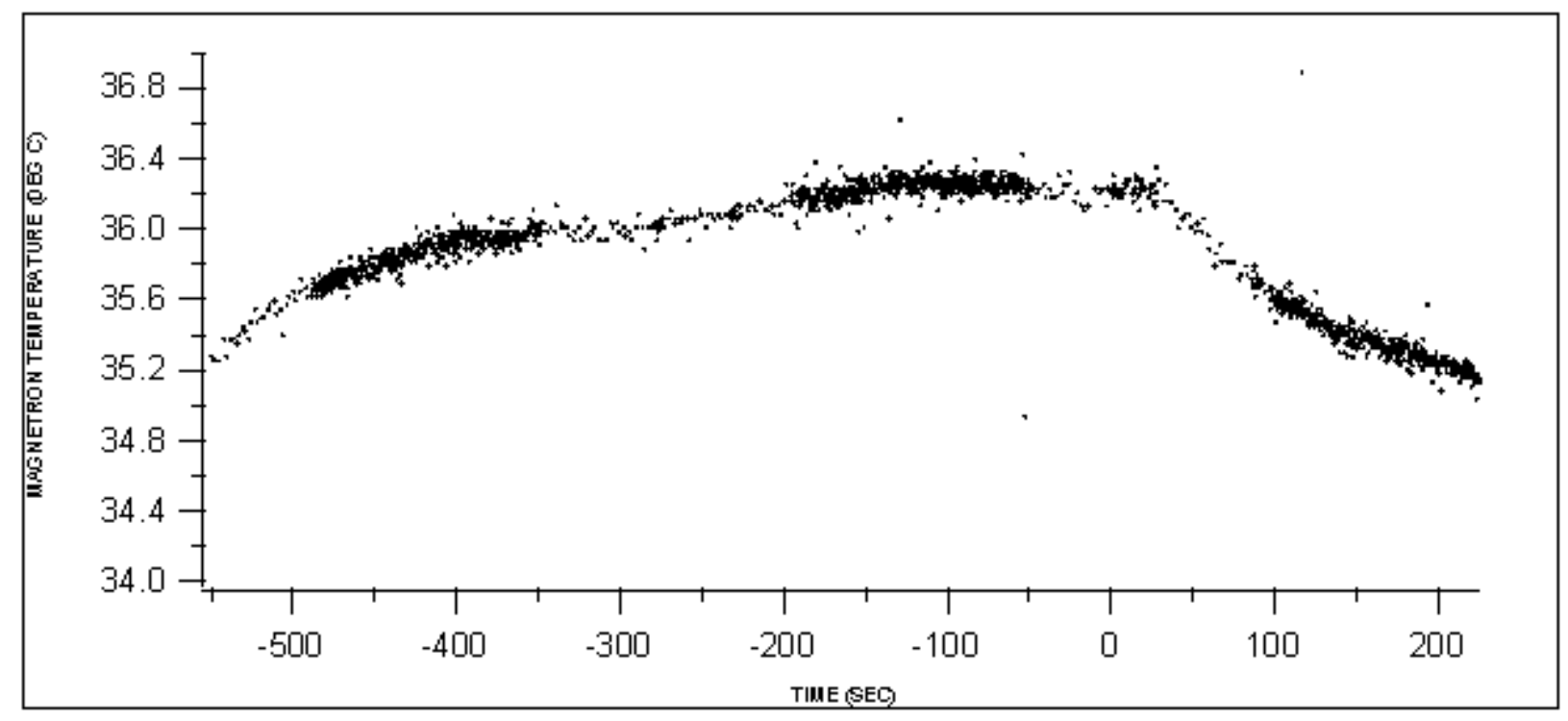

Figure C31. $8 \mathrm{MeV}$ Test Case 3, magnetron temperature. 


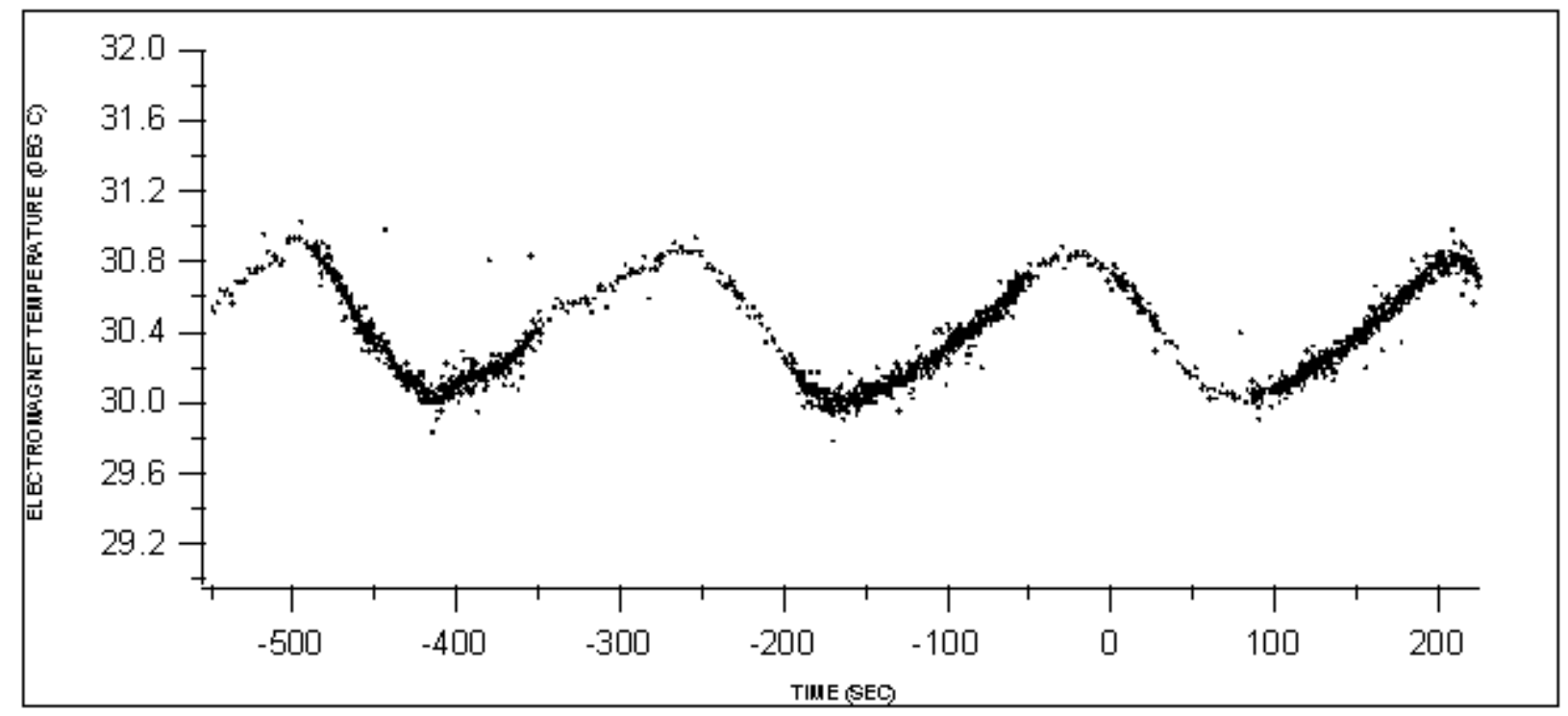

Figure C32. $8 \mathrm{MeV}$ Test Case 3, electromagnet temperature.

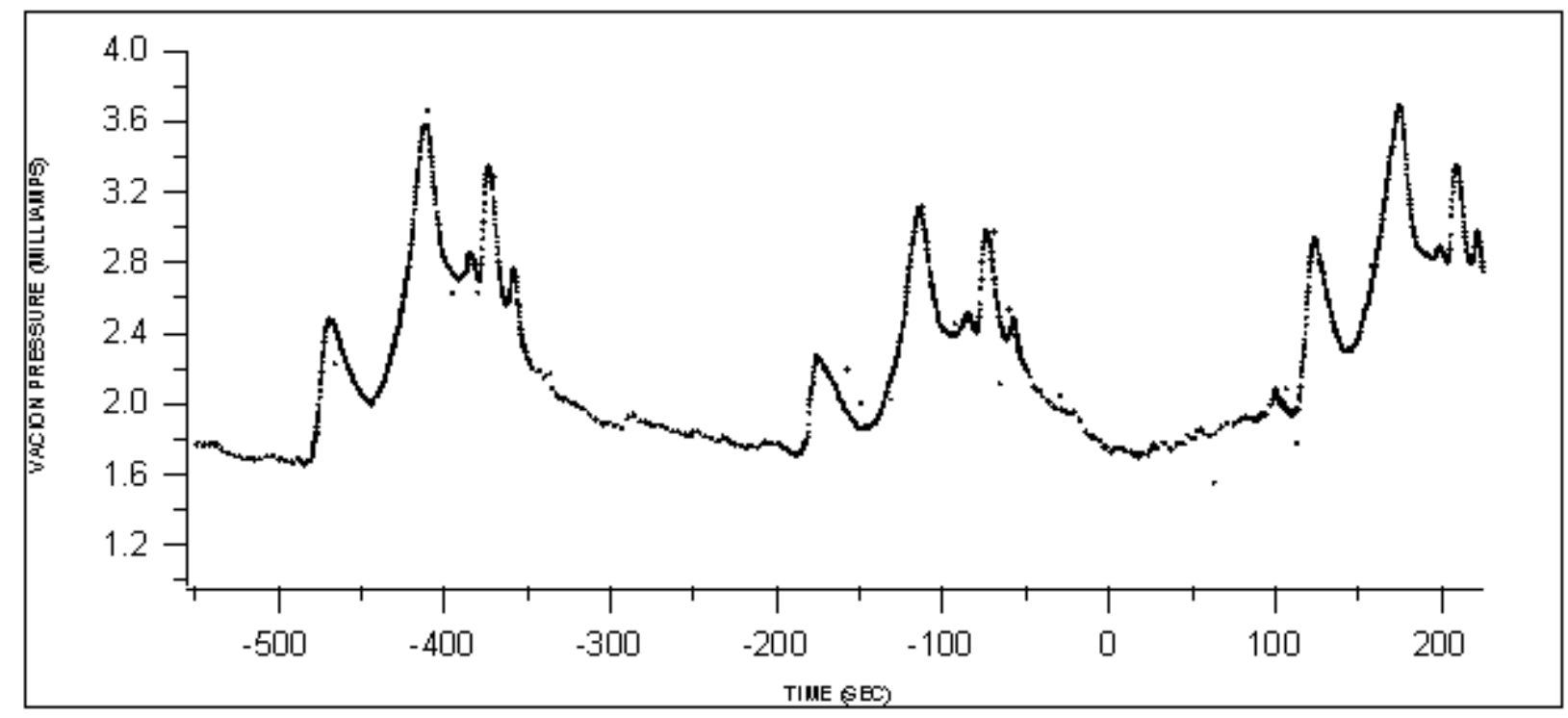

Figure C33. $8 \mathrm{MeV}$ Test Case 3, vacion pressure. 


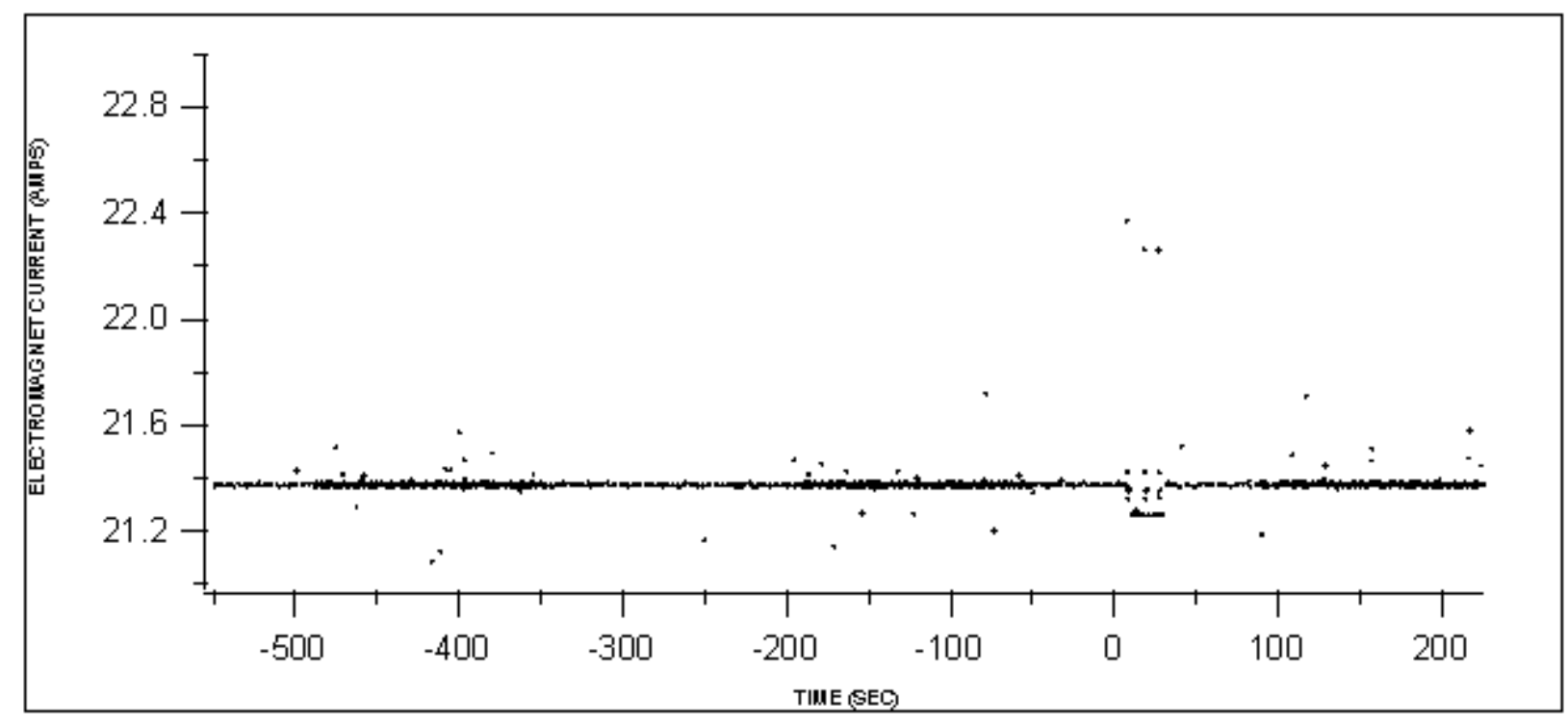

Figure C34. $8 \mathrm{MeV}$ Test Case 3, electromagnet current.

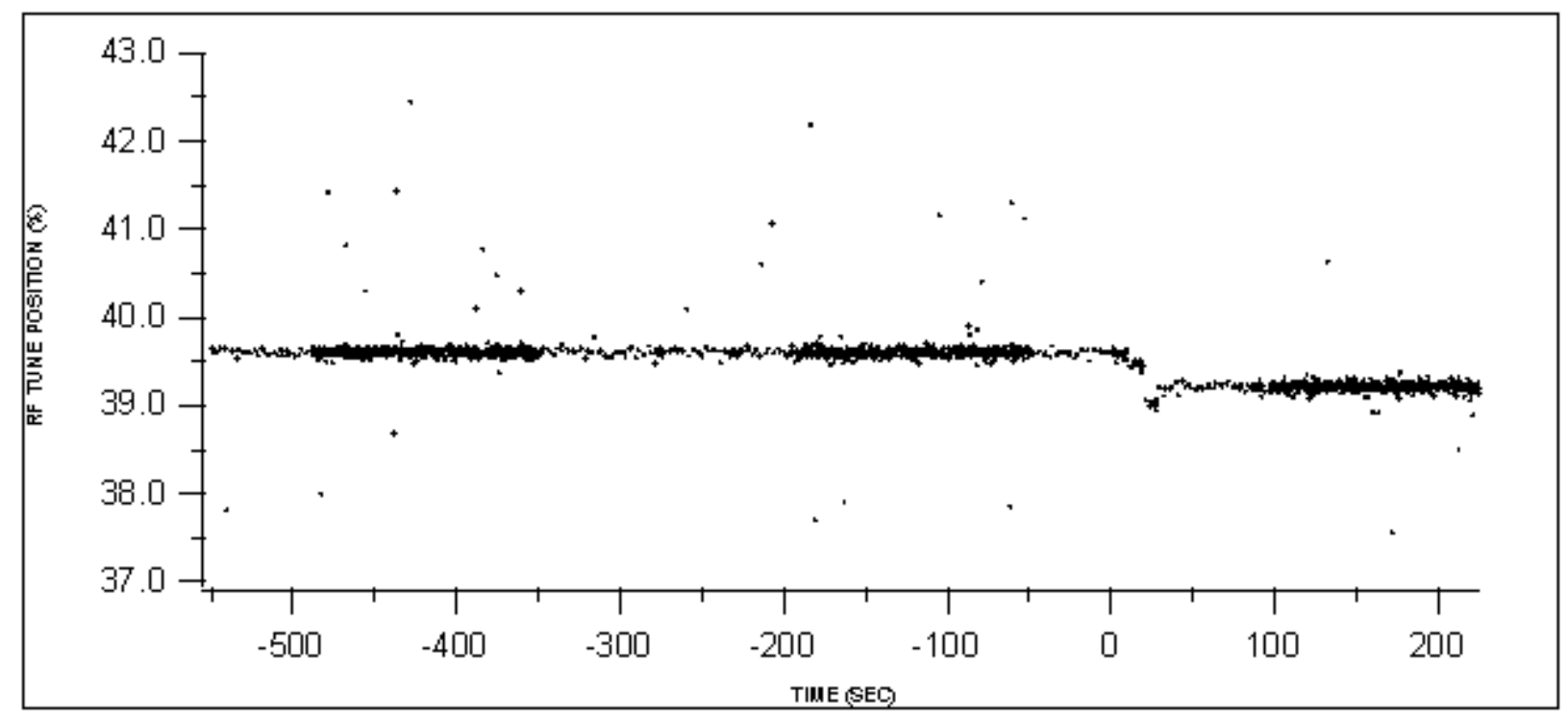

Figure C35. $8 \mathrm{MeV}$ Test Case 3, RF tune position. 


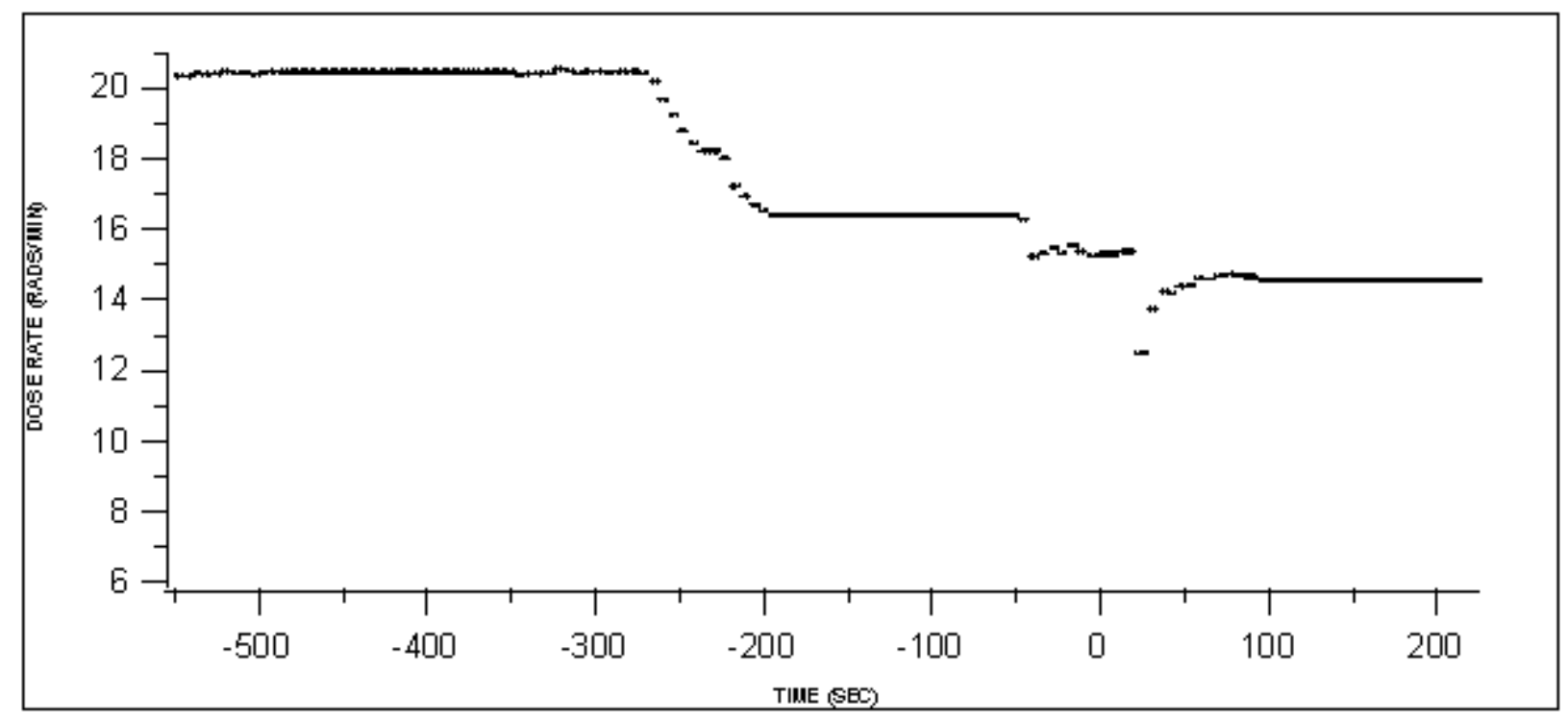

Figure C36. $8 \mathrm{MeV}$ Test Case 3, dose rate. 


\section{$8 \mathrm{MeV}$ Test Case 4}

Reference File : Composite Energy

Figure of Merit : All Parameters

Table C4. $8 \mathrm{MeV}$ Test Case 4, timing chart for operator actions.

\begin{tabular}{lcccccc}
\hline & start & end & T1 & T2 & dT & dGFV \\
\hline Auto Tune & $11: 39: 29$ & $11: 40: 13$ & -925 & -881 & 44 & \\
Beam Scan & $11: 42: 42$ & $11: 47: 18$ & -732 & -456 & 276 & \\
Perturb Tune & $11: 49: 08$ & $11: 49: 17$ & -346 & -337 & 9 & $-1.5 \mathrm{~V}$ \\
Perturb Tune & $11: 49: 44$ & $11: 49: 52$ & -310 & -302 & 8 & $-1 \mathrm{~V}$ \\
Beam Scan & $11: 50: 58$ & $11: 53: 39$ & -236 & -75 & 161 & \\
Feedback Correction & $11: 54: 54$ & $11: 55: 04$ & 0 & 10 & 10 & \\
Feedback Correction & $11: 55: 07$ & $11: 55: 20$ & 13 & 26 & 13 & \\
Beam Scan & $11: 56: 56$ & $11: 59: 11$ & 122 & 257 & 135 & \\
\hline
\end{tabular}

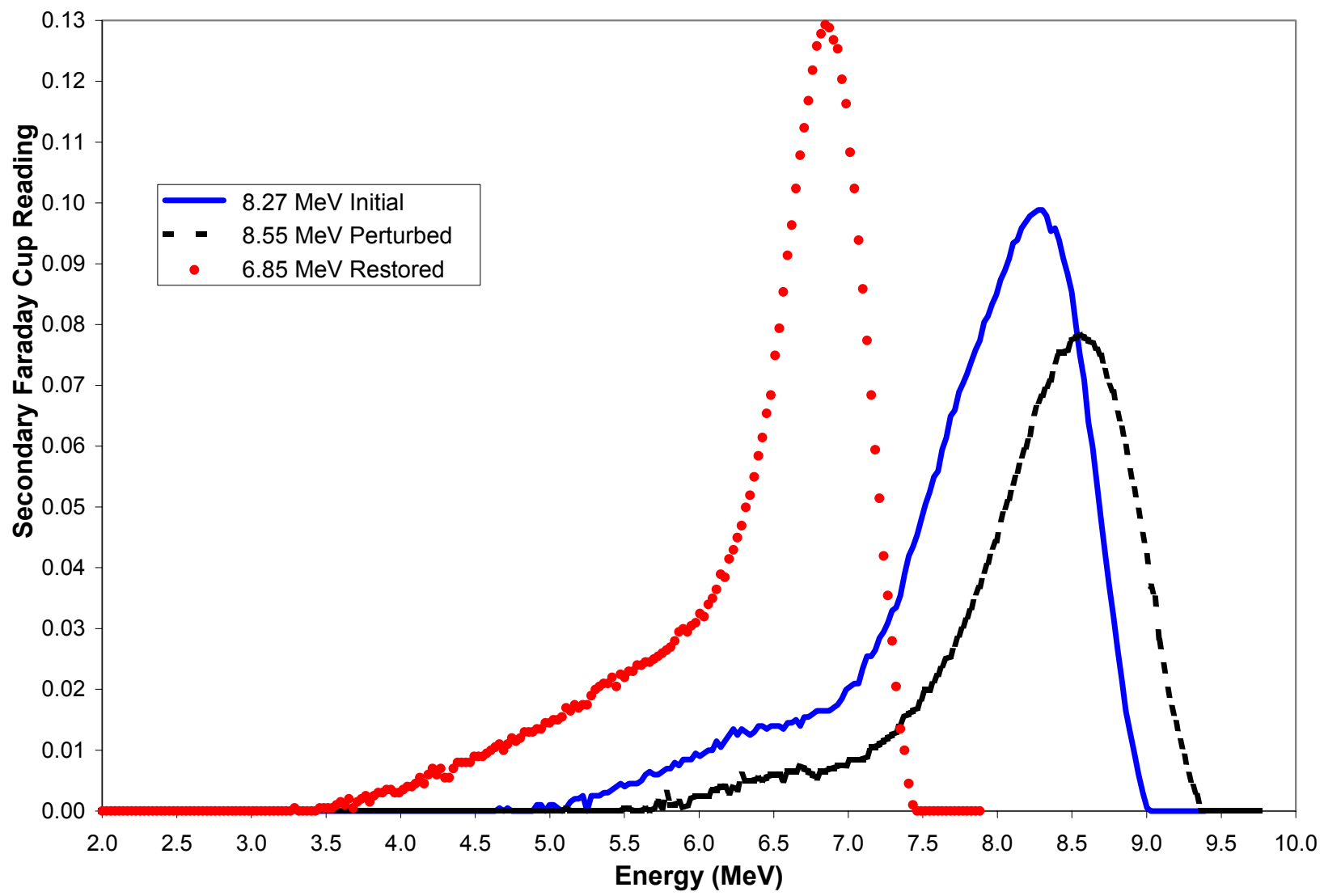

Figure C37. $8 \mathrm{MeV}$ Test Case 4, energy profiles. 


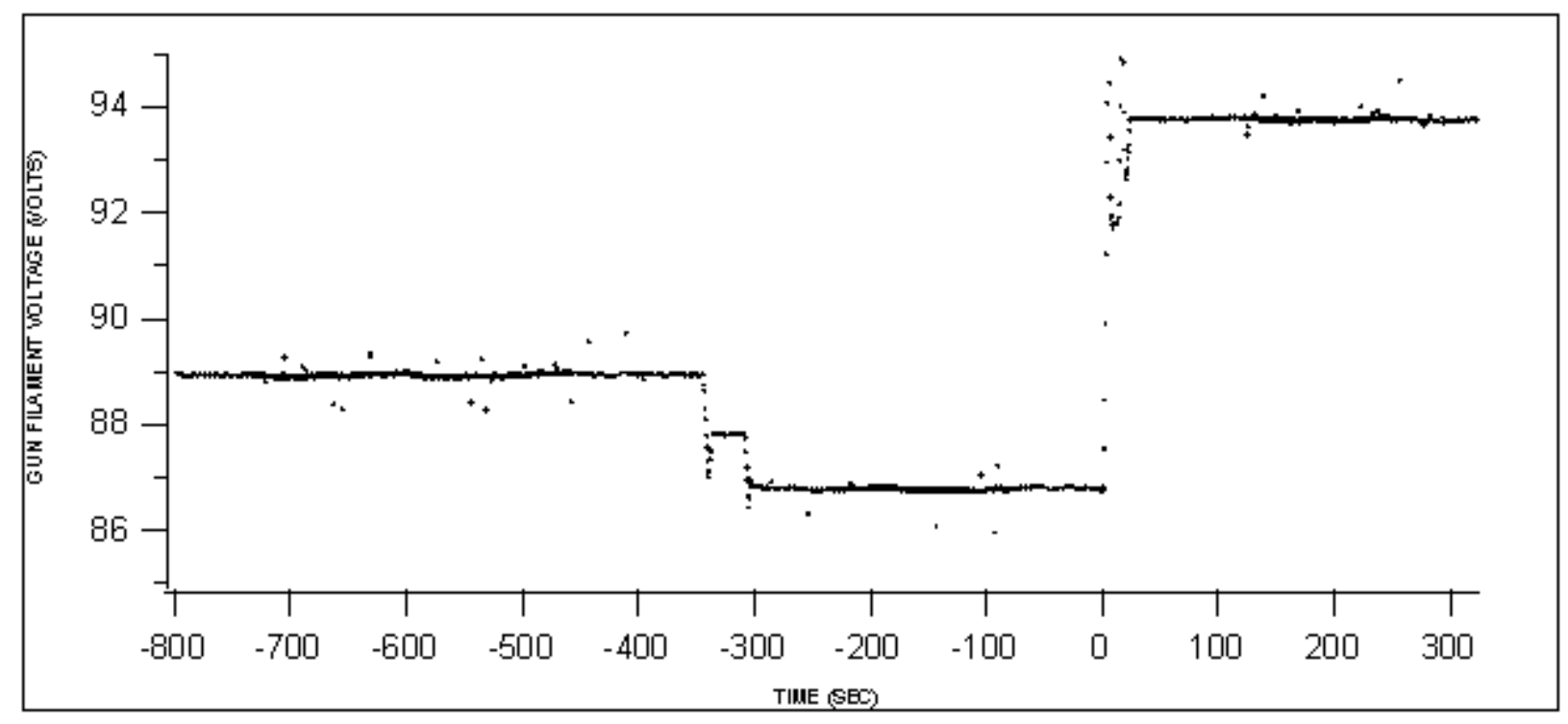

Figure C38. $8 \mathrm{MeV}$ Test Case 4, gun filament voltage.

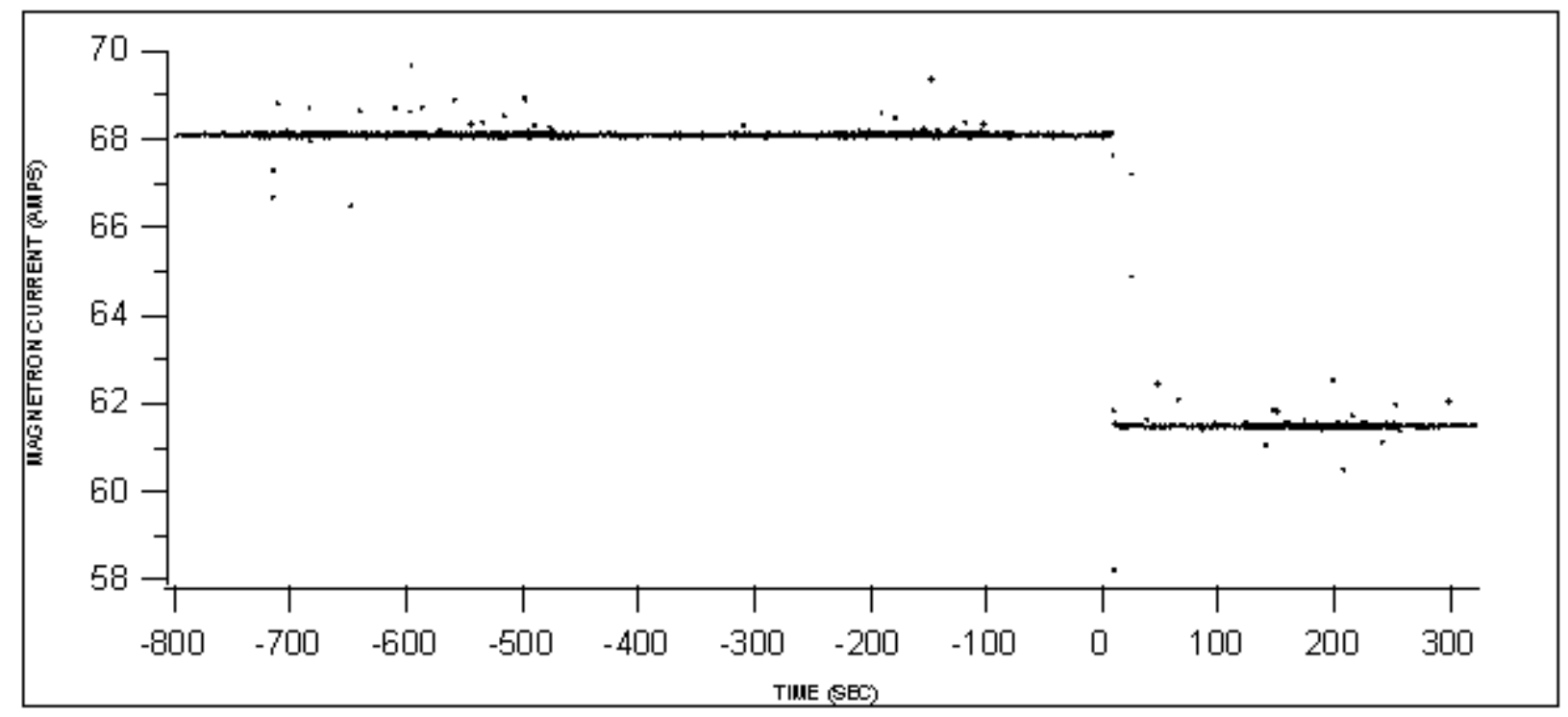

Figure C39. $8 \mathrm{MeV}$ Test Case 4, magnetron current. 


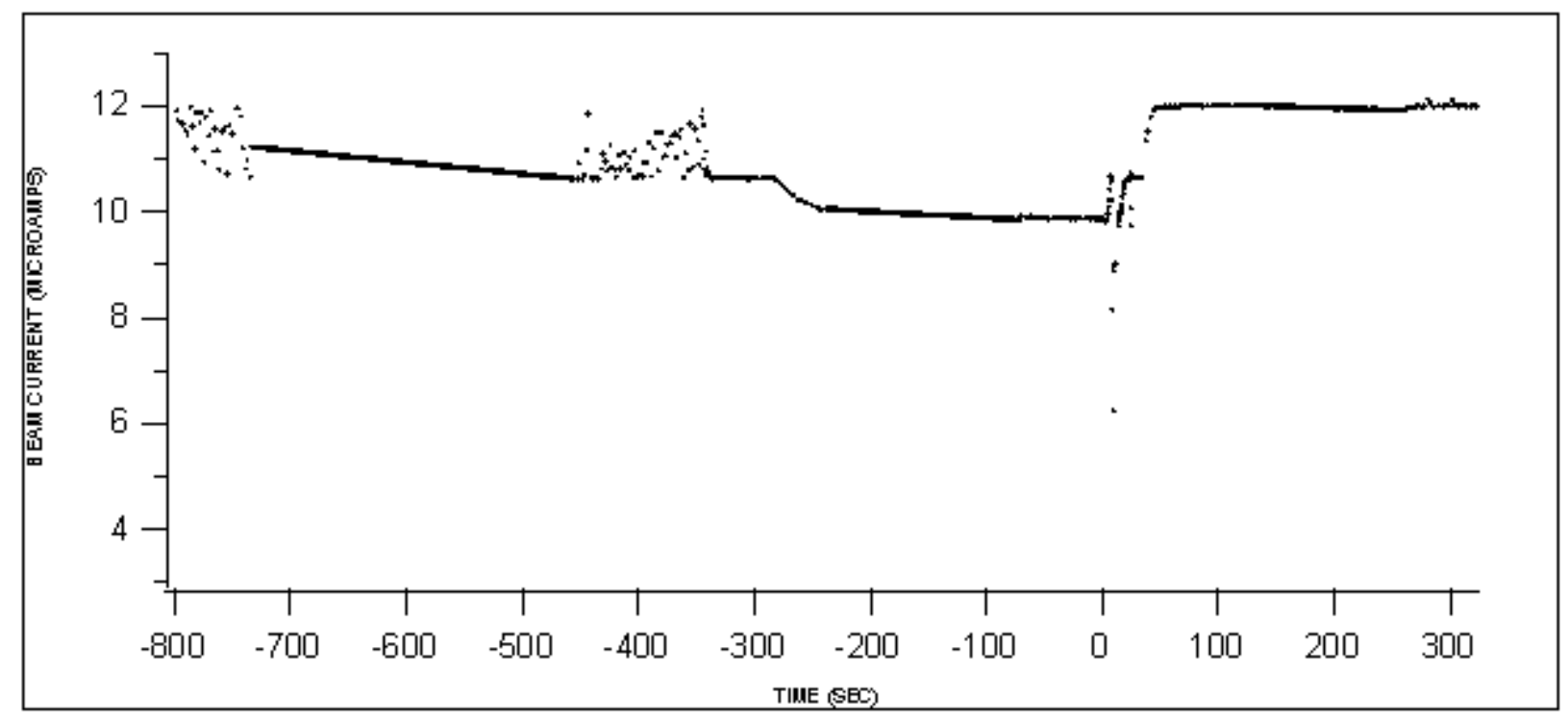

Figure C40. $8 \mathrm{MeV}$ Test Case 4, beam current.

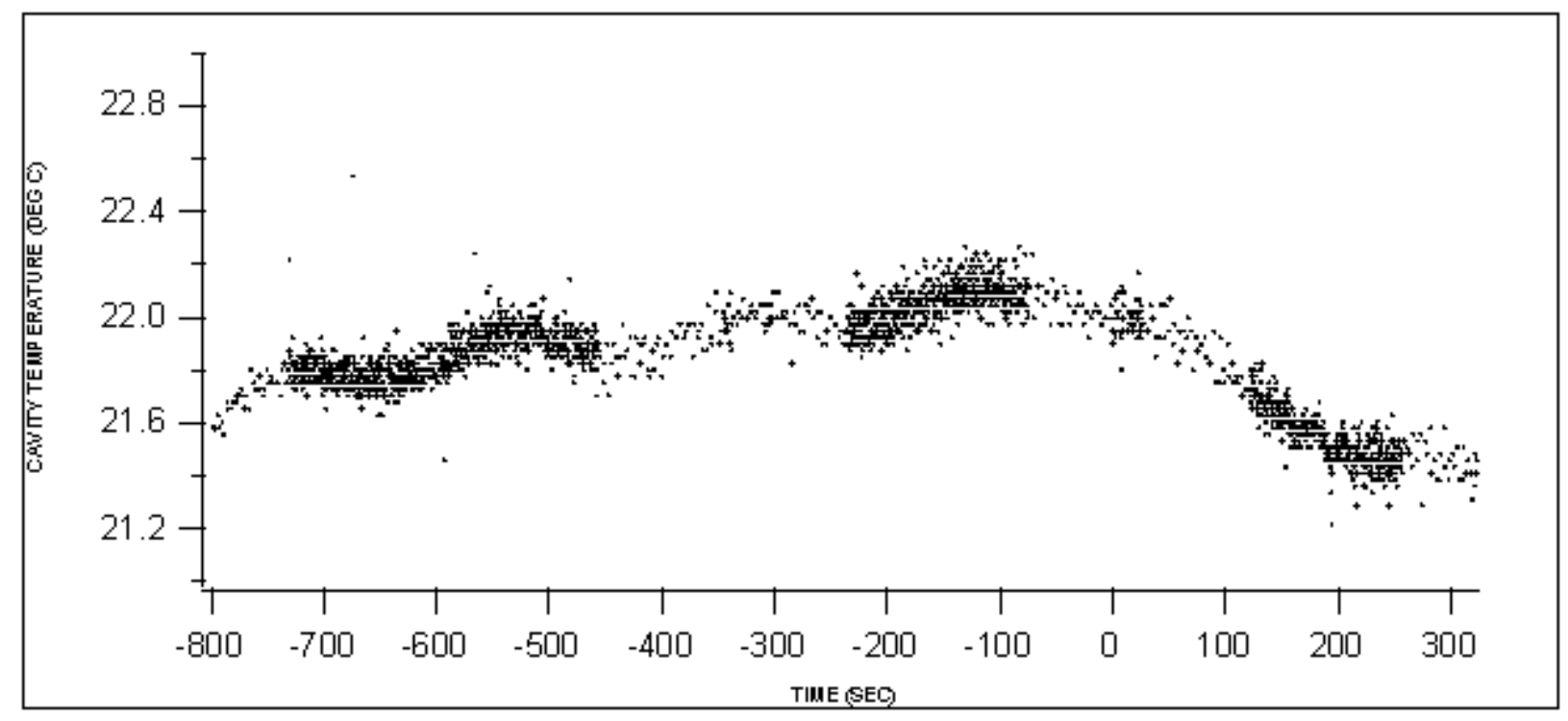

Figure C41. $8 \mathrm{MeV}$ Test Case 4, cavity temperature. 


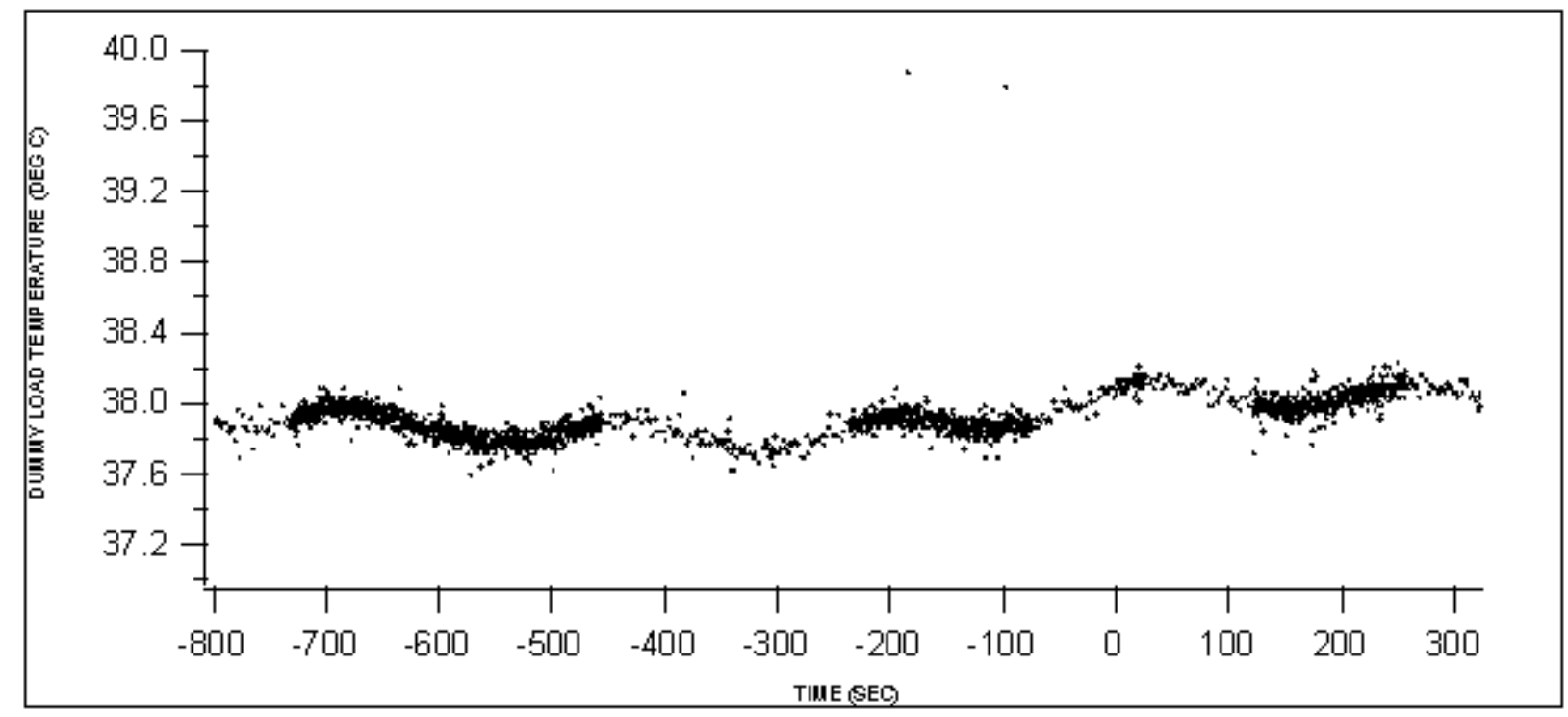

Figure C42. $8 \mathrm{MeV}$ Test Case 4, dummy load temperature.

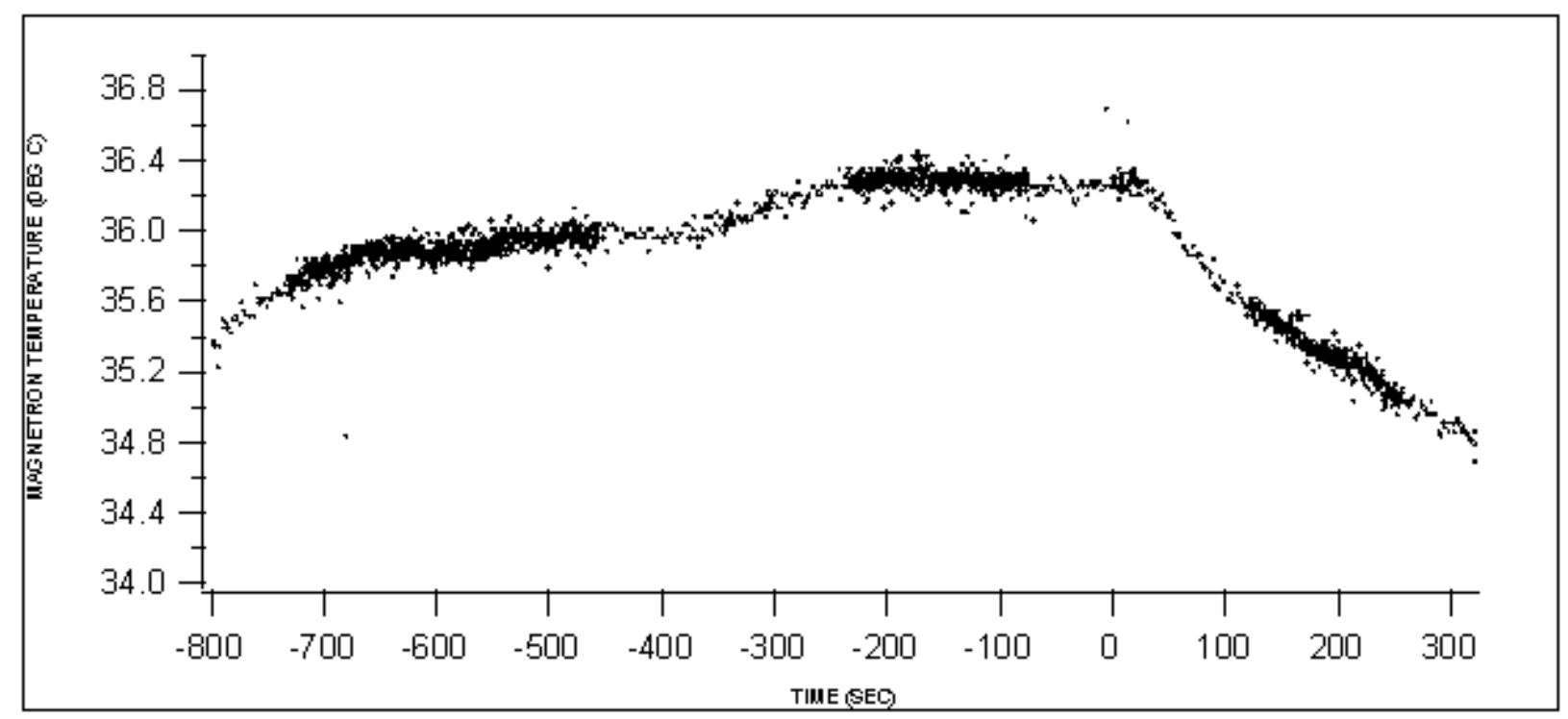

Figure C43. $8 \mathrm{MeV}$ Test Case 4, magnetron temperature. 


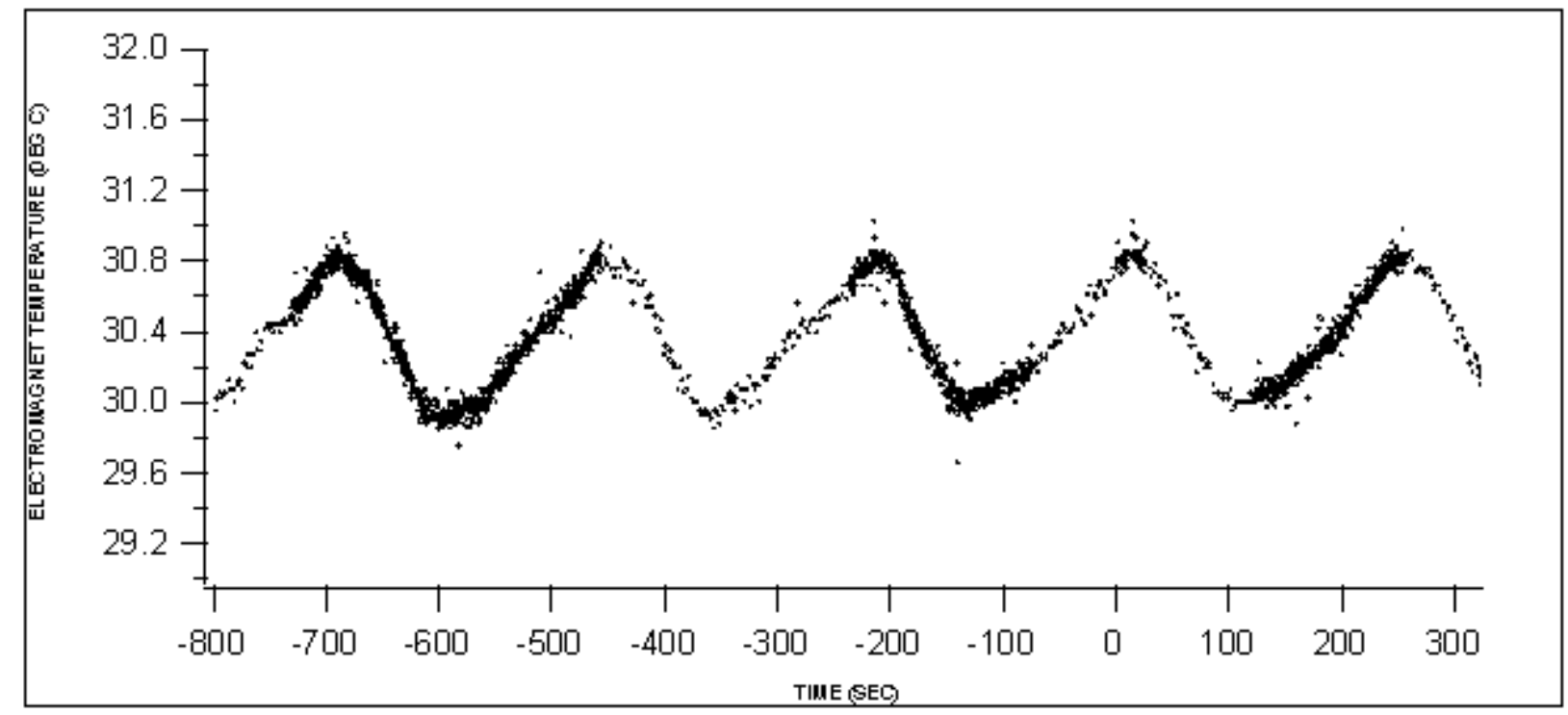

Figure C44. $8 \mathrm{MeV}$ Test Case 4, electromagnet temperature.

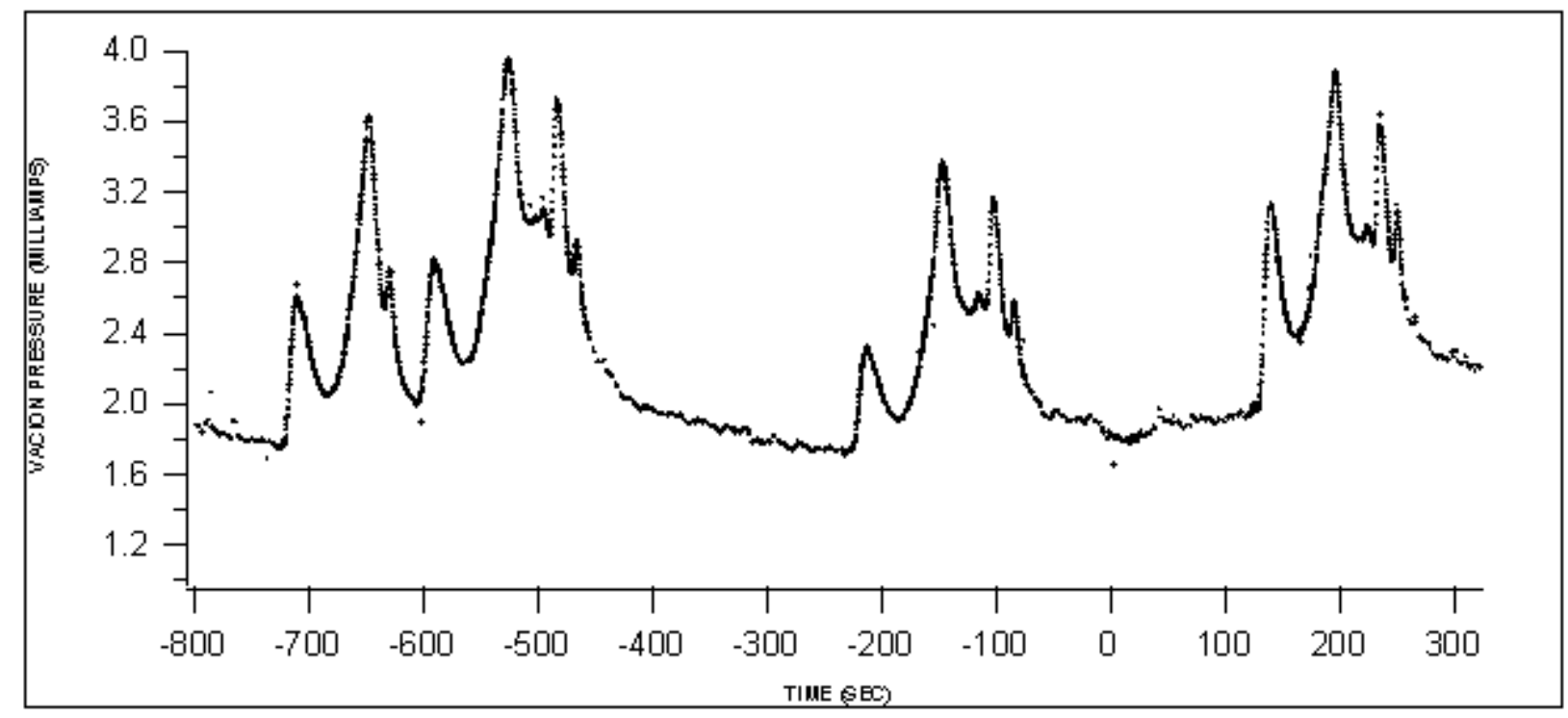

Figure C45. $8 \mathrm{MeV}$ Test Case 4, vacion pressure. 


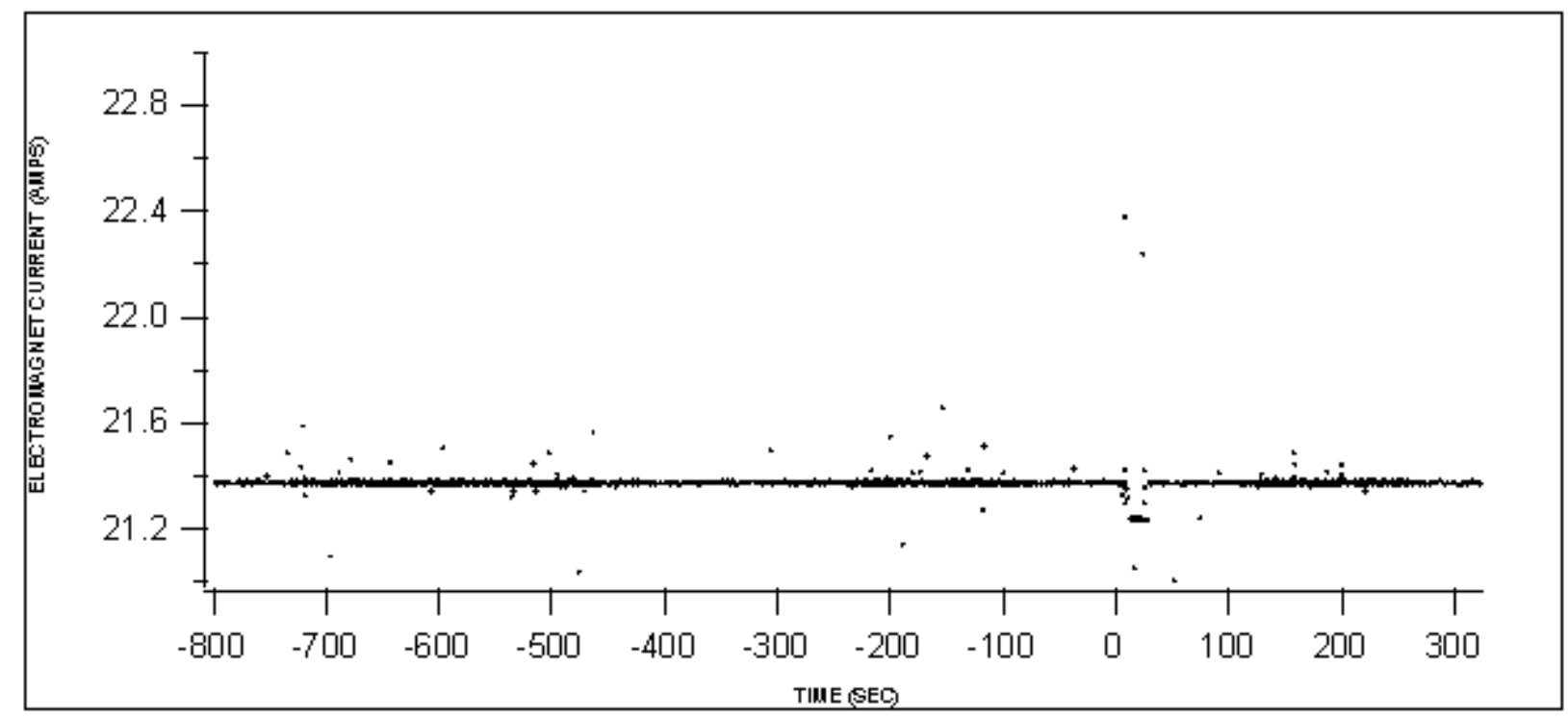

Figure C46. $8 \mathrm{MeV}$ Test Case 4, electromagnet current.

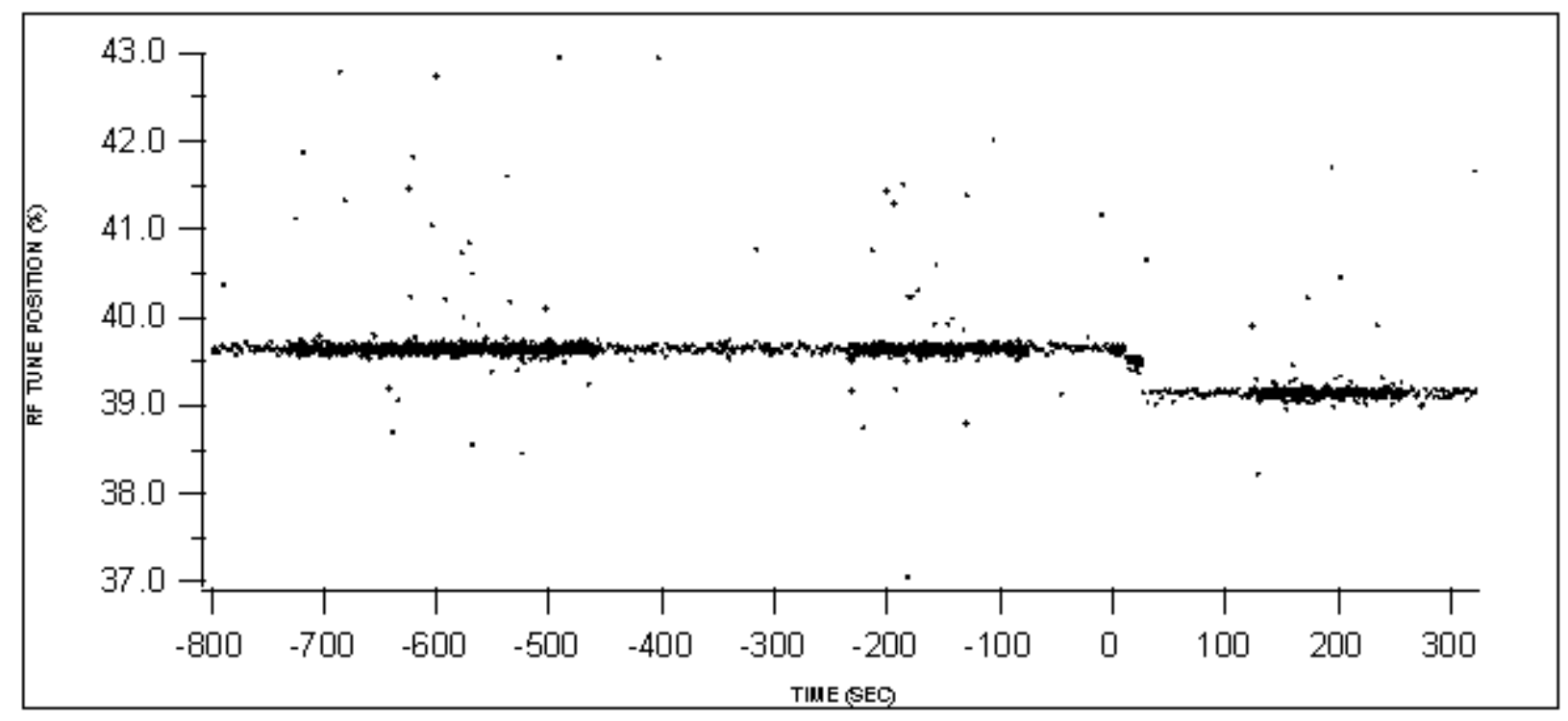

Figure C47. $8 \mathrm{MeV}$ Test Case 4, RF tune position. 


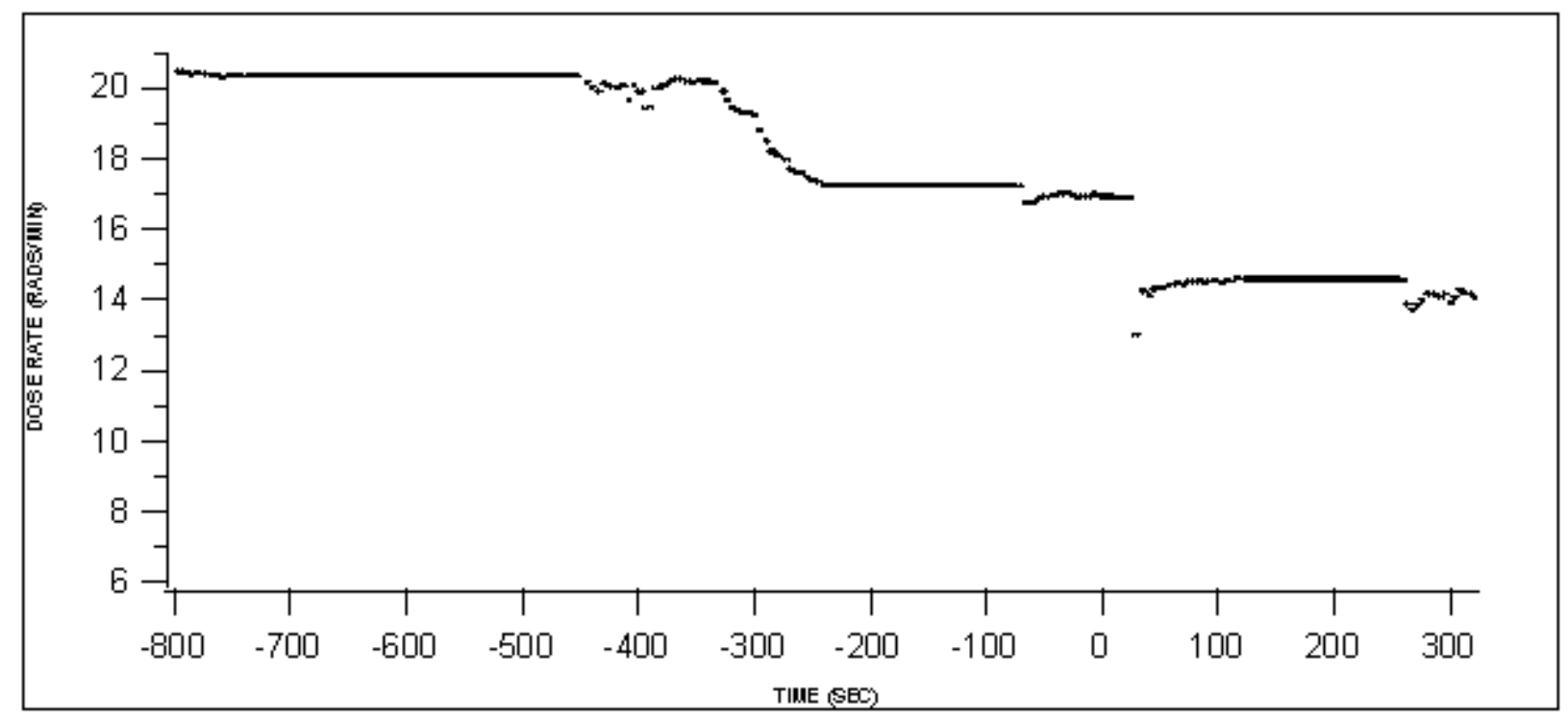

Figure C48. $8 \mathrm{MeV}$ Test Case 4, dose rate. 